\title{
Progress Implementing the IEA 25 Energy Efficiency Policy Recommendations
}

2011 Evaluation 
The International Energy Agency (IEA), an autonomous agency, was established in November 1974. Its primary mandate was - and is - two-fold: to promote energy security amongst its member countries through collective response to physical disruptions in oil supply, and provide authoritative research and analysis on ways to ensure reliable, affordable and clean energy for its 28 member countries and beyond. The IEA carries out a comprehensive programme of energy co-operation among its member countries, each of which is obliged to hold oil stocks equivalent to 90 days of its net imports. The Agency's aims include the following objectives:

- Secure member countries' access to reliable and ample supplies of all forms of energy; in particular, through maintaining effective emergency response capabilities in case of oil supply disruptions.

- Promote sustainable energy policies that spur economic growth and environmental protection in a global context - particularly in terms of reducing greenhouse-gas emissions that contribute to climate change.

- Improve transparency of international markets through collection and analysis of energy data.

- Support global collaboration on energy technology to secure future energy supplies and mitigate their environmental impact, including through improved energy

efficiency and development and deployment of low-carbon technologies.

- Find solutions to global energy challenges through engagement and dialogue with non-member countries, industry, international organisations and other stakeholders.

IEA member countries:

(C) OECD/IEA, 2012

\section{International Energy Agency}

9 rue de la Fédération 75739 Paris Cedex 15, France

www.iea.org

\section{Spain}

Sweden

\section{Switzerland}

Turkey

\section{United Kingdom}

United States 


\section{Table of Contents}

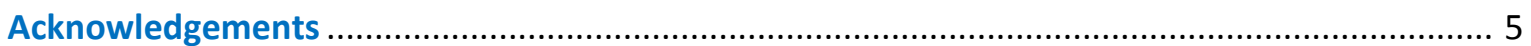

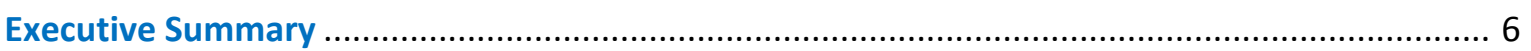

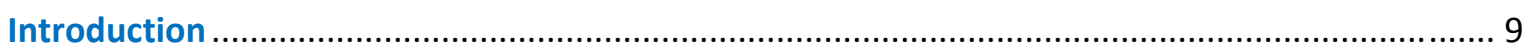

IEA 25 energy efficiency policy recommendations ........................................................... 9

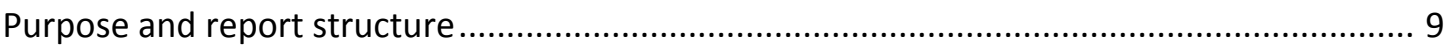

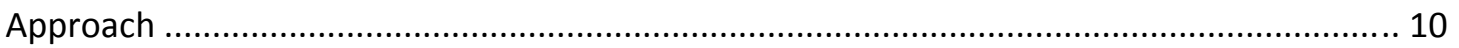

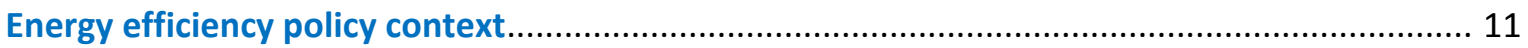

Recent energy efficiency policy developments in IEA member countries .................................. 14

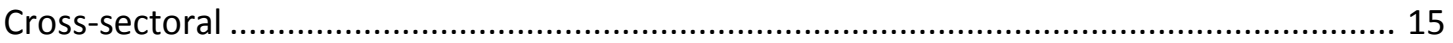

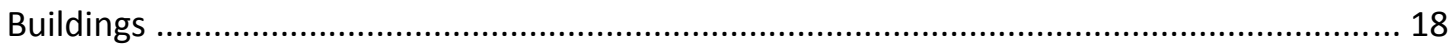

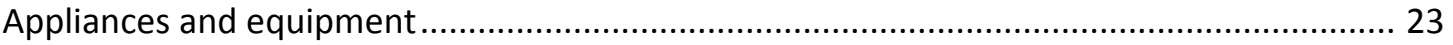

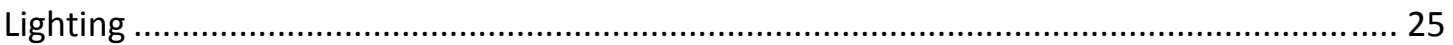

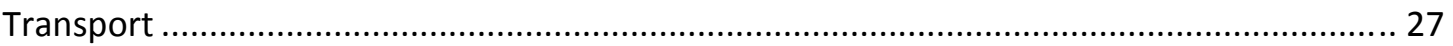

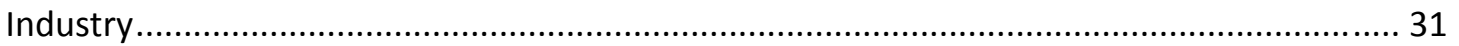

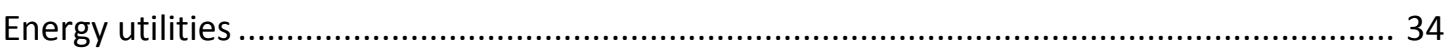

Challenges and areas for improvement in energy efficiency policy ............................................ 36

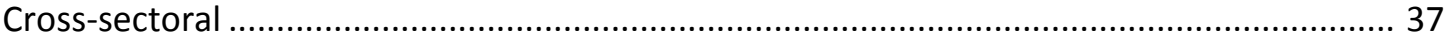

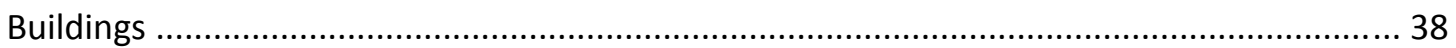

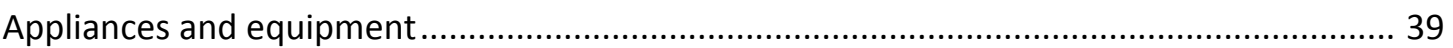

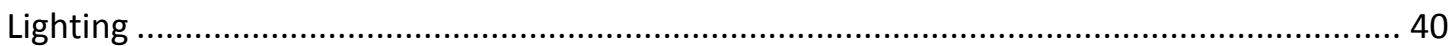

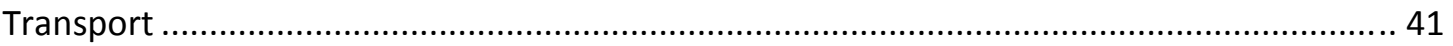

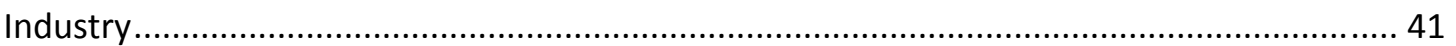

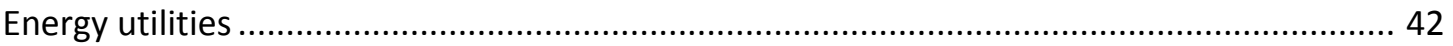

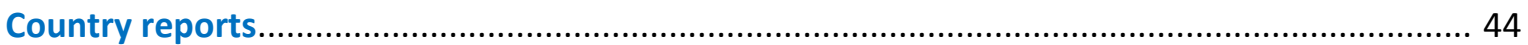

Energy Efficiency Progress Report - Australia ..................................................................... 45

Energy Efficiency Progress Report - Austria.................................................................... 48

Energy Efficiency Progress Report - Belgium ................................................................. 50

Energy Efficiency Progress Report - Canada .................................................................... 52

Energy Efficiency Progress Report - Czech Republic............................................................ 55

Energy Efficiency Progress Report - Denmark ………...................................................... 57

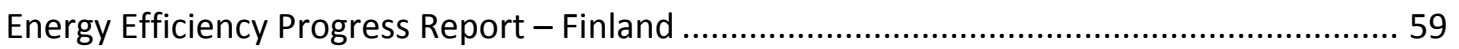

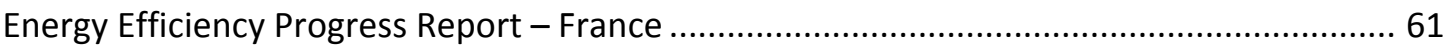

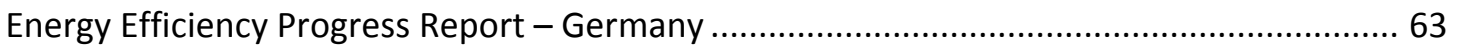

Energy Efficiency Progress Report - Greece ................................................................... 66

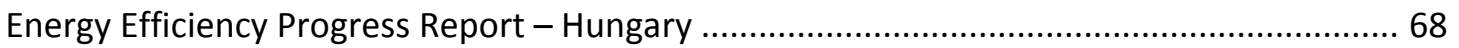

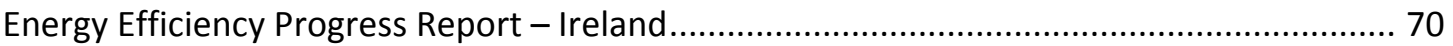

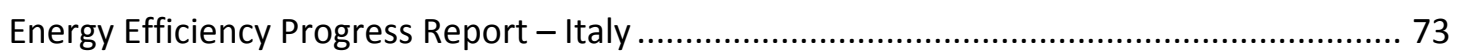

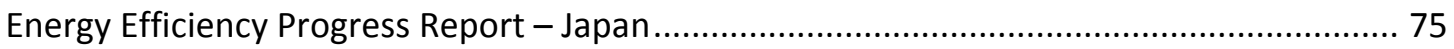




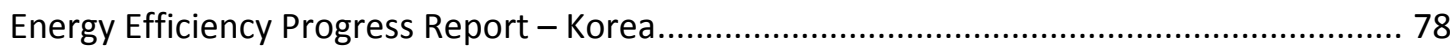

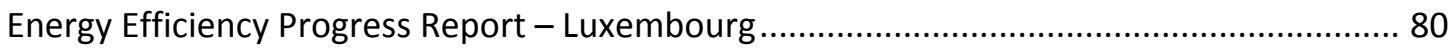

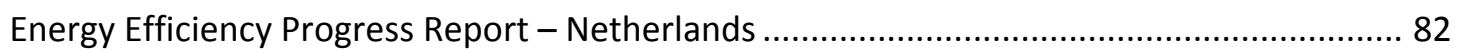

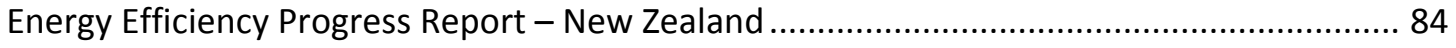

Page | 2

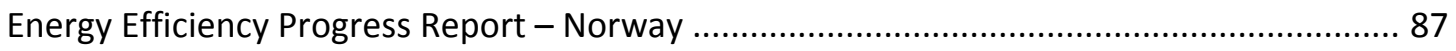

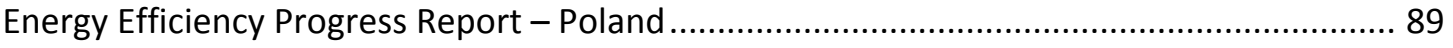

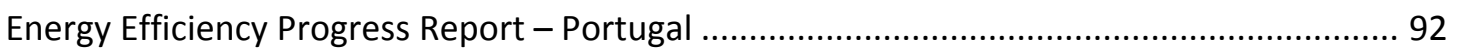

Energy Efficiency Progress Report - Slovak Republic .......................................................... 94

Energy Efficiency Progress Report - Spain ..................................................................... 96

Energy Efficiency Progress Report - Sweden ..................................................................... 98

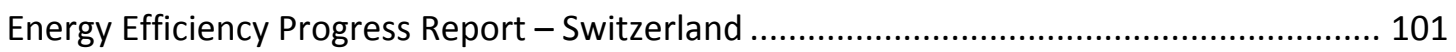

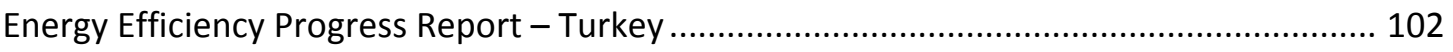

Energy Efficiency Progress Report - United Kingdom ...................................................... 104

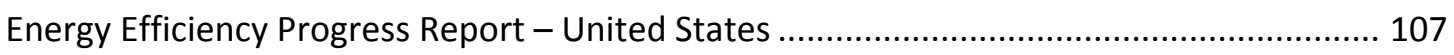

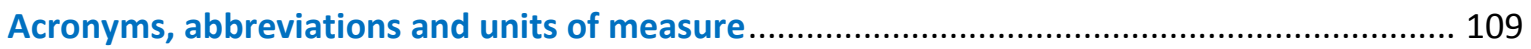

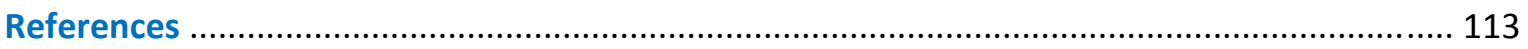

Annex 1: Consolidated list of 25 IEA energy efficiency policy recommendations .................... 114

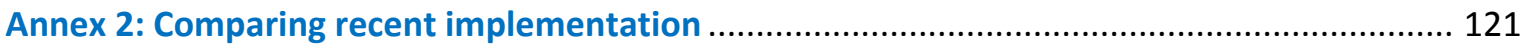

List of figures

Figure 1 Implementation of all applicable recommendations, all IEA member countries ................ 7

Figure 2 Implementation by sector of all applicable recommendations,

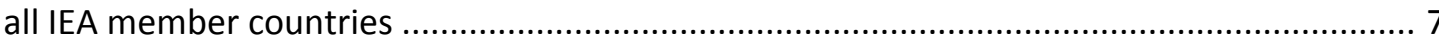

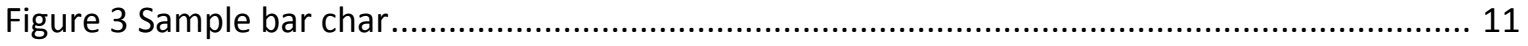

Figure 4 Economy-wide energy savings from improvements in energy efficiency, IEA17 ............. 12

Figure 5 Progress with implementing the cross-sectoral recommendations ................................. 15

Figure 6 Common energy efficiency savings verification and measurement protocols ................. 16

Figure 7 Policies to encourage private sector energy efficiency investments ................................ 17

Figure 8 Progress with implementing the building recommendations......................................... 19

Figure 9 Mandatory energy efficiency standards for new buildings in building codes ................. 19

Figure 10 Policies to support and encourage construction of PEH and ZEB .................................. 20

Figure 11 Policies to increase awareness of energy efficiency in the buildings sector................... 21

Figure 12 Mandatory building energy certification schemes....................................................... 22

Figure 13 Progress with implementing the appliance and equipment recommendations ............ 23

Figure 14 Energy efficiency policy measures for TVs and set-top boxes ...................................... 24

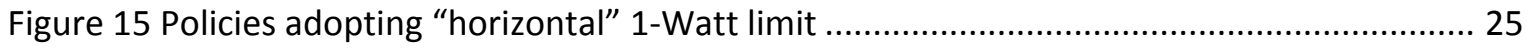

Figure 16 Progress with implementing the lighting recommendations........................................ 25

Figure 17 Phase out the most inefficient incandescent bulbs ...................................................... 26 
Figure 18 Progress with implementing the transport recommendations …................................. 27

Figure 19 International test procedures for measuring tyre rolling resistance .............................. 28

Figure 20 Measures to promote proper tyre inflation levels...................................................... 29

Figure 21 Mandatory fuel efficiency standards for light-duty vehicles ......................................... 29

Figure 22 Eco-driving support through driver training and deployment of in-car feedback ........... 31

Figure 23 Progress with implementing the industry recommendations ....................................... 32

Figure 24 MEPs for electric motors in line with international best practice ................................. 33

Figure 25 Progress with implementing policies to encourage energy utilities to promote

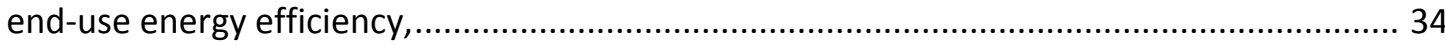

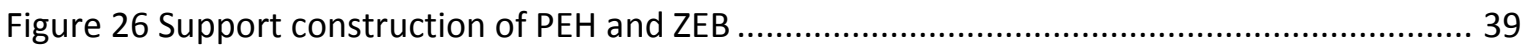

Figure 27 Policies to ensure network-connected electronic devices minimise energy consumption 39

Figure 28 Mandatory fuel-efficiency standards for heavy-duty vehicles 41

Figure 29 Incentives to adopt least-life cycle cost capital acquisition and procurement procedures for SMEs

Figure 30 Decouple energy utility revenue and profits from energy sales and allow energy savings delivery to compete on equal terms with energy sales

Figure 31. Energy efficiency measures bid into energy pools, on an equal basis to energy supply options

Figure 32 Changes in final energy intensity in IEA member countries (purchasing power parity) from 1990 to 2009

Figure 33 Changes in final energy intensity in IEA member countries (market exchange rates) from 1990 to 2009

Figure 34 Decomposition of final energy intensity changes for IEA17 countries, 1990 to $2008 \ldots 45$

Figure 35 Implementation of the IEA 25 energy efficiency policy recommendations, all IEA member countries

Figure 362009 Implementation of applicable IEA recommendations, country comparison ........ 122

Figure 372011 Implementation of applicable IEA recommendations, country comparison...

Figure 382011 Implementation of applicable cross-sectoral recommendations, country comparison.....

Figure 392011 Implementation of applicable buildings recommendations, country comparison

Figure 402011 Implementation of applicable appliance and equipment recommendations, country comparison.

Figure 412011 Implementation of applicable lighting recommendations, country comparison.

Figure 422011 Implementation of applicable transport recommendations, country comparison. 
Figure 432011 Implementation of applicable industry recommendations, country comparison.. 126

Figure 442011 Implementation of applicable energy utility recommendations 127

Page | 4

\section{List of tables}

Table 1 Colour grading system used for reporting implementation of the recommendations...... 10

Table 2 Drivers of government energy efficiency policies .............................................................. 13

Table 32011 Summary of recent policy developments in IEA member countries

Table 4 Summary of challenges and areas for improvement in IEA member country energy efficiency policy. 


\section{Acknowledgements}

This report is the product of a team of people involved in the data provision, analysis and review process. The report project manager is Sara Bryan Pasquier, IEA Energy Efficiency Policy Analyst. Aurelien Saussay contributed to data management and analysis. All members of the Energy Efficiency Unit contributed technical expertise over several months. Particular thanks go to Nina Campbell, MaryRose Cleere, Philippine de T'Serclaes, Charlotte Forbes, Grayson Heffner, Nigel Jollands, Kazunori Kojima, Jens Lausten, Jungwook Park, Vida Rozite, Lisa Ryan, Yamina Saheb and Edita Zlatic. Nathalie Trudeau, Davide D'Ambrosio and Paulo Canfora provided analysis on indicators. Georg Bussmann provided data on final energy intensity in IEA member countries. Overall supervision was provided by Robert Tromop, Head of the Energy Efficiency Unit; Rick Bradley, former Head of the Energy Efficiency and Environment Division; Philippe Benoit, current Head of the Energy Efficiency and Environment Division, and Bo Diczfalusy, Director of the Sustainable Energy Policy and Technology Directorate.

This report would not have been possible without the efforts and contributions from IEA member country government officials, the Energy Efficiency Working Party, the Standing Group on LongTerm Co-operation and the European Commission. 
Energy efficiency plays a critical role in addressing energy

Page | 6 security, environmental and economic challenges.

Substantial energy efficiency improvements can be achieved by implementing the IEA 25 energy efficiency policy recommendations.

This report investigates progress with implementing energy efficiency policies in IEA member countries from March 2009 to April 2011.

IEA member
countries have
made significant
progress with
implementing
energy efficiency
policies since 2009.

\section{Executive Summary}

Significantly improving energy efficiency remains a priority for all countries. Meetings of $\mathrm{G} 8$ leaders and IEA ministers reaffirmed the critical role that improved energy efficiency can play in addressing energy security, environmental and economic challenges. Many IEA publications have also documented the essential role of energy efficiency. For example, the World Energy Outlook and the Energy Technology Perspectives reports identify energy efficiency as the most significant contributor to achieving energy security, economic and environmental goals. Energy efficiency is clearly the "first fuel" in the delivery of energy services in the coming low-carbon energy future.

To support governments in their implementation of energy efficiency, the IEA recommended the adoption of specific energy efficiency policy measures to the $\mathrm{G} 8$ summits in 2006, 2007 and 2008. The consolidated set of recommendations to these summits is known as the 'IEA 25 energy efficiency policy recommendations' because it covers 25 fields of action across seven priority areas: cross-sectoral activity, buildings, appliances, lighting, transport, industry and energy utilities. The IEA estimates that if implemented globally without delay, the proposed actions could save as much as 7.6 giga tonnes (Gt) $\mathrm{CO}_{2} /$ year by $2030-$ almost 1.5 times the current annual carbon dioxide $\left(\mathrm{CO}_{2}\right)$ emissions of the United States.

The IEA 25 energy efficiency policy recommendations were developed to address policy gaps and priorities. This has two implications. First, the recommendations do not cover the full range of energy efficiency policy activity possible. Rather, they focus on priority energy efficiency policies identified by IEA analysis. Second, while IEA analysis, the energy efficiency professional literature and engagement with experts clearly demonstrate the broad benefits of these IEA priority measures, the recommendations are not weighted to reflect the different energy end-use make up of different economies. The IEA therefore suggests that countries implement a robust portfolio of the recommendations relevant to their energy and economic context.

In 2009, the IEA conducted an evaluation of member-country implementation of the IEA 25 energy efficiency policy recommendations and similar measures. This evaluation revealed that governments were implementing a wide array of innovative energy efficiency measures. These included national strategies and action plans, minimum energy performance requirements (MEPs) for appliances and equipment, financial instruments and other policies to improve building energy efficiency, adoption of standby power policies and the phase out of inefficient lighting. Policies also promoted proper tyre inflation and provided incentives for energy utilities to improve end-use energy efficiency.

In 2011, the IEA conducted a second evaluation, the results of which are published in this report. The findings show significant energy efficiency policy developments since 2009 (Figures 1 and 2). In 
particular, IEA member countries have implemented many of the policies in the transport, appliance and lighting sectors that were only planned in 2009.

Figure 1 Implementation of all applicable recommendations, all IEA member countries

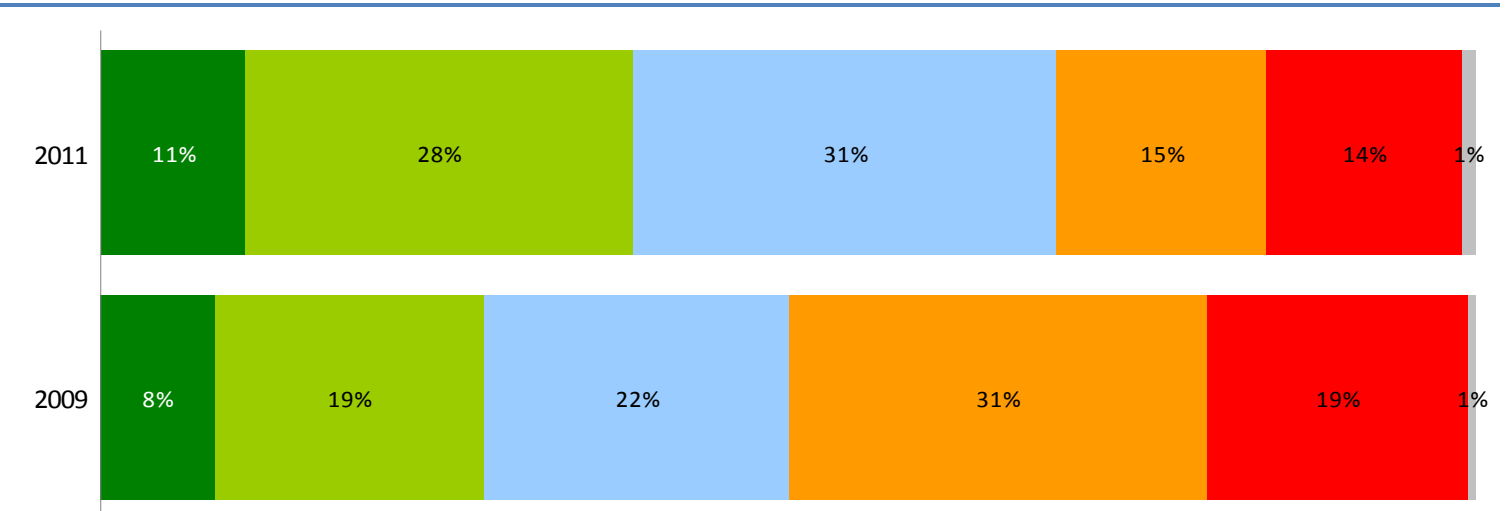

Full implementation

Plan to implement
Substantial implementation Implementation underway

- Not implemented

Figure 2 Implementation by sector of all applicable recommendations, all IEA member countries

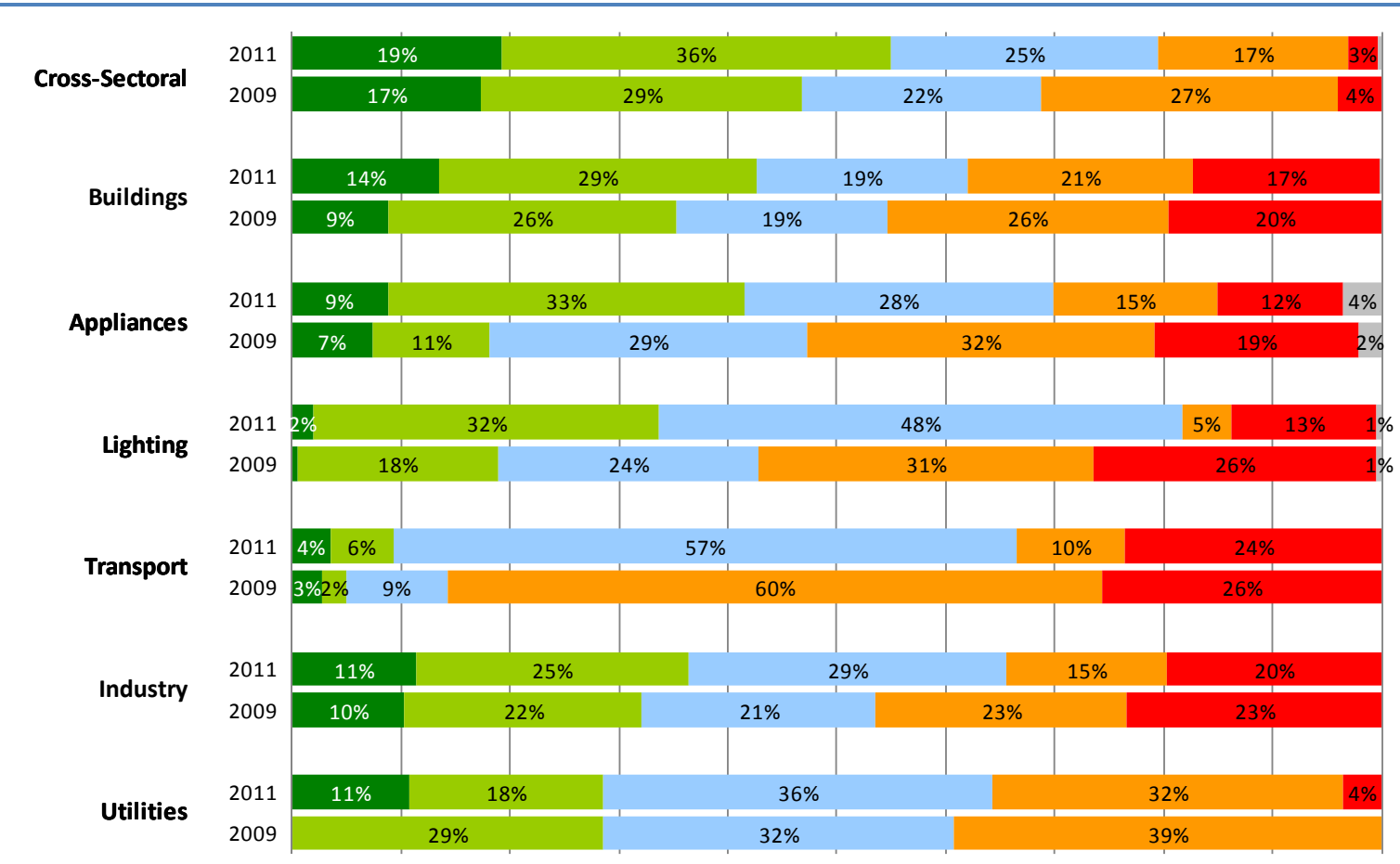

Full implementation

Plan to implement
Substantial implementation $\quad$ Implementation underway

- Not implemented

Policy developments since 2009 include strengthened MEPs in building codes, implementation of building certification schemes and increased collection and publication of information on energy efficiency in existing buildings. In the appliance and equipment sector, member countries are strengthening and expanding MEPs and implementing standby power requirements.

The transport sector has experienced noteworthy policy development since 2009, especially with 
regard to regulations for tyre-pressure monitoring systems (TPMS), tyre rolling resistance and labelling, $\mathrm{CO}_{2}$ emissions standards for passenger cars and policies to promote eco-driving and feedback instruments, particularly in EU member states. Energy management and promotion of MEPs for motors have strengthened energy efficiency policy in industry, and some countries have further implemented policies to encourage energy utilities to deliver cost-effective energy savings to end users.

These examples illustrate the significant progress IEA member countries have made in implementing energy efficiency policies since 2009. As this policy implementation experience is a valuable resource for IEA member and non-member countries alike, the IEA is disseminating it through several outreach activities, including the Policy Pathway series of publications, the International Partnership for Energy Efficiency Cooperation (IPEEC) and the newly established Training and Capacity-Building Programme. These activities seek to help member and nonmember countries implement policies that overcome pervasive barriers to energy efficiency, including lack of access to capital for energy efficiency investments, insufficient information, principal-agent problems and externalities that are not reflected in energy prices.

The benefits of implementing energy efficiency extend beyond energy security and climate change mitigation. Experience shows that energy efficiency investments can deliver significant benefits - including job creation and health improvements. IEA member and non-member countries can further gain from these multiple-benefits by identifying areas where cost-effective energy savings potential remains and implementing policies to capture these savings.

1. There have been substantial policy implementation and innovations since 2009. All IEA member countries have developed and implemented new energy efficiency policies and all sectors have benefited from recent policy developments. Nevertheless, IEA member countries still have significant unexploited energy savings opportunities that could be achieved with additional energy efficiency policy implementation.

2. Experience with implementing energy efficiency policies in IEA member countries is a valuable resource for member and non-member countries alike. Sharing experience with implementing energy efficiency policies will accelerate energy efficiency improvements globally and the transformation of markets for energy-efficient technologies.

3. IEA analysis from this and other reports indicates that the benefits of implementing energy efficiency extend beyond energy security and climate change mitigation to job creation, health improvements and others. 


\section{Introduction}

\section{IEA 25 energy efficiency policy recommendations}

Improving energy efficiency remains a priority for all countries. Meetings of G8 leaders and IEA member country ministers reaffirmed the critical role that improved energy efficiency can play in addressing energy security, environmental and economic challenges.

To help countries implement energy efficiency policies relevant to their energy economies, the IEA recommended the adoption of specific energy efficiency policy measures to the G8 summits in 2006, 2007 and 2008. The consolidated set of recommendations to these summits covers 25 fields of action across seven priority areas: cross-sectoral activity, buildings, appliances, lighting, transport, industry and energy utilities. All recommendations drew on extensive IEA technical/economic modelling, studies of international policy experience and dialogues with experts and stakeholders. Furthermore, all recommendations were subject to a rigorous set of criteria; e.g. recommendations:

- save a large amount of energy at low cost and with considerable economic advantages to consumers;

- address market imperfections or barriers by enabling consumers to make informed decisions and fully benefit from their investments;

- target a significant gap in existing policy.

The IEA 25 energy efficiency policy recommendations provide a useful portfolio of cost-effective options for countries to consider in the context of their energy economies and should lead to significant cost-effective energy and carbon dioxide $\left(\mathrm{CO}_{2}\right)$ savings on a global scale. The IEA estimates that if implemented globally without delay, the proposed actions could cumulatively save around $7.6 \mathrm{Gt}$ of $\mathrm{CO}_{2}$ /year by 2030. This is equivalent to almost 1.5 times the current annual $\mathrm{CO}_{2}$ emissions of the United States.

\section{Purpose and report structure}

\section{Evaluation}

At the 2007 IEA Ministerial Meeting, Energy Ministers strongly welcomed the IEA 25 energy efficiency policy recommendations and invited the IEA "to evaluate and report on the energy efficiency progress of IEA member and key non-member countries". In response to this invitation, in 2009, the IEA conducted an evaluation of member country implementation of the recommendations and similar measures. The 2009 report provided an overview of the areas where the IEA considered a country to be progressing towards maximising its energy efficiency policy implementation efforts, and identified areas where further action was required. The results of the 2009 Evaluation were published in the book Implementing Energy Efficiency Policies: Are IEA member countries on track? and launched at the 2009 IEA Ministerial.

\section{Evaluation}

In consultation with member countries, in 2011, the IEA again conducted an evaluation of member country implementation of the IEA 25 energy efficiency policy recommendations. The evaluation results are published in this report.

Using the 2009 Evaluation results as a benchmark, this report begins with a short overview of the 
energy efficiency policy context across IEA member countries. It then explores energy efficiency policy developments since the 2009 Evaluation, and describes areas where more policy attention should be considered. Individual country evaluation results are highlighted in the Country Reports section.

\section{Page | 10 Approach}

The analysis contained in this report is based on information gathered from several sources:

- country responses to the IEA questionnaire on implementation of the IEA 25 energy efficiency policy recommendations, and subsequent IEA review;

- energy efficiency policy reports submitted by member countries to the IEA Energy Efficiency Working Party;

- the IEA energy efficiency indicators' database;

- IEA in-depth energy policy reviews;

- the IEA energy efficiency policies and measures database;

- IEA expert knowledge of policy developments in IEA member countries.

Information in this report is current up to April 2011.

The approach used in this report applies a five-step colour grading system (Table 1).

Table 1 Colour grading system used for reporting implementation of the recommendations

\begin{tabular}{ll}
\hline Progress level & Description \\
\hline Fully implemented & $\begin{array}{l}\text { The policy recommendation - or similar policy - has been fully implemented } \\
\text { according to defined criteria. }\end{array}$ \\
\hline Substantial implementation & $\begin{array}{l}\text { The policy recommendation - or similar policy - has been implemented with } \\
\text { some minor limitations. }\end{array}$ \\
\hline Implementation underway & $\begin{array}{l}\text { The policy recommendation - or similar policy - is being implemented and the } \\
\text { policy is at a stage where regulations/instruments have been developed and } \\
\text { implemented, but with significant limitations. }\end{array}$ \\
\hline Plan to implement & $\begin{array}{l}\text { The policy recommendation - or similar policy - is planned for } \\
\text { implementation. This is indicated by regulations/instruments that have } \\
\text { already been developed but are not yet operational. }\end{array}$ \\
\hline Not implemented & \begin{tabular}{l} 
The recommendation has not been implemented. \\
\hline Not applicable
\end{tabular} \\
\hline
\end{tabular}

For each recommendation, the IEA defined criteria for achieving each progress level.

For the 2009 Evaluation, countries completed a self-evaluation questionnaire, and used the fivestep grading system to evaluate progress made in implementing the energy efficiency recommendations. For the 2011 Evaluation, IEA member countries were pre-scored based on IEA analysis and consultations with the European Commission. Countries could then review their scores and, if they disagreed with them, provide evidence to modify them.

\section{Bar charts}

Questionnaire scores from 2009 and 2011 are compared in bar charts like the one in Figure 3. Some bar charts summarise the results of all IEA member countries for a single recommendation. For example, Figure 3 can be interpreted as $29 \%$ of countries have 'substantially implemented' a particular recommendation, or equivalent measure, in 2011 versus 26\% in 2009. 
Some bar charts summarise the results for all IEA member countries across several recommendations. In this case, Figure 3 would show that the percentage of recommendations 'fully implemented' by member countries in 2009 is $9 \%$ versus $14 \%$ in 2011.

Figure 3 Sample bar char
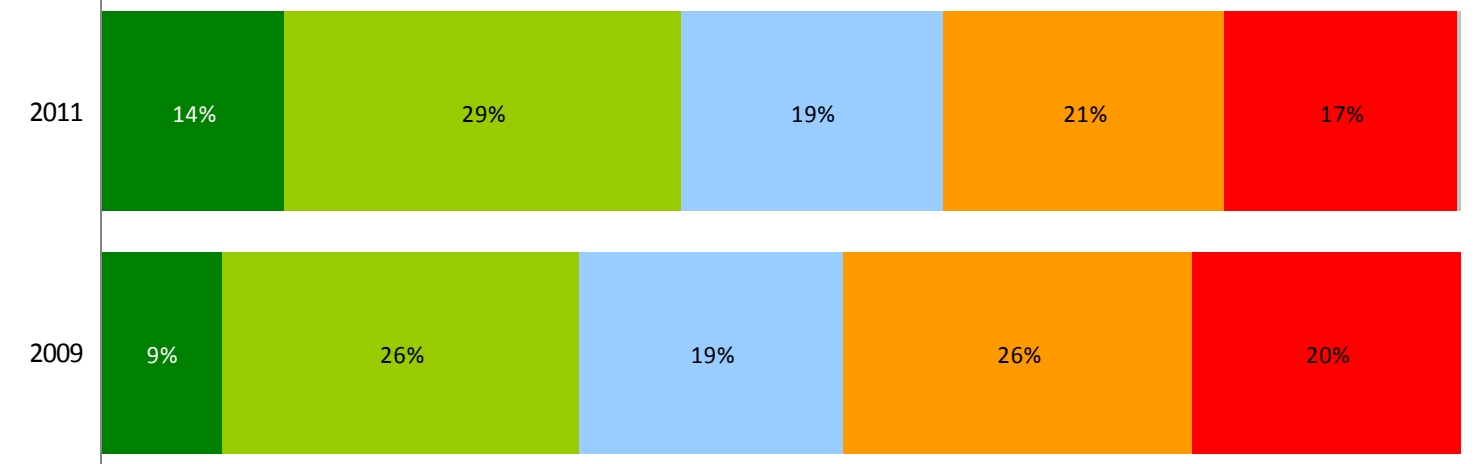

Full implementation

Plan to implement

\begin{abstract}
Substantial implementation $\square$ Implementation underway
\end{abstract}
Not implemented

\section{Energy efficiency policy context}

Since the oil shocks of the 1970s, IEA member countries have promoted energy efficiency improvements across all sectors. These policies and structural changes in their economies mean most IEA member countries have been able to decouple energy use from economic growth. This is shown in the decline in final energy intensity ${ }^{1}$ in most IEA member countries since 1990 (Figure 32 and Figure 33). Without the energy savings resulting from reduced energy intensity, IEA member country energy use would have been significantly greater. IEA analysis suggests that, for a group of IEA member countries (IEA17 ${ }^{2}$ ), total final energy consumption in the IEA17 would have been 63\% higher in 2008 (Figure 4).

In the period from 1990 to 2009, IEA member countries on average decreased their final energy intensity by $1.6 \%$ per year (Figure 32 ). But the rate of energy intensity decline has not been constant over time and IEA analyses suggest that it was higher in the two decades before the 1990s (International Energy Agency 2008a) than since the early 2000s. It appears that "the oil price shocks of the 1970s and the resulting energy policies did considerably more to control growth in energy demand and $\mathrm{CO}_{2}$ emissions than the energy efficiency and climate policies implemented in the 1990s" (International Energy Agency 2008a). However, in the last couple of years, the rate of energy intensity improvement has tended to increase. This may be due to increased energy prices and greater attention to climate change issues.

\footnotetext{
${ }^{1}$ Energy intensity is the amount of energy used per unit of activity. It is commonly calculated as the ratio of energy use to Gross Domestic Product (GDP). Energy intensity is often taken as a proxy for energy efficiency, although this is not entirely accurate since changes in energy intensity are a function of changes in several factors including the structure of the economy and energy efficiency. For a detailed discussion of the energy intensity indicator, please see International Energy Agency (2007a).

2 IEA17: Australia, Austria, Canada, Denmark, Finland, France, Germany, Greece, Ireland, Italy, Japan, Netherlands, New Zealand, Norway, Sweden, United Kingdom, United States.
} 
Figure 4 Economy-wide energy savings from improvements in energy efficiency, IEA173

Page | 12

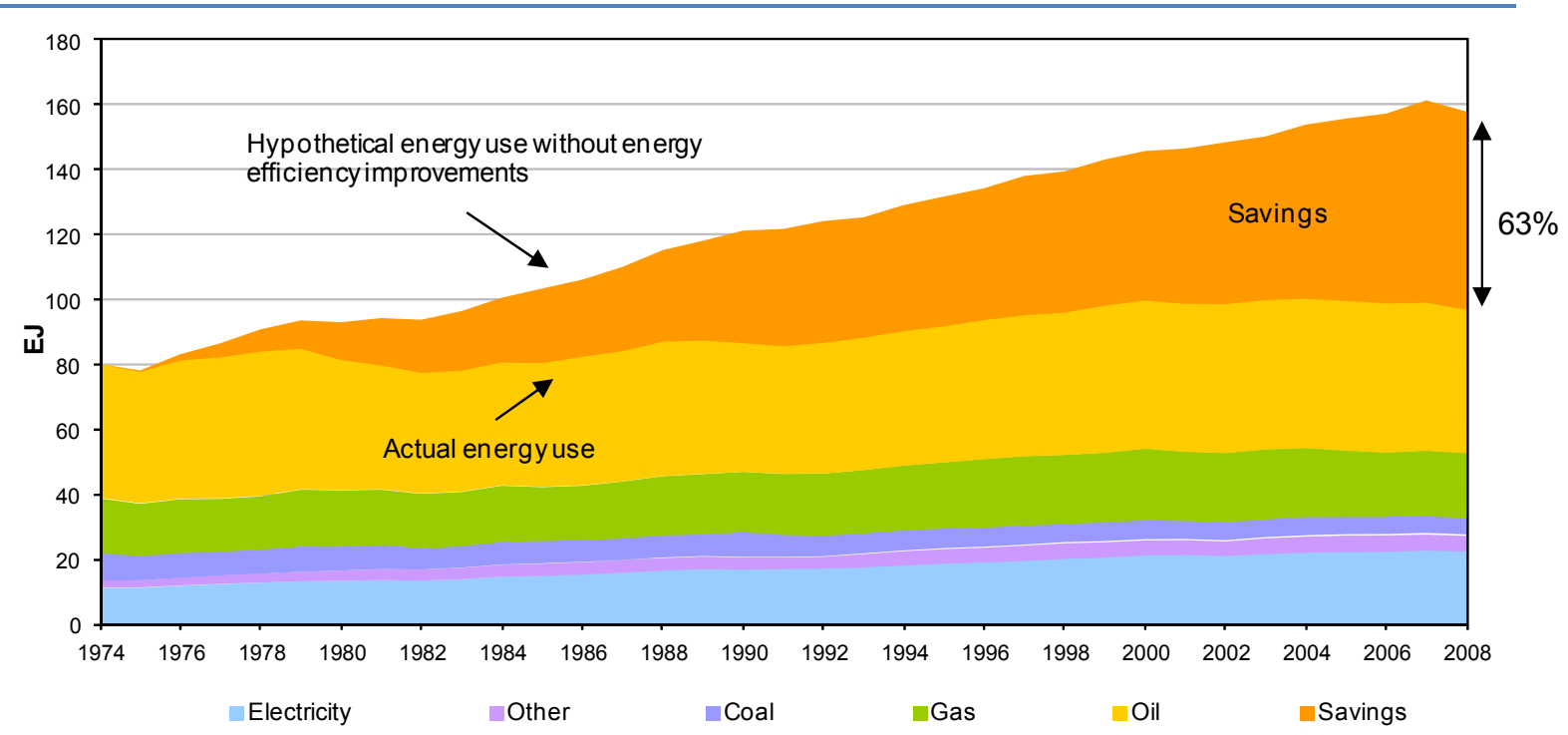

Source: IEA indicators database.

The energy efficiency policy landscape varies from country to country. In the context of implementing the 25 energy efficiency recommendations, it is important to note that while the recommendations have broad applicability across many countries, national circumstances (including energy supply, end-use economy, culture, population distribution, political systems, geography and climate) vary across countries and present different energy efficiency opportunities and barriers. These national circumstances influence energy efficiency policy priority setting and lead to a tailored mix of policies aimed at achieving the greatest energy savings at the lowest costs. Despite differences in country context, energy efficiency policy development is often in response to similar drivers (Table 2).

A driver of energy efficiency policy development at the time of the 2009 Evaluation was the global economic crisis. In an attempt to respond to the crisis and the ensuing economic downturn, many IEA member countries developed stimulus packages - the majority of which included measures for the development of clean energy and energy efficiency. In 2011, the results of the stimulus packages were coming to light.

For example, in 2009 and in 2010 Canada allocated additional funding to the ecoEnergy Retrofit Homes programme in response to unprecedented demand, bringing the total budget to CAD 745 million over four years. To date, the programme has allowed more than 510,000 Canadian homeowners to make energy-efficient retrofits to their homes.

In another example, as part of stimulus measures for the automobile industry, Italy introduced financial incentives for the replacement of old cars and trucks with newer, more efficient and less polluting vehicles. A recent evaluation reported that the programmes led to savings of $2972 \mathrm{GWh} /$ year (expressed in terms of final energy consumption achieved in 2010).

\footnotetext{
3 "Other" includes combustible renewables, waste, heat, geothermal and solar thermal energy.
} 
Table 2 Drivers of government energy efficiency policies

\begin{tabular}{|c|c|}
\hline Driver & Typical objectives \\
\hline Energy security & $\begin{array}{l}\text { - } \text { Reduce imported energy } \\
\text { - } \text { Reduce domestic demand to maximise exports } \\
\text { - Increase reliability } \\
\text { - } \quad \text { Control growth in energy demand }\end{array}$ \\
\hline $\begin{array}{l}\text { Economic development and } \\
\text { competitiveness }\end{array}$ & $\begin{array}{l}\text { - } \\
\text { - } \text { Improve industrial competitiveness } \\
\text { - } \text { Reduce production costs } \\
\text { - } \text { Deliver more affordable energy customer costs } \\
\text { - Improved efficiency of energy markets }\end{array}$ \\
\hline Climate change & $\begin{array}{l}\text { - Contribute to global mitigation and adaptation efforts } \\
\text { - Meet international obligations under the United } \\
\text { Nations Framework Convention on Climate Change } \\
\text { (UNFCCC) } \\
\text { - Meet supra-national (e.g. European Union) accession } \\
\text { requirements or directives }\end{array}$ \\
\hline Public health & $\begin{array}{ll}\text { - } & \text { Reduce indoor and local pollution } \\
\text { - } & \text { Maintain indoor temperatures to comfortable levels }\end{array}$ \\
\hline
\end{tabular}




\section{Recent energy efficiency policy developments in IEA member countries}

Since 2009, all IEA member countries have improved energy efficiency policy implementation Page | 14 (Table 3).

Table 32011 Summary of recent policy developments in IEA member countries

\begin{tabular}{|c|c|}
\hline Cross-sectoral & $\begin{array}{l}\text { - Many IEA member countries implementing policies to increase energy efficiency } \\
\text { investments. } \\
\text { - New efforts to ensure voluntary and mandatory energy efficiency policies are } \\
\text { adequately monitored, enforced and evaluated in Australia, Canada, EU member } \\
\text { states, Turkey and the United States. }\end{array}$ \\
\hline Buildings & $\begin{array}{l}\text { - New policies put in place to strengthen building codes for new buildings in Canada, } \\
\text { Korea, Luxembourg, Netherlands and the United Kingdom. } \\
\text { - } \quad \text { Building certification implemented and strengthened in EU member states. } \\
\text { - Information on energy efficiency in existing buildings systematically collected and } \\
\text { reported, with limitations, in Canada, Germany, Japan, Korea and New Zealand. }\end{array}$ \\
\hline $\begin{array}{l}\text { Appliances } \\
\text { equipment }\end{array}$ & $\begin{array}{l}\text { - Minimum energy performance requirements (MEPs) strengthened and expanded to } \\
\text { cover new appliances and equipment in many IEA member countries. } \\
\text { Introduction of new MEPs and labelling for televisions, set-top boxes and digital } \\
\text { television adaptors (DTAs) in Australia, Canada and Japan. } \\
\text { - Many standby power requirements planned in } 2009 \text { are now implemented. }\end{array}$ \\
\hline Lighting & $\begin{array}{l}\text { - } \quad \text { All but two countries continue to phase out inefficient incandescent lamps. } \\
\text { - Canada, Japan, the Netherlands, the United Kingdom and the United States support } \\
\text { international efforts to stimulate adoption of higher-efficiency alternatives to fuel- } \\
\text { based lighting in off-grid communities in developing countries. }\end{array}$ \\
\hline Transport & $\begin{array}{l}\text { - } \quad \text { EU adopted regulations for TPMS, tyre rolling resistance and labelling. } \\
\text { - Japan started voluntary tyre-labelling scheme. } \\
\text { - } \quad \text { EU adopted a regulation for } \mathrm{CO}_{2} \text { emissions for passenger cars. } \\
\text { - } \quad \text { US tightened corporate average fuel economy (CAFE) standards for model year (MY) } \\
\text { - } 2012-2016 \text {. } \\
\text { Gear-shift indicators mandatory in all new passenger cars with manual transmission } \\
\text { in EU member states. }\end{array}$ \\
\hline Industry & $\begin{array}{l}\text { - Coverage of industry energy statistics high in all countries, particularly in Canada, } \\
\text { Denmark and Switzerland. } \\
\text { Developments in policies to promote MEPs for motors in EU member states, Japan, } \\
\text { the United States and other countries. } \\
\text { - Energy management in industry strengthened in Australia, Norway, the Slovak } \\
\text { Republic and the United Kingdom. } \\
\text { - Several countries made advances in policies for small and medium-sized enterprises } \\
\text { (SMEs) including Italy, Slovak Republic, Spain and Sweden. }\end{array}$ \\
\hline Energy utilities & $\begin{array}{l}\text { - Further implementation of policies to encourage utilities to deliver cost-effective } \\
\text { energy savings to end users in Canada, Denmark, Ireland, Poland, Spain, the } \\
\text { United Kingdom and the United States. }\end{array}$ \\
\hline
\end{tabular}




\section{Cross-sectoral}

Five of the 25 IEA energy efficiency policy recommendations attempt to help governments set effective cross-sectoral frameworks for energy efficiency. These recommendations encourage policies to strengthen energy efficiency investments, strategies, goals, compliance, monitoring, enforcement, evaluation and indicators.

Since 2009, IEA member countries have made some progress in developing cross-sectoral policies (Figure 5). Several IEA member countries are implementing policies that were only planned in 2009. Others have improved implementation of policies already under way.

Figure 5 Progress with implementing the cross-sectoral recommendations

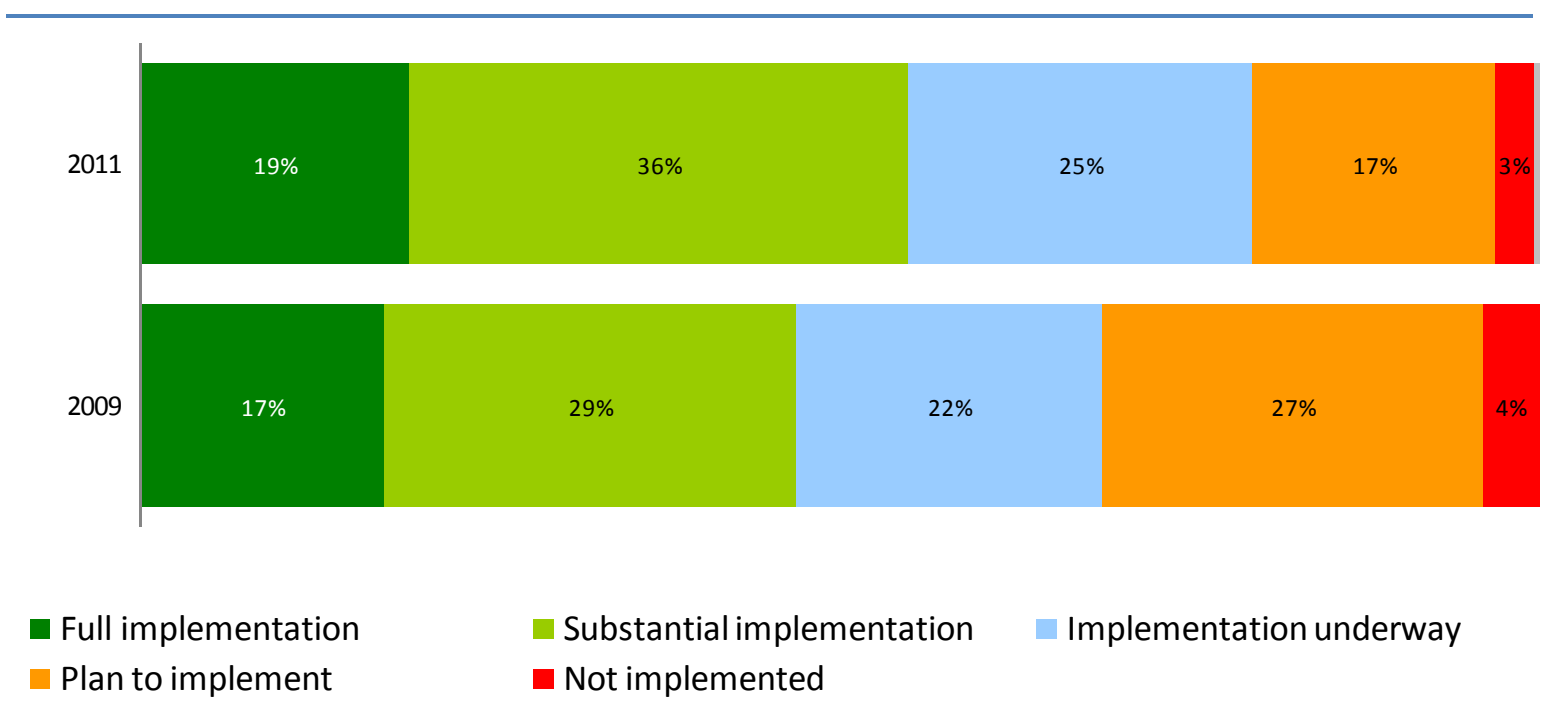

\section{Policies to increase investment}

Poor access to capital and the perceived risk of energy efficiency projects often limit investment in energy efficiency. At the time of the 2009 Evaluation, many IEA member countries were developing policies to address barriers to energy efficiency investments. Notably Germany and Japan were creating innovative financial instruments.

The 2011valuation reveals several new efforts to design and implement policies to overcome barriers to investment - particularly with regard to the development of a common savings measurement and verification protocol (Figure 6).

A number of IEA member countries, including Canada and the United States, participate in Global Superior Energy Performance (GSEP), a programme that seeks to promote public-private partnership and the adoption of an energy management system through a network of harmonised governmental certification programmes. Under GSEP, a measurement and verification (M\&V) protocol is being developed to verify conformance to ISO 50001 and energy performance improvements. In parallel, new methods for measuring and verifying energy savings are being developed that take advantage of advanced measuring devices, and new statistical methods.

All EU member states are developing energy savings protocols under the Directive on energy end-use efficiency and energy services (2006/32/EC), Articles 9 and 15.

The Slovak Innovation and Energy Agency (SIEA) operates an energy efficiency monitoring system 
according to Act No. 476/2008 Coll. on Energy Efficiency. Energy savings protocols will be gradually included as a part of the monitoring system.

\section{Figure 6 Common energy efficiency savings verification and measurement protocols}

Page | 16

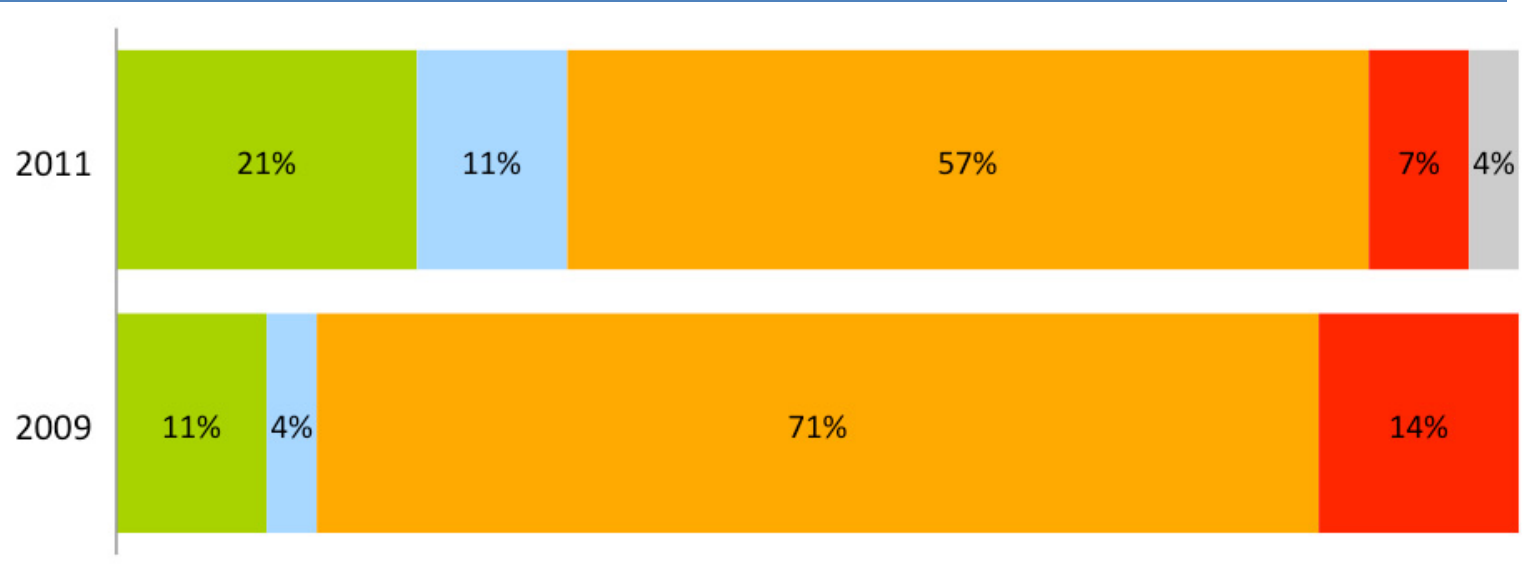

- Full implementation

- Plan to implement
Substantial implementation $\square$ Implementation underway
Not implemented

Several countries have launched programmes to fund energy efficiency improvements (Figure 7). Hungary, for example, launched a large-scale economic incentive package, called the New Szechenyi Plan, in early 2011. This multi-year programme with a EUR 2.5 billion budget seeks to improve the competitiveness of the economy. Two of the plan's seven priority areas - green economy and home-building programme - include funding for energy efficiency. The energy efficiency of small and medium enterprises will also be a priority under this plan.

The Korean Energy Management Corporation (KEMCO) partnered with a private bank to provide USD 550 million to support industry and building energy efficiency projects in 2011 . Publicprivate funding is also available through Korea's carbon fund (USD 180 million).

New Zealand reports that several energy efficiency programmes have active third party funding partnership relationships with the finance sector and are achieving useful funding outcomes.

With the help of the European Bank for Reconstruction and Development (EBRD), Poland is encouraging increased investment in energy efficiency. The EBRD is providing the Polish banks BGZ and Millennium with loans of EUR 50 million and EUR 35 million respectively to lend to small and medium enterprises (SMEs) undertaking sustainable energy investments. The loans are part of the EBRD's EUR 150 million Poland sustainable energy financing facility (PoISEFF), which is a credit line to help small and medium sized businesses in Poland invest in new, sustainable energy technologies. PoISEFF credit lines up to EUR 1 million are available through partner banks and leasing companies.

In the Slovak Republic, SIEA is collaborating with the private financial sector to establish tools to facilitate energy efficiency financing. SIEA is responsible for preparing draft model contracts for energy services and financial instruments for achieving energy savings. Also in the Slovak Republic, schemes like the Slovak Sustainable Energy Financing Facility (SLOVSEFF) are used to finance energy efficiency measures. SLOVSEFF is based on a credit line and financial resources from the Bohunice International Decommissioning Support Fund, administered by EBRD through Slovak commercial banks. Another project financed from this source and administered by SIEA is called "Energy Efficiency in Public Buildings". 


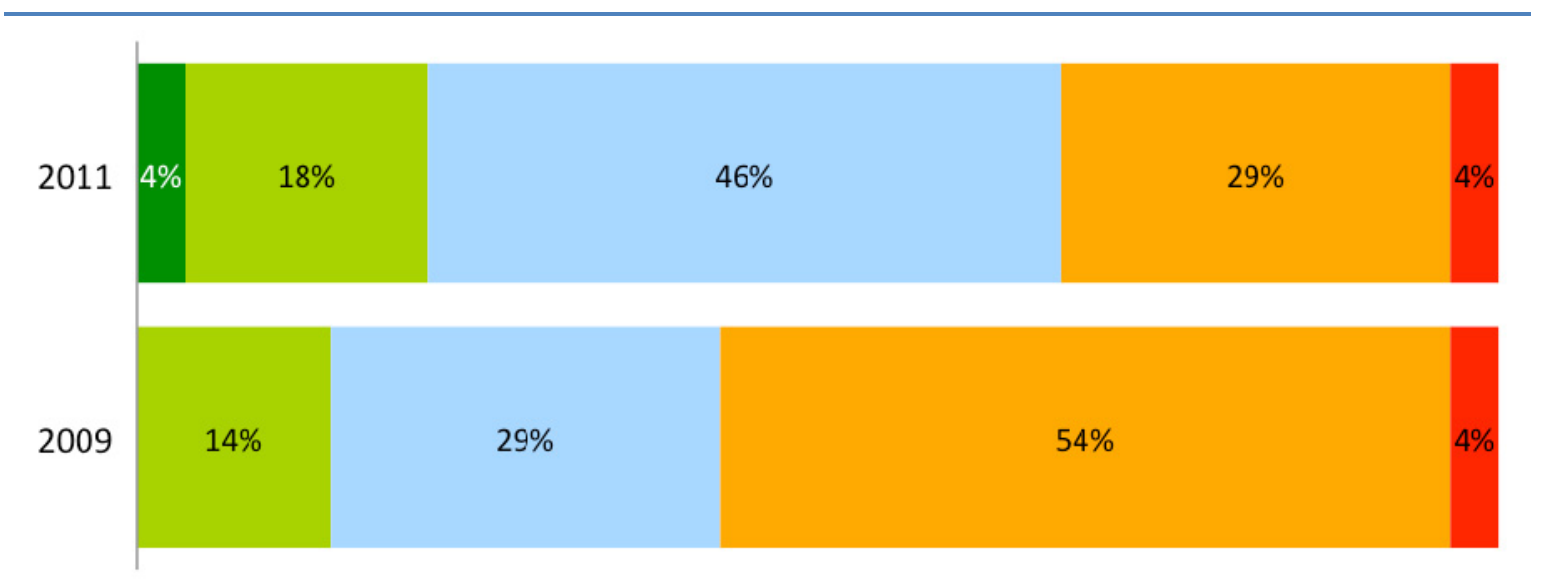

Full implementation

- Plan to implement
Substantial implementation Implementation underway
Not implemented

\section{Strategies and goals}

In 2009, most IEA member countries had already employed a strategy development or action planning process as a means to engage stakeholders, build consensus and galvanise action on energy efficiency. In fact, as of March 2009, all EU member states had created or updated National Energy Efficiency Action Plans (NEEAPs) in compliance with the European Community's Energy Services Directive 2006/32/EC. At the time of the 2011 Evaluation, EU member states mentioned efforts to finalise and submit a second NEEAP to the European Commission by endJune 2011.

Several non-EU member states, including Australia and Turkey, reported strategy and action plan development. In July 2010, Australia updated its National Strategy on Energy Efficiency (NSEE), which covers a range of policy measures designed to overcome barriers that prevent energy efficiency uptake. The NSEE focuses on demand-side energy efficiency across all end-use sectors and is accelerating energy efficiency efforts to help prepare the economy for the introduction of a carbon price mechanism. The NSEE does not contain specific energy-saving targets.

Turkey drafted the Energy Efficiency Strategy Paper, which includes indicative sectoral targets. This paper has been sent to the High Planning Council via the Ministry of Energy and Natural Resources (MENR) for formal approval.

\section{Compliance, monitoring, enforcement and evaluation}

The 2009 Evaluation found that most countries conduct ex ante evaluations of energy efficiency policies and institutional compliance infrastructures.

In the 2011 Evaluation, governments reported on efforts to ensure that voluntary and mandatory energy efficiency policies are adequately monitored, enforced and evaluated. For example, Australia's Energy Efficiency Opportunities Act (EEO Act) established measures for compliance and verification. Consultation with large energy-using companies in the EEO programme is underway to establish better monitoring and evaluation procedures for the EEO programme's second cycle, which runs from July 2011 to June 2016. Australia's MEPs and labelling programme has standard procedures for compliance, monitoring and enforcement.

Canada described a robust system for evaluating policy and programme success during and after 
implementation. Its Energy Efficiency Act requires evaluation information to be published in an annual 'Report to Parliament'. Programmes and policies are regularly audited by the Auditor General and the Commissioner of the Environment and Sustainable Development, and reviewed in annual planning and priorities submissions. In compliance with the federal Transfer Payments Policy, all programmes are also regularly evaluated and the results published.

Page | 18 Various EU member states are significantly improving compliance, monitoring and enforcement (CME) through transposition of several Directives. The Slovak Republic, for example, reported passing several acts to implement EU directives that lead to greater CME; Act No. 476/2008 Coll. on Energy Efficiency (defining reporting requirements of all stakeholders in legislation), Act No. 555/2005 Coll. on Energy Performance of Buildings, Act No. 17/2007 Coll. on Regular Inspection of Boilers, Heating Systems and Air Conditioning Systems and Act No. 529/2010 Coll. on Ecodesign.

Spain described how a CME programme is in place to validate savings derived from implementation of its NEEAP. In June 2011 EU member states were required to submit the results of such calculations to the Commission as part of the second NEEAP.

In Turkey, a new Division of Monitoring and Evaluation was established in the General Directorate of Electrical Power Resources Survey Administration (EIE) at the end of 2010. A new project will start in 2011 to establish a comprehensive monitoring and evaluation system and infrastructure.

The United Kingdom has been actively strengthening market surveillance and enforcement of product standards and labels through the appointment of the National Measurement Office as a newly dedicated central market surveillance authority.

The United States has substantially increased the resources allocated to product certification, compliance and enforcement over the last two years and has begun to implement strict new requirements for third party testing and verification of products with ENERGY STAR labels. The United States Department of Energy (US DOE) now has its own product test facility and is in the process of constructing an even larger facility. The US DOE has initiated dozens of compliance actions to ensure full compliance with its product standards and ENERGY STAR labelling requirements.

\section{Buildings}

The 2009 Evaluation found that energy efficiency requirements for buildings are a key feature of all IEA member country policies.

At the time of the 2011 Evaluation, many IEA member countries reported recent policies to improve energy efficiency in the buildings sector Figure 8 .

\section{Building codes}

In May 2010, EU member states adopted the Energy Performance of Buildings Directive Recast (2010/31/EU), which outlines minimum energy performance requirements for new and existing buildings. 
Figure 8 Progress with implementing the building recommendations

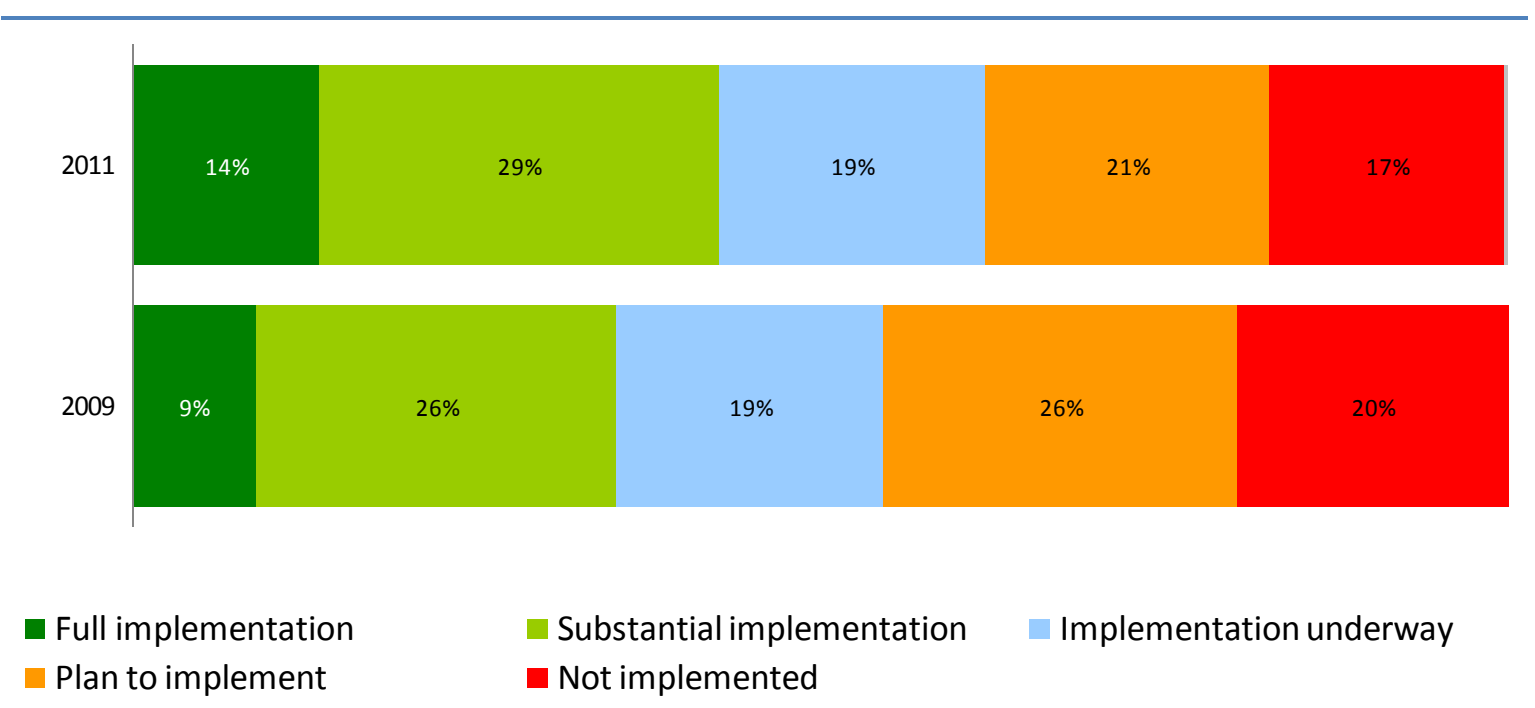

Canada published the 2011 National Energy Code of Canada in November 2011. This code provides minimum requirements for the design and construction of energy-efficient buildings and covers the building envelope, systems and equipment for heating, ventilating and airconditioning, service water heating, lighting, and the provision of electrical power systems and motors. It applies to new buildings, as well as to substantial renovations in existing ones. Canada is committed to further strengthening the 2011 building code by 2015 .

In June and December 2010, Korea reinforced building code standards and standby power. A further revision of building-code standards is scheduled in 2012.

Figure 9 Mandatory energy efficiency standards for new buildings in building codes

2011

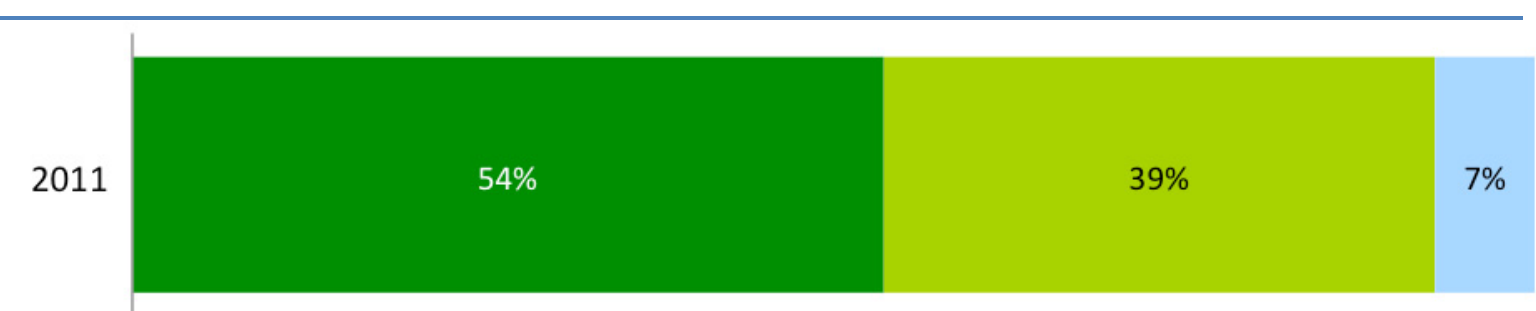

- Full implementation

- Plan to implement
- Substantial implementation $\square$ Implementation underway

not implemented

In August 2010, Luxembourg updated its building codes related to energy performance in nonresidential buildings.

The Netherlands reported that the building code standard is set for cost efficiency over the lifetime of the measures.

In the United Kingdom, building regulations were revised and strengthened in 2010. Further revisions will follow in 2013 and 2016. 


\section{Passive-energy houses and zero-energy buildings}

The 2009 Evaluation found that Austria, Denmark, France, Germany and the United Kingdom had planned policies to promote very-low or no-net energy consumption in buildings (passive-energy houses (PEH) and zero-energy buildings (ZEB)). At the time of the 2011 Evaluation, several of these countries mentioned further work to support PEH and ZEB. Denmark, for example, set targets for new builds in 2015 and 2020 at or better than the PEH standard. In accordance with a revised strategy for energy consumption reduction in buildings adopted in April 2009, all new buildings must meet requirements for low-energy houses by 2010. By 2015, new building energy consumption must be reduced by $60 \%$ compared to current requirements. Denmark's requirements for new residential buildings will, by 2015 , be equivalent to current voluntary German standards for PEH. The overall vision of the Danish government is that, in the long run, all buildings should be "plus-energy-houses", i.e. houses that produce more energy than they consume.

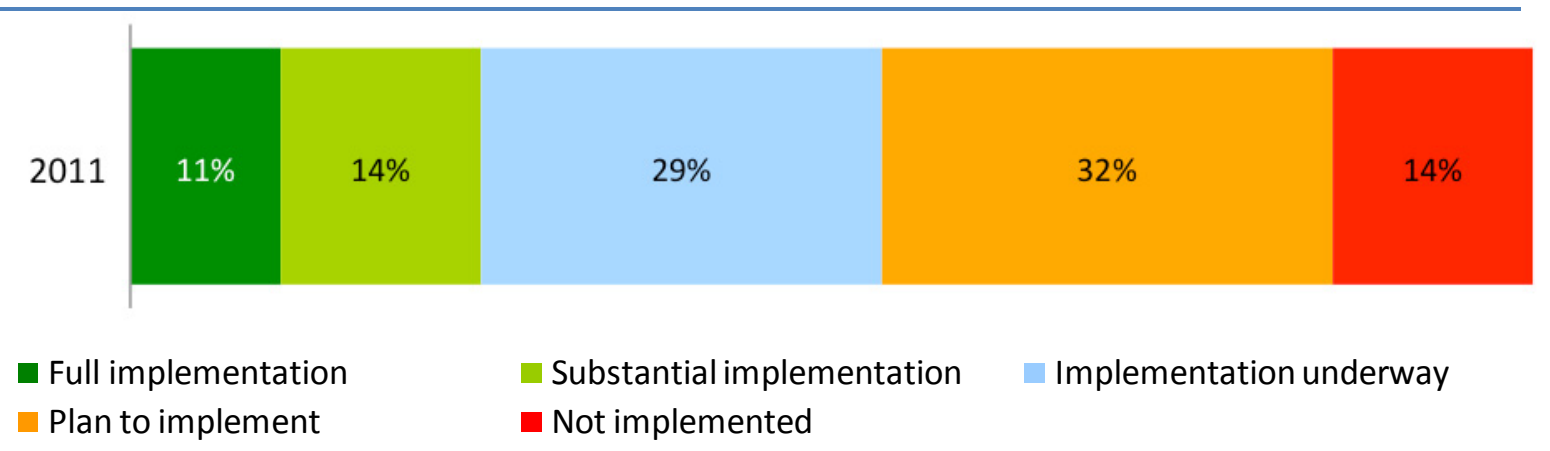

Canada and Italy are both planning policies to promote low-energy buildings. The implementation of the EPBD recast (2010/31/UE) in Italy is ongoing and will include measures to promote net-zero energy buildings. Canada has set programme objectives to make net-zero energy buildings and communities standard practice by 2050 .

\section{Existing buildings}

In the 2011Evaluation, many countries reported systematically collecting information on energy efficiency in existing buildings (Figure 11). For example, Canada communicates information on energy efficiency to building owners, operators and suppliers of professional services across the country through a monthly electronic newsletter that is sent to 20000 readers in the commercial buildings sector. Also available in all of Canada's provinces and territories, the ecoENERGY for Buildings and Houses programme has encouraged both the construction and retrofit of more energy-efficient buildings and houses and offered a wide range of information, publications, training and other resources on energy-efficient technologies and practices in buildings. Information and initiatives for industrial buildings have been provided through ecoENERGY for Industry and its Canadian Industry Program for Energy Conservation. Information is also available on the Natural Resources Canada (NRCan) web site and a special stakeholder relations team is in place to pro-actively market building energy efficiency to appropriate target audiences. 
Figure 11 Policies to increase awareness of energy efficiency in the buildings sector

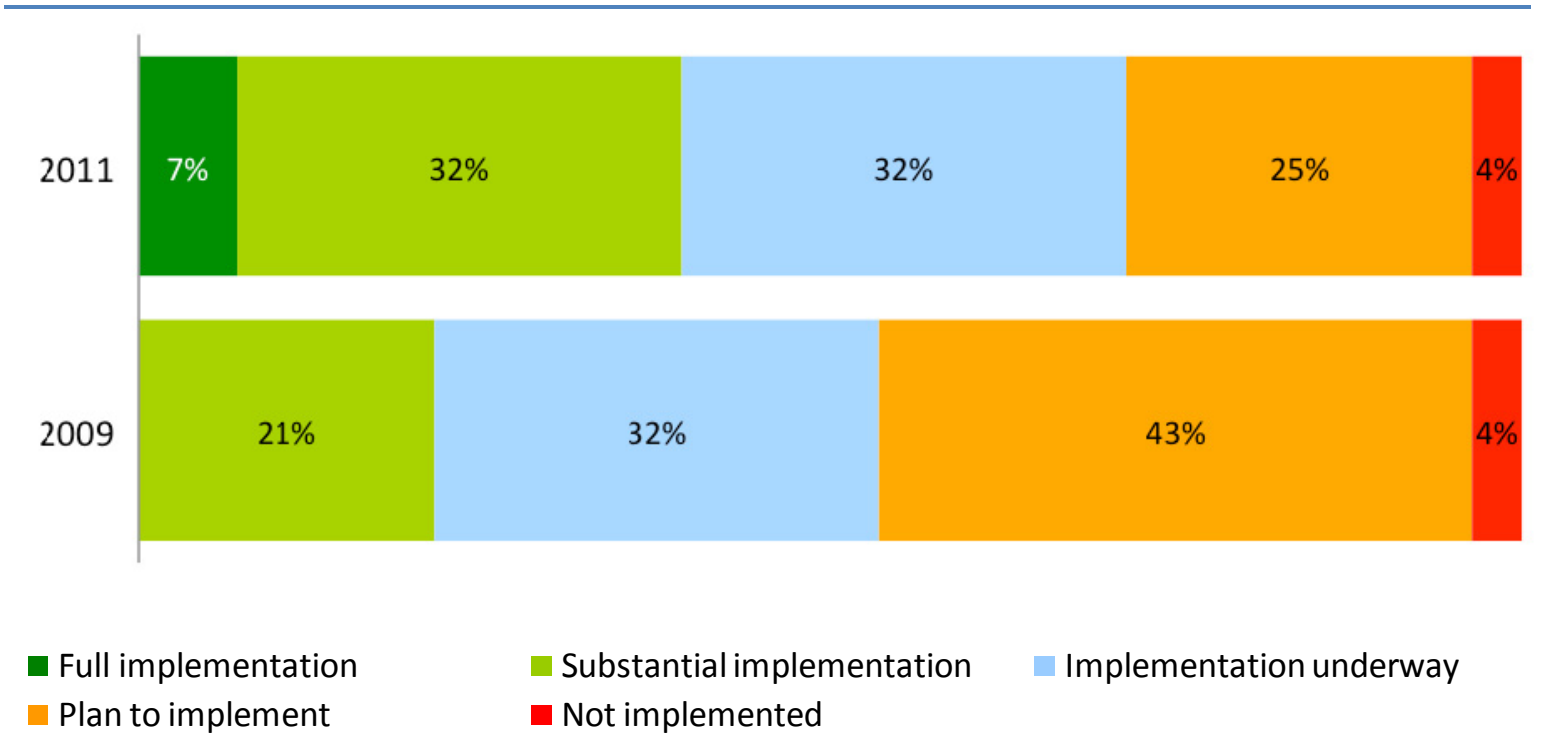

In Germany, the Energy Service Act requires energy supply companies to annually inform endusers on both available energy services and the effectiveness of energy-savings measures. The Federal office for energy efficiency (Bundesstelle für Energieeffizienz) created a publicly available national database for energy services at the end of January 2011. Further information is available through the project "Zukunft Haus", operated by the German Energy Agency (dena).

Japan's Database for Energy Consumption of Commercial buildings (DECC), includes information on building application, size, type and age.

The Housing Act in Korea requires all apartments of over 300 units to provide monthly information on energy use on the website www.k-apt.com. Moreover, all public buildings are required to display information on building energy performance in a public place, such as a lobby.

In New Zealand, a range of programmes fund upgrades in commercial buildings. A large insulation programme, Warm up New Zealand: Heat Smart, is funding upgrades of ceiling and floor insulation in homes. Grants are available for highly efficient heaters.

\section{Building certification}

In 2009, full implementation of mandatory building energy performance certificates (EPCS), used whenever a building is sold, rented or constructed, was reported by several countries, including Austria, the Czech Republic, Denmark, Finland, Germany, Ireland and Portugal. This was in line with the Energy Performance of Buildings Directive (EPBD, 2002/91/EC).

By April 2011, all EU member states had implemented mandatory EPC EPBD (2002/91/EC) requirements, although the rigour of implementation varies by country. For example, in the Netherlands, EPCs for buildings are mandatory and sanctions for noncompliance will be strengthened in January 2013. In the Slovak Republic, the monitoring system for EPCs has been in operation since 2010. Spain will pass a Royal Decree requiring EPCs. Under this decree, Spanish regions will have to register information on the energy performance of its buildings. In addition, the Ministers Council has approved and Spain has implemented measures to certify all public buildings with a thermal capacity superior to $400 \mathrm{~kW}$. 
Figure 12 Mandatory building energy certification schemes

Page | 22

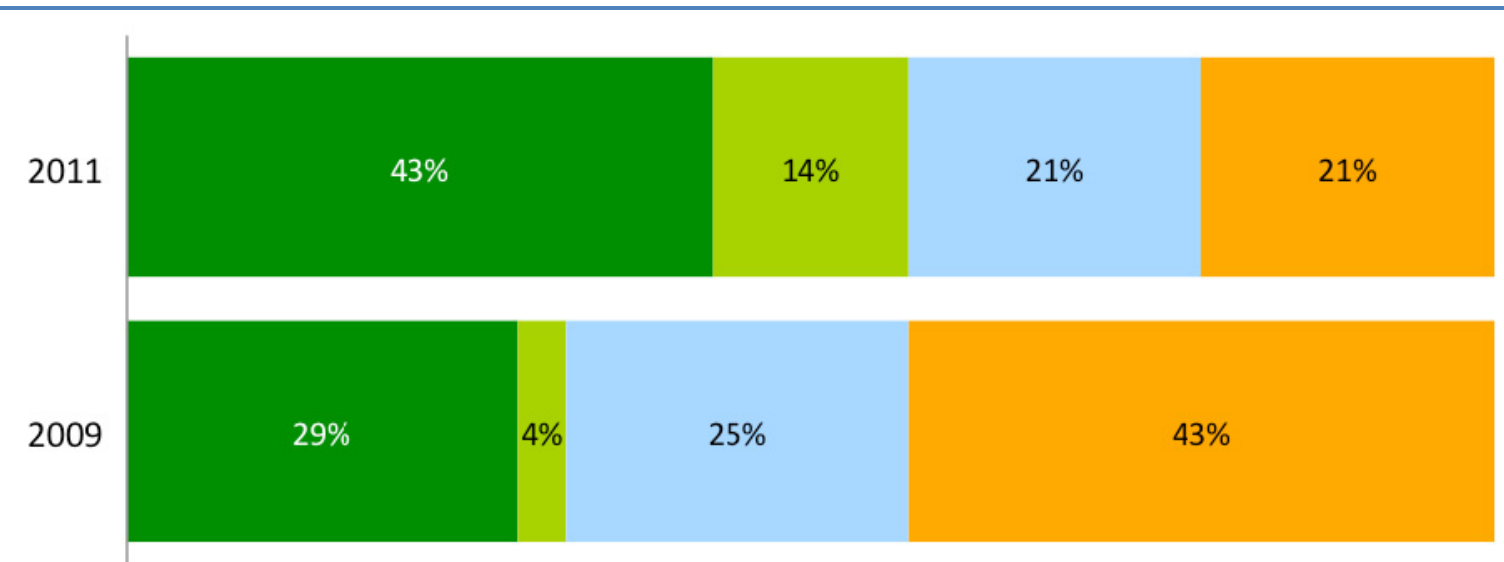

- Full implementation

- Plan to implement

$$
\begin{aligned}
& \text { Substantial implementation } \quad \text { Implementation underway } \\
& \text { Not implemented }
\end{aligned}
$$

In Sweden EPCs are also required when a building is over a certain size and holds public-sector functions. The owner is responsible for providing EPCs and in public buildings, these certificates must be visible. Energy certificates must also contain suggestions on how to improve energy efficiency (for further details, see government regulation 2006:1592 and the stipulations by the Swedish National Board of Housing (BFS 2007:4)).

The United Kingdom reported rolling out mandatory EPCs for all buildings on sale or for lease. EPCs contain recommendations for cost-effective action to improve building efficiency and links to sources of advice. Various United Kingdom (UK) government departments are currently exploring options to strengthen the EPC campaign to ensure information for buyers or tenants is relevant, targeted, and applicable to a specific property.

By the end of 2010, half of the Swiss cantons, equivalent to around $40 \%$ of the Swiss population, had voluntarily implemented the "energy passport in buildings scheme". Under this scheme, an EPC, or energy passport, is issued by the owner.

\section{Windows and other glazed areas}

In 2009, only some IEA member countries had adopted policies to promote energy-efficient glazing in windows. One country, Portugal, had fully implemented the recommendation related to establishing MEPs for windows and glazing and no country had fully implemented the recommendation on window labelling.

In the 2011 Evaluation, several IEA member countries reported implementing policies to promote efficient windows and other glazed areas. In EU member states, for example, windows and glazed areas are included in the indicative list of product groups that can be covered by the work plan (2012-2014) of the Ecodesign Directive recast (2009/125/EC) establishing energy efficiency requirements for energy-related products in the residential, tertiary and industrial sectors.

The Danish government and the Association of Danish Window manufacturers established a new labelling system for windows in 2010. Most manufactures joined the labelling system by summer 2011. Denmark's labelling scheme for double glazing is underway. All manufacturers are a part of the system and more than $95 \%$ of sales are of A-label level.

Ireland's National Standards Authority has developed an independent energy rating assessment 
scheme to promote improved energy efficiency in windows and other glazed areas. The scheme is voluntary but appears to be popular among manufacturers.

In Italy a labelling scheme for double-glazed windows, involving the largest manufacturers, is under development. This voluntary scheme will be accredited by a third-party certification body and promoted in government incentives for renovations.

In April 2011, Korea announced MEPs and mandatory energy labels for windows starting in 2012.

In Norway, energy-efficient windows are covered by the Enova label scheme "Enova anbefaler" and other grant programmes for innovative technologies, including PEH. An incentive for purchasing energy-efficient windows is provided through a variety of subsidy schemes and tax breaks (e.g. investment-type tax reductions for energy conservation renovation work, including the installation of solar power generation equipment). Moreover, the national or local governments promote the procurement of ecologically friendly products, including windows.

More than $80 \%$ of new and replacement windows in the United States are labelled according to procedures approved by the National Fenestration Rating Council (NFRC). NFRC-labelled products are required for compliance with most building codes and for ENERGY STAR labels. ENERGY STAR windows are promoted in other countries, including Canada.

\section{Appliances and equipment}

Since 2009, IEA member countries have made great progress with implementing the appliance and equipment recommendations (Figure 13).

Figure 13 Progress with implementing the appliance and equipment recommendations

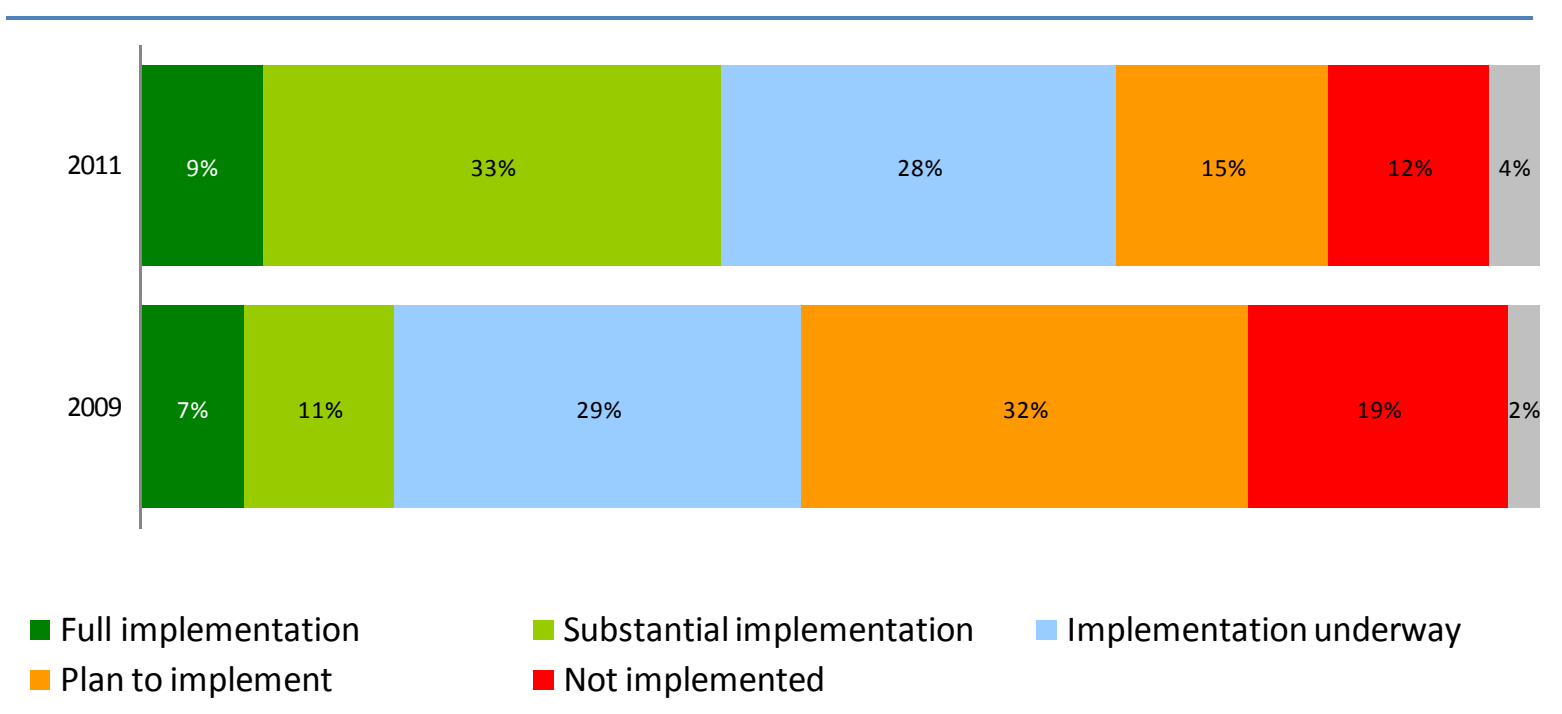

\section{Appliance and equipment MEPs and labels}

The 2009 Evaluation revealed that nearly all IEA member countries have in place minimum energy performance requirements (MEPs) for some appliances and equipment. Since 2009, governments have implemented a range of policies to enlarge the scope and stringency of MEPs. For example, in EU member states, energy requirements for numerous products covered under the Ecodesign Directive (2005/32/EC) have entered into force. In October 2009, the European Commission recast the Ecodesign Directive (2009/125/EC) to include energy-related products, such as building components. 
Also in EU member states, the European Parliament passed a directive (2010/30/EU) in May 2010 requiring labelling and standard product information on energy consumption. This directive is the recast of the previous labelling Directive (92/75/EEC).

Outside of the EU, the United States Department of Energy (US DOE) has established MEPs for over forty types of appliances and equipment and voluntary labelling guidelines for more than

Page | 24 fifty products. Over the past two years, the US DOE expanded the coverage and updated the stringency of standards for a number of major energy-using products and has allocated resources to further accelerate these efforts.

\section{Televisions, television "set-top" boxes and digital television adaptors}

In 2009, most IEA member countries had strong policies in place to address energy use in televisions and set-top boxes (STB). By the 2011 Evaluation, several new countries had introduced MEPs and labelling for these products (Figure 14). For example, Australia introduced related MEPs and/or labelling for set-top boxes from December 2008 and televisions from October 2009; and Canada amended the Energy Efficiency Act to include the regulation of television (TV) set-top boxes. Since January 2010 in Canada, pay-television STBs have been covered by voluntary code. Moreover, ENERGY STAR-rated televisions are actively promoted in the Canadian market. These televisions use approximately $40 \%$ less energy than standard units.

\section{Figure 14 Energy efficiency policy measures for TVs and set-top boxes}

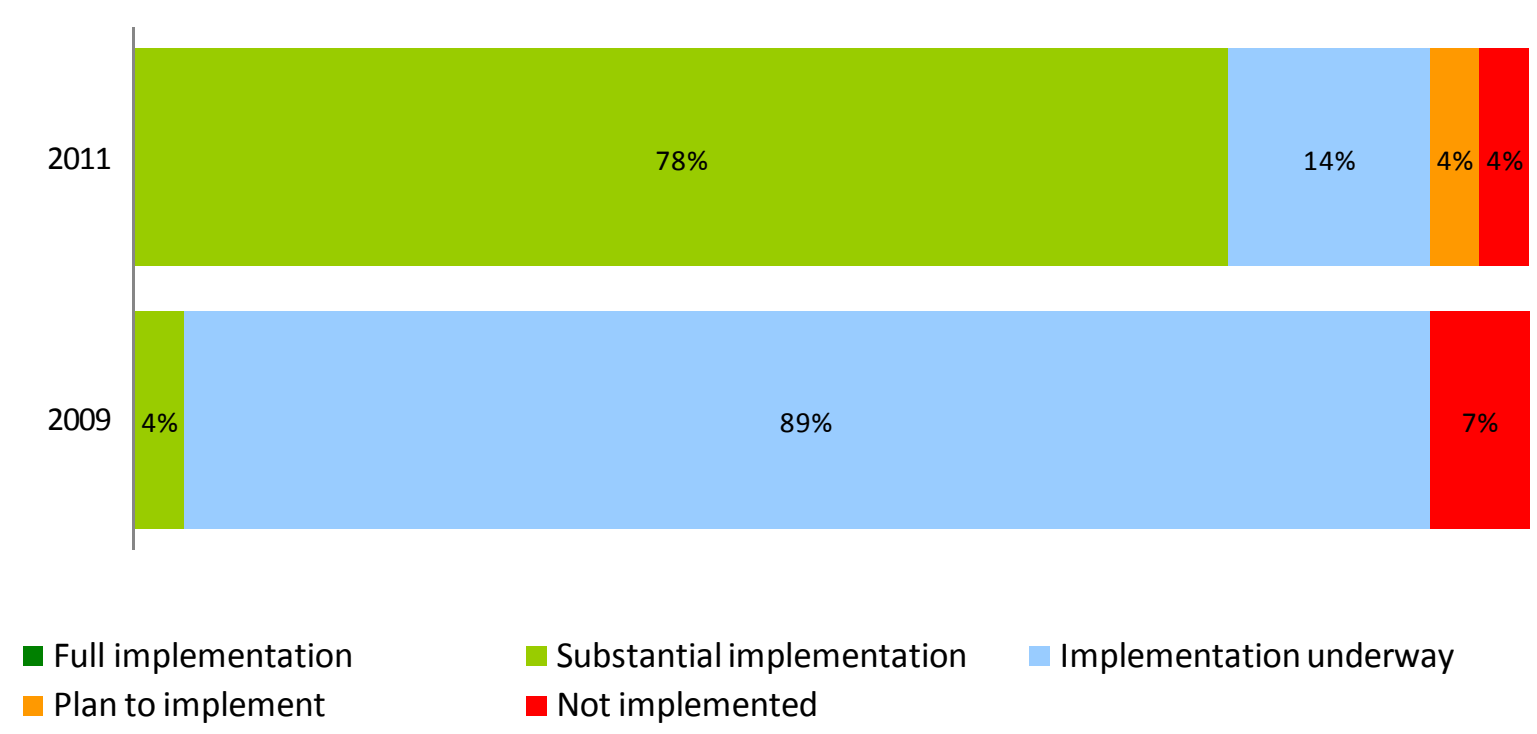

Japan revised top-runner standards for TV sets in February 2010. In this revision, TV sets using the energy efficient LED backlight were added to improve energy performance. As a result, TV set energy consumption is expected to improve by more than 37\% in 2012 compared to 2008.

Of the 23 categories covered under the Top Runner Program in Japan, 7 categories are networkconnected electric products: TV sets, DVD recorders, computers, magnetic disk units, copying machines, routers and switching units. These products are regulated to minimize energy consumption.

\section{Low-power modes for electronic equipment}

The 2009 Evaluation found that many countries were planning to implement a "horizontal" 1Watt standard. The 2011 Evaluation revealed significant progress with implementing these planned policies (Figure 15). 


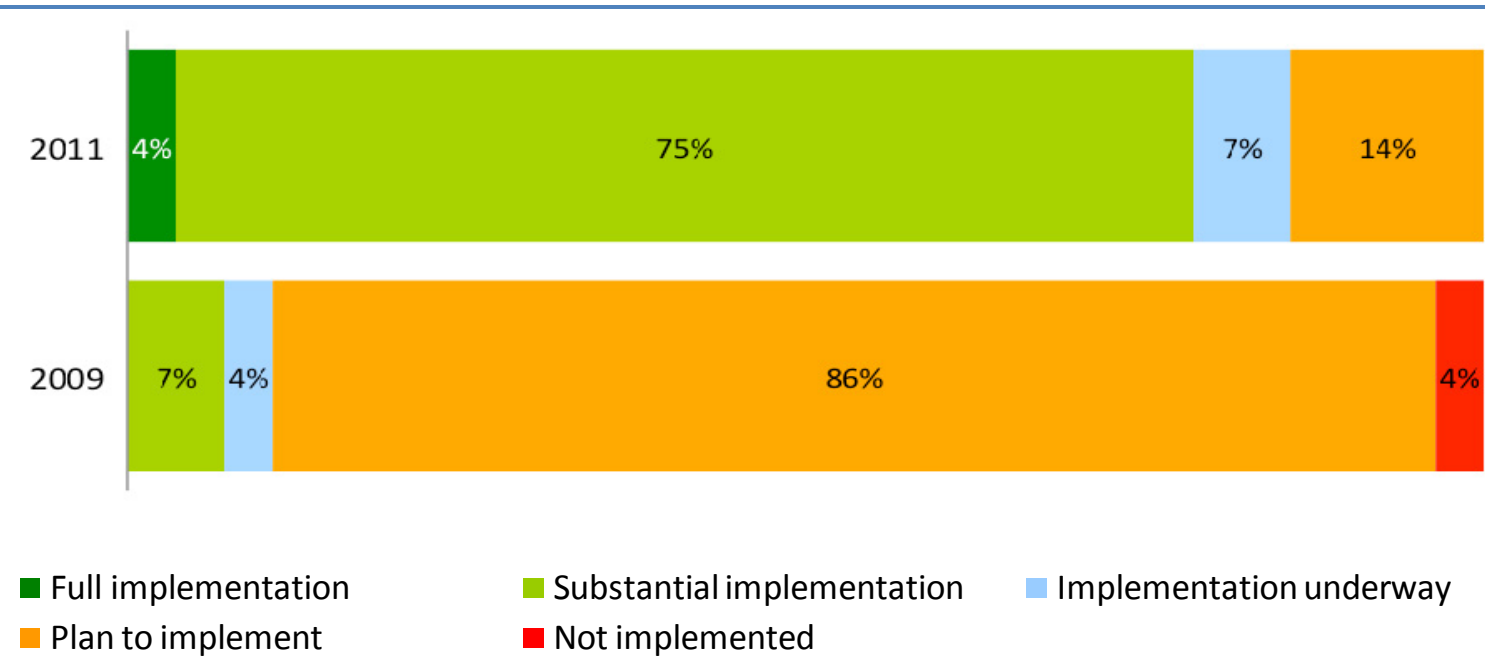

Australia, plans to implement a 1-Watt standby limit in 2013 that will apply to most energy-using appliances. Australia introduced minimum low-power mode requirements for several products including televisions in 2009 and air conditioners in 2011.

Korea is adopting policies to promote low-power modes. The Ministry of Knowledge Economy established "Standby Korea 2010", which is a roadmap to limit standby power below $1 \mathrm{~W}$ by the end of 2010. In 2011, Korea had mandatory 1 Watt standards for around thirty products through the e-Standby Program and Energy Efficiency Label and Standard Program. Since July 2010, Korea mandated an innovative standby warning label for 19 products that do not meet the specified standby-power standards.

Turkey's Ministry of Industry and Trade plans to publish a measure on standby-power consumption in line with Ecodesign (2005/32/EC) by the end of 2011.

\section{Lighting}

IEA member countries continue to implement policies to increase energy efficiency in the lighting sector (Figure 16).

Figure 16 Progress with implementing the lighting recommendations

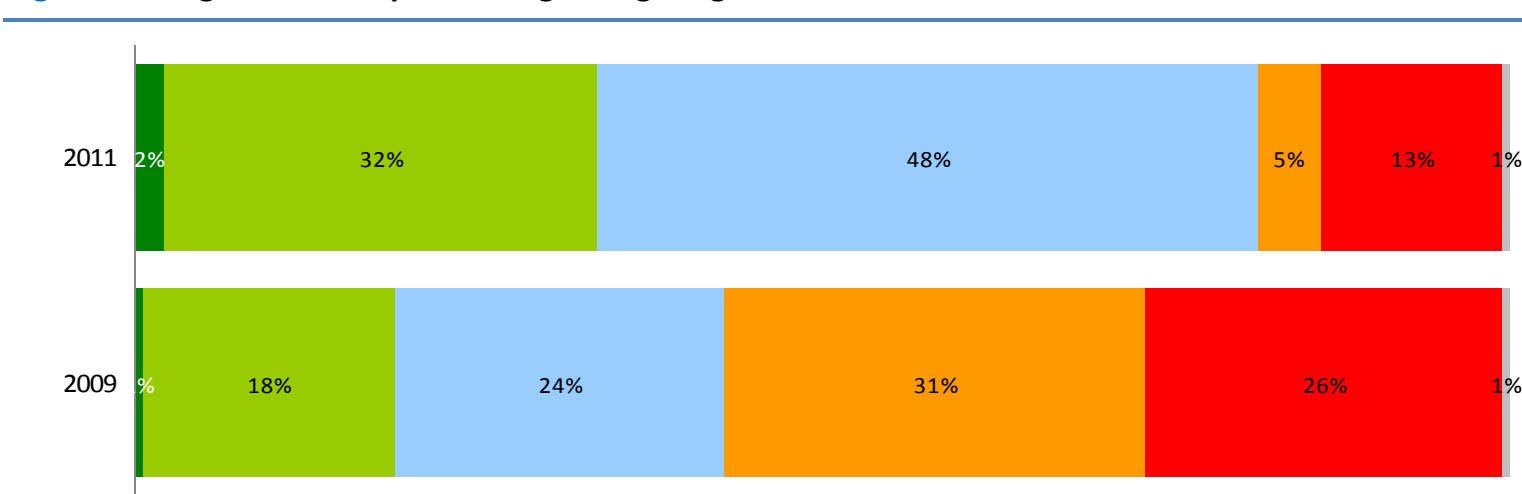

Full implementation Plan to implement
- Substantial implementation Implementation underway

- Not implemented 
The 2009 Evaluation found that almost all IEA member countries had policies in place to phase out inefficient incandescent lamps (Figure 17 Phase out the most inefficient incandescent bulbsFigure 17). At the time of the 2011 Evaluation, only New Zealand and Turkey were not planning to phase out incandescent lamps.

The 2011 Evaluation revealed further efforts to improve lighting energy efficiency. For example,

Page 26 Commission Regulation 244/2009 phases out non-directional incandescent bulbs in EU member states between 2009 and 2012. Directional (reflector) incandescent bulbs will also be phased out. The Energy Performance of Buildings Directive (2010/31/EU) requires lighting to be considered within the overall building energy performance. However, as opposed to other technical building systems, it is not mandatory for EU member states to set separate requirements on lighting systems. Non-mandatory EU harmonised standards (CEN) exist that contain reference values for different types of efficient lighting systems.

The phase out of incandescent lamps began in Korea in June 2010. Incandescent lamps of 10 to 15 lumens/Watt $(\mathrm{Im} / \mathrm{W})$ are no longer manufactured or on the market because MEPs were set at $20 \mathrm{~lm} / \mathrm{W}$. Incandescent lamps of $70 \mathrm{~W}$ to $150 \mathrm{~W}$ (mainly $100 \mathrm{~W}$, which accounts for $26 \%$ of all incandescent lamps) will be phased out of the market from January 2012. Incandescent lamps of between $25 \mathrm{~W}$ to $70 \mathrm{~W}$ (mainly $60 \mathrm{~W}$ and $30 \mathrm{~W}$, which account for $74 \%$ of all incandescent lamps) will be phased out of the market from January 2014.

Figure 17 Phase out the most inefficient incandescent bulbs

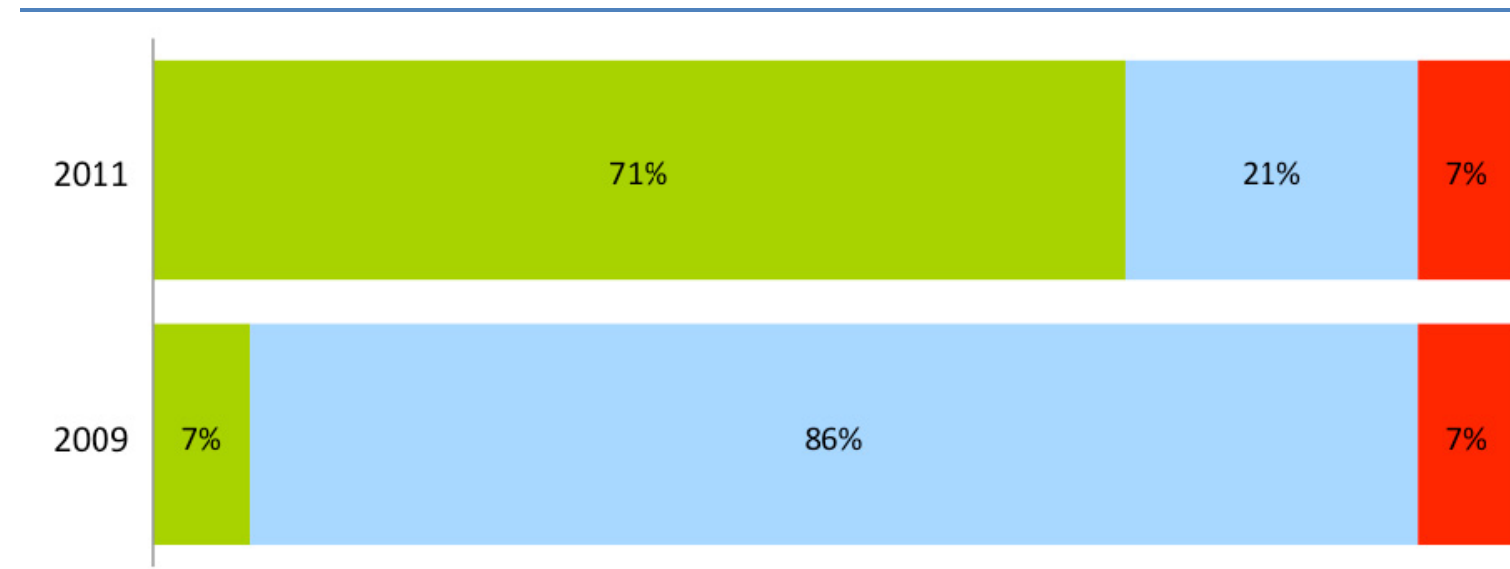

- Full implementation

Plan to implement
Substantial implementation Implementation underway

Not implemented

\section{Phase-out of inefficient fuel-based lighting}

Several governments reported on programmes that support international efforts to stimulate the adoption of alternatives to fuel-based lighting in off-grid communities in developing countries.

Canada's RETScreen International Project analysis software offers a unique decision support tool to evaluate opportunities to employ renewable and energy efficiency technologies. It applies to projects that eliminate fuel-based lighting, and has a large user community for off-grid projects in developing countries. Its website (http://www.retscreen.net) provides free downloads and training material that includes case studies of projects employing photovoltaic technology.

Japan supports the spread of solar cell based lighting in villages detached from power supply grids through the Japanese International Cooperation Agency (JICA) and the New Energy and Industrial Technology Development Organization (NEDO), a Japanese organisation promoting 
research and development, as well as the dissemination of industrial, energy and environmental technologies.

The Netherlands also supports international lighting efforts through the Energising Development programme and the Daeij Ouwens Fund.

The UK Department for International Development (DFID), both through its own programmes and working with the Development Banks, is supporting action to replace fuel-based lighting. One example is the Lighting Africa Programme.

The United States is sponsoring, through the Clean Energy Ministerial, the Solar and LED Energy Access Program (SLED), a multi-million dollar effort that focuses on the approximately 1.6 billion people without access to grid electricity. It aims to transform the global market for affordable, clean and quality-assured off-grid appliances by addressing fundamental barriers to market development. The programme will initially focus on replacing dirty, fossil fuel-based light sources like kerosene lanterns with solar LED lights. The programme is expected to improve lighting services for 10 million people within five years.

\section{Transport}

The transport recommendations focus on road transport and include policies to improve tyre energy efficiency and fuel economy standards for light and heavy-duty vehicles and promote ecodriving. IEA member countries have implemented many more of these recommendations since the 2009 Evaluation (Figure 18).

Figure 18 Progress with implementing the transport recommendations

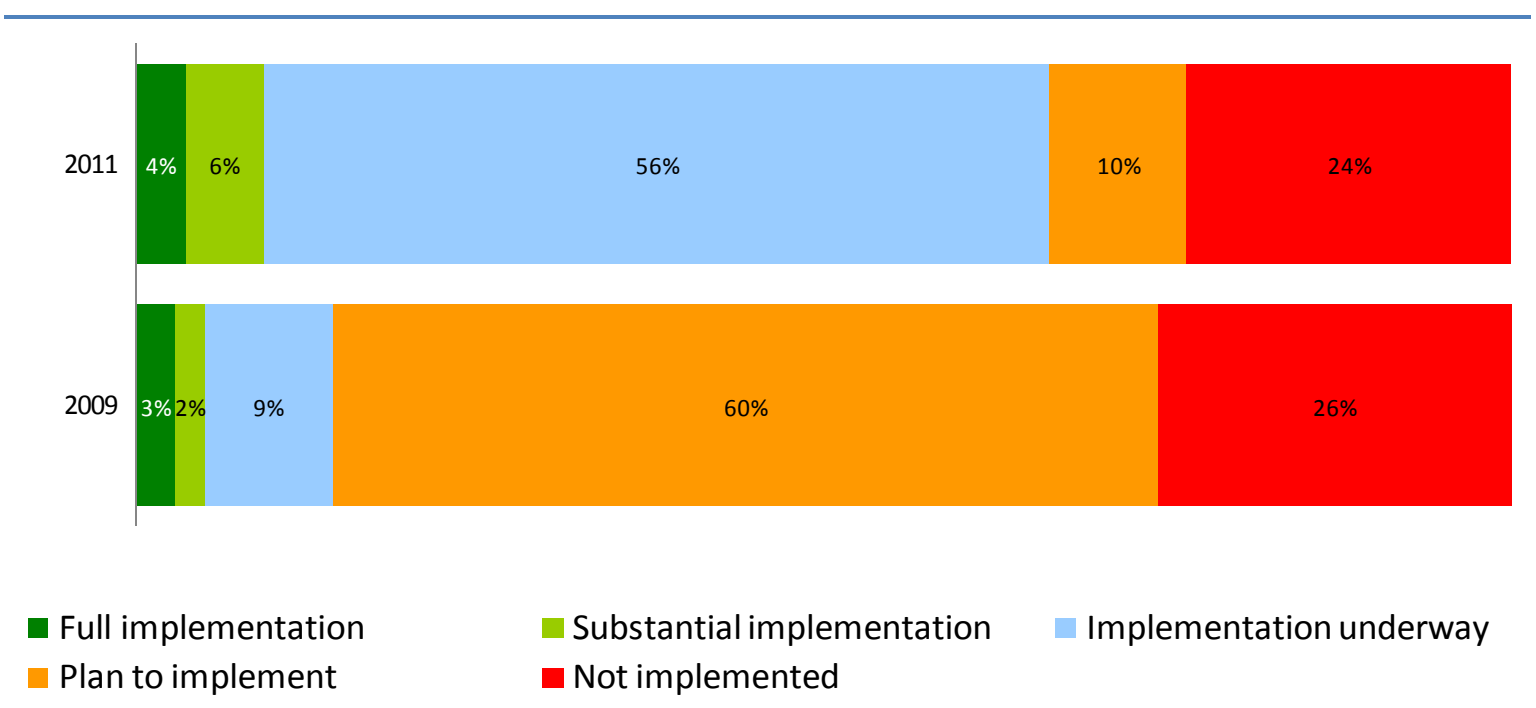

\section{Tyres}

Many IEA member countries that in 2009 had planned policies aimed at tyre rolling resistance and proper tyre inflation are now implementing those policies (Figure 19). In July 2009, for example, EU member states adopted a regulation "concerning type-approval requirements for the general safety of motor vehicles, their trailers and systems, components and separate technical units" (EC 661/2009). The European Union also adopted a separate regulation on "the labelling of tyres with respect to fuel efficiency and other essential parameters" (EC 1222/2009) in November 2009. Fuel efficiency, wet grip and external rolling noise of tyres are indicated in the label. Similar to measures for tyre rolling resistance and noise limits, this regulation will cover 
almost all tyres used on public roads, such as tyres for passenger cars, light commercial vehicles and heavy-duty vehicles. Tyre labels will be displayed at the point of sale and in technical promotional literature, including websites, by November 2012. This label will allow consumers to make more informed choices and should result in fuel cost savings, as well as a reduction of $\mathrm{CO}_{2}$ emissions, from vehicles.

Page 28 Switzerland is closely following EU tyre regulation. Tyre labelling will enter into force in November 2012.

In December 2008, the Japanese government established the Fuel-Efficient Tire Promotion Council. This council published a final report in July 2009 recommending the measurement methods of tyre rolling resistance and wet grip and the establishment of a labelling scheme. In response, the test procedures for tyre rolling resistance referring to the ISO 28580 were established as JIS D4234 in December 2009. The labelling scheme, which is applied to replacement tyres for passenger cars, has been implemented on a voluntary basis since January 2010.

In April 2010, the Korean government announced a plan to introduce tyre fuel efficiency standards and labelling for passenger cars. It will be implemented on a voluntary basis from the second half of 2011 and on a mandatory basis from the second half of 2012. By the end of June 2011, related regulations were revised and the details of the labelling scheme and test procedures were also decided. The label provides the rolling resistance coefficient and wet grip of tyres. The government is also considering the insertion of external noise and tread wear on the label.

Figure 19 International test procedures for measuring tyre rolling resistance

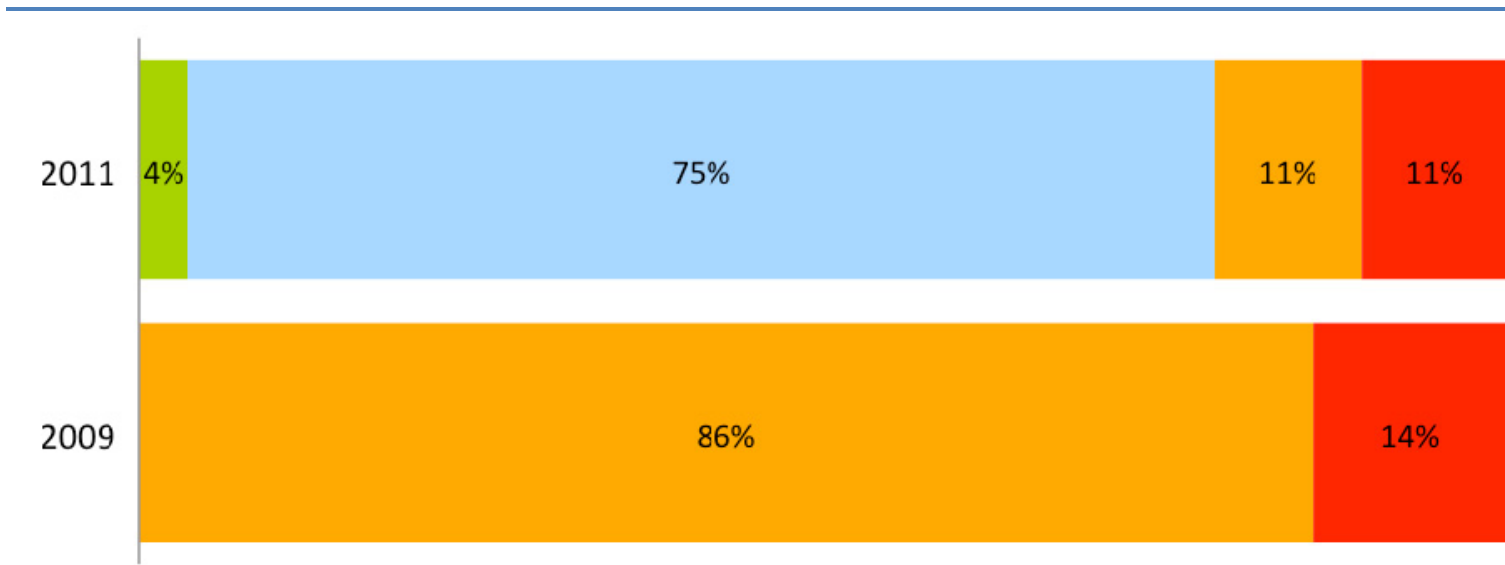

- Full implementation

- Plan to implement
Substantial implementation Implementation underway

- Not implemented

Many countries have also made progress with implementing measures to promote proper tyre inflation levels (Since 2007, the United States has mandated TPMS for all passenger cars, multipurpose vehicles, trucks and buses.

Figure 20). EU regulations EC 661/2009 and EC 1222/2009 described earlier include mandatory fitting of tyre-pressure monitoring systems (TPMS) by November 2012 for new passenger cars and by November 2014 for all newly registered passenger cars.

Since 2007, the United States has mandated TPMS for all passenger cars, multipurpose vehicles, trucks and buses. 
Figure 20 Measures to promote proper tyre inflation levels

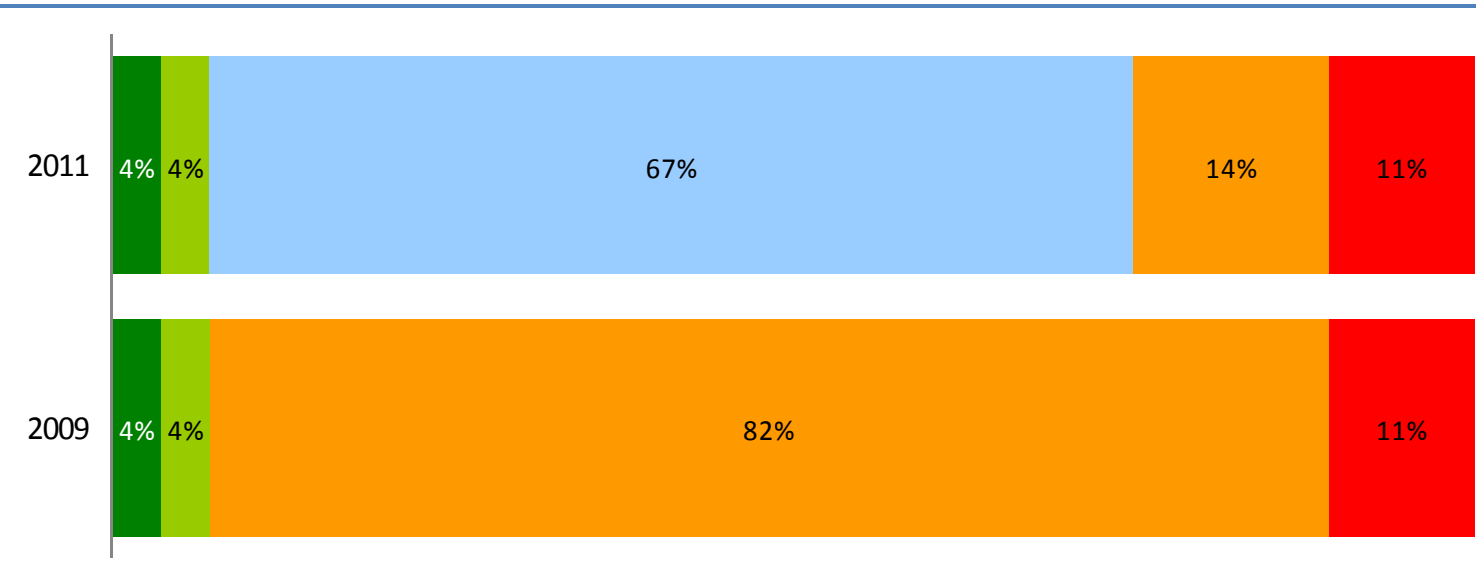

- Full implementation

- Plan to implement

\section{Substantial implementation Implementation underway}

not implemented

\section{Mandatory fuel-efficiency standards for light-duty vehicles}

Several governments reported the introduction of new mandatory fuel-efficiency standards for light-duty vehicles (Figure 21). In April 2010, for example, Canada's Ministry of Environment proposed Passenger Automobile and Light Truck Greenhouse Gas (GHG) Emission Regulations (de facto fuel efficiency standards). These regulations were finalised in October 2010 and impose stringent new standards for vehicles of Model Year (MY) 2011. Canada will increase the stringency of these regulations on an annual basis until MY 2016. For MY 2011, the Canadian standards are aligned with fuel-economy standards established by the U.S. National Highway Traffic Safety Administration. For MY 2012 to 2016, the Canadian standards are aligned with similar greenhouse gas emissions standards established by the United States Environmental Protection Agency. In its October 2010 announcement, Canada also stated its intention to further reduce GHG emissions from new cars and light-duty trucks from MY 2017, in collaboration with the United States.

Figure 21 Mandatory fuel efficiency standards for light-duty vehicles

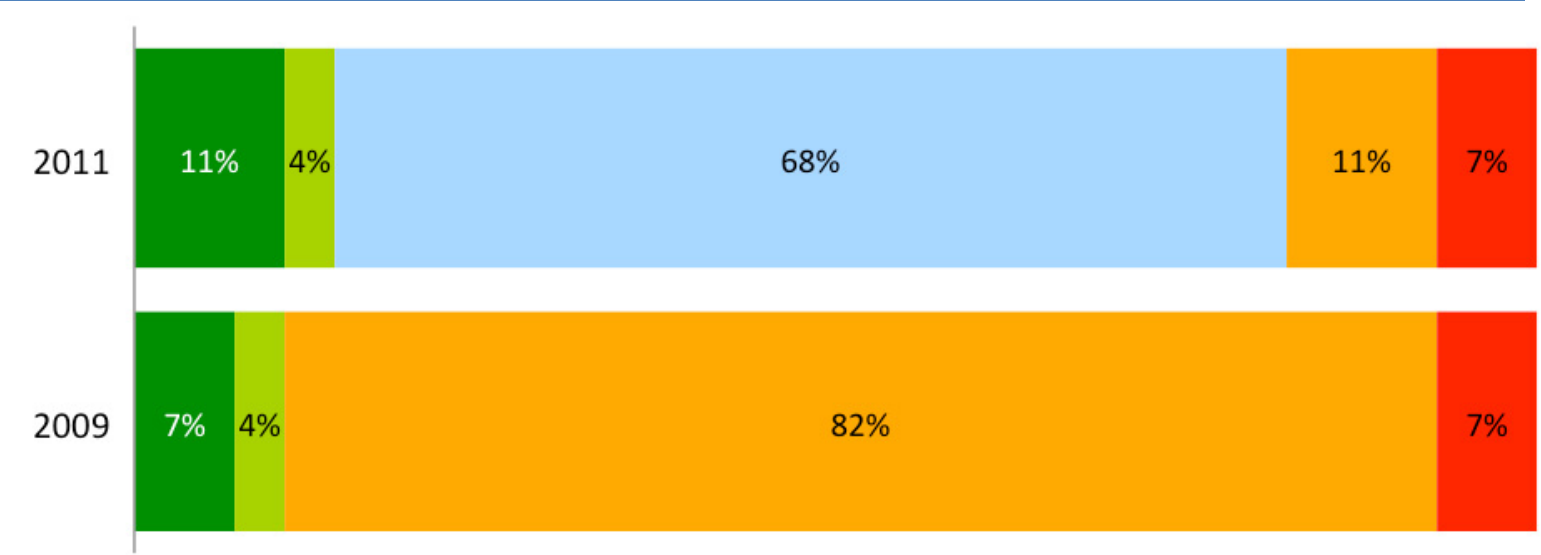

Full implementation

- Plan to implement
Substantial implementation Implementation underway

not implemented 
In April 2009, EU Member States adopted the regulation "setting emission performance standards for new passenger cars" as part of the Community's integrated approach to reduce $\mathrm{CO} 2$ emissions from light-duty vehicles (EC 443/2009). Average emissions from new passenger vehicles sold in the European Union have to reach the $130 \mathrm{~g} \mathrm{CO} / \mathrm{km}$ target by 2015 . Improvements in motor technology will reduce average emissions to $130 \mathrm{~g} \mathrm{CO} / \mathrm{km}$, while complementary measures will contribute a further emissions cut of up to $10 \mathrm{~g} \mathrm{CO} / \mathrm{km}$, thus reducing overall emissions to $120 \mathrm{~g} \mathrm{CO} / \mathrm{km}$. These complementary measures include efficiency improvements for car components with the highest impact on fuel consumption, such as tyres and air conditioning systems, and a gradual reduction in the carbon content of road fuels, notably through greater use of biofuels. Efficiency requirements for these components are being discussed and will be introduced for these car components.

In July 2009, Korea announced a new fuel-economy standard for passenger cars as part of the national Green Growth strategy. The new standards will be phased in from 2012 and then fully implemented in 2015. Automobile manufacturers can choose between two corporate average targets, $17 \mathrm{~km} / \mathrm{L}$ or $140 \mathrm{~g} \mathrm{CO}_{2} / \mathrm{km}$, allowing for flexibility as well as a phase-in approach. The design of the standard is well aligned the weight-based target values and the credit trading/carry over scheme features of US and European standards.

In May 2010, the United States required manufacturers to meet an estimated combined mpg (miles per gallon)-rating of 34.1 for light-duty vehicles by MY 2016. Government agencies have announced their intention to propose light duty vehicle fuel economy standards for the years beyond 2016 by September 2011.

In July 2010, the Australian Government announced plans to introduce mandatory $\mathrm{CO}_{2}$ emissions standards for light vehicles to take effect from 2015. A consultation process to determine emissions targets and design standards is currently underway.

\section{Mandatory fuel-efficiency standards for heavy-duty vehicles}

Japan is the only country in the world to have fuel-efficiency standards in place for heavy-duty vehicles. In 2011, however, the United States finalised fuel-economy standards for medium- and heavy-duty vehicles for MY 2014-2018. These standards should be finalised in 2011. Canada announced that it also would introduce such standards.

\section{Eco-drive}

Many IEA member countries have made strides to ensure that eco-driving is a central component of government initiatives to improve energy efficiency and reduce $\mathrm{CO}_{2}$ emissions (Figure 22). In 2009, for example, EU member states adopted regulation (EC 661/2009), which stipulates the mandatory fitting of a gear-shift indicator (GSI) in all new passenger cars with manual transmission, as part of a European strategy on reducing $\mathrm{CO}_{2}$ emissions from road vehicles. The GSI displays shifting up or down signs on the instrument panel to ensure optimal gear changing and thereby improve fuel efficiency. It is one of the in-car feedback instruments recommended by the IEA to promote fuel-efficient driving.

Korea reports that buses, taxis and vans shall be equipped with idling-stop devices from 2011. The Ministry of Knowledge Economy will subsidise the installation of an eco-driving indicator for fleet operators in 2011. 
Full implementation

Plan to implement

$$
\begin{aligned}
& \text { Substantial implementation Implementation underway } \\
& \text { Not implemented }
\end{aligned}
$$

The implementation of eco-driving training as part of the driving license test can improve fuel economy. Eco-driving measures introduced to the UK driving test require new drivers to show that they can drive fuel-efficiently as well as safely. New drivers are expected to know the basics of eco-driving such as accelerating and braking less harshly and changing gears sooner.

Many countries have implemented eco-driving through national and regional eco-driving programmes. For example, in the Netherlands, the Institute for Sustainable Mobility runs partly government-financed campaigns to promote eco-driving for professional drivers and to inform about the importance of correct tyre pressure.

Spain is promoting eco-driving through numerous eco-driving courses coordinated by the Institute for Diversification and Saving of Energy (IDAE) and various industry and community associations. As a result of these courses, more than 10800 professional drivers have been trained in efficient driving. In addition, the Traffic Department (Ministry of Home Affairs) now requires eco-driving classes for people seeking a licence to operate tourism vehicles (more than 800,000 drivers obtain a tourist driving licence every year). More than 1000 civil servants working for the Traffic Department have also been trained in eco-driving.

Outside the EU, Canada's ecoENERGY for Personal Vehicles includes eco-driving initiatives that provide tools and resources for existing licensed drivers and for new drivers.

Korea is actively promoting eco-driving. As part of the presidential committee adopted Five-Year Action Plan For Green Growth (2009-2013), several initiatives to promote eco-driving have been established. For example, Korea founded an eco-driving education centre in 2010, made agreements with entities and individuals for commitment to eco-driving, and provided information on eco-driving on government websites.

Korea acknowledges that although measures to promote eco-driving are voluntary, more and more vehicles for public transportation and freight transport, and privately-owned cars have been participating in the eco-driving initiatives.

\section{Industry}

There has been some progress with implementing policies to promote energy efficiency in industry (Figure 23). 
Figure 23 Progress with implementing the industry recommendations

Page | 32

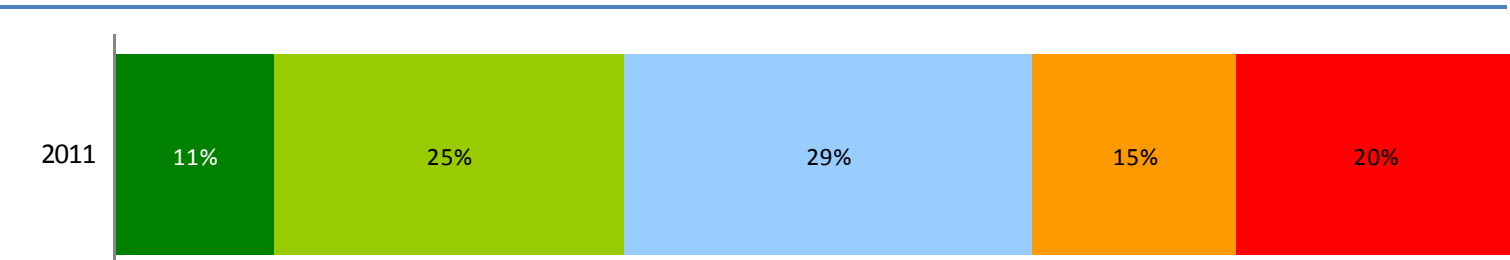

2009

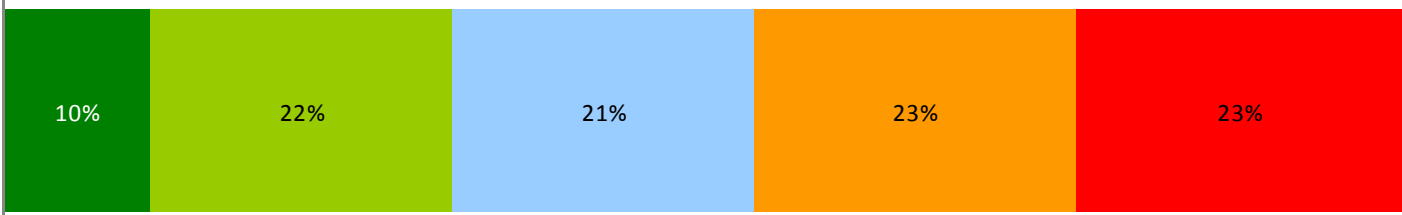

Full implementation

Substantial implementation Implementation underway

Plan to implement

not implemented

\section{Minimum energy performance requirements (MEPs) for electric motors}

Electric motor-driven systems (EMDS) consume the largest amount of electricity of any end-use more than $40 \%$ of global electricity consumption-- and most of this is for industrial processes. The IEA estimates that the efficiency of EMDS can realistically be improved by $10-15 \%$, equivalent to reducing total global electricity use by $5 \%$. MEPs are required to deliver energy efficiency improvements in EMDS

At the time of the 2009 Evaluation, most IEA member countries were planning to adopt MEPs for electric motors. Now some of these policies are being implemented (Figure 24).

EU member states, for example, adopted MEPs for certain kinds of motors in July 2009 as part of the 2009 European Commission Regulation No 640/2009 implementing Directive 2005/32/EC. An EU evidence study has been commissioned by the European Commission as the first stage in developing minimum performance standards that will cover electric motors that fell outside the scope of the initial regulation.

Japan issued JIS 4034-2-1 referring to IEC 60034-2-1, which is the international standard for motor measurement methods. Japan also issued JIS C4034-30 referring to IEC 60034-30, which classifies the efficiency of single-speed, three-phase, cage-induction motors. In January 2011, the Japanese government announced that they are planning to add three-phase induction motors to the Top Runner Program and established a committee for examining concrete standards.

Australia, Canada, Korea, New Zealand and the United States continue to report well-developed energy efficiency policies for medium-sized industrial electric motors. The United States and Canada, for example, updated standards for medium-sized electric motors. 
Figure 24 MEPs for electric motors in line with international best practice

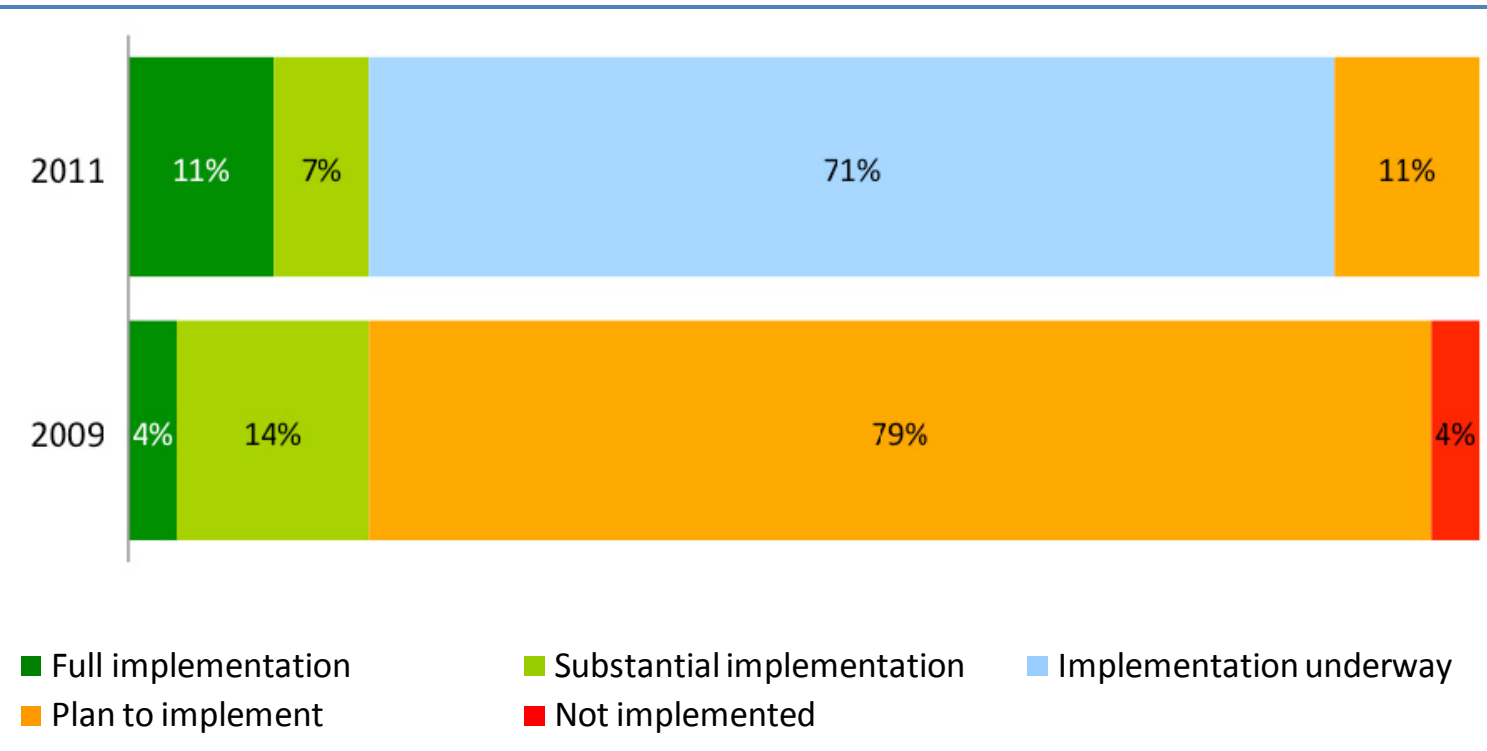

\section{Energy management}

In 2009, many IEA member countries highlighted policies to promote energy management (EM) in industry. At the time of the 2011 Evaluation, a few member countries provided updates on policies to further develop EM capability through the development and maintenance of EM tools, training, certification and quality assurance. For example, the mid-cycle review of Australia's mandatory energy efficiency assessments programme for large energy users found that the regulations and capacity-building programme had resulted in the introduction of energy management policies in companies. The EEO programme covers about $45 \%$ of Australian total energy end use, and $60 \%$ of business energy end use.

In Norway, EM is promoted as an integrated part of the industrial energy efficiency programmes. A European standard for EM has been adapted as a national standard (NS-EN 16001) and an international standard (ISO 50001) is under development.

The Slovak Republic supports, through EU Structural Funds, a system of industrial energy consumption monitoring and control, which includes installation and modernization of energy monitoring and management systems. Energy audits, on a voluntary basis, are planned measures in the Slovakian national energy efficiency action plan (NEEAP) for years 2011-2013.

The United Kingdom has done much to establish a scheme to monitor, evaluate and report industrial energy consumption. The government publishes the Digest of UK Energy Statistics, and the associated Energy Consumption in the UK, which breaks consumption down into 12 industrial subsectors. Practical examples of the monitoring, evaluation and reporting of collected data include: (i) the Carbon Reduction Commitment, a mandatory scheme aimed at large public and private sector organisations responsible for around $10 \%$ of the United Kingdom's emissions. The scheme features a published annual performance league table that ranks participants on energy efficiency performance; and (ii) Climate Change Agreements covering a wide range of industrial sectors, from major energy-intensive processes such as steel, chemicals and cement to agricultural businesses, and require measurement of energy consumption and/or carbon dioxide emissions. The results are published in a sectoral league table. 


\section{Small and medium-sized enterprises}

At the time of the 2009 Evaluation, several IEA member countries - including Finland, Ireland, Japan, Korea, Turkey and the United States, were planning or had implemented policies to promote energy efficiency in SMEs. For the 2011 Evaluation, a handful of additional countries reported energy efficiency policy developments for SMEs. Italy's National Agency for New Technologies, Energy and Sustainable Economic Development (ENEA), for example, is planning activity in this area. Portugal's Cabinet Resolution no.2/2011, passed in January 2011, created the legal framework for energy service companies (ESCOs) and procurement management of energy services for SMEs.

The Slovak Republic's SIEA is implementing the energy efficiency information project Live with Energy. This project is financed through EU Structural Funds and provides information support to different stakeholders, including entrepreneurs in SMEs.

Spain's Energy Efficiency Action Plan 2008-2012 includes subsidy programmes for SMEs to improve energy efficiency through equipment renovation and substitution of technical processes (with grants of up to $30 \%$ of the eligible cost). Spain's second NEEAP includes such support for SMEs.

Sweden implemented a support scheme for energy audits for SMEs in January 2010 (Government Regulation 2009:1577). Under this scheme, SMEs can receive a maximum of EUR 3500 (or $50 \%$ of total costs) for energy audits. The scheme will be in place until 2014.

\section{Energy utilities}

The 2009 Evaluation found that over half of IEA member countries had some form of policy to encourage utilities to promote energy efficiency (Figure 25).

Figure 25 Progress with implementing policies to encourage energy utilities to promote end-use energy efficiency ${ }^{4}$,

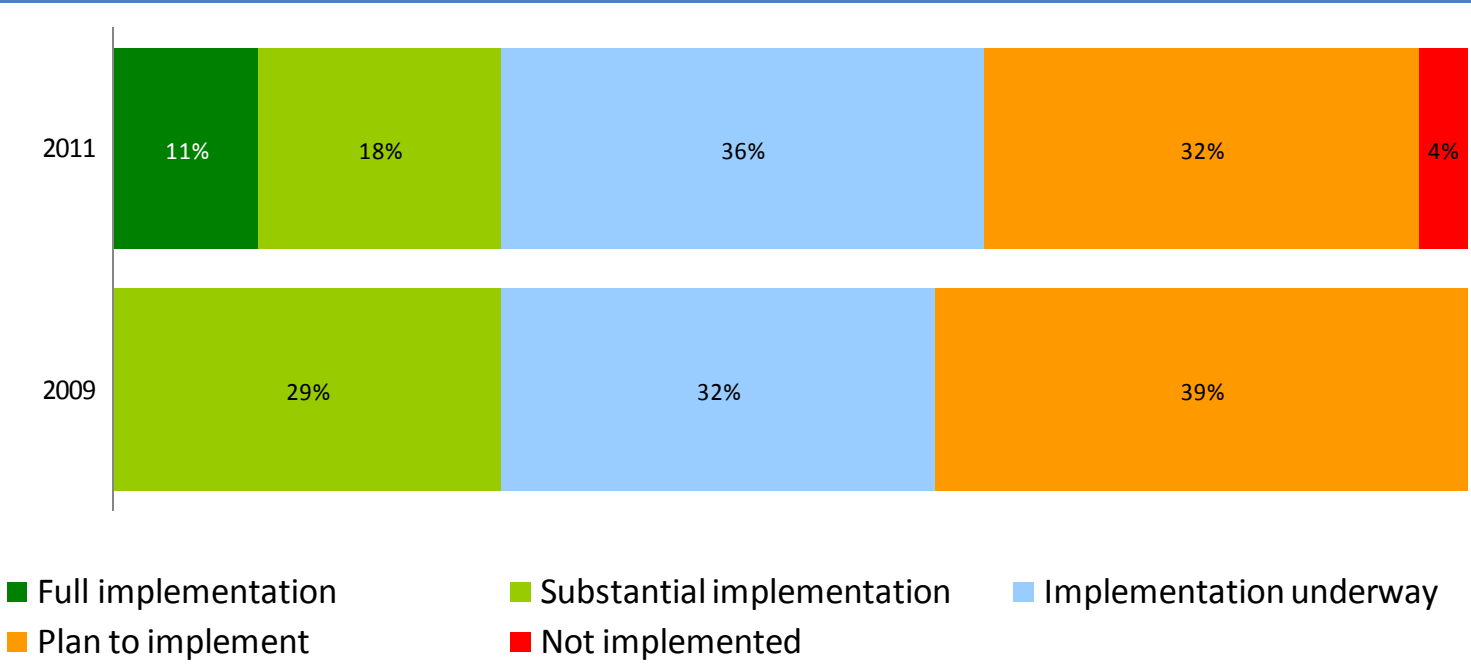

At the time of the 2011 Evaluation, several IEA member countries reported further implementation of policies to encourage utilities to deliver cost-effective energy savings to end

\footnotetext{
${ }^{4}$ This chart is based on the four elements of the utility recommendation (see Annex 1: Consolidated list of 25 IEA energyefficiency recommendations). As each of the utility recommendation elements is optional, the IEA has calculated this pie chart based on the element that achieves the highest level of policy implementation in each country.
} 
users. For example, Canada's Council of Energy Ministers supports collaborative actions to promote and support energy efficiency. Under the auspices of the Steering Committee on Energy Efficiency, the Built Environment and Equipment Working Group, with representatives from the federal, provincial, and territorial governments, has outlined tools and policy measures to encourage stakeholders to implement energy efficiency best practice. In addition, with jurisdictional authority over utilities, a number of provinces have implemented measures to encourage energy savings at the utility level. In British Columbia, for example, the 2010 Clean Energy Act commits to meeting $66 \%$ percent of future incremental electricity demand from conservation and efficiency improvements by 2020 .

In Denmark, all distribution companies have energy-saving obligations with annual targets, which were increased by $100 \%$ in 2010 . The savings are weighted in relation to life-time, Co2 reduction, non-ETS, etc.

Ireland has outlined a programme for placing obligations on energy suppliers of $>75 \mathrm{GWh}$ to Irish energy end-users. Finalisation of annual targets, eligible measures and savings credits is underway and companies have signed voluntary agreements to meet these targets. Some energy providers have already begun operating in the energy-service market in preparation for the obligation programme. Currently vehicles for trading energy savings will be left to participants who will be allowed to buy compliance from over-performing participants or to negotiate action on their behalf. For more information on the scheme, see the Department of Communications, Energy and Natural Resources consultation document.

The Energy Efficiency Law, passed in Poland in April 2011, introduces a white certificate system. From January 2013, obligations to present white certificates will be imposed on utilities selling electricity, natural gas and heat to customers.

Spain included several initiatives to incentivise utilities to deliver cost-effective energy savings to end users in its second National Energy Efficiency Action Plan.

The United Kingdom established the carbon emissions reduction target (CERT), a statutory obligation on all domestic energy suppliers in England, Scotland and Wales with a customer base in excess of 50,000. CERT is the third cycle of UK household energy supplier obligation. In June 2010, it was announced that, subject to Parliamentary approval, a restructured carbon emissions reduction target would be extended to December 2012, with a higher target and a focus on improving building insulation (rather than installing compact fluorescent lamps (CFLs). The UK government is currently exploring options for the successor to CERT, to run from 2013.

In the United States, 24 states, representing over $50 \%$ of the US population and energy demand, have placed energy efficiency resource obligations on their regulated energy utilities. 


\section{Challenges and areas for improvement in energy efficiency policy}

There have been many significant energy efficiency policy improvements in IEA member Page 36 countries since the 2009 Evaluation. Yet, there are still many areas where further implementation of cost-effective energy efficiency policy would provide benefits. Some of these areas are summarised in Table 4. Countries should consider implementing additional energy efficiency policies in the context of their energy economies.

Table 4 Summary of challenges and areas for improvement in IEA member country energy efficiency policy

\begin{tabular}{|c|c|}
\hline Cross-sectoral & $\begin{array}{l}\text { - } \quad \text { Further improve national energy efficiency strategies and action plans. } \\
\text { - } \quad \text { expand financing efforts; develop savings verification and measurement } \\
\text { protocols and establish public-private partnerships. } \\
\text { - Increase efforts to promote risk-mitigation instruments such as public-private } \\
\text { - } \quad \text { Improve quality and coverage of energy indicators. }\end{array}$ \\
\hline Buildings & $\begin{array}{l}\text { - } \quad \text { Strengthen MEPs for new and existing buildings. } \\
\text { - } \quad \text { Enforce building codes and MEPs. } \\
\text { - } \quad \text { Scale up construction of PEH and ZEB. } \\
\text { - Implement policies to increase the rate of substantial renovations to meet } \\
\text { - } \quad \text { strengthened MEPs for existing buildings. } \\
\end{array}$ \\
\hline $\begin{array}{l}\text { Appliances } \\
\text { equipment }\end{array}$ & $\begin{array}{l}\text { - Ensure network-connected electronic devices minimise energy consumption, } \\
\text { prioritising the establishment of industry-wide protocols for power } \\
\text { management. } \\
\text { Put in place policies to encourage television service providers to deliver } \\
\text { energy-efficient products. }\end{array}$ \\
\hline Lighting & $\begin{array}{l}\text { - } \quad \text { Develop measures for promoting energy efficiency in non-residential lighting. } \\
\text { - } \quad \text { Support adoption of high-efficiency alternatives to fuel-based lighting. }\end{array}$ \\
\hline Transport & $\begin{array}{l}\text { - } \quad \text { Create fuel efficiency standards and labelling for heavy-duty vehicles. } \\
\text { - } \quad \text { Ensure implementation of planned policies. } \\
\text { - } \quad \text { Include eco-driving in driver education. }\end{array}$ \\
\hline Industry & $\begin{array}{l}\text { - Examine barriers to the optimisation of energy efficiency in electric motor- } \\
\text { drive systems and design and implement comprehensive policy portfolios that } \\
\text { will overcome such barriers. } \\
\text { Design and improve policies and measures to assist small and medium-sized } \\
\text { enterprises. }\end{array}$ \\
\hline Energy utilities & $\begin{array}{l}\text { - Devote more attention to providing incentives for utilities to promote energy } \\
\text { efficiency in all IEA member countries. }\end{array}$ \\
\hline
\end{tabular}




\section{Cross-sectoral}

Across sectors, IEA member countries should:

Improve national energy efficiency strategies and action plans (NEEAPS)

Many countries are developing NEEAPs as a means to engage stakeholders, build consensus and galvanise action on energy efficiency. NEEAPs can help guide and encourage energy efficiency policy development and implementation by:

- placing energy efficiency policy within the broader policy context;

- prioritising resource allocation across the range of possible energy efficiency policies;

- capturing synergies between policies;

- engaging stakeholders and building political consensus; and

- assigning responsibility for policy development, implementation and oversight (IEA, 2009b).

While it is encouraging that EU member states are submitting improved action plans to the European Commission in summer 2011 and that NEEAPs are under development in the two IEA member countries that are currently without one, the 2011 Evaluation revealed that there is still considerable room for expanding the coverage and increasing the quality of NEEAPs across IEA member countries.

For example, a review of the current suite of EU national energy efficiency action plans identifies several limitations in many of the plans. These limitations include a lack of ambition, innovation, or prioritisation of policies, as well as a lack of coherence among fragmented measures.

The following is a checklist that may be helpful to countries developing or improving a NEEAP (IEA, 2010).

- Provide a statutory basis for strategy development and updates

- Ensure strategies reflect country context and sectoral issues

- Link energy efficiency strategies to the broader policy context

- Reinforce strategies through action and economic planning

- Adopt a learning approach

- Establish accountability

- Balance comprehensive and sectoral strategies

- Create an energy efficiency strategy development checklist

\section{Implement savings verification and measurement protocols}

The 2011 Evaluation revealed that more than two-thirds of IEA member countries have not implemented a common energy-savings verification and measurement protocol. National protocols are essential for reducing uncertainties in quantifying the benefits of energy efficiency investment and therefore stimulating increased private sector funding of energy efficiency. A common protocol would enhance international comparability of policy performance. Given the importance of this protocol, IEA member countries are urged to expedite their activities in this area.

\section{Promote risk-mitigation instruments, such as public-private partnerships}

Countries should consider doing more to promote financial risk-mitigation instruments for investments in energy efficiency. International experience suggests public-private partnerships 
are a highly effective tool for addressing the issue of perceived risk associated with energy efficiency investments (International Energy Agency 2008b). However, evaluation results suggest that one third of IEA member countries have not implemented policies in this area. The IEA Secretariat urges more effort in implementing the recommended instruments to facilitate energy efficiency financing.

\section{Strengthen quality and coverage of energy indicators}

IEA member countries also need to devote more attention to improving the quality and coverage of indicators. Many IEA member countries have been working to improve end-use data collection across sectors. The IEA expects to see the outcome of this data-collection improvement when it receives country submissions for the 2009-2010 energy efficiency data template.

At present, most countries complete a little over half of the IEA energy indicators template (scored as 'implementation underway') - and only six countries are regarded as being able to substantially complete the template (Australia, Canada, New Zealand, Switzerland, the United Kingdom and the United States). Given the potential for these policies to assist countries to achieve energy savings targets, the IEA Secretariat urges IEA member countries to consider policies in this area.

\section{Buildings}

\section{Existing buildings}

The biggest challenge facing most IEA member countries is to strengthen the energy performance of existing buildings. To do this, countries should improve MEPs for existing buildings and implement policies to increase the rate of energy performance renovations.

\section{New buildings}

At the same time, policies are needed to increase the energy performance of new buildings. Factoring in energy performance at the building-design and construction stage is highly cost effective and needs to be at the forefront of building energy efficiency policies. All IEA member countries should periodically set stronger energy efficiency requirements for buildings. But only Denmark, Germany, the Netherlands and the United Kingdom have energy efficiency requirements that are approaching the optimal 30-year least life-cycle cost level. At the other end of the spectrum, a couple of IEA member countries appear to have levels set at less than a five-year least life-cycle cost.

There is also a need to scale up construction of very low-energy building such as PEHs, which use $65 \%$ to $80 \%$ less energy than a standard house, and ZEBs. Despite the financial benefits and technical feasibility of low-energy buildings, only slightly more than half of IEA member countries have implemented policies to actively support the introduction of these buildings (Figure 26); one third of IEA member countries have set market share targets for PEH or ZEB; and one third of IEA member countries are using PEH and ZEB as benchmarks for energy efficiency standards in upcoming building regulation updates. 


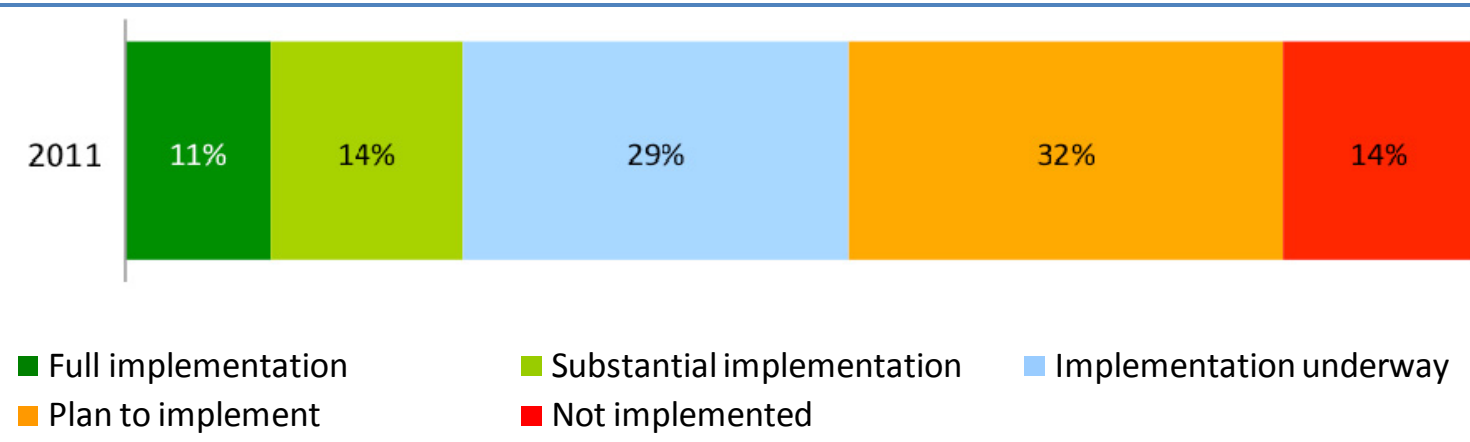

Greater effort to support highly energy-efficient buildings, such as PEH and ZEB, would significantly bolster energy efficiency in IEA member countries' building stock.

\section{Promote energy-efficient windows and glazing}

Installation of energy-efficient glazing provides significant energy-savings potential, particularly through the replacement of windows in existing buildings. Indeed, replacing old windows with energy-efficient windows is one of the most effective ways to improve the energy efficiency of existing building stock, as windows are often replaced several times during the life of a building. Furthermore, retrofitting energy-efficient windows appears cost effective in all climates.

IEA member countries continue to demonstrate relatively poor performance with respect to promoting energy-efficient glazing Twelve IEA member countries have not implemented any part of the glazing recommendation package. No country has fully implemented the recommendation relating to the labelling of windows, although it has been significantly implemented by Canada, Denmark, Japan and the United States. Only Portugal has fully implemented the recommendation relating to establishing MEPs for windows and glazing. Given the potential for these policies to assist countries to achieve energy-savings targets, the IEA Secretariat urges IEA member countries to increase their efforts in this area.

\section{Appliances and equipment}

IEA member countries have made considerable efforts to strength appliance efficiency since the 2009Evaluation. However, there are three areas where more work is strongly encouraged. First, although most countries are planning some kind of policy to ensure network-connected electronic devices minimise energy consumption, only $18 \%$ are actually implementing policies to this effect (Figure 27).

Figure 27 Policies to ensure network-connected electronic devices minimise energy consumption

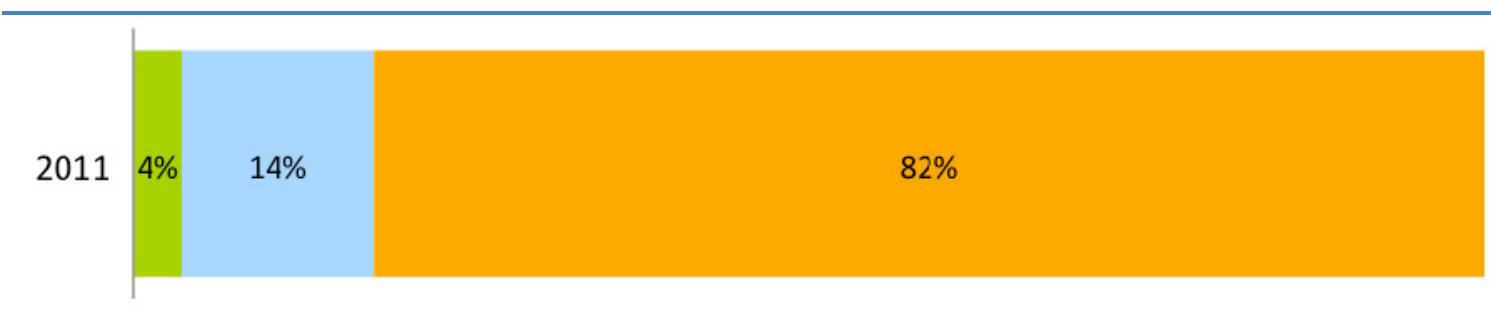

Full implementation - Plan to implement
Substantial implementation $\square$ Implementation underway

not implemented 
Second, as in 2009, very few countries have made progress with policies to encourage television service providers (TVSPs) to ensure their leased set-top boxes are as energy efficient as possible. This is important because many set-top boxes are purchased by a TVSP and leased to householders who pay the energy bill. In this case there is no incentive for the TVSP to reduce the running cost of equipment (a classic principal-agent problem (International Energy Agency 2007b)). Often consumers have little choice in selecting the model of set-top box. Policies are required to encourage TVSPs to consider energy efficiency, as currently there are no effective market drivers for them to do so. As all TVSPs operate on a licence or franchise agreement with government agencies, the license agreement should include energy performance requirements, covering both the hardware provided to customers and effective power management.

Third, with the development of new technologies, the potential to reduce TV energy consumption should be further explored. Since 2009, there have been few new policies to promote more efficient TV technologies such as OLEDs (organic light emitting diodes) backlight modulation in LCDs. Without technological improvements, electricity consumption from TVs is expected to grow at around 5\% per year to 2030 .

\section{Lighting}

To improve energy efficiency in the lighting sector, further policy developments are particularly needed to:

\section{Promote energy efficiency in non-residential lighting}

The majority of electricity used for lighting is for in-door lighting in non-residential buildings i.e within public, commercial and industrial buildings. There are many highly cost-effective opportunities to save lighting energy in these spaces from the use of efficient lamps to natural daylight and good lighting design. Policy measures, which target the performance of the lighting system as a whole and place responsibilities upon the agents who design, install and operate such systems, are needed. Such measures are complementary to policies that address the energy performance of specific lighting components e.g. lamp energy performance requirements, but aim to address key principal-agent problems, which otherwise prevent optimised lighting system design, procurement, installation and operation.

In 2009, many countries had plans to phase out inefficient street lighting technologies such as mercury vapour lamps. The 2011 Evaluation reveals that these policies are now underway. The IEA encourages further implementation.

\section{Support adoption of high-efficiency alternatives to fuel-based lighting}

Only seven IEA member countries are implementing policies to stimulate the adoption of more efficient alternatives to fuel-based lighting in off-grid communities in developing countries.

Globally, 1.6 billion people are without access to electricity through the grid (International Energy Agency 2008c). As a consequence, many rely on fuel-based lighting technologies, such as kerosene lamps, to provide illumination. Such lighting is extremely inefficient and costly. Furthermore, it provides inadequate illumination levels for many applications such as reading and gives rise to significant in-door air pollution. In areas where access to the grid is not viable in the near-term, new solid-state lighting technology can provide high-quality solar-powered task lighting at significantly lower economic, environmental and health costs over its life-cycle than fuel-based lighting. Presently, there are limited distribution channels for this technology and the initial costs can be prohibitively high for those with little or no access to credit and constrained 
cash flow. A global effort that not only supports the transition away from fuel-based lighting to more sustainable alternatives, but also provides access to technology and financing, would have a positive impact on the lives of hundreds of millions of people. It would also move us closer to attaining a variety of international development and energy policy goals. The IEA Secretariat encourages IEA member countries to undertake such efforts in the context of their overseas development assistance and related activities.

\section{Transport}

Since the 2009 Evaluation, most IEA member countries have developed policies to improve the energy efficiency of the transport sector. Despite this, policies for heavy-duty vehicles lag behind light-duty vehicles (Figure 28). Japan has policies establishing mandatory fuel-efficiency standards for heavy-duty vehicles and the United States is putting in place policies for MY 2014-2018. Heavy-duty vehicles are responsible for $30 \%$ of worldwide fuel use (International Energy Agency 2008c). IEA member countries should urgently implement policies aimed at accelerating fuelefficiency improvements and labelling in trucks and other heavy-duty vehicles.

Although the benefits of eco-driving and its cost-effectiveness as a policy to reduce energy consumption from vehicle are well-known, most countries have not yet made eco-driving an obligatory part of driver education or a requirement as part of the driving test. The IEA secretariat encourages countries to introduce this as soon as possible.

Figure 28 Mandatory fuel-efficiency standards for heavy-duty vehicles

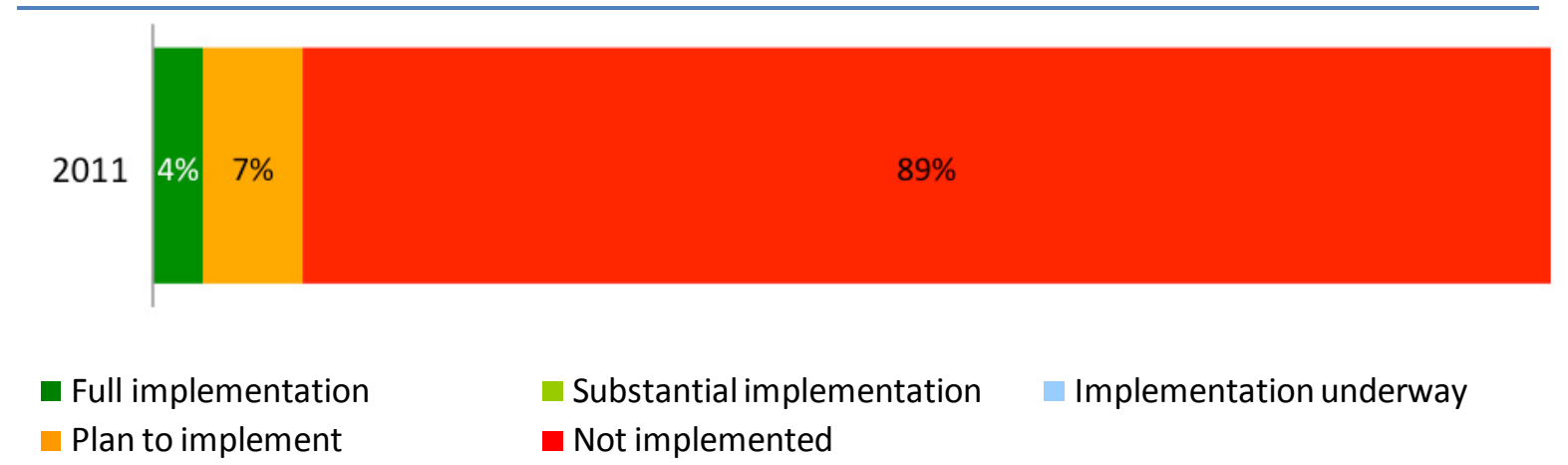

Several IEA member countries, including Korea, New Zealand, Norway, Switzerland and Turkey need to quickly put in place planned transport energy efficiency policies, and implement policies where there are currently none.

\section{Industry}

Analysis shows that substantial energy savings opportunities to improve industrial energy efficiency remain. IEA member countries can capture more energy efficiency potential in this sector by increasing policy efforts in two main areas.

First, although IEA member countries have made progress in adopting MEPs for electric motors, few countries are examining barriers to the optimisation of energy efficiency in electric motordriven systems and design or in implementing policies to overcome such barriers.

Energy savings in the order of $5-10 \%$ of global electricity demand are estimated to be achievable from optimisation of electric motor-driven systems (International Energy Agency 2011). A large part of these savings can be achieved through better matching the output of motor driven 
systems to fluctuations in mechanical loads via the use of power electronics and adjustable speed drives. However, additional policy measures are required. Some of these could target standardised motor-driven applications such as pumps, fans, compressors and circulators, but there are many other less standardised applications where more effort will be required to determine effective policy portfolios.

Page | 42 Second, while policies for SMEs are well-developed in several countries, the IEA is concerned that more attention is needed. Benchmarking information needs to be made available to SMEs. Appropriate incentives also need to be developed and implemented to encourage SMEs to make least life-cycle cost capital acquisition decisions. Currently fewer than $50 \%$ of IEA member countries are implementing such policies (Figure 29).

Figure 29 Incentives to adopt least-life cycle cost capital acquisition and procurement procedures for SMES

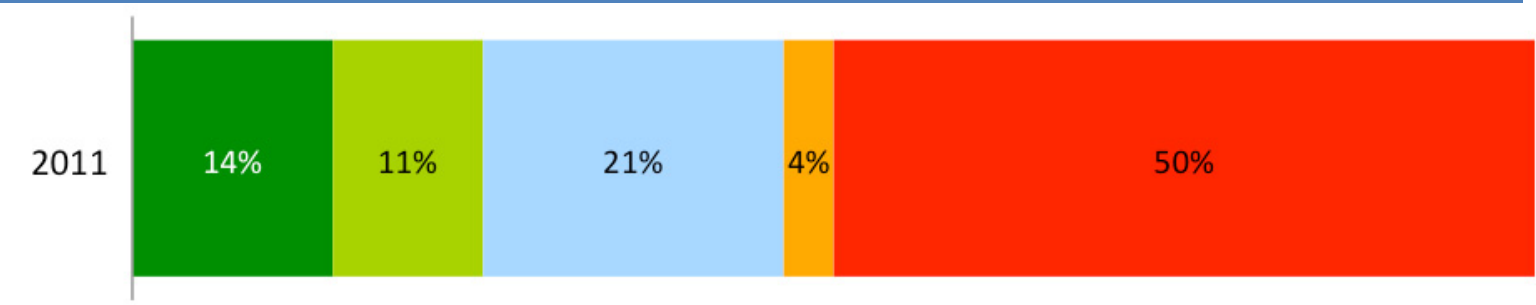

Full implementation

- Plan to implement
Substantial implementation $\quad$ Implementation underway
Not implemented

\section{Energy utilities}

If institutional framework and enabling conditions are developed, energy utilities can have an important role in delivering energy efficiency. In the United States, Canada and the United Kingdom, regulated distribution companies and competitive retail energy suppliers are one of the primary designers and implementers of energy efficiency programmes (IEA, 2010). Competitive advantages and core competencies of energy providers include: ready access to capital; an existing relationship with end users, through billing systems and market data; a familiar brand name; and a widespread service and delivery network within their jurisdiction. Importantly, many energy utilities also have resource adequacy responsibilities i.e., they must plan for, and accommodate, energy and peak demand growth.

To encourage energy utilities to deliver energy savings, the IEA recommends that countries implement one or more of the following recommendations

- Establish regulation, which decouples utility revenue and profits from energy sales and allows energy savings delivery to compete on equal terms with energy sales.

- Place energy efficiency obligations on energy utilities, the stringency of which is periodically raised by continued cost effectiveness in delivering energy services.

- Allowing energy efficiency measures to be bid into energy pools, on an equal basis to energy supply options.

- Develop other policy measures that encourage utilities to play an active part in funding and/or delivering end-use efficiency improvements among their customer base. 
Figure 30 Decouple energy utility revenue and profits from energy sales and allow energy savings delivery to compete on equal terms with energy sales

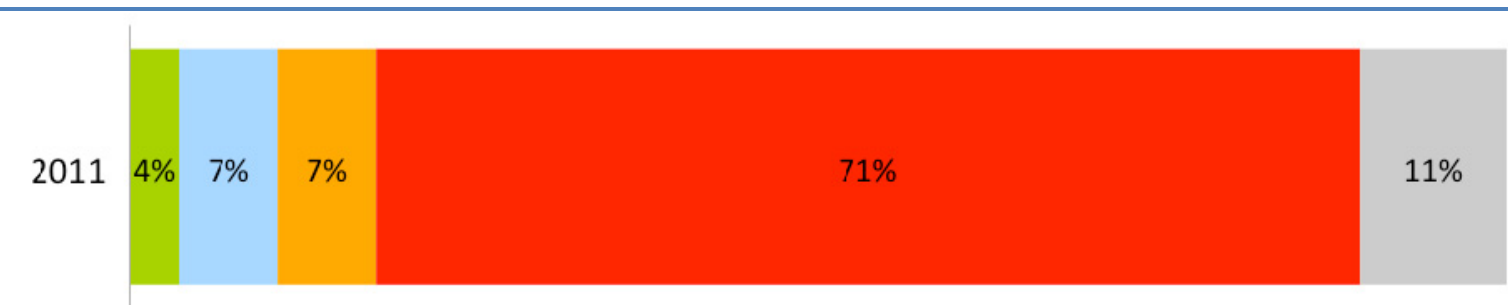

- Full implementation

- Plan to implement
Substantial implementation Implementation underway

Not implemented

Almost a third of member countries have either not implemented or are not planning to implement any of the IEA energy utility recommendations. This is particularly the case for the recommendations regarding decoupling utility revenue and profits from energy sales (Figure 30) and allowing energy efficiency measures to be bid into energy pools (Figure 31).

Figure 31. Energy efficiency measures bid into energy pools, on an equal basis to energy supply options

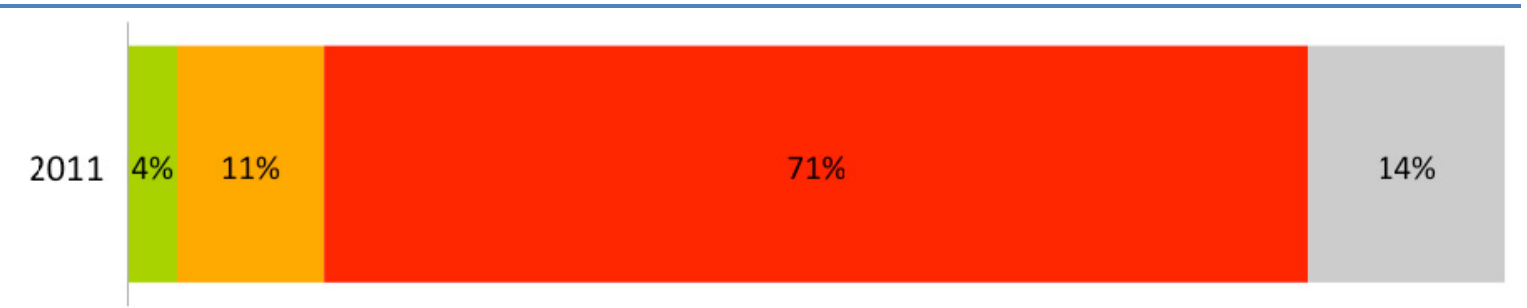

Full implementation

Plan to implement
Substantial implementation Implementation underway

Not implemented 


\section{Country reports}

This section outlines each IEA member country's progress with implementing energy efficiency policies, with a particular focus on the IEA 25 energy efficiency policy recommendations.

The overall aim of this section is to assist governments with enhancing energy efficiency policy. It is important to note that these country reports do not mention every energy efficiency policy in each country. Rather, they focus on a selection of successful and innovative policies as well as areas for further action.

In 2009, the United Kingdom and Switzerland had the lowest energy intensities of any IEA member country in terms of purchasing power parity (PPP) (Figure 32), but when market exchange rates (MER) were considered, Japan and Switzerland had the lowest energy intensities (Figure 33).

Most countries have demonstrated relatively consistent declines in energy intensity since $1990 .^{5}$

Figure 32 Changes in final energy intensity in IEA member countries (purchasing power parity) from 1990 to 2009

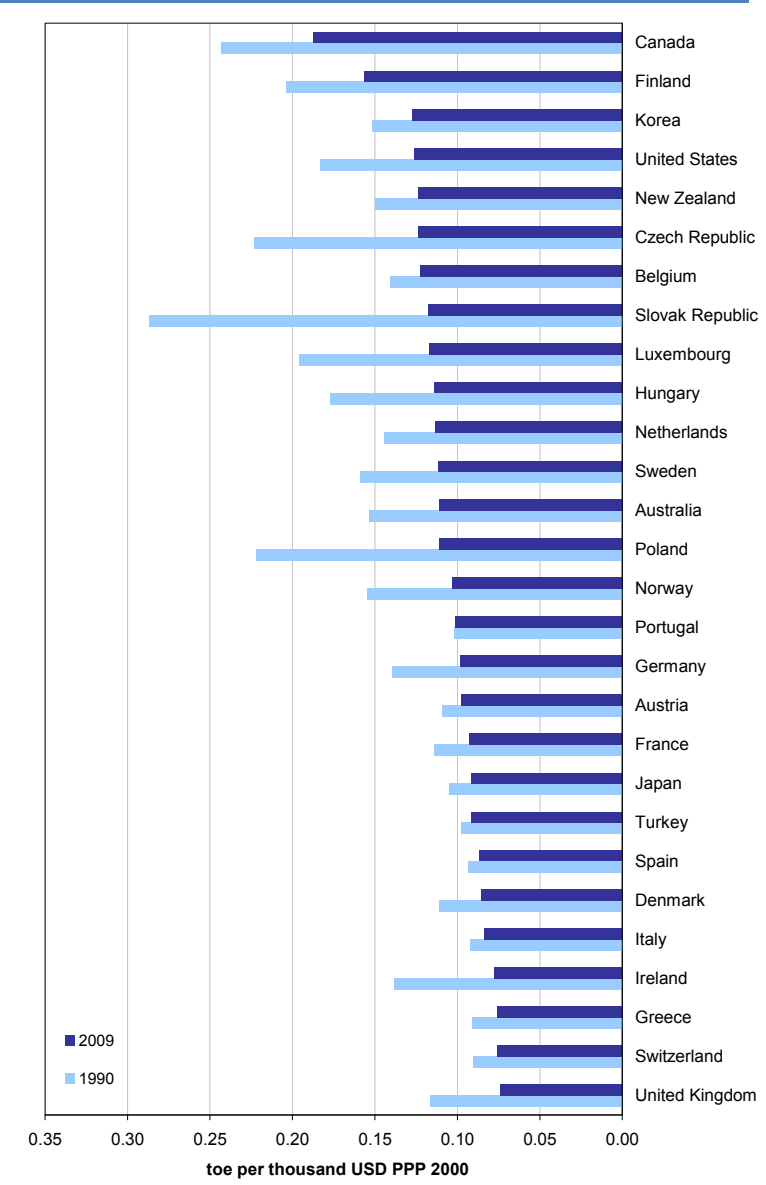

Figure 33 Changes in final energy intensity in IEA member countries (market exchange rates) from 1990 to 2009

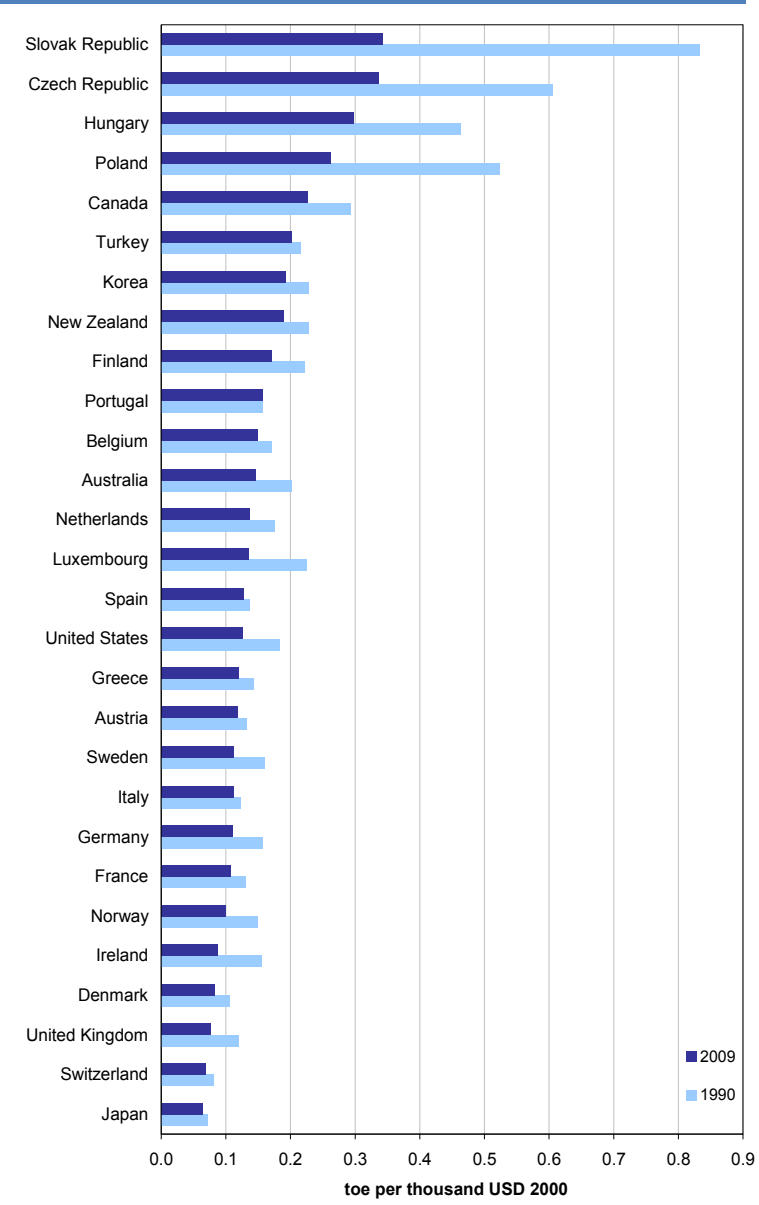

Source : IEA Indicators.

${ }^{5}$ Like in other IEA member countries, energy intensity in Spain and Portugal was lower in 2009 than in 1990. 
Figure 34 Decomposition of final energy intensity changes for IEA17 countries, 1990 to $2008^{6}$

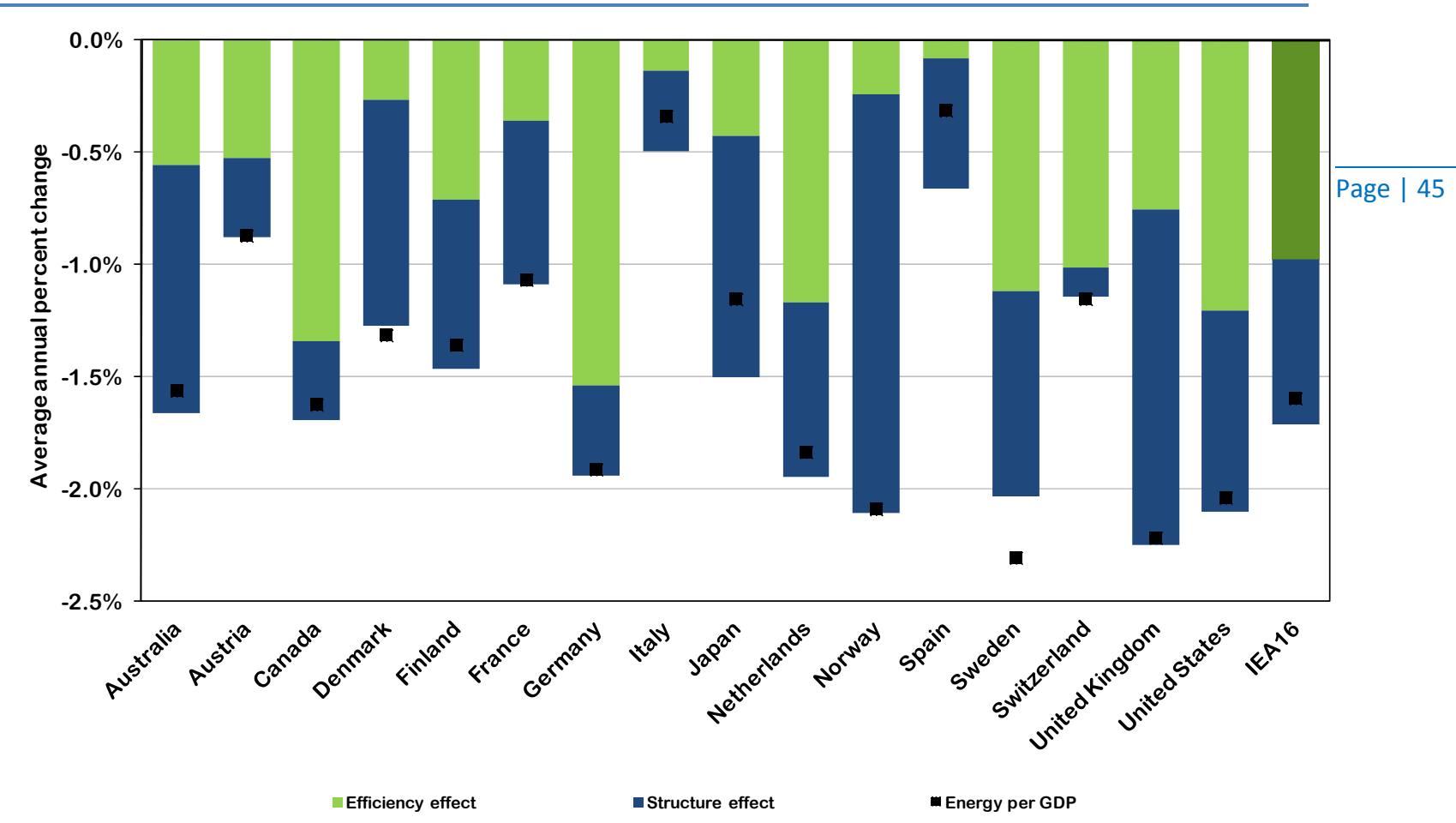

Source: IEA indicator database.

It is possible to 'decompose' or separate out the changes in energy efficiency and changes in economic activity and structure that affect aggregate energy intensity. Sweden's aggregate energy intensity decreased by around 2\% per year from 1990 to 2008 (Figure 34). Over 1\% of this decrease can be attributed to improved energy efficiency. The rest resulted from changes in economic activity and structure.

\section{Energy Efficiency Progress Report - Australia}

\section{Context}

Due largely to its relatively inexpensive energy prices, long freight-transport distances and the dominance of energy-intensive industry, Australia's energy intensity is higher than the IEA average. Over time, Australia's economy has become more service-driven resulting in a decrease in energy intensity of around 1.7\% per year between 1990 and 2009 (Figure 32).

Australia has a federal system of government and energy efficiency policy responsibility is spread across different levels of government. Cross-government energy efficiency policy is co-ordinated through the Council of Australian Governments (COAG), an intergovernmental body comprising the prime minister, state premiers, territory chief ministers and the President of the Australian Local Government Association. In July 2009, COAG agreed to the National Strategy on Energy Efficiency (NSEE), which focuses on demand-side efficiency across all end-use sectors and seeks to accelerate energy efficiency efforts by setting clear goals and addressing information barriers. The Ministerial Council on Energy (MCE), which comprises commonwealth, state and territory energy ministers, oversees and coordinates the development of cross-government energy policy, such as the regulation of electricity and natural gas markets and, until June 2011, the National

${ }^{6}$ IEA average is limited to countries shown in graph. 
Framework for Energy Efficiency (NFEE).

In February 2011, COAG agreed to reform the ministerial council system to focus on strategic national priorities and new ways to identify and address issues of national significance. As part of the Ministerial Council reforms, a new Standing Council on Energy and Resources and a Select Council on Climate Change will be established.

Consistent with its strongly market-based ethos, the Australia intends to improve energy efficiency through the introduction of a carbon price mechanism, which it expects to roll out in mid 2012.

\section{Energy efficiency policy developments}

In October 2010, Australia released the Prime Minister's Task Group on Energy Efficiency report. In addition to the introduction of a carbon price, the report recommended five key measures for the government to make a step-change improvement in Australia's energy efficiency performance. Australia is currently considering its response to the report, with work having already commenced on many of the sectoral measures recommended by the Task Group. The report notes that the most important element in a vision of a step-change in Australia's energy efficiency improvement is the presence of a carbon price.

Low Carbon Australia (formerly the Australian Carbon Trust) is leading efforts to develop a range of innovative financing and delivery models for energy-efficiency improvements across nonresidential sectors.

Australia has an exemplary Minimum Energy Performance Requirements (MEPS) programme, which includes standard procedures for compliance, monitoring and enforcement. The Australian programme covered 22 products for MEPs and 7 for mandatory labelling as of December 2010 and will double product coverage by 2020. Australia recently introduced new MEPs and/or labelling requirements for televisions and lighting products (tungsten filament lamps; low voltage non-reflector halogen lamps; self ballasted CFLs; Extra low voltage (ELV) halogen reflectors; and > $40 \mathrm{~W}$ candle, and decorative lamps). Revised energy labelling requirements and more stringent MEPs were also introduced for refrigerators, freezers and single and three phase air conditioners. A voluntary energy-rating labelling programme is also underway for swimming pool pumps to increase consumer awareness and assist the manufacturing industry in preparing for future MEPS. In addition to increasing regulated product coverage, Australia is implementing stage one of a phase-out of inefficient electric hot water systems. Work is also well underway to develop demand response interfaces for a range of major appliances as a means to manage peak load demands caused by appliances.

In the lighting sector, the phase out of incandescent lighting, started in 2009, is expected to deliver a savings of 28 million tonnes of $\mathrm{CO}_{2}$ by 2020. In 2010, Australia updated its building code to impose a limit on general service lighting systems in commercial buildings of no more than $10 \mathrm{~W} / \mathrm{m}^{2}$ of internal floor area. The government is also taking steps to help developing and emerging economies to phase-out inefficient lighting and replace fuel-based lighting with efficient alternatives through its participation in the Building and Appliances Taskforce of the Asia-Pacific Partnership on Clean Development and Climate.

To improve energy efficiency in the industrial sector, the 2006 Energy Efficiency Opportunities (EEO) programme implements a mix of mandatory and voluntary approaches to encourage large energy consumers to implement adapted energy efficiency measures. Companies are required to undertake energy efficiency assessments. Although companies are not required to implement opportunities identified in assessments, they must report on these opportunities to their boards and the public. This improves the quality of information to decision makers. Consultation with 
companies is underway to improve existing monitoring and evaluation procedures for the second five-year EEO cycle, which is due to start in 2012. As of December 2010, companies representing $44 \%$ of Australia's energy end use had reported that they had committed to implementing annual savings of $1 \%$ of Australia's total 2008-09 emissions.

In its 2009 NSEE, COAG identified a lack of information as the primary barrier to the optimisation of energy efficiency in industrial electric motor-driven systems. As a result, targeted outreach information is being developed, which will be disseminated to industry on the Energy Efficiency Exchange (EEX) website.

\section{Challenges and areas for improvement}

While lead responsibility for Australian Government energy efficiency policy rests with the Department of Climate Change and Energy Efficiency (DCCEE), responsibility for aspects of developing and implementing energy efficiency policy continues to be shared by commonwealth, state and territory agencies. To improve energy efficiency policy coordination, a National Partnership Agreement on Energy Efficiency was signed by all state and federal governments in July 2009 on the 10 year National Strategy on Energy Efficiency. This consistency will be further improved in the appliances' area with the development of national legislation on standards and labelling to be adopted in 2012. Prior to the 2012 legislation, intent was agreed with the states but then implemented state by state.

Little progress has been made in the buildings sector since the last IEA review. The IEA recommends encouraging PEH and ZEB through benchmarking and objective setting.

While progress has been made, particular challenges remain for Australia's transport sector, particularly in light of the population's high reliance on private vehicles. The government has committed to introducing mandatory $\mathrm{CO}_{2}$ emissions standards for light-duty vehicles to take effect from 2015. A consultation process to determine emissions targets and design standards is underway, with the initial consultation phase completed in mid-2011. Much more work will be needed to improve energy efficiency in this sector. Consideration should be given to setting energy efficiency standards and test procedures for tyres as well as implementing labelling schemes in line with international best practice. Australia could also consider extending mandatory vehicle labelling in relation to fuel consumption and $\mathrm{CO}_{2}$ emissions for light and heavy-duty vehicles. The IEA notes that, more generally, the EEO programme covers the largest energy-using companies and includes road transport and mining companies using heavy-duty vehicles. The EEO programme requires companies to identify and report on the most costeffective opportunities to improve energy efficiency, which often includes driver training and tyre pressure maintenance.

With regard to utilities, Australia should increase efforts to develop an incentive scheme to encourage companies to manage demand or implement efficient non-network alternatives. The government should also consider implementing nation-wide obligations for utilities to deliver energy efficiency to their customer base, as per the recommendation of the Prime Minister's Task Group on Energy Efficiency. Such obligations would replace those already existing in three States.

The government should continue efforts to implement cost-effective energy efficiency policies. 


\section{Australia's progress with implementing IEA energy efficiency recommendations}

Page $\mid 48$

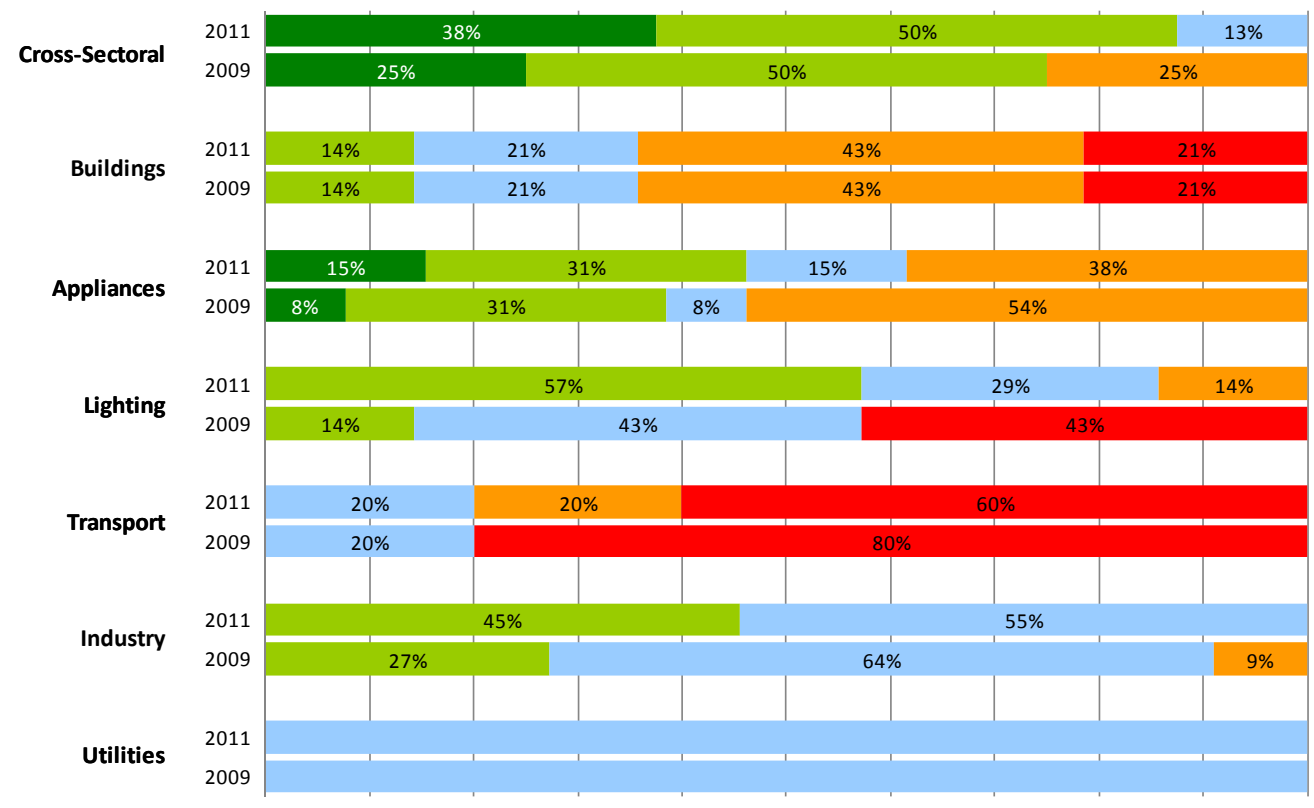

Full implementation

Plan to implement
Substantial implementation $\square$ Implementation underway

not implemented

\section{Energy Efficiency Progress Report - Austria}

\section{Context}

Energy efficiency is an integral part of Austria's energy policy. Austria's energy intensity, adjusted for PPP, has declined on average by $0.6 \%$ per year between 1990 and 2009, compared with the IEA member country average of $1.6 \%$ (Figure 32 ).

Following its commitment under the EU Energy Services Directive, Austria's NEEAP aims to achieve a 9\% energy efficiency improvement target for 2016 and a $2 \%$ intermediate target for 2010. Many of Austria's measures go beyond EU legislation, particularly the EPBD, and offer diverse financial, legislative, promotional and informational instruments and transposition with more stringent provisions.

\section{Energy efficiency policy developments}

Since 2009, Austria has improved its energy efficiency policies.

In the buildings sector, Austria has made good progress in addressing minimum energy performance requirements for windows and other glazed areas. Following the trend towards low-energy and passive houses, the Austrian market has developed triple glazed windows with Uvalues of significantly less than 1.0 (ranging from 0.65 to 0.9 ). The use of windows with U-values of 1.3 or above is significantly decreasing because of effective public awareness campaigns and the availability of high-efficiency windows at affordable prices.

Related to the appliance and lighting sectors, energy requirements for numerous products covered under the Ecodesign Directive (2005/32/EC) have entered into force, and Austria is 
transposing the October 2009 Ecodesign Directive recast (2009/125/EC), which includes energyrelated products, such as building components.

Austria is also transposing the May 2010 Directive (2010/30/EU), which requires labelling and standard product information on the consumption of energy and other resources by energyrelated products.

In the transport sector, Austria is implementing EU regulations to lower rolling resistance and promote appropriate tyre inflation pressure. Austria is also implementing EU regulations, which require average emissions from new passenger vehicles sold in Austria, and other EU member states, to reach the $130 \mathrm{~g} \mathrm{CO}_{2} / \mathrm{km}$ target by 2015 .

In line with EU regulations, minimum energy performance requirements (MEPs) for motors are being implemented to improve energy efficiency in the industrial sector.

\section{Challenges and areas for improvement}

Considerable energy savings potential remains in all sectors of Austria's economy.

To improve energy efficiency in the transport sector, for example, Austria should push the EU to consider implementing policies that require mandatory fuel-efficiency standards for heavy-duty vehicles.

Energy efficiency could be improved in new buildings by speeding up planned policies to set energy efficiency standards that minimise costs over a 30-year lifetime. Moreover, in addition to supporting construction of very-low energy consumption buildings, Austria could set objectives for PEH and ZEB as a market share of all new construction by 2020. Austria should also consider using PEH and ZEB as a benchmark for energy efficiency standards in future updates of building recommendations.

With regard to appliances, Austria should ensure the implementation of industry-wide protocols that minimise the energy consumption of network-connected electronic devices.

Austria implemented voluntary agreements in 2010 in order to motivate utilities to deliver energy savings for their final customers. According to this scheme, utilities agreed to set energy efficiency measures in order to save more than $10 \mathrm{PJ}$ (petajoule) of final energy consumption per year. This target is expected be reached in 2016. To further encourage utilities to deliver energy savings, Austria could require energy efficiency measures and energy supply options to compete on a level playing field with energy sales or establish regulations, which decouple energy sales' revenue and profits from energy savings.

In the industrial sector, Austria could develop and implement incentives for SMEs to adopt least life-cycle cost capital acquisition procedures. Austria could also speed up efforts to adopt and publicise common energy-efficiency savings and verification measures, as this would more likely lead to a boost in private sector investment in energy efficiency. 


\section{Austria's progress with implementing IEA energy efficiency recommendations}

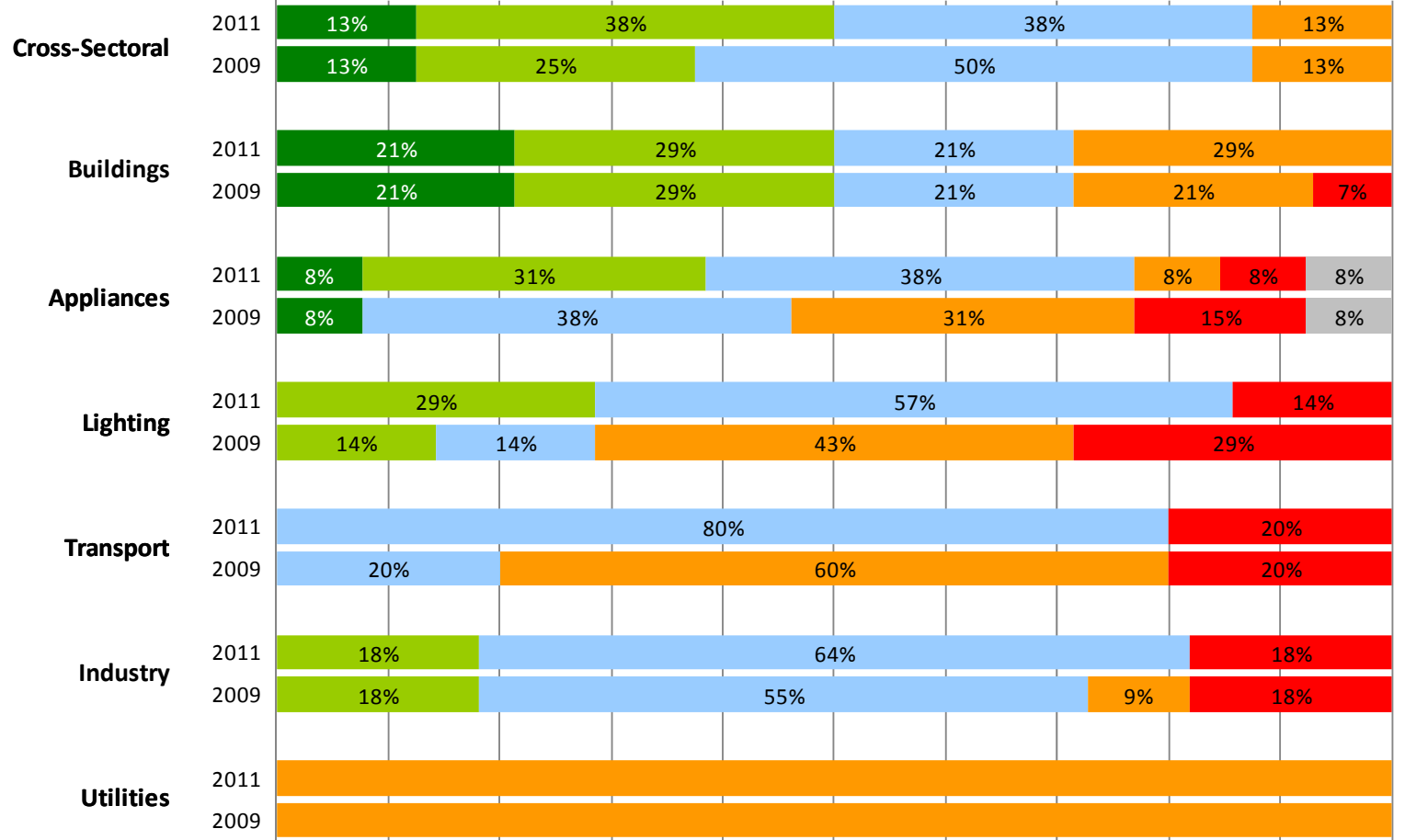

Full implementation

- Plan to implement
Substantial implementation Implementation underway

- Not implemented

\section{Energy Efficiency Progress Report - Belgium}

\section{Context}

Energy efficiency policy is primarily under the purview of the three Belgian regions - BrusselsCapital, Flanders and Wallonia. In accordance with the EU Directive on energy end-use efficiency and energy services (ESD), Belgium's indicative target is to achieve 9\% energy efficiency improvement between 2007 and 2016 (equivalent to $27515 \mathrm{GWh}$ ). In 2007, the country submitted to the European Commission a NEEAP consisting of one federal and three regional plans. Each region has set an energy efficiency target and adopted a number of diverse measures to promote energy efficiency. Although there is no specific federal target ${ }^{7}$, the federal government contributes to enhancing energy efficiency by energy-related taxes and various fiscal incentives, for equipment, energy labelling, soft loans and other measures. A coordination body, CONCER/ENOVER, has been set up to harmonise and create synergy between the policies implemented by the federal government and the three regions.

Energy intensity of Belgium's economy is higher than the IEA average. This is due in part to a very energy-intensive industrial sector with a large share of iron and steel industry and chemicals. Energy intensity, adjusted for PPP, grew through most of the 1990s. It started improving in 1999

\footnotetext{
${ }^{7}$ The national target is the sum of the three regional ones.
} 
and declined on average by $2.7 \%$ per year between 2000 and 2009, for a $0.7 \%$ per year average decline from 1990 to 2009.

\section{Energy efficiency policy developments}

Belgium has made some progress in implementing energy efficiency policies since the 2009 Evaluation, particularly relating to transposition of EU directives and regulations.

In the transport sector, Belgium is implementing EU regulations to lower rolling resistance and promote appropriate tyre inflation pressure. Belgium is also implementing EU regulations, which require average emissions from new passenger vehicles sold in Belgium, and other EU member states, to reach the $130 \mathrm{~g} \mathrm{CO}_{2} / \mathrm{km}$ target by 2015 .

The regions and the federal government have made significant efforts to improve energy efficiency in buildings, which account for the largest share of domestic primary energy demand. The federal government has set up a EUR 250 million "Fund for the Reduction of Energy Costs", which serves to finance energy efficiency improvements in buildings by households. As part of the economic recovery plan, the federal government has provided EUR 210 million over five years for improving energy efficiency in public buildings. Belgium continues to transpose the EPBD into domestic law. The Belgian regions have mandatory energy efficiency standards for new buildings in building codes and are working towards strengthening them. The regions are also developing systems for certification of buildings energy performance.

As for utilities, in the Flanders and Brussels-Capital regions distribution network operators are required to encourage energy savings for their final customers. Electricity network operators in Flanders are obliged to reach annual energy savings of $2 \%$ for residential users and $1.5 \%$ for nonresidential users.

Belgium provides fiscal incentives (both at the federal and regional levels) to enterprises making investments in energy efficiency. The Flanders and Wallonia regions have voluntary agreements with energy-intensive industry and the Brussels-Capital region is considering a similar mechanism. At present, the Brussels-Capital region has a system of "eco-dynamic" labels, which are given to enterprises with sustainable management practices.

\section{Challenges and areas for improvement}

The overall effectiveness of Belgian energy efficiency policy could be improved further by addressing several challenges. First, there is room for improvement in streamlining the existing support measures. There is overlap between federal, regional and local policies and measures covering various sectors and there seems to be no clear understanding among various stakeholders, including end-users, about how all these different policies interact. In particular, there are many financial support schemes targeting the same measure, especially in the buildings sector. Better coordination of the financial support schemes and improving information is therefore strongly recommended.

In the buildings sector, additional measures could be introduced to improve energy efficiency. For example, Belgium currently lacks actions to promote efficient windows and other glazed areas, which represent great opportunities for energy savings. Belgium should also consider using $\mathrm{PEH}$ and ZEB as a benchmark for energy efficiency standards in future revisions of building regulations.

Belgium could do more to speed up efforts to implement policies to adopt and publicise common energy-efficiency savings and verification measures to encourage a boost in private sector investment in energy efficiency. Such efforts need to be supported by optimal procedures for 
compliance, monitoring and evaluation of energy efficiency policies and by reliable legislative and institutional infrastructure for enforcement.

While there is significant potential for further energy efficiency improvements in most sectors of the Belgian economy, reducing energy use in the transport sector is the most challenging, as in all IEA member countries. Implementing EU transport-related policies will be an important step in

Page $\mid 52$ addressing energy efficiency in the sector.

\section{Belgium's progress with implementing IEA energy efficiency recommendations}

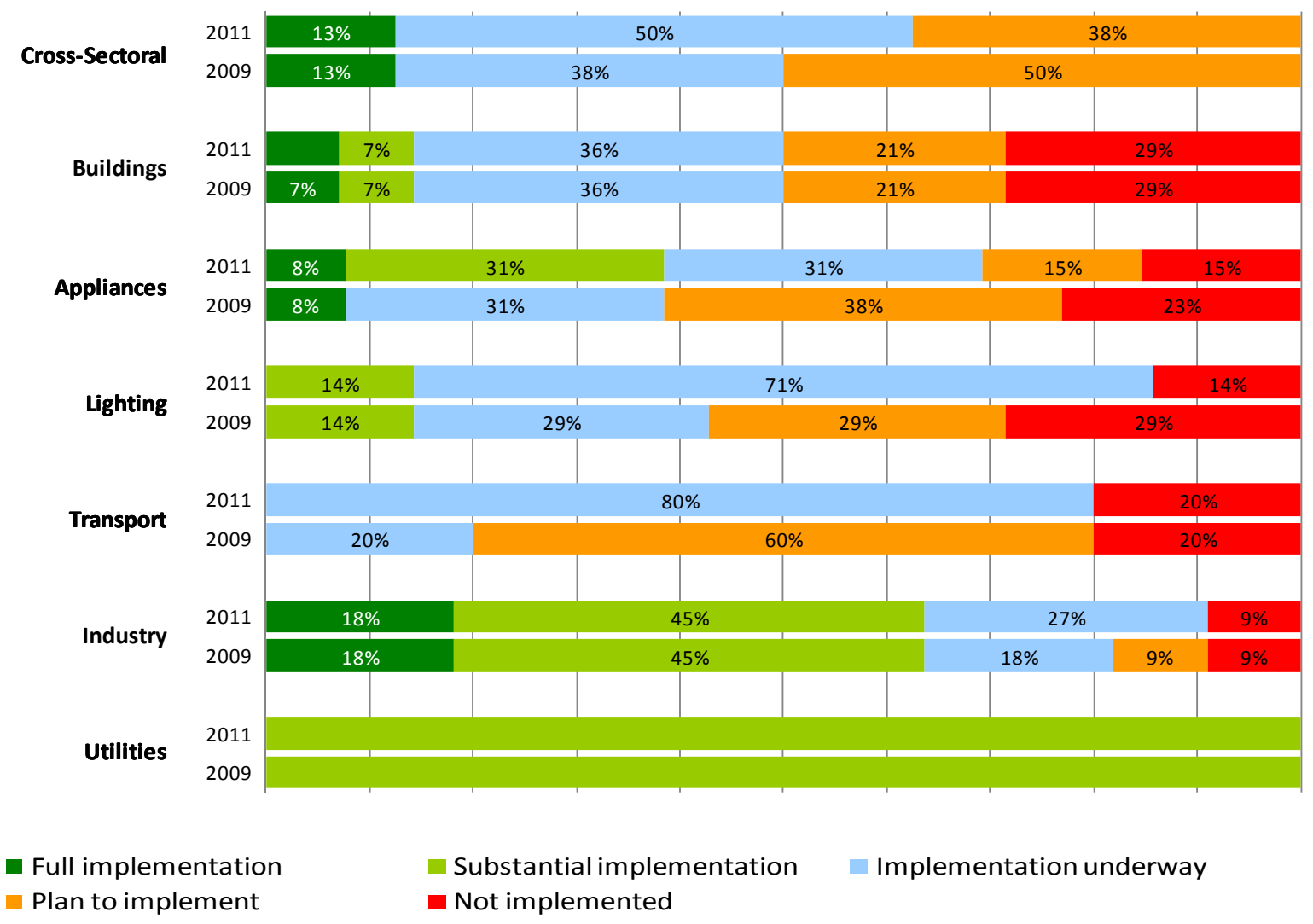

\section{Energy Efficiency Progress Report - Canada}

\section{Context}

Canada has higher energy intensity, adjusted for PPP, than any IEA member country. This is largely due to its concentration of output in energy-intensive sectors, cold climate, large distances and high standard of living. Final energy consumption has grown continuously over the past decade, though at a lower rate than the economy as a whole. Canada's energy intensity, adjusted for PPP, has declined on average by 1.4\% per year between 1990 and 2009.

The majority of annual intensity improvements from 1990 to 2009 were due to energy efficiency gains, with the rest resulting from changes in sector mix (Figure 32). Canada is reviewing its proposed regulatory regime for GHG emissions from major industrial sources to align with the regulatory regime emerging in the United States. Canada is also aiming to improve efficiency in the transport sector, with recent legislation regulating the fuel efficiency of cars and light trucks. 


\section{Energy efficiency policy developments}

Canada has strengthened energy efficiency policies across all sectors since the 2009 Evaluation. Canada is supporting three pilots under the Global Superior Energy Performance (GSEP) international task group to advance implementation of the ISO 50001 energy management systems standard. Canada adopted a national energy management systems standard in 2011 and is currently developing plans to facilitate adoption of the standard by industry.

A robust system for evaluating policy and programme success during and after implementation has been established by the Energy Efficiency Act and published in the annual Report to Parliament. Programmes and policies are audited through Government of Canada-wide procedures of audits (e.g. by the Auditor General and the Commissioner of the Environment and Sustainable Development), and annual planning and priorities submissions. In compliance with the federal Transfer Payments Policy, all programmes are regularly evaluated and the results published.

In the buildings sector, Canada has strengthened building codes for new buildings. It is resourcing the design and construction of new houses and buildings to be $25 \%$ more energy efficient than current practices by 2011 for commercial buildings and 2012 for houses, by working with all levels of government to support the development of a more stringent National Energy Code for Buildings. The federal government also supports provinces and territories in the adoption and implementation of mandatory energy efficiency requirements (MEPs) for all new housing using the EnerGuide for Houses rating tool. Canada is committed to undertaking work to further strengthen the 2011 building code by 2015. The ecoENERGY for buildings and houses programme, available in all provinces and territories, encourages both the construction and retrofit of more energy-efficient buildings and houses and offers a wide range of information, publications, training and other resources on energy-efficient technologies and practices in buildings.

Also in the buildings sector, Canada reported efforts to systematically collect information on energy efficiency in existing buildings. For example, Canada communicates information on energy efficiency to building owners, operators and suppliers of professional services across the country through a monthly electronic newsletter that is sent to 20,000 users in the commercial buildings sector. Information and initiatives for industrial buildings have been provided through ecoENERGY for Industry and its Canadian Industry Program for Energy Conservation. Information is also available on the NRCan web site and a special stakeholder relations' team pro-actively markets building energy efficiency to appropriate target audiences.

The Energy Efficiency Act has been amended to include the regulation of TV set-top boxes. Pay TV STB have been covered by a voluntary code of conduct since January 2010. ENERGY STARqualified televisions are actively promoted in the Canadian market. These televisions use approximately $40 \%$ less energy than standard units. A proposed mandatory EnerGuide label for TVs is being developed.

To improve lighting energy efficiency, Canada supports the development of high-efficiency lighting alternatives through research into new solid-state technologies. The Solid State Lighting Project is a three-year initiative to develop silicon lighting and demonstrate its application in commercially viable lighting products.

With regards to transportation, the Passenger Automobile and Light Truck Greenhouse Gas (GHG) Emission Regulations (de facto fuel efficiency standards) were finalised in October 2010. These regulations impose stringent new standards that came in force for MY 2011 and will increase in stringency on an annual basis until MY 2016r. For MY 2012-2016, Canadian standards are aligned with similar GHG standards established by the US Environmental Protection Agency. 
Canada's Council of Energy Ministers is developing collaborative actions to encourage energy utilities to promote and support energy efficiency. The Demand Side Management Working Group of the Steering Committee on Energy Efficiency, which includes representatives from the federal, provincial and territorial governments, has outlined tools and policy measures to encourage stakeholders to implement energy efficiency best practice. In addition, with jurisdictional authority over utilities, a number of provinces such as Ontario and British Columbia have implemented diverse measures to encourage energy savings at the utility level. In British Columbia, for example, the 2010 Clean Energy Act commits to meeting 66\% percent of future incremental electricity demand from conservation and efficiency improvements by 2020 .

\section{Challenges and areas for improvement}

Despite Canada's energy efficiency policy achievements, there are still areas for additional policy development. In the area of lighting, for example, Canada is encouraged to continue development of new regulations on efficient street lighting. Mercury vapour lamps are among the lighting types proposed for regulation.

In the transport sector, Canada should adopt new international test procedures for measuring the rolling resistance of tyres, with a view to establishing labelling and maximum rollingresistance limits where appropriate. Canada should also adopt proposed regulations under the Canadian Environmental Protection Act, 1999, to limit greenhouse gas emissions (de facto improve fuel efficiency) from new on-road heavy-duty vehicles from model year 2014.

While progress has been made in promoting energy efficiency in the buildings sector, this is one area requiring further effort. Low-energy buildings, such as PEH and ZEB, should be used as a benchmark for MEPs in future updates of building regulations. Canada should also implement mandatory energy certification schemes to ensure purchasers and tenants receive information on building energy efficiency and opportunities for energy savings.

\section{Canada's progress with implementing IEA energy efficiency recommendations}

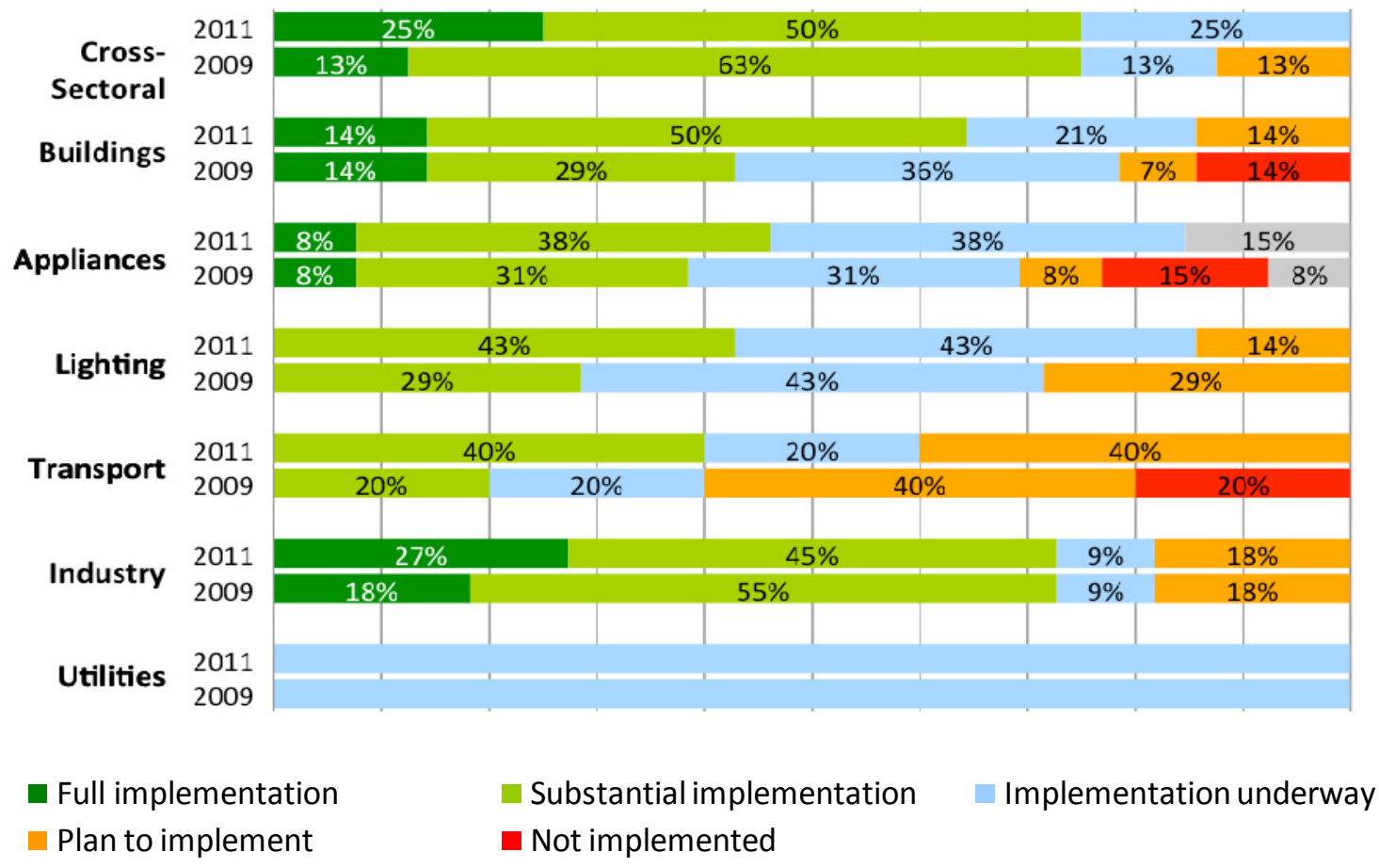




\section{Energy Efficiency Progress Report - Czech Republic}

\section{Context}

Energy intensity in the Czech Republic decreased around 3.1\% per year between 1990 and 2009 (Figure 32), compared with an IEA average decrease of $1.6 \%$.

The Czech Republic committed to a 1\% national energy savings target in 2010 and a $9 \%$ target in 2016 as part of its 2008-2016 National Energy Efficiency Action Plan (NEEAP). Projected energy savings are divided into households, services, industry, transport and agriculture. Around $30 \%$ of savings are expected to be achieved in the buildings sector, followed by $24 \%$ in the industrial sector and $23 \%$ in transport.

\section{Energy efficiency policy developments since 2009}

Since 2009, the Czech Republic has progressed in implementing energy efficiency policies, particularly in the appliance, lighting and transport sectors. Most of these policy developments were in line with transposition of EU directives in the Czech national legislation.

The Energy Performance of Buildings Directive (EPBD) has been fully implemented, including provisions on mandatory energy performance certificates for both new and existing buildings and penalties for non-compliance. The Green Investment Scheme (i.e. the Greenlight to Savings in the Czech Republic) came into force in April 2009 and was revised in August 2009. It provides subsidies and grants for energy-saving measures in the buildings sector and EUR 950 million was allocated to fund this scheme over 2009-2012. This scheme provides households with grants of up to half the cost of insulating their homes. It also gives grants to enable new construction to meet passive-energy house standards, as well as for the installation of heating equipment using renewable energy sources. Improvement measures must result in specific annual heat savings to qualify.

The Czech government has set aside funds to evaluate the impact of heating on energy consumption after the current programme ends in 2012. This evaluation will lead to proposing new programmes and other measures.

Regarding the appliances sector, energy performance requirements for numerous products covered under the Ecodesign Directive (2005/32/EC) have entered into force, and the October 2009 Ecodesign Directive recast (2009/125/EC), which includes energy-related products, such as building components, is being transposed.

The Czech Republic is also transposing the May 2010 Directive (2010/30/EU), which requires labelling and standard product information on the consumption of energy and other resources by energy-related products.

The Czech Republic is implementing EU regulations to lower rolling resistance, maintain appropriate tyre inflation pressure through mandatory fitting of TPMS and set the average emissions target for new passenger vehicles at $130 \mathrm{~g} \mathrm{CO} / \mathrm{km}$, by 2015 .

\section{Challenges and areas for improvement}

Great potential for energy efficiency improvement still remains in the Czech Republic. There are many opportunities for energy efficiency policy developments beyond those specified by EU directives and regulations. For example, minimum energy efficiency standards for windows should be enforced. In the transport sector, the Czech Republic encourage the EU to consider implementing mandatory fuel-efficiency standards for heavy-duty vehicles. 
To improve energy efficiency in the industrial sector, the Czech Republic should adopt MEPs for electric motors in line with international best practices. Implementing formalised energy management policies at the company level would also prove critical to the improvement of energy efficiency in the industrial sector.

To encourage utilities to deliver energy savings, the Czech Republic could require energy efficiency measures and energy supply options to compete on a level playing field with energy sales. It could also place energy efficiency obligations on utilities and establish regulations, which decouple energy sales' revenue and profits from energy savings.

Some cross-sectoral policies should also be strengthened, notably regarding compliance monitoring, enforcement and evaluation of energy efficiency policies. Increased involvement of the private sector in financing energy efficiency projects should also be promoted.

\section{The Czech Republic's progress with implementing IEA energy efficiency recommendations}

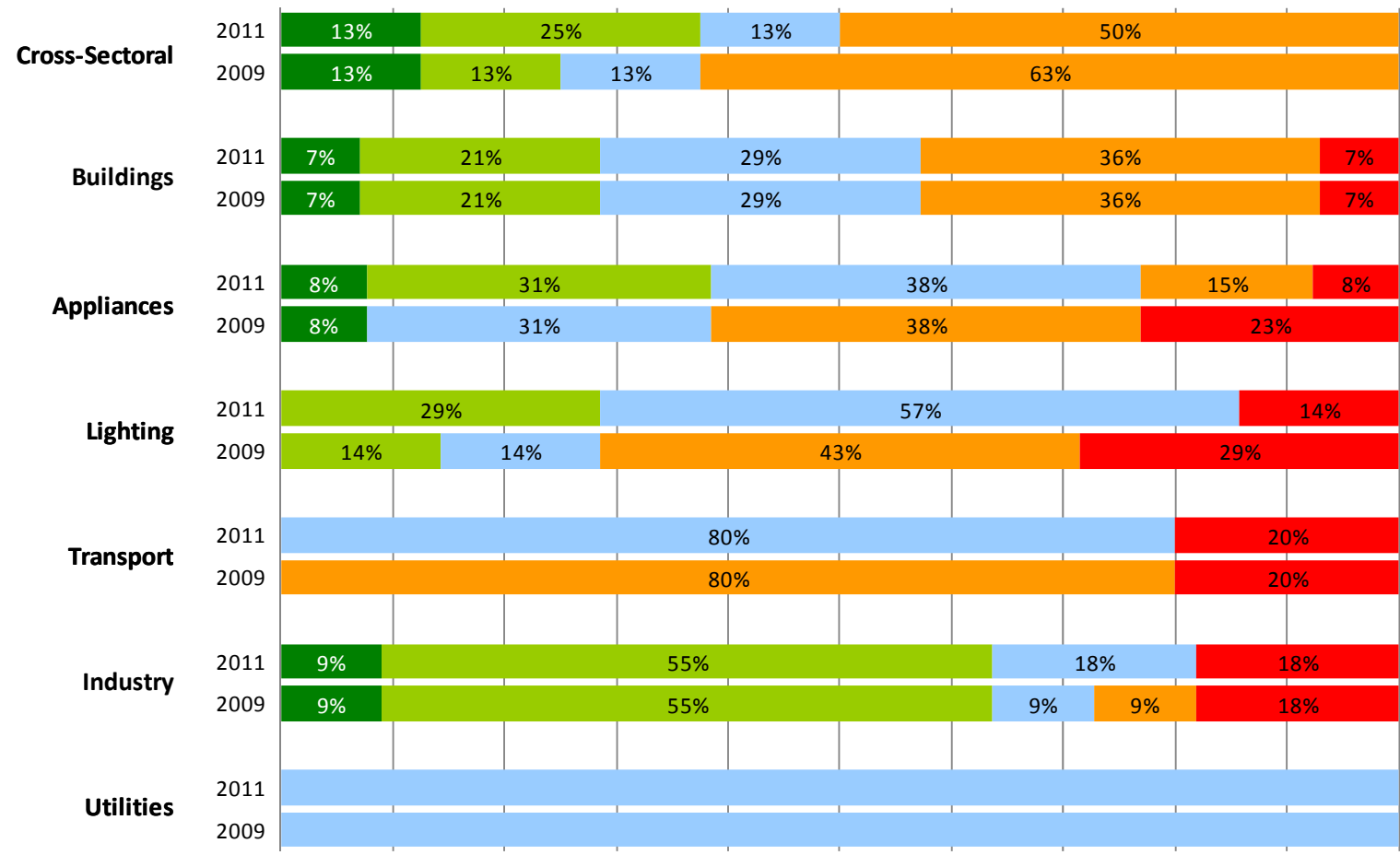

Full implementation Plan to implement
- Substantial implementation $\quad$ Implementation underway

Not implemented 


\section{Energy Efficiency Progress Report - Denmark}

\section{Context}

Denmark's energy intensity, adjusted for PPP, declined on average by $1.3 \%$ per year between 1990 and 2009. The decrease in energy intensity was largely due to structural changes in the economy. The National Energy Agreement 2008-2011 sets two targets for gross energy consumption: a short term reduction target of $2 \%$ by 2011 ; and a long term reduction target of $4 \%$ by 2020 , both relative to 2006 .

A national energy savings council was established in 2010. The goal of this council is to ensure coordination of energy efficiency measures implemented by state agencies, institutions and energy utilities, and to provide advisory services. In early 2011 the Danish government published a new energy strategy for achieving independence from fossil fuels by 2050 and significantly reducing greenhouse gas emissions. Energy efficiency in all sectors is an essential part of the strategy.

\section{Energy efficiency policy developments since 2009}

In March 2010, the scope of the Danish Electricity Saving Trust, which is financed by an energy savings charge, was expanded to cover savings for all forms of energy in all sectors, other than transport. This centre promotes energy savings through campaigns, knowledge sharing, market introductions, the development and presentation of standard energy saving products and solutions, and project financing.

Denmark has made good progress in strengthening energy efficiency policies since the 2009 Evaluation. In the buildings sector, Denmark is a world leader in energy efficiency requirements and has a system for successive strengthening of energy efficiency requirements for new buildings; After 2015, all new buildings will require less energy use than a passive house. The government's long-term vision adopted in April 2009 is for all buildings to be 'plus energy' houses, meaning that they produce more energy than they use.

In 2009, Denmark established a knowledge centre to provide advice for building professionals on materials and methods for achieving energy savings.

Denmark has established energy requirements for the refurbishment of existing buildings. This includes energy efficiency requirements for major renovations and for the replacement of components such as windows and roof insulation. Energy certification for the sale and rental of all types of buildings has been mandatory for more than a decade. After a revision, a new certification scheme was launched in early 2011. Public buildings have mandatory energy efficiency improvement requirements, based on the regular certification of these buildings every five years. Denmark has made considerable progress in the area of glazing and in 2010 established a new voluntary labelling scheme for windows, which manufacturers have joined. A public information campaign was also initiated.

Denmark is implementing EU directives on appliances and equipment. Voluntary agreements with industry are to be adopted in the areas of Set-Top Boxes and Digital Television Adaptors. The Energy Savings Trust runs various information and certification schemes aimed at consumers. These initiatives support the mandatory EU labelling of household appliances, resulting in a high share of appliances that meet the most efficient categories. Denmark has made considerable progress in the area of lighting. As part its assistance within the field of sustainable energy, Denmark supports international efforts to stimulate the adoption of higherefficiency alternatives to fuel-based lighting in off-grid communities. Denmark also promotes energy management in industry through voluntary agreements and provides incentives through 
tax rebates. Similar to other countries in the EU, Denmark sets annual savings' obligations for energy distribution companies. From January 2010 , these obligations were increased by $100 \%$. The target corresponds to more than $1.2 \%$ of total final energy consumption. From 2011, savings are weighted by a simple factor reflecting life-time, $\mathrm{CO}_{2}$ emission reductions and savings in areas outside the Emission Trading Scheme. Denmark's Energy Strategy 2050 proposes that the obligations of energy distribution companies will be raised again by $50 \%$ from 2013 and by $75 \%$ in 2017-2020.

Denmark has developed a comprehensive strategy to create a greener transport sector, which was confirmed in the broad political agreement on a green transport policy in January 2009. In line with this strategy, a knowledge centre for green transport has been established. The centre carries out campaigns, including those for the promotion of eco-driving and proper inflation levels of tyres; and administrates a scheme for demonstration projects in the area of energy efficient transport solutions. Denmark is also implementing EU regulations to improve proper tyre inflation and lower $\mathrm{CO}_{2}$ emissions from light-duty vehicles.

\section{Challenges and areas for improvement}

Despite its achievements, Denmark can further improve its energy efficiency policy portfolio. One area that Denmark could usefully consider expanding is its enforcement systems. In particular, emphasis should be placed on ensuring that systems for assessing compliance are transparent and that the methods and approaches used to assess compliance are standardised and clear. There is also room for improvement with respect to policies promoting the financing of energy efficiency. More effort should be made to stimulate the development of evaluation criteria and tools for quantifying the economic returns of energy efficiency projects. Existing subsidies and incentive systems should also be reviewed and necessary changes made to create conditions favourable to private investment in energy efficiency.

Further work is needed to promote energy efficiency in industry including schemes to monitor, evaluate, and report on industrial energy consumption and efficiency at company, sector, and national level. Emphasis should also be placed on the development of appropriate benchmarks both for large industry and SMEs. Regarding energy efficiency in SMEs, further measures are needed to ensure that incentives for increased uptake of energy efficient technologies are in place. Denmark should also work towards addressing barriers to the optimization of electric motor system efficiency.

In the area of transport, Denmark should encourage the EU to adopt fuel-efficiency standards for heavy-duty vehicles. In respect to appliances, the EU is currently investigating the need for measures aimed to decrease energy losses for networked devices. Denmark should take an active role in promoting the development of effective policies and instruments in this area. 


\section{Denmark's progress with implementing IEA energy efficiency} recommendations

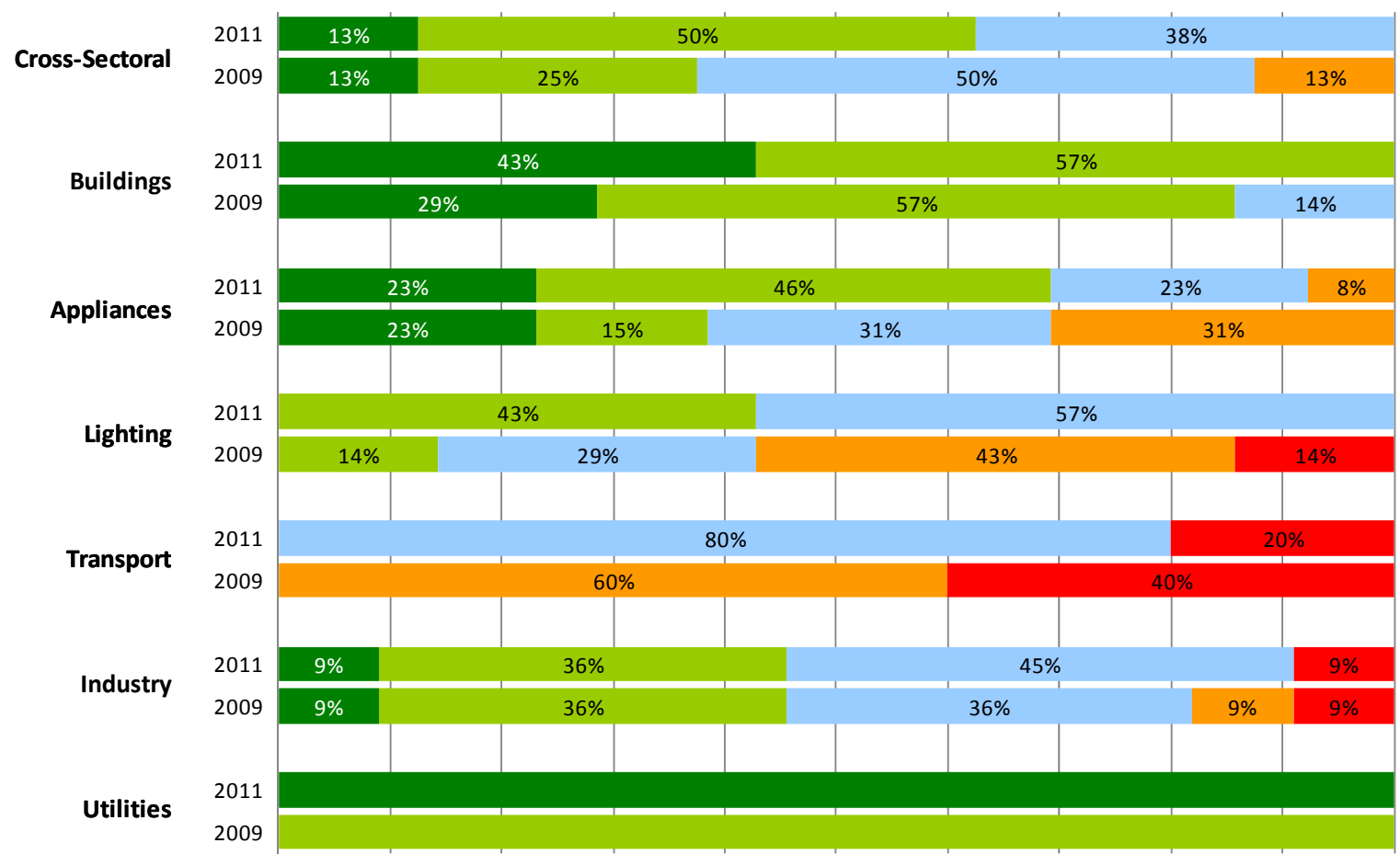

\section{Energy Efficiency Progress Report - Finland}

\section{Context}

Finland's energy intensity declined by $1.4 \%$ per year between 1990 and 2009, compared with the IEA average of $1.6 \%$. Finland's significant heavy industry sector and cold climate have resulted in Finland having a higher energy intensity, adjusted for PPP, than most other IEA member countries.

Finland's energy efficiency policy is mostly conducted by the Ministry of Employment and the Economy (MEE) along with Motiva Oy, a state-owned company acting as the Finnish energy efficiency agency. Policy guidelines are provided by the Action Plan for Energy Efficiency (APEE), and the National Energy and Climate Strategy (NECS). Improvements in industrial energy efficiency are mainly achieved through voluntary agreements between the MEE and industry. New agreements were signed in December 2007, for 2008 -2016.

\section{Energy efficiency policy developments since 2009}

There have been a few policy developments related to the 25 energy efficiency recommendations in Finland since the 2009 Evaluation. For example, in January 2010, a law on the services of energy companies entered into force. This law creates obligations for energy companies to provide information on customer energy use and energy efficiency measures. 
Finland is actively transposing EU directives and regulations. It is implementing EU regulations to lower rolling resistance, maintain appropriate tyre inflation pressure through mandatory fitting of TPMS and set the average emissions target for new passenger vehicles at $130 \mathrm{~g} \mathrm{CO}_{2} / \mathrm{km}$, by 2015.

Regarding the appliances sector, energy performance requirements for numerous products covered under the Ecodesign Directive (2005/32/EC) have entered into force, and the October 2009 Ecodesign Directive recast (2009/125/EC), which includes energy-related products, such as building components, is being transposed.

Finland is also transposing the May 2010 Directive (2010/30/EU) which requires labelling and standard product information on energy consumption.

In preparing energy efficiency plans for state administrations, the public sector is leading by example. The Ministry of Employment and the Economy finalised a plan in spring 2011 and published updated guidelines to promote energy efficiency in public procurement.

In its National Building Code, Finland has set MEPs for the thermal insulation and ventilation of new buildings since 1976. These requirements have been improved several times, and most recently in 2010. The 2012 revision of the building code will tighten requirements by $20 \%$.

Also to improve consumer energy efficiency advice, in December 2009 the Ministry of Employment and the Economy and Sitra, the Finnish Innovation Fund, agreed to finance 14 pilot projects organised by municipalities, regional energy agencies and nationwide organisations. These projects provide consumers with information on how to improve energy efficiency in the household, during building renovations and in the transport sector. The goal of the pilot projects is to provide a foundation for larger and more comprehensive efficiency advice programmes. The total budget for all projects is EUR 3.5 million over two years.

\section{Challenges and areas for improvement}

There remain many opportunities for energy efficiency policy developments. For example, to improve energy efficiency in industry, Finland could examine the barriers to the optimisation of energy efficiency in electric motor-driven systems and design and implement comprehensive policy portfolios aimed at overcoming such barriers. To support improved energy efficiency in small and medium enterprises, Finland could implement a package of policies including the provision of energy performance benchmarking and incentives to adopt least-life cycle cost capital acquisition and procurement procedures.

There is potential for improved energy efficiency in the buildings sector. In 2010, a committee formed under the Ministry of the Environment recommended a package of policies to encourage PEHs and ZEB. Finland should now take steps to implement those recommended policies.

In the transport sector, Finland could support the development of mandatory fuel-efficiency standards for heavy-duty vehicles, and scale up efforts to promote eco-driving training. 


\section{Finland's progress with implementing IEA energy efficiency recommendations}

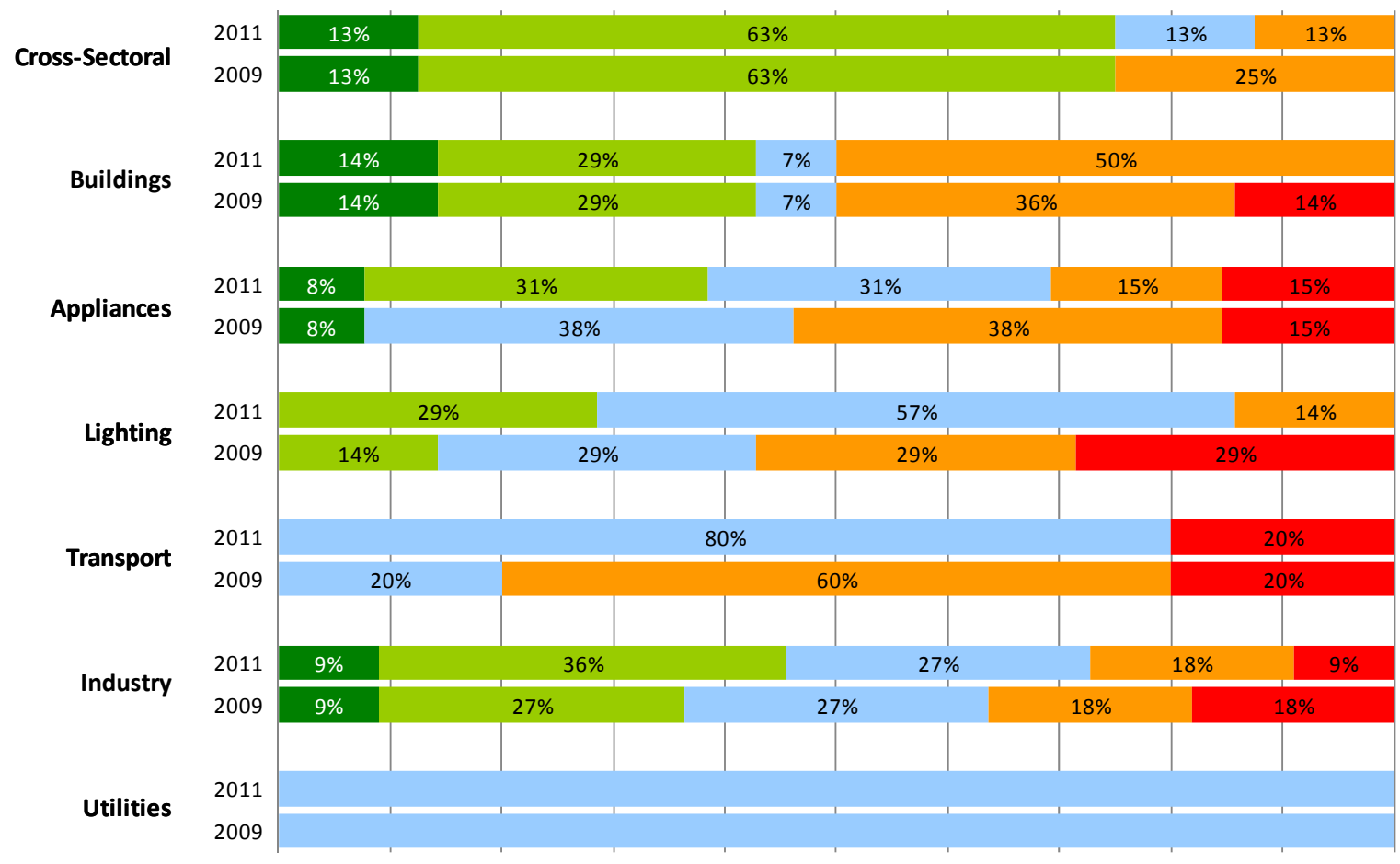

\section{Energy Efficiency Progress Report - France}

\section{Context}

France has pursued energy efficiency policies along with energy diversification since the oil shocks of the 1970s. These efforts are estimated to have saved 15 million tonnes of oil equivalent (Mtoe) to date. Energy efficiency currently forms a key part of France's climate change mitigation, energy security and environmental policies. The government aims to reduce energy intensity by $2 \%$ per year by 2015 , and $2.5 \%$ per year by 2030 . Energy intensity has been steadily decreasing; final energy intensity, adjusted for PPP, declined on average by $1.1 \%$ per year between 1990 and 2009. Less than half of annual intensity improvements were due to energy efficiency gains, the rest resulted from structural changes in the economy. The government is now aiming for specific energy efficiency improvements in the transport and buildings sectors.

\section{Energy efficiency policy developments since 2009}

Since the 2009 Evaluation, France progressed in implementing energy efficiency policies, particularly in the appliance, lighting and transport sectors. Most of these policy developments were in line with transposition of EU directives.

Regarding the appliances sector, energy performance requirements for numerous products covered under the Ecodesign Directive (2005/32/EC) have entered into force, and the 
October 2009 Ecodesign Directive recast (2009/125/EC), which includes energy-related products, such as building components, is being transposed.

France is transposing the May 2010 Directive (2010/30/EU), which requires labelling and standard product information on the consumption of energy and other resources by energyrelated products.

France is also implementing EU regulations to lower rolling resistance and maintain appropriate tyre inflation pressure by mandatory fitting of TPMS, along with the $130 \mathrm{~g} \mathrm{CO}_{2} / \mathrm{km}$ average emissions target for new passenger vehicles, which is to be reached by 2015 .

In the buildings sector, the national government's 2007 environmental and energy sustainability plan, Grenelle de l'environnement, includes elements for a very active policy for efficient buildings at a national level. This entails a programme to facilitate a breakthrough of technology to ensure that by 2020 , the majority of new buildings consume little energy or are net positive ${ }^{8}$, with an intermediate target that at least a third of all new construction be low, or positive, energy by 2013. The Grenelle strategy also provides for demonstration projects for positive energy buildings in the coming years and a gradual reduction of energy consumption in all new buildings. These ambitious objectives are now implemented in the Plan Bâtiment. Its core incentive programme, the Eco-Prêt à Taux Zéro (zero-interest loan), will help spur investments to improve energy efficiency in existing private homes.

Funding for the zero-interest loan for energy efficiency improvements doubled as part of France's economic stimulus plan. In addition, the 2009 Finance Law provides a zero-interest loan for the purchase of a new or existing home. This loan is significantly increased if the home exceeds current building code requirements (low and positive energy buildings). In addition, tax credits for interest paid on home acquisition or construction loans have been modified to ensure all construction meets latest thermal efficiency standards, and are increasingly preferential when current standards are exceeded.

\section{Challenges and areas for improvement}

Despite achievements in energy efficiency in France, there remain many areas for improvement. The collection of data on buildings energy efficiency could be improved and studies of barriers in this sector are urgently needed. Such information could be used to develop a comprehensive policy package of measures to improve the energy efficiency of new and existing building stock, based on the declarations and targets set in the Grenelle. France could also implement policies to promote PEH and ZEB and MEPs for windows.

In the transport sector, France should encourage the EU to put in place MEPs for heavy-duty vehicles.

There is much room for energy efficiency policy developments in the industrial sector. In July 2009 France, as a member of the EU, adopted MEPs for certain kinds of motors. France should now examine barriers to the optimisation of energy efficiency in electric motor-driven systems and implement a comprehensive policy portfolio aimed at overcoming such barriers.

France should also develop and adopt a formal energy management policy, which could include requiring appointment of full-time energy managers at an enterprise and plant-specific level. To promote energy efficiency in SMEs, France should create policies to ensure that energy audits are widely and easily accessible and provide energy performance benchmarking information to allow international, and within economy, comparisons.

\footnotetext{
${ }^{8}$ Meaning that they produce more energy than they consume.
} 
Finally, enforcement of domestic laws and policies that transpose the EU energy efficiency directives is the responsibility of member states. Enforcement is important for maximising energy savings and for ensuring the credibility of the schemes. France needs to ensure that it has comprehensive legal and physical capacity so as to adequately enforce these policy measures.

\section{France's progress with implementing IEA energy efficiency recommendations}

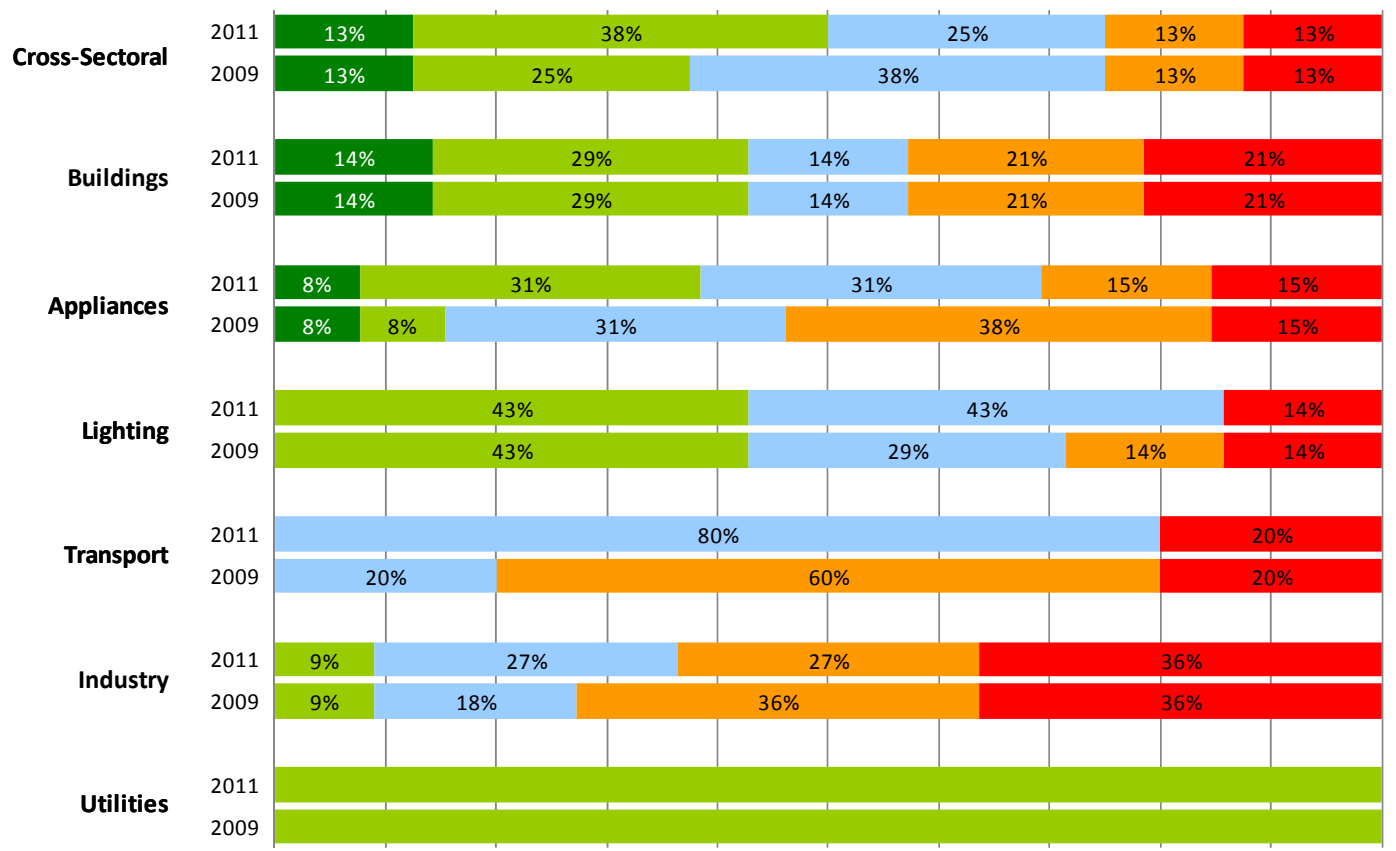

- Full implementation

Plan to implement
- Substantial implementation $\square$ Implementation underway

- Not implemented

\section{Energy Efficiency Progress Report - Germany}

\section{Context}

Since the oil shocks of the 1970s, Germany has promoted energy efficiency improvements across its economy, and particularly in the industrial and residential sectors. German industry decoupled energy consumption from growth relatively early on in the 1970s and energy consumption has remained steady since 1990. Overall energy intensity has been steadily decreasing since 1990, due to a combination of policy packages aimed at improving energy efficiency, as well as structural changes in the economy. Germany's energy intensity, adjusted for PPP, declined on average by $1.8 \%$ per year between 1990 and 2009. Most of the decline was due to energy efficiency improvements.

Following its commitment under the EU Energy Services Directive, Germany's 2007 NEEAP aims to achieve 9\% energy efficiency improvement between 2007 and 2016, incorporating a target of 933 PJ, with an interim target of 510 PJ for 2010. Germany's measures target energy efficiency improvements in all sectors, with most projected energy savings coming from the residential sector, seen as holding untapped and cost-effective improvement potential. 


\section{Energy efficiency policy developments since 2009}

Germany has made significant strides in its energy efficiency policy in recent years. In November 2010, the Act on Energy Services and Energy Efficiency Measures (Gesetz über Energiedienstleistungen und andere Energieeffizienzmaßnahmen - EDL-G) entered into force and this transposes EU Directive (2006/32/EC) on energy end-use efficiency and energy services (ESD) into German law. The aim is to increase energy end-use efficiency through energy services and other energy efficiency measures in a cost-effective way.

The Federal Office for Energy Efficiency (Bundesstelle für Energieeffizienz - BfEE), which was established in January 2009 at the Federal Office of Economics and Export Control (Bundesamt für Wirtschaft und Ausfuhrkontrolle - BAFA), has responsibility for implementation of the ESD Directive. It will monitor the market for energy services and other energy efficiency improvement measures and will submit proposals on how to promote this market. The Office will also keep a record on providers of such services, thus creating more transparency for end-customers.

With regard to the buildings sector, Germany is a global leader. Energy requirements in German building codes are set at the national level. With the last amendment of the Energy Saving Ordinance in 2009, MEPS were raised by $30 \%$ on average. Germany has also set MEPs for building envelopes. Currently, Germany is evaluating whether it is economically feasible to further strengthen those requirements in the amendment planned for 2012/2013. If these standards are further strengthened, it is expected that Germany's building code energy requirements will be close to the optimum of a 30-year least life-cycle cost.

Germany is one of a handful of IEA member countries with policies to support construction of passive and other highly-efficient new buildings. Passive houses are hence taking a growing share of the market in Germany and related passive-house technologies are becoming more commonly available in most parts of the country.

Additionally, Germany has a range of policies in place for the energy-efficient refurbishment of existing buildings, including a high target to increase the refurbishment process in the old building stock. The Kreditanstalt für Wiederaufbau (KfW), a non-profit public banking group, manages a loans programme for the refurbishment of old buildings and ecological construction. The goal of this programme is to help customers meet the increased upfront costs of energy efficiency refurbishment.

According to Article $\S 4$ of the Act on Energy Services and Energy Efficiency Measures (EDL-G), energy supply companies have to inform end-users about available energy services and the effectiveness of energy savings measures on a yearly basis. If there is not a sufficient number of energy audit providers, it is the responsibility of the energy supply companies to establish energy audit services to identify and quantify options to save energy. EDL-G also stipulates that the public sector shall set a good example in using energy services and carrying out energy improvement measures.

As with all EU member states, the EU emissions trading scheme puts a price on carbon in the industrial and power sectors in Germany and continues to help drive energy efficiency in these areas.

\section{Challenges and areas for improvement}

Despite recent energy efficiency policy developments, Germany can further improve its energy efficiency policy portfolio.

Germany should introduce a formal energy management policy for industry, which should include requirements and incentives: for companies to report progress to their management 
board; to appoint energy managers; to monitor and report energy consumption; and to compare against benchmarks for their sector.

Germany should also continue to strengthen its policies to assist SMEs implement energy efficiency. The recent increase in resources allocated for energy efficiency in SMEs is important. The government should further strengthen this by ensuring that the project Partnership for Climate Protection, Energy Efficiency and Innovation ${ }^{9}$ delivers, as planned, access to energy audits, provision of energy efficiency benchmarking information as well as the adoption of least life-cycle cost capital acquisition.

To encourage utilities to deliver energy savings, Germany could require energy efficiency measures and energy supply options to compete on a level playing field with energy sales. It could also place energy efficiency obligations on utilities and establish regulations, which decouple energy sales revenue and profits from energy savings.

Although progress has been made in implementing energy efficiency policy in the transport sector as a result of the adoption of EU regulation, Germany should take further action by developing mandatory fuel-efficiency standards for heavy-duty vehicles, and scaling up efforts to promote eco-driving training.

\section{Germany's progress with implementing IEA energy efficiency recommendations}

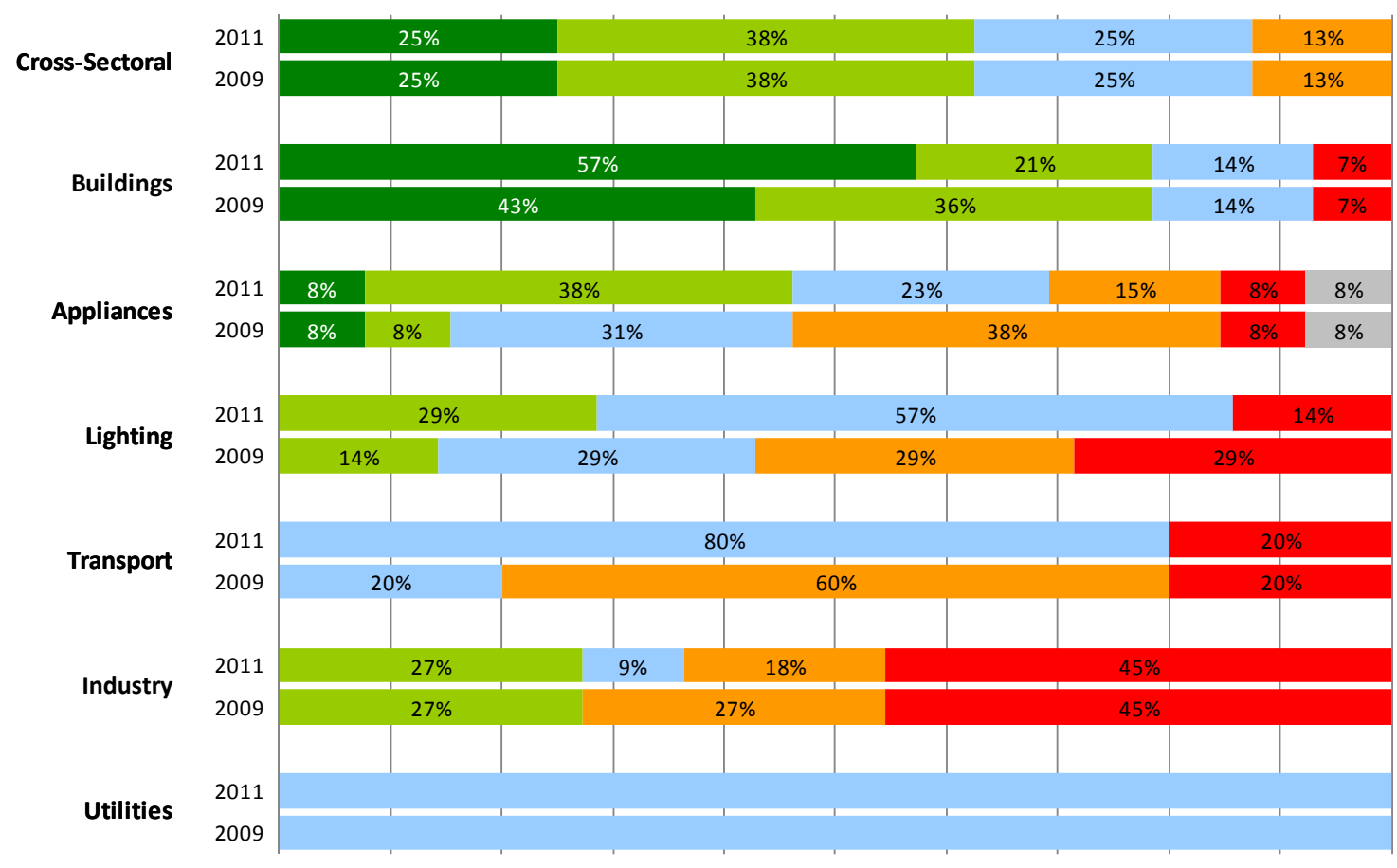

Full implementation

- Plan to implement
Substantial implementation Implementation underway

- Not implemented

\footnotetext{
${ }^{9}$ A collaborative project between the Federal Ministry of Economics and Technology (BMWi) and the Federal Ministry for the Environment, Nature Conservation and Nuclear Safety (BMU) together with the Association of German Chambers of Industry and Commerce (DIHK).
} 


\section{Energy Efficiency Progress Report - Greece}

\section{Context}

Greece's total final consumption of energy (TFC) was 21.2 Mtoe in 2008, up 46\% from 1990. Page | 66 Transport took the largest share of TFC, accounting for around $36 \%$ of the total. The residential sector accounted for $25 \%$ and industry for $24 \%$. The service sector consumed $10 \%$ of TFC and the primary sector $5 \%$ in 2008 . In comparison, the IEA member country averages in 2008 were $32 \%$ for transport, $19 \%$ for residential, $33 \%$ for industry, and $16 \%$ for other sectors.

Since 1990, TFC in Greece has increased in all sectors, driven by strong economic growth to 2008. Reflecting the economic downturn, however, TFC fell from 2008 to 2009. The sectoral breakdown of TFC has changed in a manner typical to developed economies. Industry has seen its share decline from one-third to less than a quarter, while the residential and service sectors have increased their share. The share of transport in TFC has remained stable from 1990 to 2008.

The Ministry of Environment, Energy and Climate Change (MEECC) has the overall responsibility for energy efficiency policy in Greece. Within MEECC, the Renewable Energy Sources and Energy Saving Directorate and the Special Service of Energy Inspection are actively involved in energy efficiency policy development and implementation. The Centre for Renewable Energy Sources and Saving (CRES), under the supervision of MEECC, promotes renewable energy and energy efficiency at a national level, facilitates national energy planning, assists in the formulation of energy policies and is involved in the development of R\&D activities. The Ministry of Infrastructure, Transportation and Networks and the Ministry of Economy also have energy efficiency mandates.

\section{Energy efficiency policy developments since 2009}

Greece's energy efficiency policy is laid out in the National Energy Efficiency Action Plan (June 2008). In general, energy efficiency policy implementation closely follows key EU legislation.

Since the 2009 Evaluation, some headway has been made to improve energy efficiency in the appliance sector. In May 2010, Greece adopted the Presidential Decree 32/2010 to implement measures for energy-using products to be placed on the market. This Decree, along with the amendment of the Presidential Decrees 335/1993 and 178/1998 and the Joint Ministerial Decision D6/B/17682/2001, transposes into national law requirements set under the Ecodesign Directive (2005/32/EC).

Greece has also implemented the "Changing air-conditioners" programme to improve energy efficiency in this sector. Under this programme that ran from June to August 2009, a 35\% purchase price subsidy (up to EUR 500) was provided for replacement of old energy-intensive domestic air-conditioners. Around 140000 air-conditioners were replaced with new ones with inverters and class $A$ to At+ ratings. All replaced air-conditioners were recycled. The European Regional Development Fund (ERDF) provided partial funding for this EUR 45 million project.

In the transport sector, Greece is implementing EU regulations to lower rolling resistance and maintain appropriate tyre inflation pressure through mandatory fitting of TPMS. Greece is also implementing EU regulations that require average emissions from new passenger vehicles sold in Greece, and other EU member states, to reach the $130 \mathrm{~g} \mathrm{CO}_{2} / \mathrm{km}$ target by 2015 .

In the buildings sector, Greece's Law 3661/2008 transposes the EU Energy Performance of Buildings Directive (EPBD). The government has passed the Energy Performance of Buildings decision and has adopted a Presidential Decree concerning energy auditors so as to enable implementation of this law. 


\section{Challenges and areas for Improvement}

All sectors in the Greek economy still have energy savings potential. To tap into these savings, Greece should consider implementing some of the following policies.

To improve energy efficiency in industry, Greece could provide assistance in the development of energy management (EM) capabilities through the development and maintenance of EM tools, training, certification and quality assurance. Greece should also consider encouraging major industrial energy users to adopt comprehensive EM procedures and practices. Examining barriers to the optimisation of energy efficiency in electric motor-driven systems and designing and implementing comprehensive policy portfolios to overcome such barriers would be worthwhile.

To encourage utilities to deliver energy savings, Greece could require energy efficiency measures and energy supply options to compete on a level playing field with energy sales. It could also place energy efficiency obligations on utilities and establish regulations, which decouple revenue and profits from energy sales from energy savings.

Greece could speed up efforts to implement policies to adopt and publicise common energyefficiency savings and verification measures to encourage a boost in private investment in energy efficiency. Such efforts need to be supported by optimal procedures for compliance, monitoring and evaluation of energy efficiency policies and by reliable legislative and institutional infrastructure for enforcement.

There remains considerable potential in Greece's buildings sector. Greece could tap into more of these savings by encouraging passive-energy houses and zero-energy buildings through benchmarking and objective setting. It could also require window labelling schemes and promote energy-efficient windows and glazing demonstration projects.

\section{Greece's progress with implementing IEA energy efficiency recommendations}

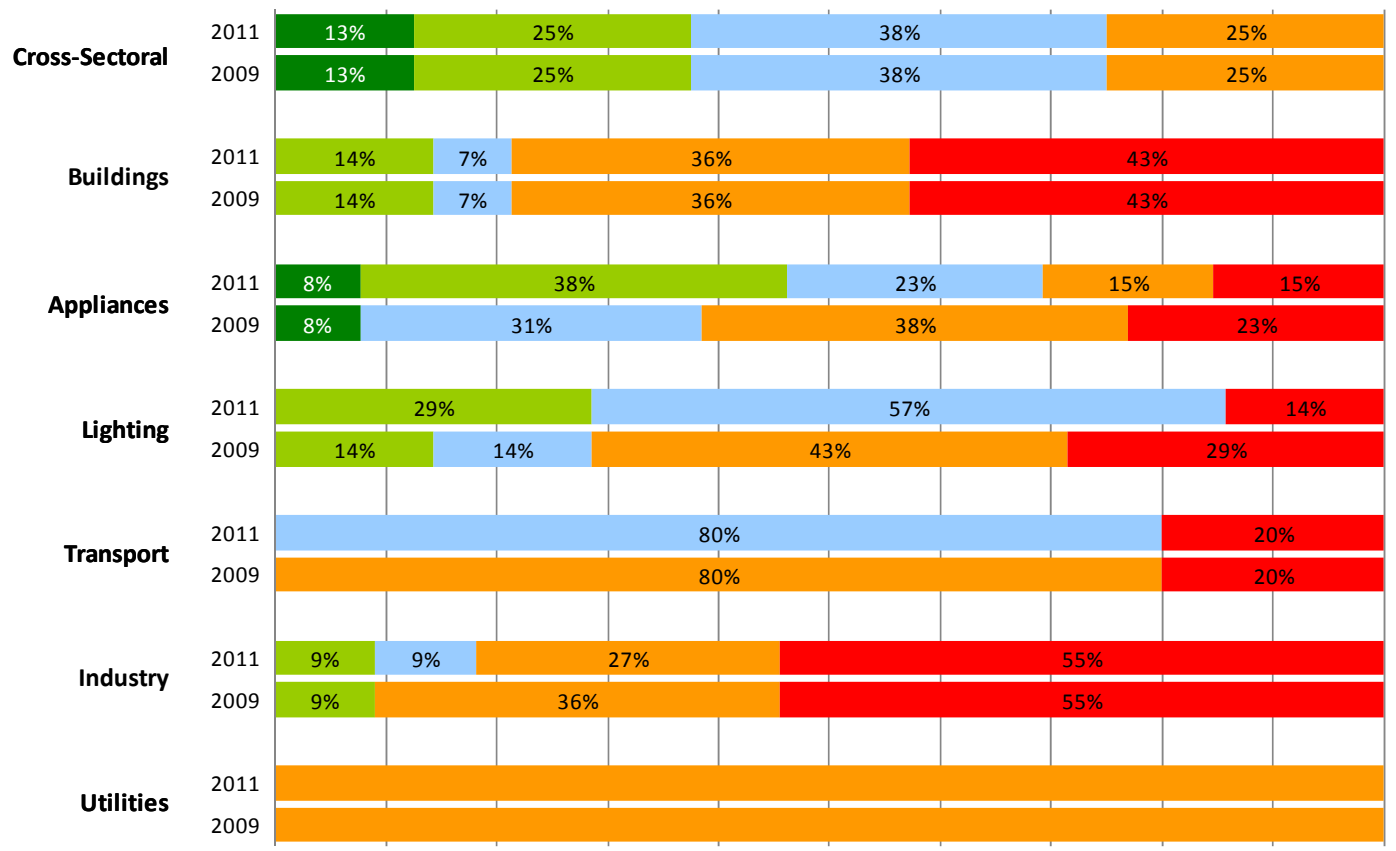

Full implementation Plan to implement
Substantial implementation $\quad$ Implementation underway

Not implemented 


\section{Energy Efficiency Progress Report - Hungary}

\section{Context}

Hungary's energy intensity improved by $1.4 \%$ in 2009 . This prolongs a long-term trend, with an average reduction in energy intensity adjusted for PPP of 2.3\% between 1990 and 2009. This reduction helped Hungary meet Kyoto $\mathrm{CO}_{2}$ mitigation targets and sell resulting carbon allowances to neighbouring countries. Hungary channelled the proceeds from the sale of these allowances into programmes that focused largely on improving the energy efficiency of Hungary's housing stock and promoting renewable energy.

In 2010, the government stated that its main objective is to improve Hungary's economic competiveness through a package of measures including improved energy efficiency.

\section{Energy efficiency policy developments since 2009}

In addition to improving its existing National Energy Efficiency Strategy, Hungary launched the "Széchenyi Plan", a large-scale economic incentive package designed to encourage an economic revival through various measures, including developing a green economy and increased exploitation of renewable energy sources. With a EUR 3.5 billion multi-year budget, the Plan boosts investment in energy efficiency and has made substantial progress in laying the foundations for cross-sectoral implementation of energy efficiency improvements.

Considerable work has also been undertaken to promote energy efficiency in the lighting sector. Hungary has advanced implementation of best practise across all of the IEA recommendations in this sector, keeping step with the EPBD recast (2010/31/EU). Substantial progress has been made on the phase-out of inefficient lighting under Commission Regulation 244/2009 and, in particular, in setting targets for internationally coordinated action on incandescent bulbs. Thanks to new funding allocated for public lighting programmes, improvement of energy efficiency in non-residential and street lighting is also now underway.

Hungary's implementation of European directives has kept pace with the schedule anticipated by the National Energy Efficiency Plan. Progress has also been made in rolling out energy performance labelling for household appliances, including setting minimum energy performance requirements (MEPs) for standby power modes, set-top boxes and digital television adaptors in line with Directives 2010/30/EU and 2009/125/EC.

The transport sector is another area of focus for efficiency improvements. Hungary is implementing European transport standards, which aim to reduce $\mathrm{CO}_{2}$ emissions from new passenger cars. In addition, Hungary is pursuing the EU-led development of tyre-labelling requirements, which seek to harmonise information on the energy performance of tyres.

Hungary has also implemented a home-building programme scheduled to fund energy efficiency refurbishments on 100000 flat units annually, delivering energy savings of between 40 and $80 \%$. This programme, which includes a target to gradually replace inefficient building stock with around 45000 new flat units, considers home construction as key to reinvigorating Hungary's economy and anticipates the development of new energy efficiency construction criteria.

\section{Challenges and areas for improvement}

As part of the ambitious Széchenyi Plan to increase economic competitiveness, Hungary should seek to implement policies that improve both the energy efficiency of the industrial sector and the delivery of energy efficiency by energy utilities. Since the 2009 Evaluation, no significant energy efficiency policies have been implemented in these sectors. 
Implementation of energy management schemes and least-life-cycle cost calculations in small and medium enterprises (SMEs) is lacking in Hungary and this could be addressed as part of the EU-funded support SMEs are to receive under the economic recovery scheme.

Hungary has yet to implement policies to enable energy efficiency measures and energy supply options to compete with energy sales, including regulations that decouple energy sales revenue and profits from energy savings.

Hungary could speed up the implementation of policies to adopt and publicise common energyefficiency savings and verification measures to encourage a boost in private sector investment in energy efficiency. For enforcement, optimal procedures for compliance, monitoring and evaluation of energy efficiency policies by reliable legislative and institutional infrastructure are needed.

Despite recent progress, considerable potential still remains in Hungary's buildings sector, particularly in encouraging passive-energy houses and zero-energy buildings through benchmarking and objective setting.

\section{Hungary's progress with implementing IEA energy efficiency recommendations}

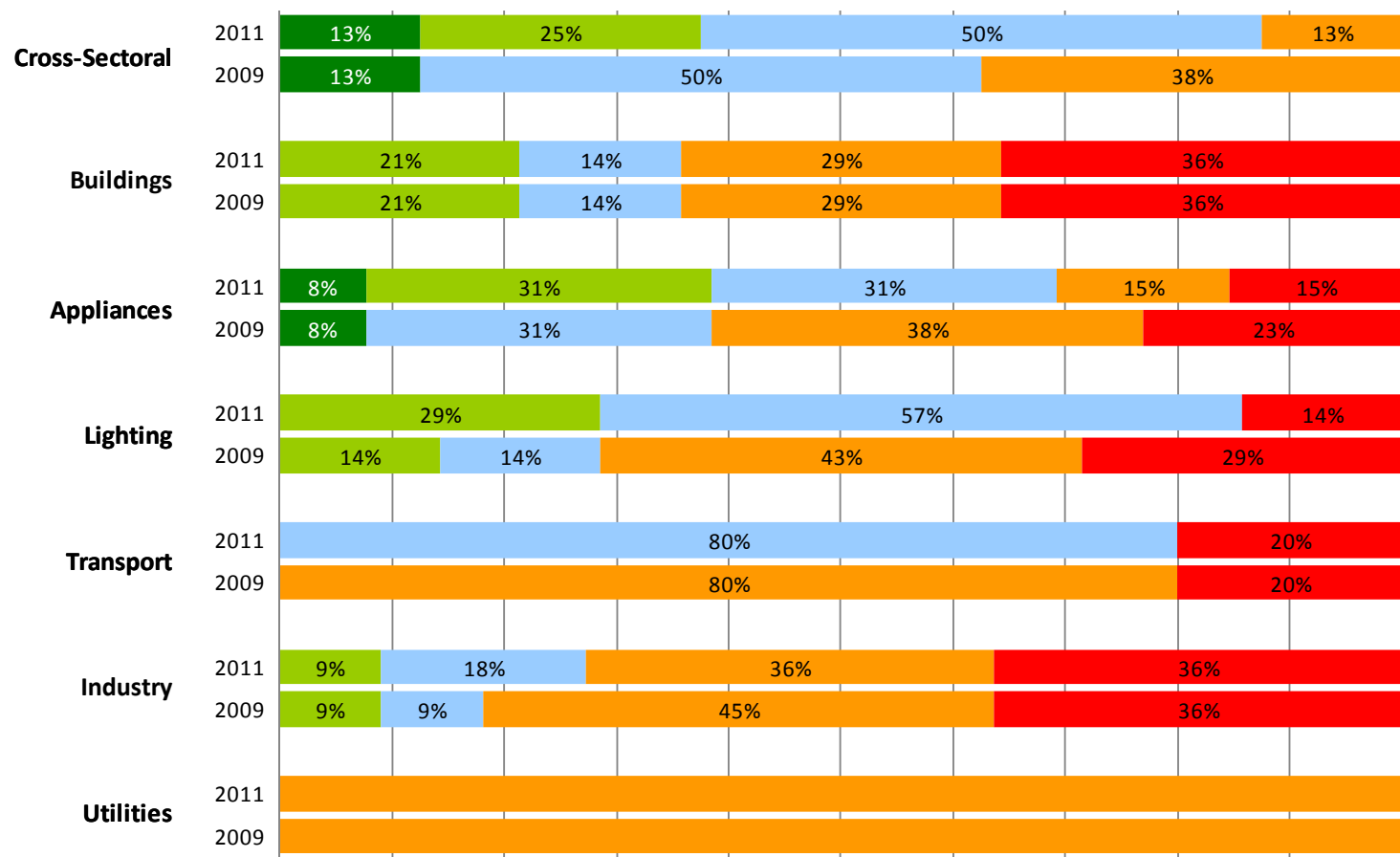

- Full implementation Plan to implement
Substantial implementation Implementation underway

Not implemented 


\section{Energy Efficiency Progress Report - Ireland}

\section{Context}

Page | 70 Ireland has a very pro-active energy efficiency policy and a national target of $20 \%$ energy savings in 2020 adopted as part of the government's Energy Policy Framework 2007 to 2020, Delivering a Sustainable Energy Future for Ireland. Ireland's energy intensity, adjusted for PPP, is among the lowest in the IEA and has been declining steadily since 1990 at an average rate of 3\% per year. This is an impressive achievement compared to the average decline rate in IEA member countries of just 1.4\% per year. Ireland's National Energy Efficiency Action Plan (NEEAP) was published in May 2009. It updates and expands the 2007 Action Plan submitted to the European Commission (EC) in the context of the EU Directive on energy end-use efficiency and energy services (ESD). The second Irish NEEAP was scheduled for submission to the EC in June 2011 and the Department of Communications, Energy, and Natural Resources is finalising a revised NEEAP, drawing together a steering group of departments and agencies that are involved in its implementation. There has also been consultation with stakeholders and industry on priorities for inclusion in the second NEEAP.

The Sustainable Energy Authority of Ireland (SEAI) was set up in 2002 as Ireland's national energy agency with a mission to promote and assist with the development of sustainable energy. The SEAI manages programmes aimed at supporting Government decision making through advocacy, analysis and evidence; driving demand reduction and providing advice to all users of energy; driving the decarbonisation of energy supply; raising standards in sustainable energy products and services; building markets based on quality, confidence and proven performance; fostering innovation and entrepreneurship; and improving the coherence of Irish energy research and development.

\section{Energy efficiency policy developments since 2009}

Since 2009, Ireland has made several positive developments in its energy efficiency policy portfolio and has made progress, for example, in utility-delivered energy efficiency policy. The government has outlined a programme, Better Energy: The National Upgrade Programme, for placing obligations on energy suppliers of $>75 \mathrm{GWh}$ to Irish energy end-users. Annual targets, eligible measures and savings credits have been finalised and it is intended that companies will have signed voluntary agreements to meet these targets by March 2012. Some energy providers have already begun operating in the energy-service market in preparation for the obligation programme. As part of this programme, public sector bodies are supported to achieve an ambitious national energy savings target of $33 \%$. This will ensure the government is leading by example in the demonstration of the benefits of investing in improved energy efficiency.

In addition, the carbon tax introduced in January 2010 provides, with the EU emissions trading scheme (ETS), an incentive for energy efficiency in all sectors. The government recently announced a staged increase of the carbon tax which will result in a doubling to EUR 30 per tonne by 2014.

Ireland has implemented sound policies in the buildings sector. Its Low Carbon Homes programme, launched in 2008, supported very low-energy/-carbon buildings as a precursor to revisions in building regulations. Irish mandatory minimum energy efficiency requirements for buildings are now among the most stringent in Europe. There are plans to further strengthen the standards for both housing and non-residential buildings and to implement a low- energy/carbon standard in 2013 , but there has been no policy change since 2009 . Measures are in place 
to monitor and enforce compliance. Building owners are required to provide prospective buyers or tenants with a certificate indicating the building's energy efficiency and an accompanying advisory report indicating how energy efficiency can be improved. In addition, a national Home Energy Saving Scheme was launched in February 2009, which incentivised the implementation of energy savings measures in over 100000 homes and which has recently been integrated into Better Energy: The National Upgrade Programme.

In April 2011, Ireland introduced a grant scheme for all vehicles with $\mathrm{CO}_{2}$ emissions of less than $75 \mathrm{~g} \mathrm{CO}_{2} / \mathrm{km}$. Qualifying vehicles sold after 1 January 2011 are eligible for a purchase subsidy of up to EUR 5 000. A total of EUR 5 million has been allocated for this purpose. The aim is to have $10 \%$ of vehicles (approximately 220000 ) powered or partially powered by electricity from the grid by 2020. Eco-driving has been included in the new syllabus for learner driver training.

To promote improved energy efficiency in windows and other glazed areas, an independent energy rating assessment scheme has been developed by the National Standards Authority of Ireland. The scheme is voluntary in nature, although early indications are that it has proved popular among manufacturers.

In the area of lighting, Ireland was one of the first countries to announce a ban on incandescent light bulbs in 2007 and has, like other EU countries, removed incandescent light bulbs from the market.

Ireland is among the leading countries in implementing industrial energy efficiency policy. A formal energy management policy is in place for large industry and SMEs. In particular, the SEAI Energy Agreements Programme helps companies analyse their energy use and opportunities for savings, and advises on appropriate monitoring and management. The SEAl also implements other effective measures to stimulate industrial energy efficiency, such as providing high quality information on energy efficiency best practices. Minimum energy performance requirements for certain kinds of electric motors have been adopted under European Commission Regulation No 640/2009 and will be in force in 2011, and apply in Ireland also. Tax allowances are available for companies that purchase approved energy-efficient products, further promoting the market for best-in-class energy using equipment across ten different equipment categories and 49 associated technologies

Significant progress has been made in implementing policies related to energy efficient appliances and equipment. A major component of Irish policy on appliances and equipment entails transposition and implementation of the Ecodesign Directive. As a result there have been improvements in market surveillance of products and the standby $1 \mathrm{~W}$ limit has applied to products covered under this Directive since January 2010. Televisions and set-top boxes are required to meet MEPs and the most efficient products are promoted through the labelling and "Power of One" scheme. There have also been improvements in measurement test procedures.

\section{Challenges and areas for improvement}

Despite Ireland's recent energy efficiency policy achievements, many opportunities for improved energy efficiency remain across the economy.

The transport sector continues to be the weakest in terms of energy efficiency policy implementation, but Ireland has made good progress since the 2009 Evaluation. Ireland is implementing EU regulations to lower rolling resistance, maintain appropriate tyre inflation pressure through mandatory fitting of TPMS, and require average emissions from new passenger vehicles sold in Ireland, and other EU member states, to reach the $130 \mathrm{~g} \mathrm{CO}_{2} / \mathrm{km}$ target by 2015 .

The alignment of vehicle taxes with vehicle $\mathrm{CO}_{2}$ emissions since July 2008 has been very successful in changing vehicle purchasing choices. To further support energy efficiency in the 
transport sector, Ireland should support the development of mandatory fuel-efficiency standards for heavy-duty vehicles at EU level.

As for appliances, the Ecodesign Directive should improve the energy efficiency of all new products. Ireland should consider supporting international efforts to stimulate the adoption of higher efficiency alternatives to fuel-based lighting in off-grid communities in developing

Page 72 countries.

Across sectors, Ireland could speed up efforts to implement policies to adopt and publicise common energy-efficiency savings and verification measures in order to encourage a boost in private sector investment in energy efficiency. Such efforts need to be supported by optimal procedures for compliance, monitoring and evaluation of energy efficiency policies and by reliable legislative and institutional infrastructure for enforcement.

\section{Ireland's progress with implementing IEA energy efficiency recommendations}

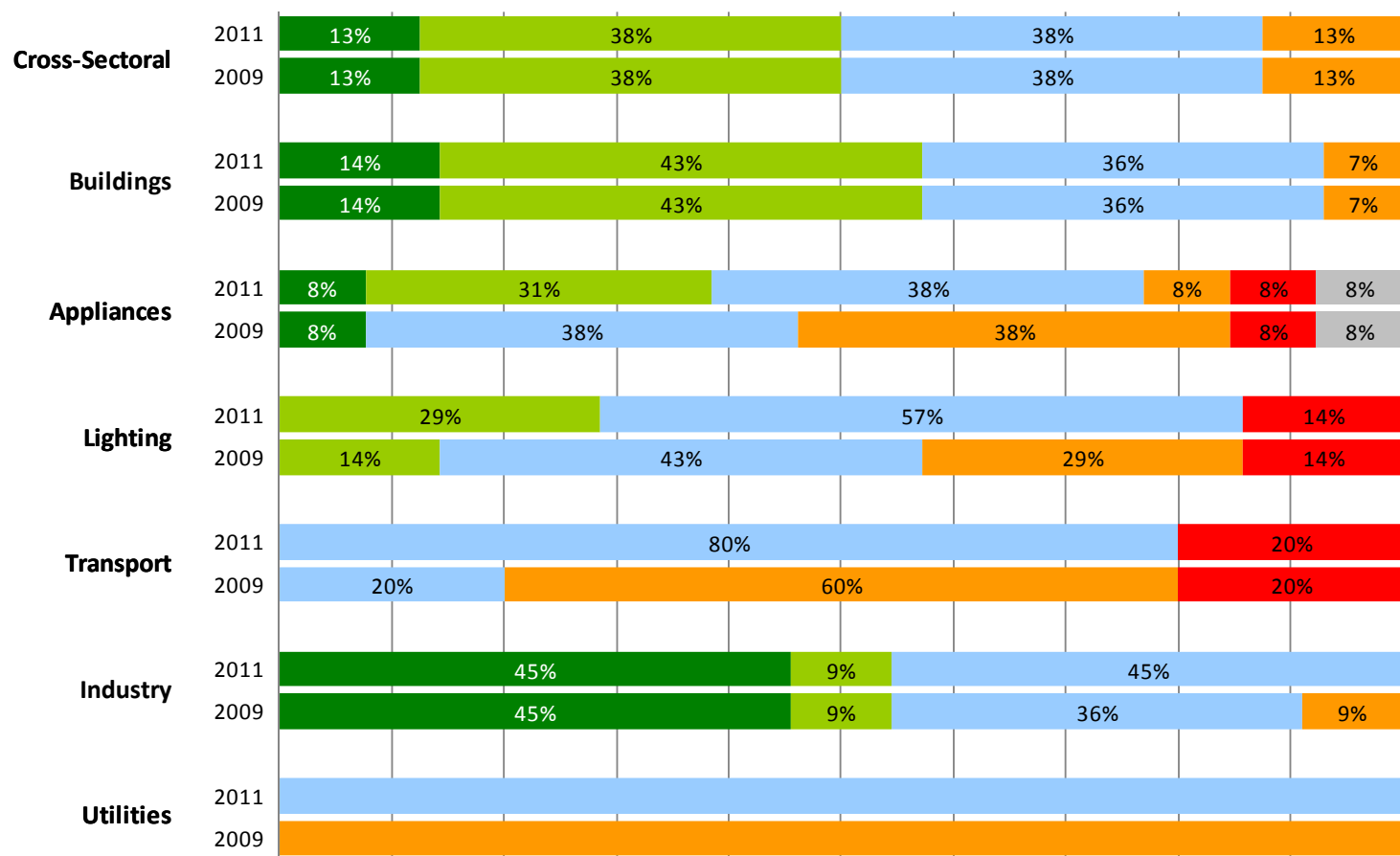

Full implementation Plan to implement
Substantial implementation $\square$ Implementation underway

- Not implemented 


\section{Energy Efficiency Progress Report - Italy}

\section{Context}

Compared to other IEA member countries and major economies, Italy's energy intensity has traditionally been low. However, while the energy intensity of many other IEA member countries has constantly improved over the past 30 years, Italy's energy intensity has remained relatively stable since the early 1980s. Italy is now roughly equal to the IEA European member country average. The Italian government expects energy intensity to improve significantly from now until 2030 , in line with other industrialised countries.

Italy has continued on the path of adopting stronger national action in energy efficiency, working towards the overall energy efficiency target of $9.6 \%$ by 2016 set in its National Energy Efficiency Action Plan (NEEAP). The 2010 NEEAP evaluation found that the intermediary energy-savings target $(3 \%$ by 2010$)$ has been surpassed $(4,3 \%)$ in part because of policies implemented in the buildings sector. These policies include the EPBD Directive, a White Certificate scheme and a tax deduction for renovations to improve energy performance in residential buildings.

\section{Energy efficiency policy developments since 2009}

Since 2009, Italy has improved energy efficiency policy implementation in almost all sectors. Much of this policy implementation has been guided by EU directives and regulations, particularly in the transport, appliance, lighting, and buildings sectors.

In the Italian transport sector, Italy is implementing EU regulations to lower rolling resistance and maintain appropriate tyre inflation pressure through mandatory fitting of TPMS. Italy is also implementing EU regulations, which require average emissions from new passenger vehicles sold in Italy, and other EU Member states, to reach the $130 \mathrm{~g} \mathrm{CO}_{2} / \mathrm{km}$ target by 2015 .

In November 2010, the Council of Ministers approved Directive 2009/125/EC, the new Ecodesign Directive, which applies to energy-consuming products

Directive 2010/30/EU requires labelling and standard product information on energy-consuming products and has also been transposed into Italian law.

In the buildings sector, Italy fully transposed the Energy Performance of Buildings Directive (EPBD) with decrees 192/05 and 311/06. An energy performance certificate (EPC) is now mandatory when a building or flat is sold. Two regions, Emilia Romagna and Lombardy, currently provide EPCs when a building or flat is rented. The rest of Italy will implement this in 2012.

Regarding energy utilities, Italy's White Certificate Scheme is a leading programme to encourage energy utilities to deliver effective low-cost energy savings. The White Certificates scheme, amended by inter-ministerial decree and with a duration extending to 2012, is an example of Italy's continuing leadership in the energy utilities sector. Other examples are the growing number of energy service companies (ESCOs) within Italy and standards such as UNI CEI 11352/2010 and UNI CEI EN 15900/2010. Italy has also moved forward with more stringent inspections, productions of new standard forms to ask for white certificates, creation of a complete database of all proposals treated so far and automation of the technical/administrative assessment procedure of the proposals.

The white certificates scheme is proving to be a particularly effective mechanism in encouraging energy savings and improving the sustainability and competitiveness of the Italian energy system.

Also of note, Italy has shown leadership in the field of energy efficiency through its participation 
in the International Partnership for Energy Efficiency Co-operation (IPEEC). Through this forum, member countries exchange best practices in energy efficiency and facilitate partnerships between energy efficiency actors and supporting energy-efficient initiatives.

\section{Challenges and areas for improvement}

Page | 74 Italy has made progress in its overall energy efficiency policy portfolio, yet many challenges remain.

Implementing measures under EU directives and regulations requires a considerable expansion of energy efficiency policy. Italy needs to ensure that it has comprehensive legal and physical capacity to enforce these policy measures and maximise their effectiveness.

While maintaining the implementation of policies relating to directives and regulations, Italy should at the same time be mindful to implement energy efficiency policies not covered by EU directives. For example, much is still to be achieved in the industrial sector, where, despite specific measures targeted in this domain as provided by the Budget Law of 2007, there is still a need to provide assistance in developing energy management capability and shaping policy packages to promote energy efficiency in small and medium-sized enterprises (SMEs). Although Italy's National Agency for new technologies, Energy and Sustainable Economic Development (ENEA), is progressing in this area by planning a package of policies and measures to promote energy efficiency in SMEs, more can be done. For example, Italy could develop and implement incentives to adopt least-life cycle cost capital acquisition and procurement procedures.

Progress should also be made by the Italian government among financial institutions and in the financial sector at large in order to secure future investment and enable training of staff on energy efficiency products. Moreover, there is a general lack of knowledge and awareness of measures and results taken at various institutional levels in Italy.

There is significant potential to substantially strengthen the energy efficiency of Italy's building stock, particularly by promoting passive-energy houses (PEH) and zero-energy buildings (ZEB). Italy has started well by including policies in its NEEAP to encourage low-energy buildings. But to further support low-energy buildings, Italy should consider setting objectives for PEH and ZEB as a market share of all new constructions by 2020 and using PEH and ZEB as benchmarks for energy efficiency standards in future updates and building regulations.

For existing buildings, Italy should systematically collect high quality and comprehensive information for the entire building stock, including information on use, building size, construction type and age. Information collected should also include insulation levels, types of windows, heating, ventilation, and air-conditioning (HVAC) systems. Italy should also consider conducting studies to identify, target and document barriers to increased energy efficiency in the buildings sector. 


\section{Italy's progress with implementing IEA energy efficiency recommendations}

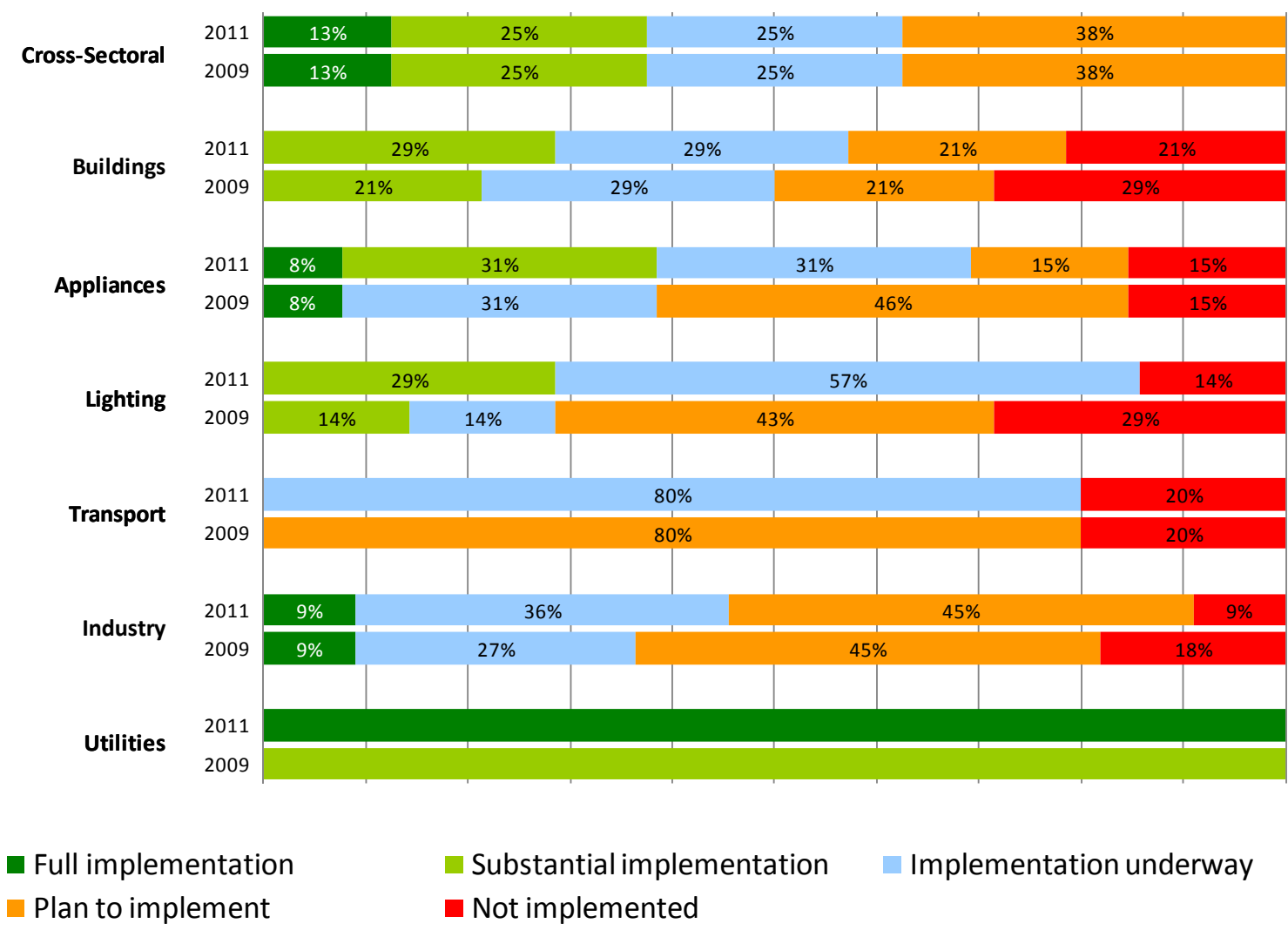

\section{Energy Efficiency Progress Report - Japan}

\section{Context}

Japan has improved energy efficiency by around $30 \%$ in the last 30 years as a result of action undertaken by the public and private sectors. Japanese TPES per GDP is one of the lowest in the world owing to vigorous energy conservation measures taken in various sectors. However, since the mid-1980s, this improvement has levelled off somewhat, with an average annual decline in energy intensity, adjusted for PPP, of $0.7 \%$ between 1990 and 2009. Japan's decreasing energy intensity during this period was due mainly to structural changes in the economy, rather than to energy efficiency improvements. As a result, Japanese energy intensity advantage over other countries has steadily been eroded. The Japanese government is now aiming for an improvement of at least another $30 \%$ in terms of final energy consumption per unit of GDP by 2030 compared with 2003.

Energy conservation measures in the industrial sector, which accounts for the largest portion of the energy consumption in Japan, and the civil (commercial/residential) sector have been enhanced in a broad range of fields through regulation and government support programmes.

An earthquake and tsunami struck Eastern Japan in March 2011, forcing several large nuclear and thermal power stations out of service for an extended period. To avoid blackouts, the government decided to implement an energy-saving strategy. This strategy includes mandatory rationing by large industry, information campaigns and technical energy-saving assistance. 


\section{Energy efficiency policy developments since 2009}

Japan is the only country in the world to have either implemented or planned to implement all 25 IEA energy efficiency policy recommendations.

Since the 2009 Evaluation, there have been several positive energy efficiency policy Page $\mid 76$ developments.

Japan's innovative Top Runner Program, which encourages competition among appliance and equipment manufacturers to improve appliance and equipment efficiency, extended standards to several new products. In January 2011, for example, Japan added three-phase induction motors to the programme and established a committee for examining concrete standards. Japan also issued JIS C 4034-2-1 in line with the international standard for motor measurement methods and JIS C4034-30 in line with standards for efficiency classes.

In February 2010, Top Runner standards for appliances were extended to include TV sets using energy-efficient LED backlight. As a result, the energy consumption of TV sets is expected to improve more than $37 \%$ by 2012 over 2008.

In conjunction with Top Runner standards, in May 2009, Japan implemented the Eco-Point System financial incentive scheme.

Japan is also actively promoting the exchange of information on standards and labelling of energy-saving devices, and supporting various countries' development and use of international measurement criteria through participation in the Super-efficient Equipment and Appliance Deployment (SEAD) Initiative and the Partnership for Energy Efficiency and Conservation (IPEEC). Moreover, Japan has signed the IEA/4E Implementing Agreement, and has been actively involved in the mapping and benchmarking of energy-saving devices in IEA/4E and actively supporting various countries' development and use of international measurement criteria.

In the lighting sector, Japan supports international efforts to stimulate the adoption of higher efficiency alternatives to fuel-based lighting in off-grid communities. For example, Japan supports the spread of solar cell based lighting in villages detached from power supply grids through the Japanese International Cooperation Agency (JICA). NEDO promotes research and development, as well as the dissemination of industrial, energy and environmental technologies.

Japan has made progress in the buildings sector since 2009. Japan's Database for Energy Consumption of Commercial buildings (DECC), includes information on building application, size, type and age and is now available to the public. In addition, Japan is supporting energy-efficient windows through a variety of subsidy schemes and tax breaks.

In the transport sector, Japan is still the only country in the world with fuel standards for heavyduty vehicles. In December 2008, the Japanese government established the Fuel-Efficient Tire Promotion Council. This council published a final report in July 2009 recommending the measurement methods of tyre rolling resistance and wet grip and the establishment of a labelling scheme. In response, the test procedures for tyre rolling resistance referring to ISO 28580 were established as JIS D4234 in December 2009. The labelling scheme, which is applied to replacement tyres for passenger cars, has been implemented on a voluntary basis since January 2010.

\section{Challenges and areas for improvement}

Despite being a leader in energy efficiency policy, Japan can make improvements in several areas. Mandatory building requirements for energy efficiency should be further strengthened to include all types of residential, commercial and public-use buildings regardless of their size. A committee 
formed by METI has recommended several measures on ZEB, such as broadening the scope of ZEB to all new buildings, a comprehensive evaluation based on the energy consumption of the whole building. Japan should implement these measures as soon as possible. In addition, more policies could be undertaken to target existing buildings, including strengthening building certification schemes.

In the transport sector, Japan launched a voluntary scheme for tyre labeling, but only a limited number of tyres are covered by this programme. Japan should expand the scope to include all tyres available in the market. Although Japan is currently discussing implementation of tyrepressure monitoring systems (TPMS), no related policy is currently in place. Japan should quickly implement a policy to require TPMS.

With respect to appliances and equipment, verification and enforcement processes form a vital component of national standards and labelling programmes. They ensure the credibility of the scheme for consumers, and safeguard investments made by manufacturers in more efficient products. A high degree of transparency and visibility in these processes therefore not only acts to deter non-compliance, but provides confidence to participants. The system used in Japan, which is based on self-declaration by manufacturers of both performance and sales data, contains many elements of a good verification and enforcement regime. However, it would benefit from greater transparency, such as the regular publication of testing results, data on noncompliance and the results of enforcement action, and increased verification of sales data.

\section{Japan's progress with implementing IEA energy efficiency recommendations}

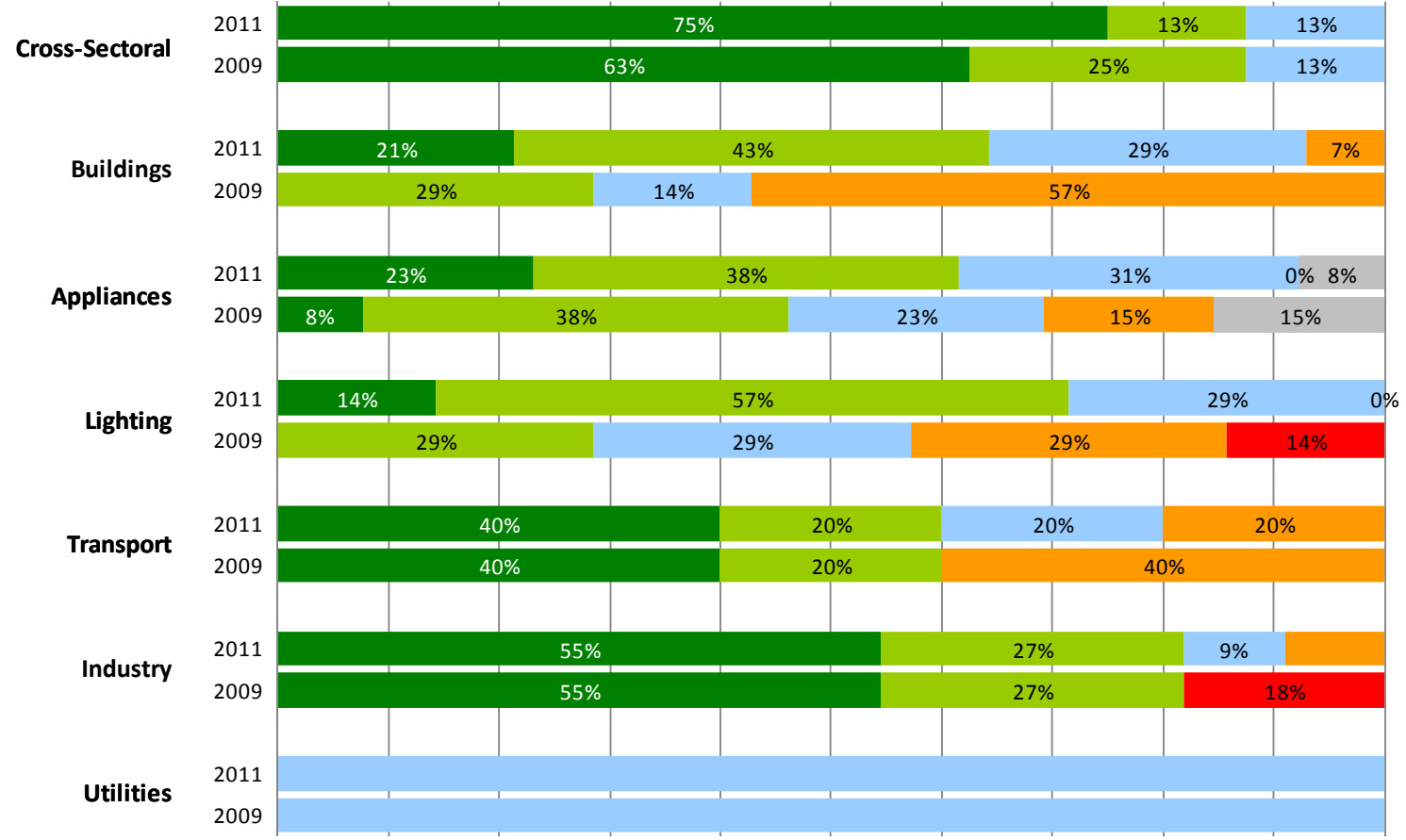

Full implementation Plan to implement
Substantial implementation $\square$ Implementation underway

Not implemented 


\section{Energy Efficiency Progress Report - Korea}

\section{Context}

Korea is an energy-intensive country, ranking eleventh highest worldwide in terms of energy consumption and ninth in terms of oil consumption. Korea's economy has relied on energyintensive industry, such as steel, petro-chemicals and cement. As a result energy consumption in the industrial sector is extremely high, accounting for $55 \%$ of total national consumption.

At one-quarter higher than the IEA as a whole, Korea's energy intensity, adjusted for PPP, has been declining relatively steadily since its peak in 1997, falling at an average annual rate of $0.9 \%$ between 1990 and 2009. Despite this declining trend, Korea's energy intensity was still expected to remain above that of most IEA member countries through 2010.

The Ministry of Knowledge Economy (MKE) and the Korea Energy Management Corporation (KEMCO) are the administrators of energy efficiency policies and measures. In general, the MKE shapes energy efficiency policies and its affiliated KEMCO executes energy policies and measures on behalf of the MKE.

\section{Energy efficiency policy developments since 2009}

Since the 2009 Evaluation, Korea has planned and implemented many new policies in various sectors to improve energy efficiency under the new Green Growth strategy.

As part of its efforts to improve energy efficiency in the industrial sector, in 2011, the Korean government introduced a "GHG and energy target scheme" for energy-intensive plants in addition to the existing "Voluntary Agreements for Energy Saving and GHG Reductions". Based on this new scheme, 372 industrial energy users submitted implementation plans to negotiate an energy efficiency target with the government. Performance-based penalties and incentives will be applied. In 2009, Korea also introduced an energy management system (EMS) certification programme based on national standard (KS A 4000: 2007) to improve the energy management capability of industrial plants and buildings.

To facilitate the private sector's involvement in energy efficiency investments, KEMCO has partnered with a private bank to provide USD 550 million to support industry and building energy efficiency projects in 2011. Public-private funding is also available through Korea's carbon fund (USD 180 milion).

Thanks to the Energy Efficiency Labels and Standards Program, High-efficiency Appliance Program and e-Standby Program, Korea's white goods are among the most energy efficient in the world. The efficiency level of refrigerators, air conditioners and washing machines stand out as highly successful examples (e.g. the average domestic air conditioner's energy efficiency ratio (EER) is higher than in any other country).

In 2011, Korea adopted mandatory $1 \mathrm{~W}$-standards for around 30 products through the e-Standby Program and Energy Efficiency Label and Standard Program. Starting in July 2010, Korea mandated an innovative standby warning label for 19 products that do not meet specified standby power standards.

Korea is moving ahead with policies to phase out the most inefficient incandescent bulbs. The phase out of incandescent lamps began in Korea in June 2010. By setting the level of MEPs for Incandescent lamps at $20 \mathrm{~lm} / \mathrm{W}$, all incandescent lamps will be phased out of the market by January 2014. 
Policy implementation progress was also made in the transport sector since the 2009 Evaluation. In July 2009, Korea announced a new and more stringent fuel economy standard for passenger cars as part of the national Green Growth strategy. The new standards will be phased in from 2012 and then fully implemented in 2015. Each automobile manufacturer can choose between two corporate average targets, i.e. $17 \mathrm{~km} / \mathrm{L}$ or $140 \mathrm{~g} \mathrm{CO}_{2} / \mathrm{km}$. The Korean government also provides fiscal incentives for cars with low $\mathrm{CO}_{2}$ emissions.

Korea is also actively involved in promoting eco-driving. As part of the presidential committee of the five-year action plan for green growth (2009-2013), several initiatives to promote eco-driving have been established. For example, Korea founded an eco-driving education centre in 2010, made agreements with entities and individuals to commit themselves to carrying out eco-driving, and provided information on eco-driving through an internet homepage. Korea reports that buses, taxis and vans shall be equipped with idling stop devices from 2011. The Ministry of Knowledge Economy will give a subsidy to fleet operators to install an eco-driving indicator in 2011. Korea acknowledges that although measures to promote eco-driving are voluntary, a greater number of public transportation and freight transport vehicles and privately-owned cars have participated in the eco-driving initiatives.

To improve energy efficiency in the buildings sector, in June and December 2010, Korea reinforced building code standards related to insulation, standby power and LED lighting. A further revision of building-code standards is scheduled in 2012. From January 2010, it became mandatory for all public buildings to obtain the highest energy performance certificate (EPC) grade. The government announced plans in November 2009 that all new buildings in Korea should be constructed as zero-energy buildings from 2025. Mandatory application of MEPs and the indication of an energy efficiency grade ( 1 to 5 ) will be applied to windows starting from 2012.

\section{Challenges and areas for improvement}

While Korea has planned many new policies, implementation will now be crucial to capturing the great energy-savings potential that remains. Opportunities for further policy developments also be explored, particularly in the transport, buildings and lighting sectors. For example, to improve energy efficiency in the transport sector, Korea could adopt fuel-efficiency standards for heavyduty vehicles. In 2010, Korea announced a plan to introduce tyre fuel efficiency standards and labelling. Korea should ensure that these standards and labelling systems are based on international test procedures for measuring rolling resistance. Korea should also speed up planned policies to promote proper tyre inflation levels.

While Korea does have mandatory Building Energy Saving Design Codes, the scope should be further expanded to cover a wider range of building types. There is also room to improve the stringency of building codes and to implement policies to encourage low-energy houses. Korea could also further develop initiatives to address barriers to energy efficiency in buildings.

According to the government, lighting consumes approximately one-fifth of national energy. Further efforts to strengthen policies targeting efficiency in lighting should therefore be pursued, particularly for non-residential buildings. 


\section{Korea's progress with implementing IEA energy efficiency recommendations}

Page | 80

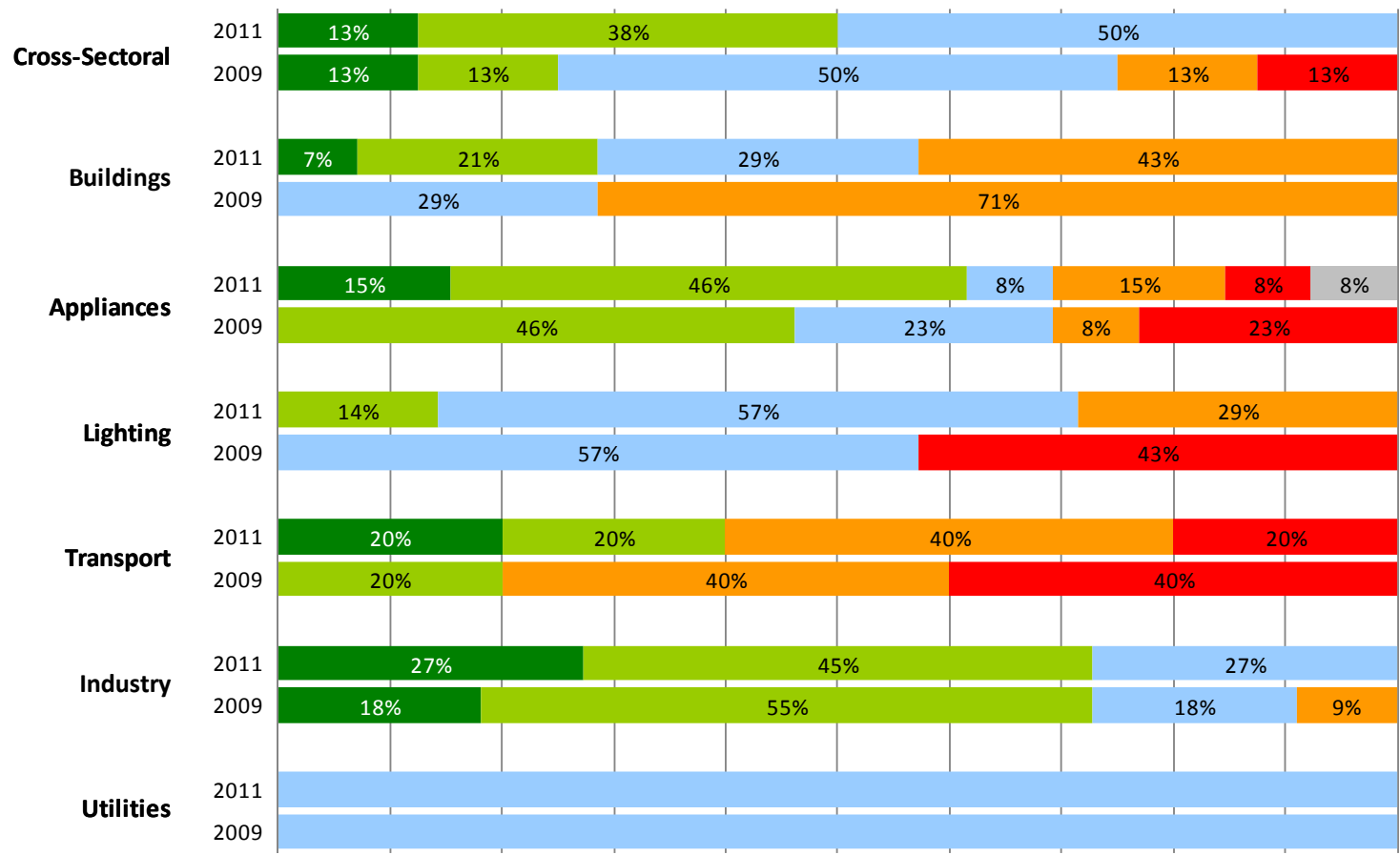

- Full implementation

Plan to implement
Substantial implementation $\square$ Implementation underway

not implemented

\section{Energy Efficiency Progress Report - Luxembourg}

\section{Context}

Luxembourg's energy intensity has improved over the past two decades and is now similar to the IEA European average. Energy intensity, adjusted for PPP, has improved by $2.7 \%$ per year from 1990 to 2009, mainly owing to structural changes in industry and the overall economy.

Although Luxembourg's economy is characterised by high value-added financial services, it also has substantial heavy industry in relation to the size of its economy, unlike IEA member countries of comparable size and wealth.

Broken down by sector, transport was the largest energy user in 2008, accounting for $56 \%$ of total final consumption (TFC). Industry's share was $24 \%$ and the residential, services and primary sectors accounted for $20 \%$ of the total. These shares have been fairly stable over the past five years. In comparison, the IEA average in 2008 was $23 \%$ for industry, and $32 \%$ for transport and $45 \%$ for other sectors.

Energy use in industry and the residential/commercial sector has remained relatively flat since the mid-1990s. Industry has modernised and restructured itself, and, counterbalancing the impact of rapid population growth, energy use in buildings has become more efficient. The transport sector, in turn, has seen a dramatic increase in energy use over the past decade. This can be largely attributed to transit traffic, including foreign lorries crossing Luxembourg and to daily commuters from across Luxembourg's borders. 


\section{Energy efficiency policy developments since 2009}

Since the 2009 Evaluation, Luxembourg has made progress with implementing energy efficiency policies in the building, transport, appliance and lighting sectors.

To improve the energy efficiency of the buildings sector, Luxembourg passed Grand-Ducal Regulations in November 2008 and August 2010. These regulations introduce stricter energy efficiency performance requirements for new residential buildings and existing buildings undergoing retrofits. Additionally, these regulations require building energy certification whenever a commercial or residential building is sold, rented, modified, transformed or constructed. Certification is also required for public buildings. Support of EUR 1000 per tonne of $\mathrm{CO}_{2}$ saved is available during the renovation of municipal buildings.

Luxembourg provides investment subsidies for energy efficiency improvements in new and existing buildings. Grants range from EUR 21 to EUR 45 per $\mathrm{m}^{2}$ for new low-energy houses and from EUR 57 to EUR 160 per $\mathrm{m}^{2}$ for PEH, depending on the surface area. Investment subsidies are also provided for refurbishments that improve roof insulation and window replacement.

The myenergy programme continues to provide information and advice on energy efficiency in buildings (including subsidies for building renovations, passive and low-energy building construction and building certification). Interested parties can call a free hotline or make an appointment with a counsellor at myenergy information centres located throughout the country.

In the transport sector, Luxembourg is implementing EU regulations to lower rolling resistance and maintain appropriate tyre inflation pressure through mandatory fitting of TPMS. It will also require average emissions from new passenger vehicles sold in Luxembourg to reach the $130 \mathrm{~g} \mathrm{CO}_{2} / \mathrm{km}$ target by 2015 .

Related to the appliance and lighting sectors, Luxembourg is transposing the Ecodesign Directive and its October 2009 recast aims to improve energy efficiency throughout a product's lifecycle.

Luxembourg will transpose the May 2010 Directive 2010/30/EU, which requires labelling and standard product information on energy consumption by energy-related products.

\section{Challenges and areas for improvement}

There are still many policy opportunities to improve energy efficiency in Luxembourg. In the industrial sector, Luxembourg should encourage the development of energy management (EM) capability through the development and maintenance of EM tools, training, certification and quality assurance. Luxembourg could examine the barriers to the optimisation of energy efficiency in electric motor-driven systems and design and implement comprehensive policy portfolios aimed at overcoming such barriers.

To encourage utilities to deliver energy savings, Luxembourg could require energy efficiency measures and energy supply options to compete on a level playing field with energy sales. Luxembourg could also place energy efficiency obligations on utilities and establish regulations, which decouple energy sales revenue and profits from energy savings.

Across sectors, Luxembourg could speed up efforts to implement policies to adopt and publicise common energy-efficiency savings and verification measures, to encourage a boost in private investment in energy efficiency. Such efforts need to be supported by optimal procedures for compliance, monitoring and evaluation of energy efficiency policies and by reliable legislative and institutional infrastructure for enforcement. 


\section{Luxembourg's progress with implementing IEA energy efficiency recommendations}

Page | 82

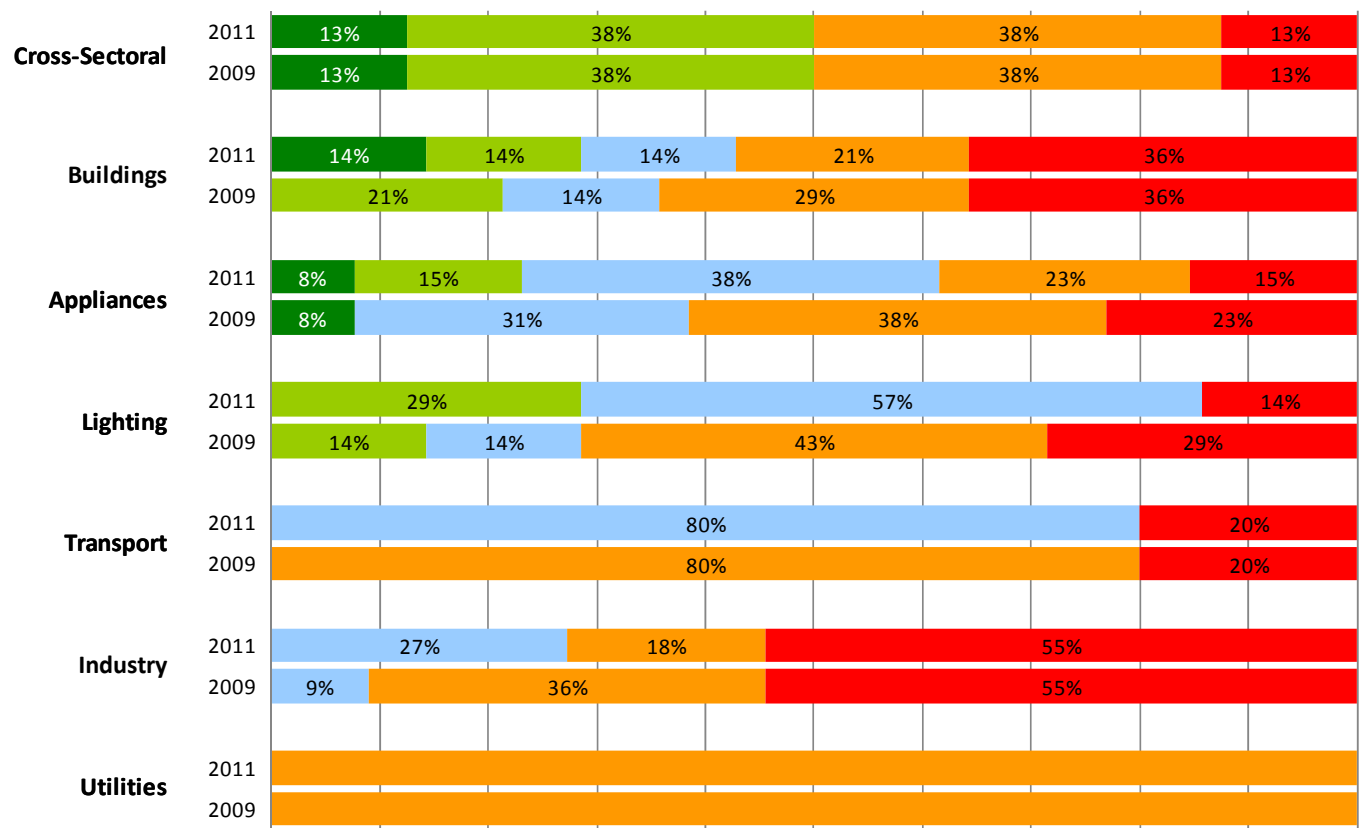

- Full implementation

Plan to implement
- Substantial implementation
Implementation underway
not implemented

\section{Energy Efficiency Progress Report - Netherlands}

\section{Context}

Energy efficiency forms a key part of the Netherlands' climate change mitigation, energy security and environmental policies. Under its Clean and Efficient programme, the Dutch government has set up a target to achieve an annual energy efficiency improvement of $2 \%$ by 2020 , which is more than twice the current rate. Other key policy documents - Energy Report 2008 strategy and the Energy Transition framework - also emphasise energy efficiency. The Netherlands' energy efficiency policies and measures are outlined in its NEEAP submitted to the EC in 2007 and again in 2011 in the context of the EU Energy Services Directive.

At present, the energy intensity of the Netherlands' economy is slightly higher than the IEA average. This is mainly due to its energy-intensive industrial sector, including refineries and chemicals. Energy intensity has been declining steadily since the 1970s although the decline rate has slowed down in recent years from an average 1.9\% per year between 1990 and 2000 to $0.7 \%$ per year between 2000 and 2009. This gives the Netherlands an average decline in energy intensity, adjusted for PPP, of 1.3\% per year from 1990 to 2009.

\section{Energy efficiency policy developments since 2009}

In recent years, the Netherlands has made energy efficiency a key policy priority and set a very ambitious energy efficiency improvement target. To achieve this target, the government spent around EUR 1.2 billion for 2008-2011 to stimulate energy efficiency improvements in different 
sectors.

In the buildings sector, the Netherlands reported that the building code standard is set for cost efficiency over the lifetime of the measures. Energy performance certificates for buildings are mandatory and sanctions for noncompliance will be strengthened in July 2012. The Netherlands has strong building codes, implemented within the framework of the EU Directive on energy performance of buildings. For new buildings, the energy performance coefficient for residential buildings is being tightened considerably from 0.8 to 0.6 in 2011 and to 0.4 in 2015, with the aim of reducing energy use by $50 \%$ in new buildings (building code standard 2007). By 2020, the aim is for all new buildings will be energy neutral.

The Netherlands supports international efforts to stimulate the adoption of higher efficiency alternatives to fuel-based lighting in off-grid communities through the Energising Development programme and the Daeij Ouwens Fund.

The Netherlands is also implementing EU regulations to lower rolling resistance and maintain appropriate tyre inflation pressure through mandatory fitting of TPMS, along with the $130 \mathrm{~g} \mathrm{CO}_{2} / \mathrm{km}$ average emissions target for new passenger vehicles, which is to be reached by 2015. The Netherlands is also implementing eco-driving programmes. The Institute for Sustainable Mobility runs a partly government-financed campaign to promote eco-driving for professional drivers. It also runs a partly government-financed campaign to promote the importance of correct tyre pressure.

In the appliance sector, the Netherlands actively supports the European Commission in implementing ambitious levels for minimum energy performance requirements (MEPs) for numerous products covered under the Ecodesign Directive (2009/125/EC).

The Netherlands is also transposing the May 2010 Directive (2010/30/EU), which requires labelling and standard product information relating to the consumption of energy and other resources on energy-related products. The first revised energy labelling regulations will become effective by the end of 2011.

In the industrial sector, the Netherlands supports energy-efficiency improvement through longterm agreements. These agreements set energy efficiency targets for each sector and each company. The government supports this exercise by providing the necessary expertise to help draft energy efficiency investment plans.

\section{Challenges and areas for improvement}

There are still many opportunities for the Netherlands to enhance energy savings. For example, the Netherlands should enable energy utilities to deliver energy efficiency. There are a variety of ways the government can do this e.g .by providing energy utilities with incentives to deliver costeffective energy savings to end-users, establishing regulation that decouples utility revenue and profit from energy sales, placing energy efficiency obligations on energy utilities and allowing energy efficiency measures to be bid into energy pools on an equal basis with energy supply options.

The transport sector is another area where more work is needed. To improve energy efficiency in this sector, the Netherlands should encourage the UE to adopt fuel-efficiency standards for heavy-duty vehicles.

There is much scope for energy efficiency policy developments in the industrial sector. In July 2009 the Netherlands, as a member of the EU, adopted MEPs for certain kinds of motors. The Netherlands could also examine barriers to the optimisation of energy efficiency in electric motor-driven systems and implement a comprehensive policy portfolio aimed at overcoming 
such barriers.

Also in the industrial sector, the Netherlands should extend its support for SMEs. In particular, the government could provide energy performance benchmarking information and develop incentives for SMEs to adopt least life-cycle cost capital acquisition procedures. The Netherlands should also develop and adopt a formal energy management policy, which could include

Page | 84 requiring appointment of full-time energy managers at an enterprise and plant-specific level.

To improve energy efficiency in the buildings sector, the Netherlands should implement policies to promote passive-energy houses (PEH) and zero-energy buildings (ZEB).

\section{The Netherland's progress with implementing IEA energy efficiency recommendations}

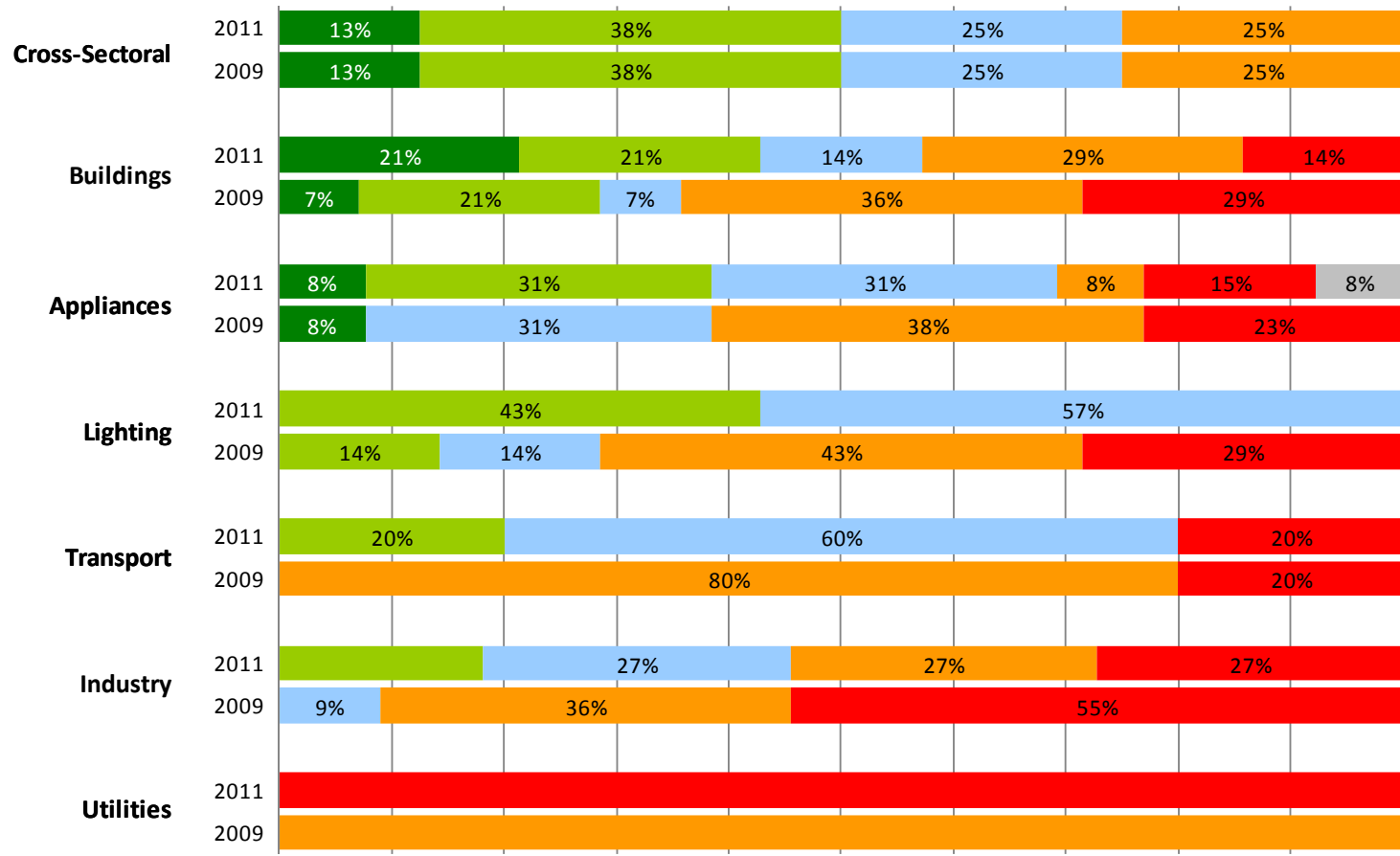

- Full implementation

- Plan to implement
- Substantial implementation Implementation underway

Not implemented

\section{Energy Efficiency Progress Report - New Zealand}

\section{Context}

New Zealand's energy intensity, adjusted for PPP, has declined relatively consistently since 1990 at an average of $1.0 \%$ per year. New Zealand's energy intensity in 2009 was slightly higher than the IEA average - mainly because of the large proportion of energy-intensive sectors in the New Zealand economy. According to the Energy Efficiency and Conservation Authority (EECA), overall energy efficiency improvements saved New Zealand 38 PJ of energy between 2001 and 2007.

Transportation is the largest and fastest-growing energy-consuming sector in New Zealand. In 
2008 , transport accounted for $39 \%$ of final energy consumption outstripped the industrial sector $(35.8 \%)$, residential sector $(11.7 \%)$, commercial sector $(9.7 \%)$ and agriculture sector $(3.8 \%)$.

New Zealand has a strong commitment to an undistorted and transparent energy market. As a result, New Zealand is the first non-EU member to introduce an emissions trading scheme. Its ETS combined with complementary policies, means New Zealand is well positioned to exploit its energy efficiency potential.

New Zealand has a history of promoting energy efficiency policies. The country has a strong legislative and institutional base for its energy efficiency policies, in the form of the Energy Efficiency and Conservation Act (2000). The Act established the Energy Efficiency and Conservation Authority (EECA) as a stand-alone entity with an enduring role to promote energy efficiency across all sectors of the economy. The Act also empowers the preparation of regulations to implement product MEPs and labelling and to compile statistics on energy efficiency, energy conservation and renewable energy.

\section{Energy efficiency policy developments since 2009}

New Zealand works in conjunction with Australia, and other international partners, to implement minimum energy performance requirements (MEPs), and mandatory energy performance labelling (MEPL) for a wide range of energy-using products. As a result, New Zealand's MEPs and associated labelling regimes are relatively strong. Furthermore, the compliance monitoring and evaluation regime for these programmes is robust.

In addition to MEPs, New Zealand is implementing a mandatory vehicle fuel economy labelling scheme (VFEL) covering light passenger vehicles manufactured from the year 2000 onwards $^{10}$ and sold domestically, including imported used cars (an aspect of vehicle fuel economy labelling that is unique to New Zealand).

Through EECA, New Zealand has developed a world-class energy efficiency indicators and monitoring system. EECA is responsible for performing comprehensive ex ante and ex post evaluations of the central government's energy efficiency programmes.

The roll out of Warm Up New Zealand: Heat Smart has been managed well and appears to be delivering good results nationwide. More than 100000 homes were retrofitted with insulation or provided with a clean heating device, or both, during the first year of the scheme.

\section{Challenges and areas for improvement}

There are several areas for energy efficiency policy improvement. At a strategic level, the IEA is concerned that the revision of the New Zealand Energy Efficiency and Conservation Strategy (NZEECS) is still unresolved as NZEECS remains in draft form almost two years since the beginning of the review. Formal adoption of the strategy is important to reinforce its status and provide certainty to the implementation agency.

Historical growth in the transport sector, caused by an increasing number of vehicles on the road, appears to be one the biggest energy-saving challenges in New Zealand. Two issues make addressing transport sector energy efficiency particularly difficult. Firstly, a critical concern is that responsibilities for policy development in this sector are unclear. There is an urgent need to clarify which agencies lead policy making in each sector. Secondly, once these issues are resolved, New Zealand should consider adopting policies on proper tyre inflation levels and introducing

\footnotetext{
${ }^{10}$ Exemptions apply to motorcycles and vehicles over 3.5 tonnes and to vehicles where the information is not available - most likely those manufactured prior to 2000 .
} 
fuel-efficiency standards for light and heavy-duty vehicles.

Amendments to the Building Code in 2008 imposed tougher MEPS for new buildings and major renovations. This has led to an effective increase in insulation requirements for residential homes and smaller commercial buildings. Given the significance of energy use in the commercial sector, it is critical that the regulation of building MEPs be extended to commercial buildings larger than Page | $86300 \mathrm{~m}^{2}$.

Whilst acknowledging that that much of New Zealand has a temperate climate, which effects New Zealand's energy building use, the IEA is concerned to see a lack of policies promoting energy efficiency beyond the requirements in the building code. . But energy efficiency gains can still be realised by implementing policies to provide information on building use (through home energy rating schemes (HERS) and building certification) and promoting and developing PEH and ZEB.

While New Zealand has a well-developed product efficiency programme, it can do more to implement robust appliance and lighting energy efficiency policies. Policies to promote greater energy efficiency (via MEPS) for flat-screen high-definition televisions and networked devices are critical as these technologies gain increased market share and account for a growing portion of energy demand. New Zealand has a very good lighting programme (www.rightlight.govt.nz) which focuses on a partnership with lighting suppliers, provides information to consumers on energy-efficient lighting technologies and provides subsidies for CFL lighting. Though New Zealand has MEPs for tubular fluorescent lamps and an ENERGY STAR programme for CFLs, there are currently no plans to implement the IEA recommended phase-out of incandescent lamps.

\section{New Zealand's progress with implementing IEA energy efficiency recommendations}

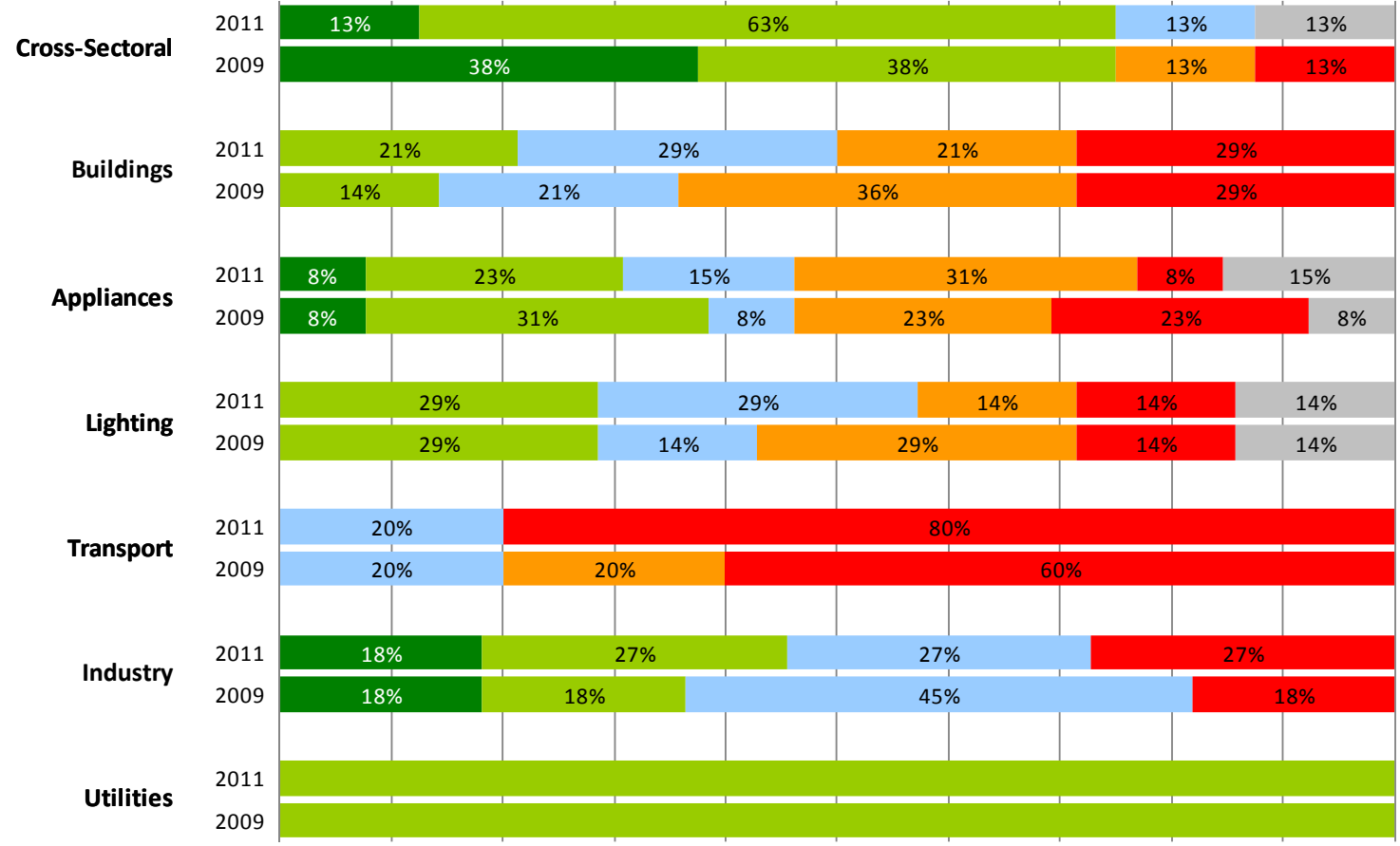

Full implementation Plan to implement
Substantial implementation Implementation underway

- Not implemented 


\section{Energy Efficiency Progress Report - Norway}

\section{Context}

Although not an EU member country, Norway is required to adopt much of the EU legislation as part of its participation in the European Economic Area (EEA). In addition to meeting requirements under the EEA, Norway has chosen to opt into many EU programmes, institutions and activities, especially in the area of energy efficiency.

Norway's energy intensity, adjusted for PPP, improved on average by $2.1 \%$ per year between 1990 and 2009. This is one of the highest rates of improvement among IEA member countries. The decline in energy intensity is largely due to structural changes in the economy (principally a shift away from energy-intensive sectors), with energy efficiency accounting for just under $0.2 \%$ per year.

Unlike in many EU member states, rather than requiring utilities to deliver energy efficiency, Norway imposes a levy on electricity consumption of NOK 0.01 per kilowatt hour (kWh). Together with budget allocations, this levy contributes to an Energy Fund that is managed by Enova, one of Norway's primary implementing agencies for energy efficiency policy. The Energy Fund is used to finance programmes and initiatives that support and underpin national objectives including in the area of energy efficiency. Enova has the freedom to choose its policy measures and the responsibility to establish incentives and financial funding schemes that will result in costeffective and environmentally sound investments. The current portfolio in the area of energy efficiency includes a wide range of programmes for households, industry, businesses, buildings, and municipalities.

The Norwegian government strengthened Enova by renewing its contract for 2008-2011 and increasing the annual budgets of the Energy Fund by approximately $135 \%$ from NOK 788 million (USD 113 million) in 2007 to NOK 1850 million in 2011 (USD 264 million). Enova has the overall objective to deliver $18 \mathrm{TWh}$ (terawatt hour) /year in energy savings and renewable energy from 2001 to the end of 2011. At the end of 2010, Enova reported results of $15.5 \mathrm{TWh} /$ year.

\section{Energy efficiency policy developments since 2009}

Norway has implemented several new energy efficiency policies since 2009. For example, the EU EPBD Directive was implemented in 2010 and energy performance certificates are required when buildings are built, sold or rented. Public and commercial buildings above $1000 \mathrm{~m}^{2}$ are required to have energy performance certificates that are visible for the users of the building.

Also in the buildings sector, a Norwegian national standard for passive-energy houses (PEH) has been developed. Norway has established a low-energy programme focused on capacity building and pilot projects to increase the share of PEH in the Norwegian market. Enova offers a grant programme for $\mathrm{PEH}$ that covers all building categories (residential, public and commercial buildings) and provides investment aid to cover up to $60 \%$ of the additional costs of building a $\mathrm{PEH}$. It is expected that the Enova investment aid programme will lead to a reduction of the cost of PEH components.

The availability of cheap and clean domestically-produced electricity has encouraged the development of energy-intensive industry in Norway. Norway is making progress in the area of industrial energy efficiency; and wants to ensure that Norwegian industry will be leaders in energy efficiency. Measures are in place to ensure that all enterprises have energy consumption targets by 2015; further actions will be taken to address key barriers, namely, inefficient technologies, lack of incentives, limited access to capital and lack of awareness and capacity. This 
year Enova launched a comprehensive package of energy efficiency measures in industry. This programme targets small and medium-sized enterprises.

There are several programmes in place that aim to improve energy efficiency in industry. Some sectors receive tax exemptions by joining a programme for energy efficiency in energy-intensive industries. This includes a commitment to establish an energy management system, perform Page 88 regular energy audits, and to implement energy efficiency measures. Enova has established a benchmarking scheme for industrial energy use. Information on industrial energy use is collected and published by Statistics Norway.

Norway is implementing EU directives on efficiency in appliances. The EU Directive establishing a framework for setting Ecodesign requirements has been implemented through a Norwegian regulation. Following the adoption of the recast of the EU Labelling Directive in May 2010, the mandatory labelling requirement will be expanded to cover more energy-related products.

In the lighting sector, Norway has implemented several measures under the EU Ecodesign Directive. Municipalities and other owners of large facilities and outdoor lighting infrastructure can apply to Enova for assistance with refurbishing street lighting and installing management systems for lighting in buildings.

Norway has several policies to promote energy-efficient vehicles. A vehicle registration tax for light-duty vehicles in Norway is progressive based on its three base components, namely weight, effect, and carbon dioxide emissions. From 2012, the target for new cars is a maximum of $130 \mathrm{~g} \mathrm{CO}_{2} / \mathrm{km}$. Tax deduction rates for vehicles emitting less than $130 \mathrm{~g} / \mathrm{km}$ are in place. Electric vehicles are exempted from most taxes. They have the right to use bus lanes and are allocated free parking on publicly owned parking lots.

Norway is developing a model contract for energy performance certificates (EPC) and has decided to roll out smart meters by 2016.

\section{Challenges and areas for improvement}

Norway can further improve its energy efficiency policy portfolio. The EU Directive on energy end-use efficiency and energy services (ESD) has not been implemented in the EEA agreement and hence not in Norway. Norway therefore has no National Energy Efficiency Action Plan (NEEAP), nor an individual target encompassing all national energy efficiency measures, as required in the directive. Norway should consider bringing together its various policies and measures under a single national strategy on energy efficiency.

There is also room for improvement with respect to policies promoting the financing of energy efficiency - particularly from the private sector. Norway should implement policies to promote the benefits of energy efficiency investments to financial institutions so as to assist them with developing energy efficiency investment products and risk-mitigation measures. Progressing with with implementation of EU directives in the appliance and equipment sector while adequately resourcing mandatory energy performance levels is also advisable. In this respect, particular focus should be placed on promoting energy efficiency in the area of home entertainment, including minimising energy used by TVSP customers and promoting the uptake of new energyefficient television technologies. In the area of lighting, Norway could work towards expanding the coverage of MEPs and limiting whole building lighting power in new non-residential buildings. Furthermore, Norway should support international efforts to stimulate the adoption of higher efficiency alternatives to fuel-based lighting in off-grid communities.

In the transport sector, Norway has implemented fuel and vehicle-registration taxes, but should also consider implementing planned EU-wide policies, which require average emissions from new passenger vehicles sold in the European Union to reach a $130 \mathrm{~g} \mathrm{CO}_{2} / \mathrm{km}$ target by 2015 . Norway 
should also investigate measures aimed to further promote fuel-efficient practices including ecodriving and fuel-efficient tyres.

\section{Norway's progress with implementing IEA energy efficiency recommendations}

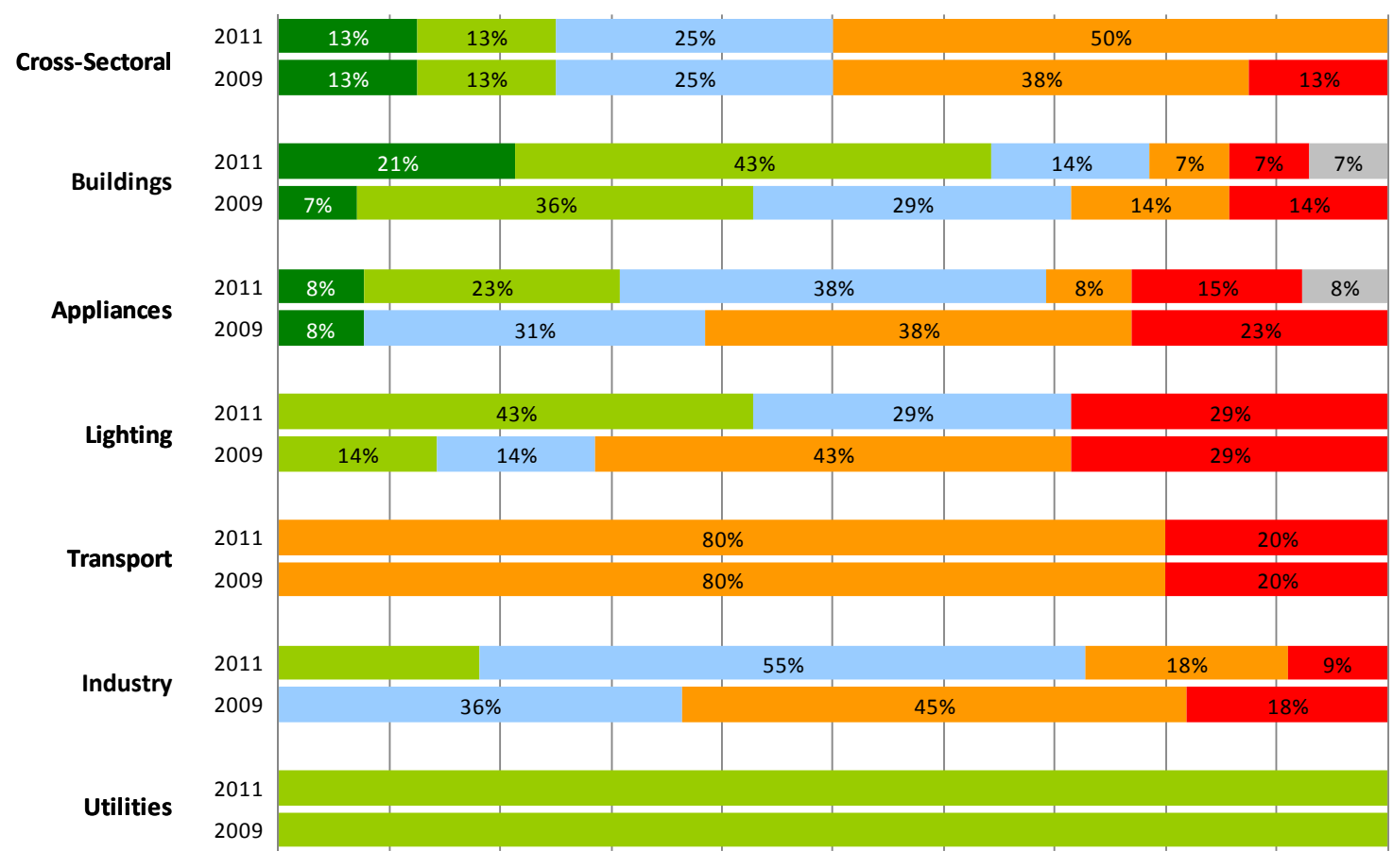

\section{Energy Efficiency Progress Report - Poland}

\section{Context}

Energy efficiency is becoming a prominent component of Poland's energy security and environmental policies. It is one of the key objectives of the country's Energy Policy to 2030, adopted in November 2009. Polish energy efficiency policy is mainly guided by EU requirements. In accordance with the EU Directive (2006/32/EC) on energy end-use efficiency and energy services (ESD), Poland has an indicative target to reduce energy consumption by $9 \%$ in 2016 (53 $452 \mathrm{GWh}$ ). Poland's energy efficiency policies and measures are outlined in the NEEAP submitted to the EC in 2007. At present, the legal framework for energy efficiency is set by the 1997 Energy Law and a new energy efficiency law, adopted in April 2011 and in force since August 2011.

Poland's energy intensity, adjusted for PPP, dropped on average 3.6\% per year between 1990 and 2009. Energy intensity improved at an average rate of 7.1\% per year between 1995 and 2000 (compared to the average $1.8 \%$ for all IEA member countries), but the decline rate slowed to an average $2.2 \%$ per year between 2000 and 2009 . 


\section{Energy efficiency policy developments since 2009}

Since the 2009 Evaluation, Poland has progressed in implementing policies related to EU regulations and directives in the transport, appliance, lighting and buildings sectors.

In the transport sector, for example, from November 2012, the EU regulation to lower rolling Page | 90 resistance and maintain appropriate tyre inflation pressure through mandatory fitting of TPMS will apply. Poland is also implementing EU regulations that require average emissions from new passenger vehicles sold in Poland, and other EU member states, to reach the $130 \mathrm{~g} \mathrm{CO}_{2} / \mathrm{km}$ target by 2015 (starting from 2012).

Regarding the appliances and equipment sector, energy performance requirements for numerous products covered under the Ecodesign Directive (2005/32/EC) have entered into force, and the October 2009 Ecodesign Directive recast (2009/125/EC), which includes energy-related products, such as building components, was transposed.

Poland is also transposing the May 2010 Directive (2010/30/EU) which requires labelling and standard product information on the consumption of energy and other resources by energyrelated products.

In the buildings sector, Poland is transposing the Energy Performance of Buildings Directive and its recast. An energy performance certificate (EPC) is now mandatory when a building or flat is sold.

With the help of the European Bank for Reconstruction and Development (EBRD), Poland is encouraging increased investment in energy efficiency. The EBRD is providing the four Polish banks (BGZ, WBK, BNP Paribas and Millennium) with loans of EUR 50 million and EUR 35 million respectively for small and medium enterprises (SMEs) undertaking sustainable energy investments. The loans are part of the EBRD's EUR 150 million Poland Sustainable Energy Financing Facility (PoISEFF), which is a credit line to help small and medium sized businesses in Poland invest in new, sustainable energy technologies. PoISEFF credit lines of up to EUR 1 million are available through partner banks and leasing companies.

Since 2011, the "Effective use of energy" programme provides entities with a minimum average energy consumption of $50 \mathrm{GWh}$ with energy audits and support for energy efficiency investments. The National Fund for Environmental Protection and Water Management, in operation since 1989, provides this programme with loans of around EUR 205 million for 20112015.

Poland is also encouraging energy utilities to deliver energy efficiency savings. For example, the Energy Efficiency Law, passed on 15 April 2011, introduced a White Certificate Scheme. From January 2013, obligations to present white certificates will be imposed inter alia on utilities selling electricity, natural gas and heat to customers.

Starting in late 2011, energy utilities will be required to provide customers with a comparison of current electricity consumption with the same period in the previous year. They will also be required to provide information on average electricity consumption of other, similar customers, energy efficiency measures and technical characteristics of energy-efficient appliances.

\section{Challenges and areas for improvement}

Energy efficiency policy in Poland can be strengthened further. For example, implementing measures under EU directives and regulations requires a considerable expansion of energy efficiency policy. Poland needs to ensure that it has comprehensive legal and physical capacity to enforce these policy measures and maximise their effectiveness. 
While maintaining the implementation of policies relating to Directives and regulations, Poland should at the same time be mindful to implement energy efficiency policies not covered by EU directives. For example, much is to be achieved in the industrial sector, where there is still a need to provide assistance in developing energy management capability and shaping policy packages to promote energy efficiency in small and medium-sized enterprises (SMEs).

There is significant potential to substantially strengthen the energy efficiency of Poland's building stock, particularly by promoting passive-energy houses (PEH) and zero-energy buildings (ZEB). Poland should consider setting objectives for PEH and ZEB as a market share of all new constructions by 2020. Using PEH and ZEB as benchmarks for energy efficiency standards in future updates and building regulation is also advisable.

For existing buildings, Poland should systematically collect comprehensive information for the entire building stock, including information on all types of use and sizes of buildings for all types of construction and ages. Information collected should also include insulation levels, types of windows and HVAC systems. Poland should also consider conducting studies to identify, target and document barriers to increased energy efficiency in the buildings sector.

\section{Poland's progress with implementing IEA energy efficiency recommendations}

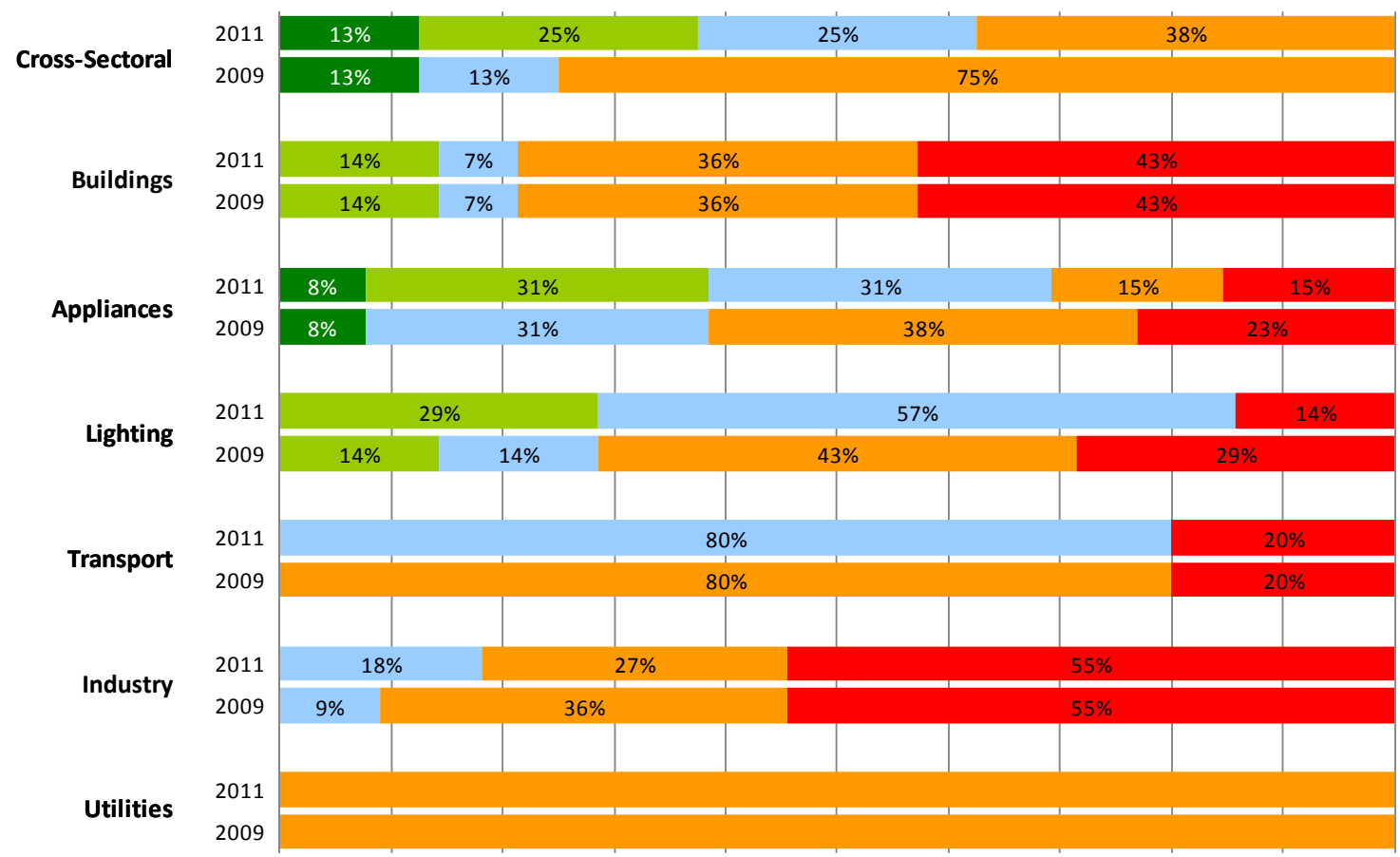

- Full implementation

- Plan to implement
Substantial implementation Implementation underway

Not implemented 


\section{Energy Efficiency Progress Report - Portugal}

\section{Context}

The Portuguese government has placed energy efficiency policy at the heart of its energy portfolio. Portugal published its draft NEEAP, Portugal Efficiency 2015, in May 2008. The Plan sets a target of reducing energy consumption by $9.8 \%$ by 2015 , and elaborates a series of 12 programmes establishing targets to 2015 and measures to be taken across various sectors in order to achieve this goal. A key strength of the plan is its interaction with both the National Climate Change Programme (PNAC 2006) and the National Allocation Plan for Emission Allowances (PNALE).

While Portugal's energy intensity, adjusted for PPP, increased from 1990 through 2000, this trend was reversed since 2000 with an average decrease of $0.4 \%$ between 2000 and 2009 . This brought back Portugal's energy intensity to its 1990 level.

\section{Energy efficiency policy developments since 2009}

Portugal has made some progress in implementing energy efficiency policies since the 2009 Evaluation, particularly relating to transposition of EU directives and regulations in the transport, industry, appliance and lighting sectors.

In the transport sector, Portugal is implementing EU regulations to lower rolling resistance and maintain appropriate tyre inflation pressure through mandatory fitting of TPMS. Portugal is also implementing EU regulations, which require average emissions from new passenger vehicles sold in Portugal, and other EU member states, to reach the $130 \mathrm{~g} \mathrm{CO}_{2} / \mathrm{km}$ target by 2015 .

Regarding the appliance sector, energy performance requirements for numerous products covered under the Ecodesign Directive (2005/32/EC) have entered into force, and the October 2009 Ecodesign Directive recast (2009/125/EC), which includes energy-related products, such as building components, was transposed.

Portugal is also transposing the May 2010 Directive (2010/30/EU) which requires labelling and standard product information on the consumption of energy by energy-related products.

In the buildings sector, an energy certification system became mandatory in July 2007 and every building is required to have an energy performance certificate, stating the building's energy consumption and proposed measures towards its reduction. Furthermore, two new buildingsrelated regulations were implemented, the Regulation on Energy Systems and Air Handling in Buildings (RSECE) and the Regulation on Thermal Behaviour Characteristics in Buildings (RCCTE). This regulatory package will have a significant impact on the energy efficiency of buildings by establishing higher construction standards, notably by enforcing a mandatory obligation to install thermal solar panels in all new buildings.

Also, the Management System of Intensive Energy Consumption (SGCIE) has been launched, which promotes energy efficiency and monitoring energy consumption in energy intensive installations (CIE). Portugal's Cabinet Resolution no. 2/2011, passed in January 2011, created the legal framework for energy service companies (ESCOs) and procurement management of energy services.

\section{Challenges and areas for improvement}

More energy efficiency policies are needed to tap the large energy savings possible from the transport and industrial sectors. In the transport sector, for example, Portugal could support the 
development of mandatory fuel-efficiency standards for heavy-duty vehicles, and scale up efforts to promote eco-driving training.

As for energy efficiency measures in the industrial sector, Portugal should work to establish measures to optimise energy efficiency in motor-driven systems. For example, Portugal should examine the barriers to the optimisation of energy efficiency in electric motor-driven systems and design and implement comprehensive policy portfolios aimed at overcoming such barriers.

To encourage utilities to deliver energy savings, Portugal could require energy efficiency measures and energy supply options to compete on a level playing field with energy sales. It could also place energy efficiency obligations on utilities and establish regulations, which decouple energy sales revenue and profits from energy savings.

Considerable potential also remains in Portugal's buildings sector. Portugal could tap into some of these savings by encouraging passive-energy houses and zero-energy buildings through benchmarking and objective setting and by supporting labelling and energy-efficient window and glazing demonstration projects.

Portugal should also ensure their energy efficiency policies are supported by adequate indicators by endeavouring to collect end-use data on all energy types, across all sectors.

\section{Portugal's progress with implementing IEA energy efficiency recommendations}

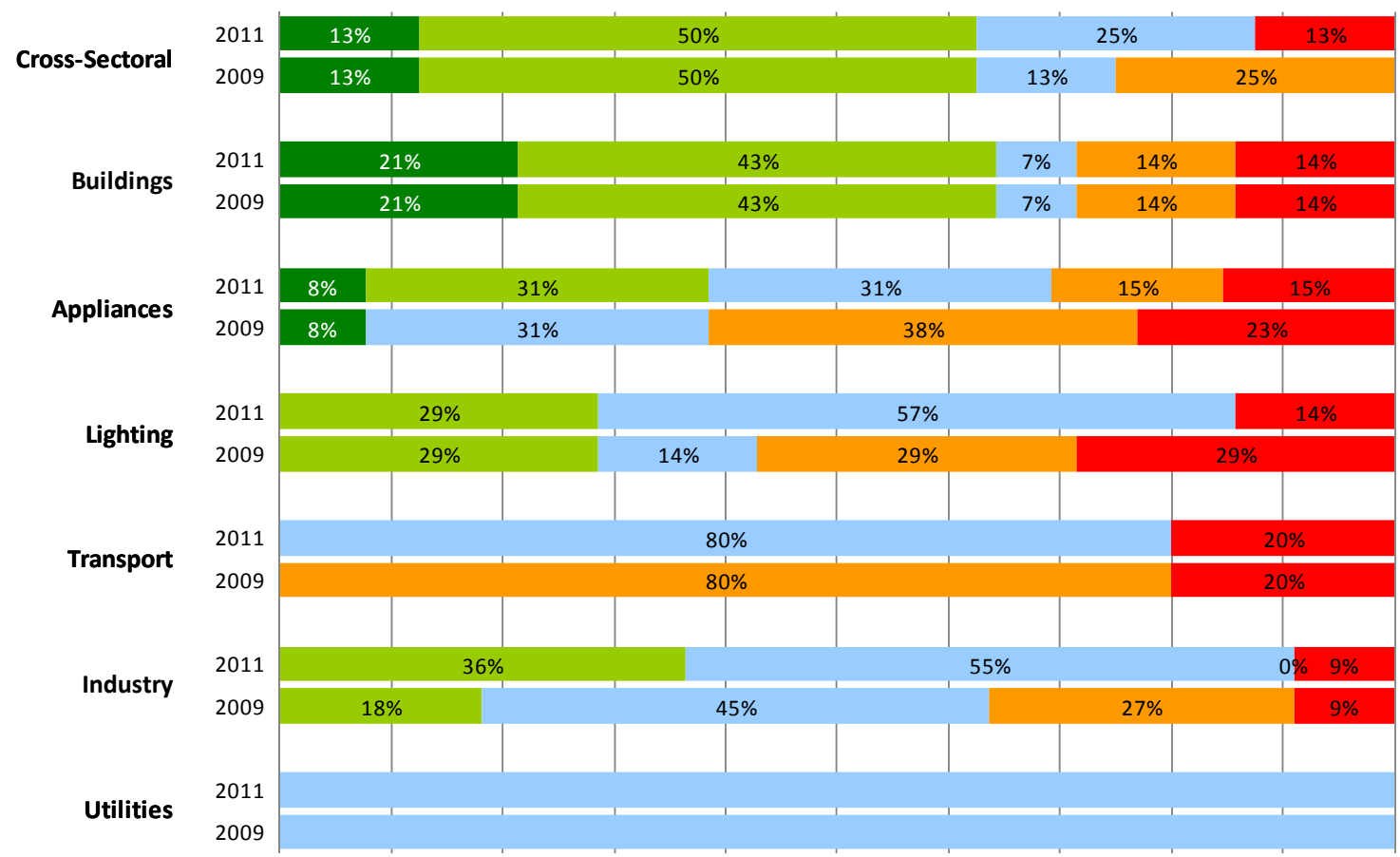

- Full implementation

- Plan to implement
Substantial implementation Implementation underway

- Not implemented 


\section{Energy Efficiency Progress Report - Slovak Republic}

\section{Context}

Of all IEA member countries, the Slovak Republic has experienced the greatest improvement in energy intensity between 1990 and 2009 (decrease of 4.6\% per year). Changes in the economy and energy sector, as well as real efficiency gains in industry, have resulted in a sustained energy intensity improvement despite economic growth. While efforts to develop a strategy for energy conservation began in 1999, more broad and comprehensive energy efficiency objectives were adopted in 2006, and have since continued. The Slovak Republic currently aims to improve energy efficiency by $1 \%$ per year, as laid out in the EU Energy Services Directive. The Slovak NEEAP sets a national energy savings target of $9 \%$ for 2016, with an intermediate target of $3 \%$ in 2010. This will entail achieving an average of $4135 \mathrm{TJ}$ per year of savings in final energy consumption. Since joining the EU in 2004, the Slovak Republic has pursued transposition and implementation of major EU directives covering important energy end-use sectors.

\section{Energy efficiency policy developments since 2009}

Since 2009, the Slovak Republic has substantially enhanced its energy efficiency policies, making sound progress in the cross-sectoral, buildings, appliances, lighting and transport sectors.

Most of this progress has been driven by the implementation of EU directives. Notably, acts were passed that transposed the latest revisions of the Energy Performance of Buildings Directive and the Ecodesign Directive. Policies on Compliance, Monitoring and Enforcement, and the Regular Inspection of Boilers, Heating Systems and Air Conditioning Systems were also passed. This recent implementation was also reflected in the new National Energy Efficiency Action Plan (NEEAP), which spans the years 2011-2013.

Monitoring of energy efficiency has also been improved. The Slovak Innovation and Energy Agency (SIEA) now operates an energy efficiency monitoring system according to Act 476/2008 on Energy Efficiency, which improves the quality of energy efficiency data submitted in the annual template developed by the IEA.

In the appliances sector, the Slovak Republic passed an Act transposing Directive (2010/30/EU), which requires labelling and standard product information on the consumption of energy and other resources by energy-related products. This Act mandates that public procurement in the appliance sector should meet the most stringent energy efficiency requirements available.

To improve energy efficiency financing, SIEA is collaborating with the private sector to establish tools to facilitate energy efficiency investments, such as draft model contracts for energy services and financial instruments aimed at achieving energy savings. Schemes like SLOVSEFF, which is based on a credit line and financial resources from the Bohunice International Decommissioning Support Fund, are used to finance energy efficiency measures. SLOVSEFF is administered by the EBRD through Slovak commercial banks and was originally set up by the EU and multilateral donors to help the Slovak Republic's decommissioning of the Bohunice nuclear power plant. "Energy Efficiency in Public Buildings", a project administered by SIEA, is another example of a project financed by this fund.

In the industrial sector, an EU structural fund supports a system of industrial energy consumption monitoring and control, which includes installation and modernization of energy monitoring and management systems. Energy audits, on a voluntary basis, are planned measures in the 20112013 NEEAP. In addition, SIEA is implementing the energy efficiency information project "Live with Energy". This project is financed through EU Structural Funds and provides information 
support to different stakeholders, including entrepreneurs in SMEs.

\section{Challenges and areas for improvement}

There is room for improvement of the Slovak Republic's energy efficiency policies. Notably, while most energy efficiency related EU directives have been transposed in the Slovak legislation, a sustained implementation effort is needed to realise their full potential.

Moreover, there are many opportunities for energy efficiency policy developments beyond those specified by EU directives. Examples include policies to promote passive-energy houses (PEH), zero-energy buildings (ZEB) and minimum energy efficiency standard for windows. The Slovak Republic should also consider mandating that public procurement in the appliance sector meets the most stringent energy efficiency requirements available. In the transport sector, the Slovak Republic should encourage the EU to implement mandatory fuel efficiency standards for heavyduty vehicles.

To improve energy efficiency in the industrial sector, the Slovak Republic could examine the barriers to the optimisation of energy efficiency in electric motor-driven systems and design and implement comprehensive policy portfolios aimed at overcoming such barriers. Implementing formalised energy management policies at the company level is also critical.

To encourage utilities to deliver energy savings, the Slovak Republic could require energy efficiency measures and energy supply options to compete on a level playing field with energy sales. The Slovak Republic could also place energy efficiency obligations on utilities and establish regulations, which decouple energy sales revenue and profits from energy savings.

Finally, while energy efficiency data collection and monitoring has improved overall since 2009, the data provided on the service and transport sector is still insufficient and incomplete.

\section{The Slovak Republic's progress with implementing IEA energy efficiency recommendations}

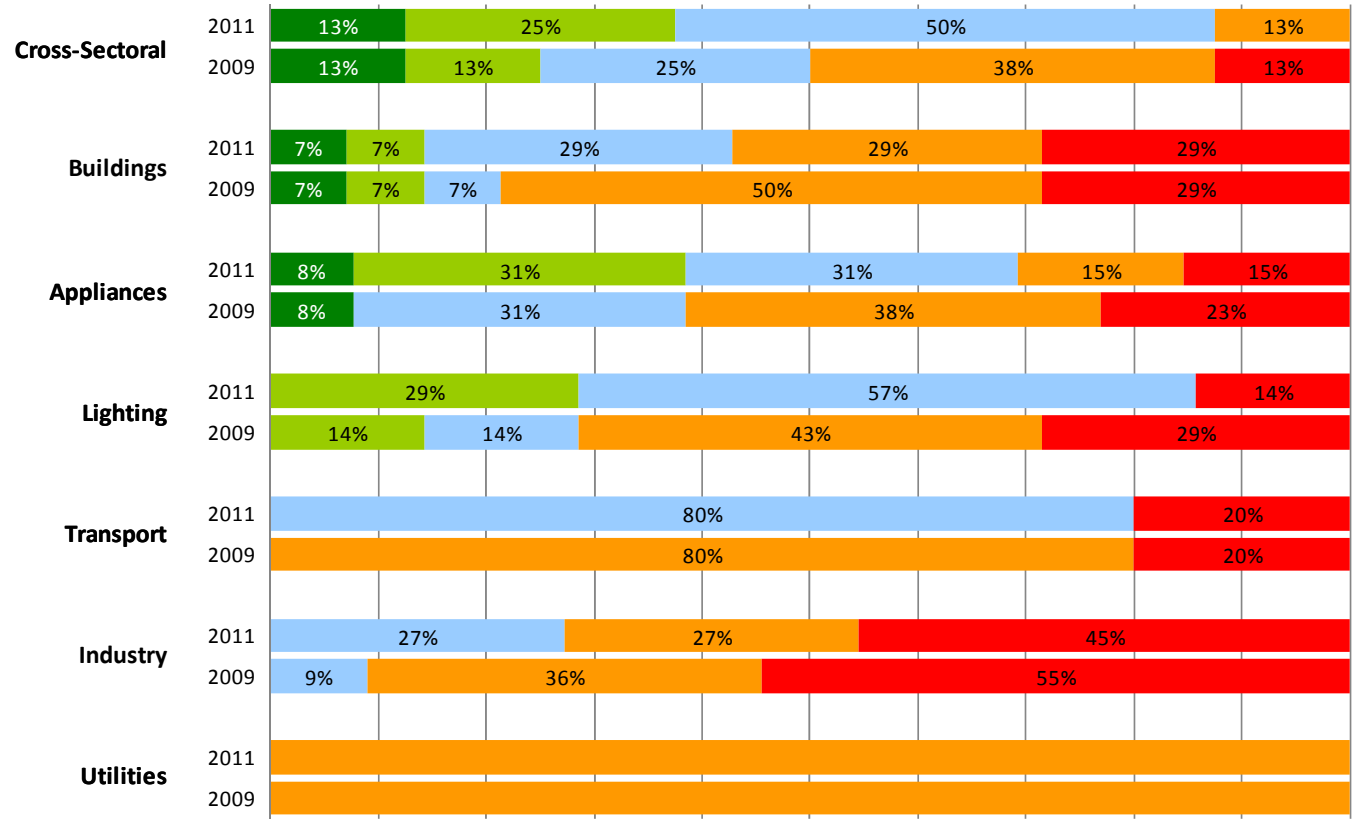

Full implementation Plan to implement
Substantial implementation Implementation underway

not implemented 


\section{Energy Efficiency Progress Report - Spain}

\section{Context}

Spain's energy intensity is slightly below the IEA average. In 2007, for every USD 1000 of Page | 96 GDP (MER), the country needed 0.14 toe of final energy. Energy intensity, adjusted for PPP, has slightly decreased from 1990 to 2009, at around 0.4\% per year. As Spaniards have become wealthier, private car use has grown and so has oil use in road transport, by around $87 \%$, making transport the largest energy user ( $38 \%$ of TFC). Also, electricity use in services and households increased at an above-average rate, and more than doubled in the period.

Spain's energy efficiency policy is laid out in the 2004-2012 Energy Saving and Efficiency Strategy (E4) and the 2008-2012 Action Plan. The goal is to save 16.9 Mtoe of final energy in 2012, equalling an estimated $12.4 \%$ of TFC that year as compared to business-as-usual. Spain has achieved target energy efficiency improvements in all sectors, with a good half of the projected energy savings coming from the transport sector and a quarter from industry.

\section{Energy efficiency policy developments since 2009}

Since the 2009 Evaluation, Spain has made progress in implementing policies related to the 25 energy efficiency recommendations.

In the transport sector, for example, Spain is implementing EU regulations to lower rolling resistance and maintain appropriate tyre inflation pressure through mandatory fitting of TPMS. Spain is also implementing EU regulations, which require average emissions from new passenger vehicles sold in Spain, and other EU member states, to reach the $130 \mathrm{~g} \mathrm{CO}_{2} / \mathrm{km}$ target by 2015 . To promote eco-driving, numerous eco-driving courses are coordinated by the Institute for Diversification and Saving of Energy (IDAE), a state-owned, business entity that reports to the Ministry of Industry, Tourism and Trade through the State Secretary for Energy, regional governments and various industry associations. In addition, the Traffic Department (Ministry of Home Affairs) now requires eco-driving classes for people seeking a licence to operate tourism vehicles.

Regarding the appliances sector, energy performance requirements for numerous products covered under the Ecodesign Directive (2005/32/EC) have entered into force, and the October 2009 Ecodesign Directive recast (2009/125/EC), which includes energy-related products, such as building components, is being transposed.

Spain is also transposing the May 2010 Directive (2010/30/EU) which requires labelling and standard product information on energy consumption by energy-consuming products.

In the buildings sector, Spain is transposing the May 2010 Directive (2010/31/EU). The Royal Decree, to be published in 2011, will require energy performance certificates (EPC) when an existing building or flat is sold (for new buildings the regulation was implemented in 2007). The Ministers Council approved an initiative to certify all tertiary buildings with a thermal capacity of more than $400 \mathrm{~kW}$.

Also in the buildings sector, in December 2009 Spain established a framework for public-private collaboration to support ESCOs. This framework, approved by the Cabinet in July 2010, extends the scope of an earlier plan to provide public financing for energy efficiency improvements in public buildings and street lighting. In March 2011, the Cabinet approved the "Plan of Intensification of Energy Saving and Efficiency", which includes a financial line of EUR 600 million to ESCOs, through the Institute of Official Credit (ICO). IDAE contributes EUR 30 million for insurance. This financing line has overcome a main barrier to ESCOs' project development. 
IDAE has prepared model contracts for public-private collaboration on more efficient lighting and developed pilot projects for the integral reform of municipal street lighting.

In the industrial sector, Spain's Energy Efficiency Action Plan 2008-2012 includes subsidy programmes of up to $30 \%$ of costs for SMEs to improve energy efficiency through equipment renovation and substitution of technical processes. Spain's second NEEAP, submitted to the European Commission at the end of June 2011, also includes such support for SMEs.

\section{Challenges and areas for improvement}

While most energy efficiency-related EU directives have been transposed in the Spanish legislation, a sustained policy implementation effort is needed. Enforcement is particularly important to ensure both the maximisation of energy savings and the credibility of the schemes. Comprehensive legal and physical capacity will be needed to adequately enforce policy measures and maximise their effectiveness.

To improve energy efficiency in the industrial sector, Spain adopted MEPs for certain kinds of motors in July 2009. Also, in its 2008-2012 National Energy Efficiency Action Plan (NEEAP), Spain implemented several initiatives to promote the adoption of more efficient electric-motor driven systems. Spain could further examine barriers to the optimisation of energy efficiency in electric motor-driven systems and implement comprehensive policy portfolios aimed at overcoming such barriers. Other policies to help industrial energy efficiency include implementing formalised energy management policies at the company level.

There are many opportunities for energy efficiency policy developments beyond those specified by EU directives. Examples include policies to promote passive-energy houses (PEH) and zeroenergy buildings (ZEB). In the transport sector, Spain should encourage the EU to put in place mandatory fuel efficiency standards for heavy-duty vehicles.

Spain reports that it will include initiatives to incentivise utilities to deliver cost-effective energy savings to end users in its second National Energy Efficiency Action Plan. The IEA encourages Spain to quickly implement these planned incentives. 


\section{Spain's progress with implementing IEA energy efficiency recommendations}

Page | 98

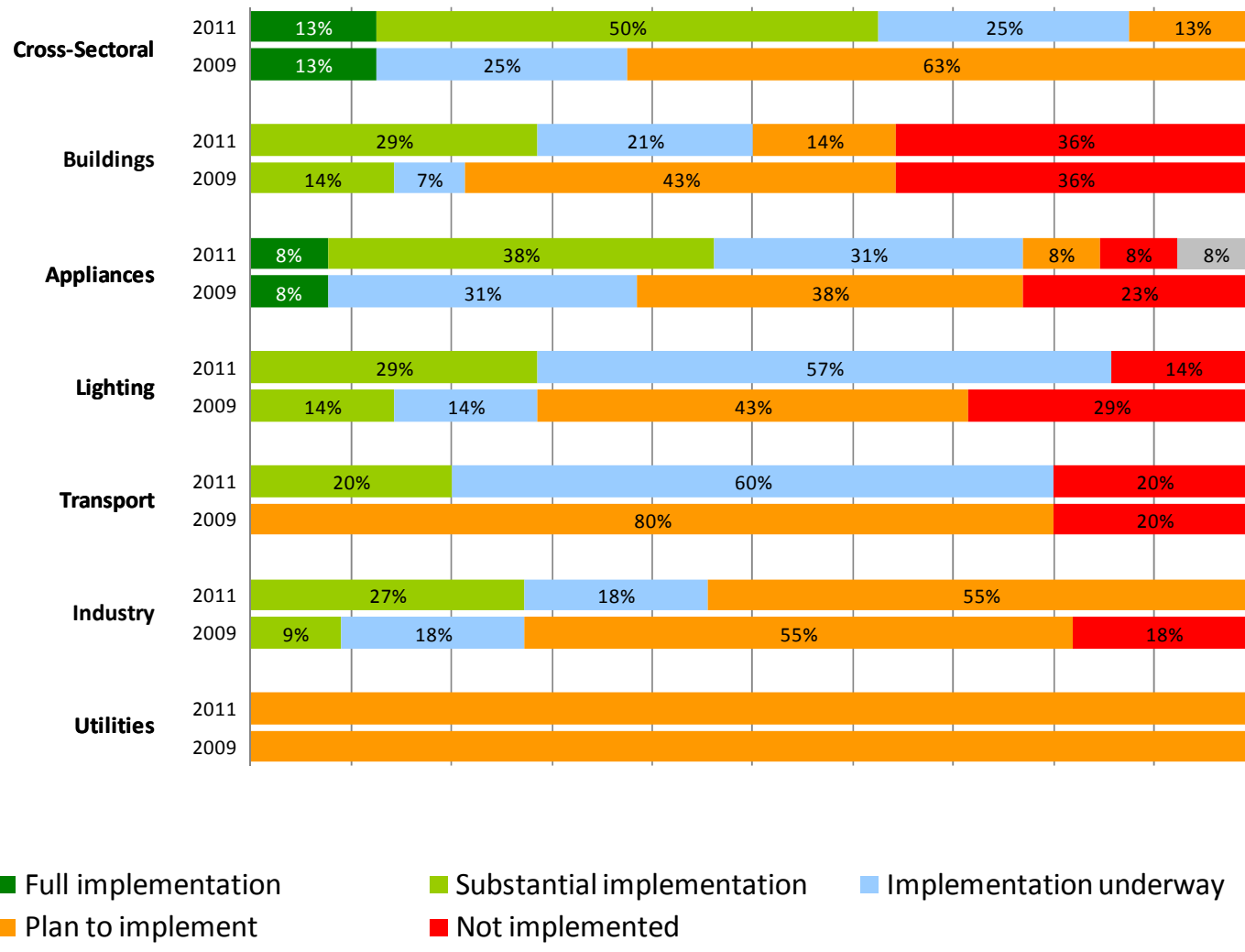

\section{Energy Efficiency Progress Report - Sweden}

\section{Context}

Since the early 1970s, Sweden's TFC has remained remarkably steady, while TPES has grown by a third. This stability results partly from more efficient use of energy and a relatively slow economic growth. But it mostly reflects changes in the structure of energy supply: secondary energy electricity and heat - has replaced on-site use of fuels, mainly oil. Electricity use has almost doubled in the period, and space heating is now dominated by district heating, electric heating and heat pumps. In addition, combined heat and power (CHP) is widely used.

Sweden's energy intensity is roughly equal to the IEA average. In 2007, for every USD 1000 of GDP (in terms of MER), the country needed 0.12 toe of final energy. This is an impressive achievement, given the large heating requirements of a cold climate, and the energy needs of the dominant heavy industries, primarily pulp and paper and iron and steel. Energy Intensity, adjusted for PPP, has improved by $1.8 \%$ per year from 1990 to 2009 , mainly owing to structural changes in the economy - services and light industry are growing faster than the energyintensive sectors - but there are also improvements in energy efficiency.

Following its commitment under the EU Energy Services Directive, Sweden's 2008 NEEAP aims to save $9 \%$ of final energy, from the annual average of 2001 to 2005, to 2016, incorporating a savings target of $32.3 \mathrm{TWh}$. Sweden has achieved target energy efficiency improvements in all sectors outside the EU Emissions Trading Scheme, with most projected energy savings coming from the residential sector. 


\section{Energy efficiency policy developments since 2009}

In keeping with its tradition of highly effective instruments to enhance energy efficiency across sectors, Sweden has made progress in implementing energy efficiency policies measures since the 2009 Evaluation.

In the buildings sector, Sweden has made strides in implementing building energy certificates. An energy certificate is required whenever a building is sold, rented or constructed, or is large and holds public-sector functions. The owner is responsible for providing an energy certificate, which must contain suggestions of how to improve energy efficiency (for further details, see government regulation 2006:1592 and the stipulations by the Swedish National Board of Housing (BFS 2007:4)). Certificates must be visible in public buildings.

Sweden has also implemented policies to increase awareness of efficiency in the buildings sector. For example, the Swedish Energy Agency has implemented (voluntary) policies, which address energy efficiency, in particular networks for procurement of energy-efficient technology.

A model for energy savings in buildings, called Total Project, more than halves the consumption of electricity and heat, while at the same time enabling the property owner to reduce costs. These networks cover various target groups, such as commercial spaces, rental apartments, public sector facilities, etc. The government has also implemented energy-mapping vouchers with government funding support.

Also in the buildings sector, in 2010, Sweden launched the LÅGAN support programme for stimulating the construction of buildings with very low energy use (at least $50 \%$ lower than existing regulations). The programme seeks to foster a broad supply of producers and service providers and to assure demand for their products.

To improve energy efficiency in industry, in January 2010, Sweden implemented a support scheme for energy audits for small and medium-sized enterprises (SMEs) (Government Regulation 2009:1577). Under this scheme, which runs until 2014, SMEs can receive a maximum of EUR 3500 (or $50 \%$ of total costs) for energy audits. .

In the transport sector, an EU cap for fleet average $\mathrm{CO}_{2}$ emissions of $130 \mathrm{~g} / \mathrm{km}$ from new passenger cars will apply in full in Sweden from 2015 onwards. Sweden is one of several IEA member countries with an Eco-drive programme. Driver education programmes and compulsory installation of feedback systems are two ways in which Sweden enforces its vigorous eco-driving programme. A special label for winter tyres is under development, in accordance with Regulation EC 1222/2009.

Regarding the appliances sector, energy performance requirements for numerous products covered under the Ecodesign Directive (2005/32/EC) have entered into force, and the October 2009 Ecodesign Directive recast (2009/125/EC), which includes energy-related products, such as building components, is being transposed.

Sweden is also transposing the May 2010 Directive (2010/30/EU), which requires labelling and standard product information on energy consumption by energy-related products.

Sweden started a programme to support energy efficiency measures in buildings by regional and municipal actors in January 2010. The programme has received applications from 75 municipalities and 9 regional councils. For 2010-2014, the government has allocated SEK 99 million (EUR 10 million) annually to support local and regional projects that include at least two of the measures listed in Annex VI of the EU Energy Efficiency Directive (2006/32/EC). The aim of this support scheme is twofold; first, to allow municipalities and county councils to set a good example for effective energy use and second, to contribute to and adopt goals set by the parliament concerning energy efficiency. 


\section{Challenges and areas for improvement}

There is scope for Sweden to improve its energy efficiency policy portfolio.

Although relatively strict requirements exist for new buildings, Sweden should consider setting national targets to ensure a market share for PEH, ZEB and other ultra low-energy consuming new constructions by 2020. Sweden should consider using such PEH and ZEB as benchmarks for energy efficiency requirements in future updates of building regulations. The Swedish government should also consider setting up a policy package to improve energy efficiency in windows and other glazed areas.

With regard to utilities, Sweden should consider implementing mechanisms that strengthen the incentives for utilities to deliver cost-effective energy savings to end-users. For example, Sweden could establish a regulation, which decouples utility revenue and profits from energy sales and allows energy savings delivery to compete on equal terms with energy sales.

Policies should also be put in place to improve energy efficiency in SMEs. Energy performance benchmarking information, ideally structured to allow international and within economy comparisons, should be provided. Sweden should also consider developing and implementing appropriate incentives to adopt least-life cycle cost capital acquisition and procurement procedures.

\section{Sweden's progress with implementing IEA energy efficiency recommendations}

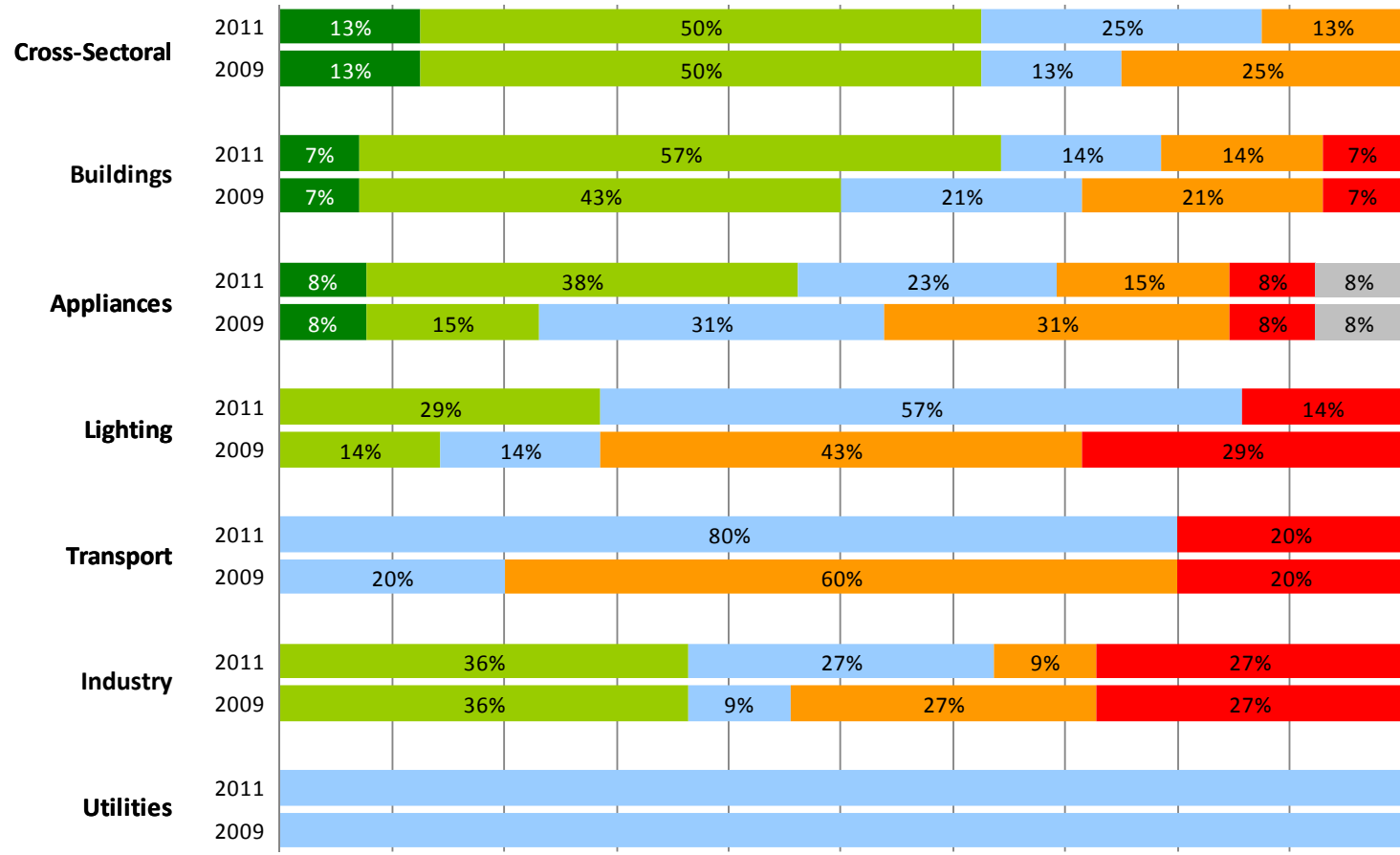

Full implementation - Plan to implement
Substantial implementation Implementation underway

- Not implemented 


\section{Energy Efficiency Progress Report - Switzerland}

\section{Context}

Switzerland has the second lowest energy intensity among IEA member countries (in MER terms). In 2007, for every USD 1000 of GDP, Switzerland used 0.07 toe of final energy. Intensity is low partly because the Swiss economy relies heavily on high value-added services, and heavy industry Page | 101 is scarce. However, energy efficiency has improved.

Switzerland's economic structure and energy consumption patterns have been fairly stable from 1990 to 2009, energy intensity, adjusted for PPP, decreased on average $0.9 \%$ per year.

Switzerland's 2008 Action Plan for Energy Efficiency aims to reduce fossil fuel use by $20 \%$ by 2020 and to cap electricity demand growth at 5\% between 2010 and 2020. The plan includes 15 broad measures, with most projected energy savings coming from the residential and service sectors.

\section{Energy efficiency policy developments since 2009}

Since 2009, Switzerland has significantly improved its energy efficiency policies with substantial progress in the buildings, appliances, transport and industrial sectors.

In the buildings sector, a refurbishment programme was implemented in January 2010, with a first evaluation of its outcome conducted in March 2011. Furthermore, a Regional Certificate on Buildings Energy Use (GEAK) was in place in 2009. This labelling scheme grades the energy consumption of a building on a scale from $A$ to $G$, and helps make energy performance a criterion for real estate transactions.

Switzerland has also passed regulations aligned with the EU directives relative to energy efficiency. Notably, the minimum energy performance requirements for appliances and lighting have been adjusted in line with EU regulations.

In the transport sector, Switzerland is closely following the EU tyre regulation. Switzerland also plans to enact the average $\mathrm{CO}_{2}$ emissions standards for new cars, in line with the latest $\mathrm{EU}$ legislation, as part of its post-2012 revision of the national $\mathrm{CO}_{2}$ Law.

Regarding industry, Switzerland has set minimum energy performance requirements for industrial electric motors, which are also aligned with EU requirements.

\section{Challenges and areas for improvement}

While Switzerland has managed to implement an impressive energy efficiency portfolio, there is still room for improvement. Especially as a number of regulations that have been passed over the past two years still await full enforcement.

Policies in other sectors can also be strengthened. Private sector financial support for energy efficiency should be further encouraged, by promoting instruments that reduce uncertainty and quantify the benefits of energy efficiency investments.

In the buildings sector, objectives for passive-energy houses (PEH) and zero-energy buildings (ZEB) market share by 2020 should be set. With regard to appliances, mandatory minimum energy performance requirements should be set for network-connected devices. Appliances used in the public sector and government-sponsored agencies should also meet the most stringent energy efficiency requirements available.

In the transport sector, mandatory fuel efficiency standards for heavy-duty vehicles should be implemented. 


\section{Switzerland's progress with implementing IEA energy efficiency recommendations}

Cross-Sectoral

2011
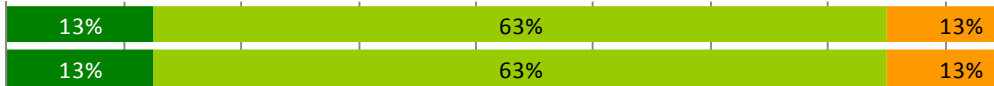

$63 \%$

$13 \%$

$13 \%$

Buildings

2011

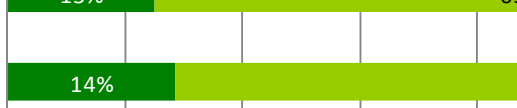

Appliances

\begin{tabular}{|l|l|l|}
\hline $14 \%$ & $57 \%$ \\
\hline
\end{tabular}

Appliances

\begin{tabular}{|l|l|l|}
2011 & $31 \%$ & $23 \%$
\end{tabular}

$23 \% \quad 23 \%$

Lighting

2009

\begin{tabular}{|l|l|l|l|}
\hline $15 \%$ & $31 \%$ & $31 \%$ \\
\hline
\end{tabular}

\begin{tabular}{|l|l|l|l|}
2011 & $14 \%$ & $29 \%$ & $29 \%$ \\
\hline
\end{tabular}

2009

\begin{tabular}{|l|l|l|l|l|}
\hline $14 \%$ & $29 \%$ & $29 \%$ \\
\hline & & & & \\
\hline
\end{tabular}

Transport

2011

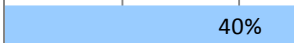

$40 \% \quad 40 \%$

$\%$

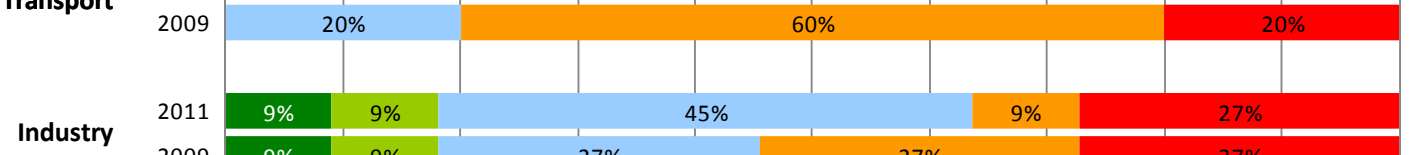

Industry

Utilities

2009

$9 \% \quad 9 \%$

$27 \%$

2011

2009

Full implementation

- Plan to implement
Substantial implementation $\square$ Implementation underway

- Not implemented

\section{Energy Efficiency Progress Report - Turkey}

\section{Context}

As in the previous progress report, Turkey's energy intensity, adjusted for PPP, comes close to the IEA average.

Turkey's energy intensity has remained relatively stable over the past decades. Energy intensity has been reduced by a faster growth in services than in the more energy-intensive industry, but this reduction has been offset by expanding energy use linked to the increasing wealth of the country's young, growing and urbanising population. This resulted in an average decrease of energy intensity adjusted for PPP of 0.3\% per year from 1990 to 2009.

Turkey's 2007 Energy Efficiency Law guides its energy efficiency policy and the subsequent bylaws. These, in turn, meet the 2004 Energy Efficiency Strategy's goal of harmonising Turkey's energy efficiency legislation with that of the European Union. An update of the Energy Efficiency Strategy has been drafted.

\section{Energy efficiency policy developments since 2009}

Turkey has made some progress in implementing energy efficiency policies since the 2009 Evaluation. In the industrial sector, for example, between 2009 and 2010, Turkey trained and certified 1525 energy managers. The total number of certified energy managers in Turkey 
reached more than 4200 in mid-2011. It also hosted the 9th international energy manager course in June 2010. Measures and voluntary agreements, begun in 2009, to encourage energy efficiency in industrial establishments were continuing in 2010.

Turkey is attempting to improve methods to ensure both voluntary and mandatory energy efficiency policies are adequately monitored, enforced and evaluated. For example, a new Division of Monitoring and Evaluation was established in the General Directorate of Electrical Power Resources Survey Administration (EIE) at the end of 2010. A new project is planned for 2011 to establish a comprehensive monitoring and evaluation system and infrastructure.

Turkey has made a positive step towards implementing future energy efficiency policies by drafting the Energy Efficiency Strategy Paper, which includes indicative sectoral targets. This paper includes some amendments suggested by the Energy Efficiency Coordination Board (EECB), public and private bodies and institutions. it was recently conveyed to the prime minister's office via the Ministry of Energy and Natural Resources (MENR), for formal approval by the High Planning Council (YPK).

\section{Challenges and areas for improvement}

Turkey should continue to take advantage of proved practices in other countries to improve energy efficiency.

The transport sector is an area where urgent attention is needed. Turkey should set ambitious fuel-economy standards for vehicles and regulate non-motor components that affect vehicle energy efficiency (e.g. tyre rolling resistance and tyre pressure). Taxation should be used to favour the purchase of more efficient vehicles.

Energy saving potential still untapped in the buildings sector is a matter for Turkish policy makers to look at in the long term. Energy labelling of buildings is a recent positive development, but more policy developments are needed to implement energy performance requirements in building codes in new buildings; there is also a need for systematic and rigorous collection of energy efficiency information on existing buildings and on barriers to energy efficiency.

The role of energy utilities to deliver energy savings should not be underestimated in Turkey planned measures to allow energy efficiency measures to be bid into energy pools on an equal basis to energy supply options should be implemented, or other relevant policy measures should be considered.

On a horizontal level, Turkey should scale up energy efficiency financing mechanisms and invest in technical capacity building. For example, Turkey should consider encouraging financial institutions to train their staff and develop evaluation criteria and financial tools for energy efficiency projects. It should review current subsidies and fiscal incentive programmes to encourage private energy efficiency investments and collaborate with the private financial sector to establish public-private tools to facilitate energy efficiency financing. It should also examine possibilities to promote risk mitigation instruments, such as securitisation or public-private partnerships and implement institutional frameworks to ensure regular co-operation and exchanges on energy efficiency issues between the public sector and financial institutions. 


\section{Turkey's progress with implementing IEA energy efficiency recommendations}

Cross-Sectoral

2011

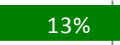

$13 \%$

$50 \%$

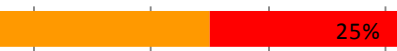

Buildings

Appliances

2011

$13 \%$ $13 \%$

Appliances

8011 \begin{tabular}{l|l|l}
\hline $14 \%$ & $14 \%$ & \\
\hline $14 \%$ & $7 \%$ & $71 \%$
\end{tabular}

20

Transport

2011

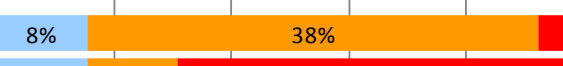

$8 \% \quad 8 \%$

2011

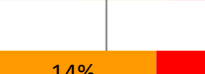

(1)

$2009 \quad 14 \%$

2011

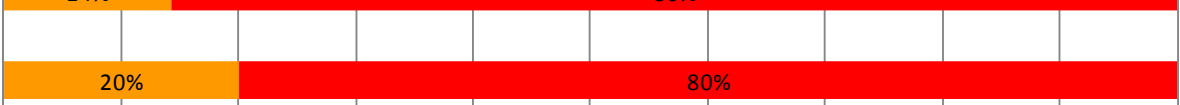

Industry

2011

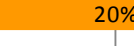

2009

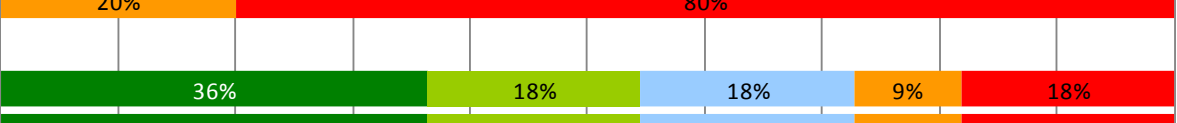

Utilities

2011

2009

Full implementation

- Plan to implement
Substantial implementation $\square$ Implementation underway

not implemented

\section{Energy Efficiency Progress Report - United Kingdom}

\section{Context}

Total final energy consumption in the United Kingdom rose considerably less than in OECD countries as a whole between 1973 and 2004 . The role of energy efficiency in climate change mitigation policies has been emphasised particularly since 2004 when the United Kingdom's first Energy Efficiency Action Plan was adopted. Between 1990 and 2009, the United Kingdom achieved 2.3\% improvement in annual energy intensity, adjusted for PPP. The decrease in energy intensity was largely due to structural changes, with end-use efficiency improvements of around $0.8 \%$ per year.

\section{Energy efficiency policy developments since 2009}

Many of the strengths of the United Kingdom's energy efficiency policy portfolio were highlighted in the 2009 Evaluation. For example, in the buildings sector, the UK implemented measures to strengthen building codes based on a zero-carbon approach, set objectives for passive-energy houses, constructed a package of initiatives to address market barriers, made information available to all actors in the buildings sector, and included lighting energy limits in the building codes.

Since the 2009 Evaluation, the United Kingdom has made further progress in the buildings sector. The Energy performance certificates (EPCS) scheme is now fully rolled out and includes an A-G 
rating for building performance, recommendations for cost-effective action to improve building efficiency and links to sources of advice.

Furthermore, UK building regulations were revised and strengthened in 2010. Additional revisions will follow in 2013 and 2016 so that by 2016, all new-residential buildings will adhere to a zero-carbon standard. There are plans for these requirements to extend to non-residential buildings by 2019 .

In the area of appliances and equipment, substantial progress has been made in the United Kingdom with regard to enforcement of minimum energy performance requirements. A strengthened monitoring and enforcement regime has also been implemented. The United Kingdom recently established the National Measurement Office as the central market surveillance authority.

In common with other EU member states, a major component of UK policy entails transposition and implementation of the Ecodesign Directive. The standby $1 \mathrm{~W}$ limit applies to products covered under this Directive since January 2010.

There has been progress in implementing energy efficiency policies in the lighting sector with $71 \%$ of the IEA lighting policy recommendations substantially implemented. The UK Department for International Development, both through its own programmes and working with the development banks, is supporting action to phase out fuel-based lighting. One example is the Lighting Africa Programme.

Policies to promote action in the business and industrial sectors include the UK CRC Energy Efficiency Scheme (previously known as the Carbon Reduction Commitment), which is a new, mandatory, energy saving and carbon emissions reduction. Qualifying organisations (i.e. large public and private sector organisations that use more than 6000 megawatt hour (MWh) per annum of half hourly metered electricity - around 5000 organisations across the United Kingdom) were required to register between 1 April and 30 September 2010.

The UK Carbon Trust has produced a series of energy benchmarking tools, including for the industrial buildings sector. These encourage implementation of comprehensive energy management procedures and practices and provide a comprehensive package of energy and carbon management advice and information for business and the public sector.

To improve the delivery of energy efficiency by energy utilities, the United Kingdom established the carbon emissions reduction target (CERT), a statutory obligation on all domestic energy suppliers in England, Scotland and Wales with a customer base in excess of 50000 . CERT is the third cycle of the UK's household energy supplier obligation. In June 2010, it was announced that a restructured carbon emissions reduction target would be extended to December 2012, with a higher target and a focus on improving building insulation (rather than installing CFLs). The UK government is currently exploring options for the successor to CERT, to run from 2013.

To improve energy efficiency in the transport sector, the United Kingdom is implementing EU regulations to lower rolling resistance, maintain appropriate tyre inflation pressure through mandatory fitting of TPMS and require average emissions from new passenger vehicles sold in the UK, and other EU member states, to reach the $130 \mathrm{~g} \mathrm{CO}_{2} / \mathrm{km}$ target by 2015 . Moreover, the UK introduced eco-driving as part of driving license tests in 2008.

As with all EU countries, the EU emissions trading scheme puts a price on carbon in the industrial and power sectors and continues to help drive energy efficiency in these areas. 


\section{Challenges and areas for improvement}

There remains room for improvement in the United Kingdom's energy efficiency policy. The European Commission's proposal for the mandatory fitting of tyre pressure monitoring systems should be extended to heavy-duty vehicles. The United Kingdom should also encourage the European Union to develop mandatory fuel efficiency standards for heavy-duty vehicles.

Policies promoting the financing of energy efficiency, particularly from private sector, could also be improved. The UK government plans to create a Green Investment Bank to deliver financial interventions to deal with market failures specific to green investment, thereby stimulating growth while supporting environmental objectives. It is intended that the Green Investment Bank will be privately financed. The UK government is currently still considering and market testing options and it expects the Bank to be operational in late 2012. Also in 2012, the UK government plans to implement the "Green Deal". This initiative seeks to enable private firms to offer consumers energy efficiency improvements at no upfront cost, and to recoup payments through a charge in instalments on the energy bill.

In the industrial sector, although EU member states adopted MEPs for certain kinds of motors in July 2009 as part of the 2009 European Commission Regulation No 640/2009, the United Kingdom should also examine barriers to the optimisation of energy efficiency in electric motor-driven systems and then implement comprehensive policy portfolios aimed at overcoming such barriers.

\section{The UK's progress with implementing IEA energy efficiency recommendations}

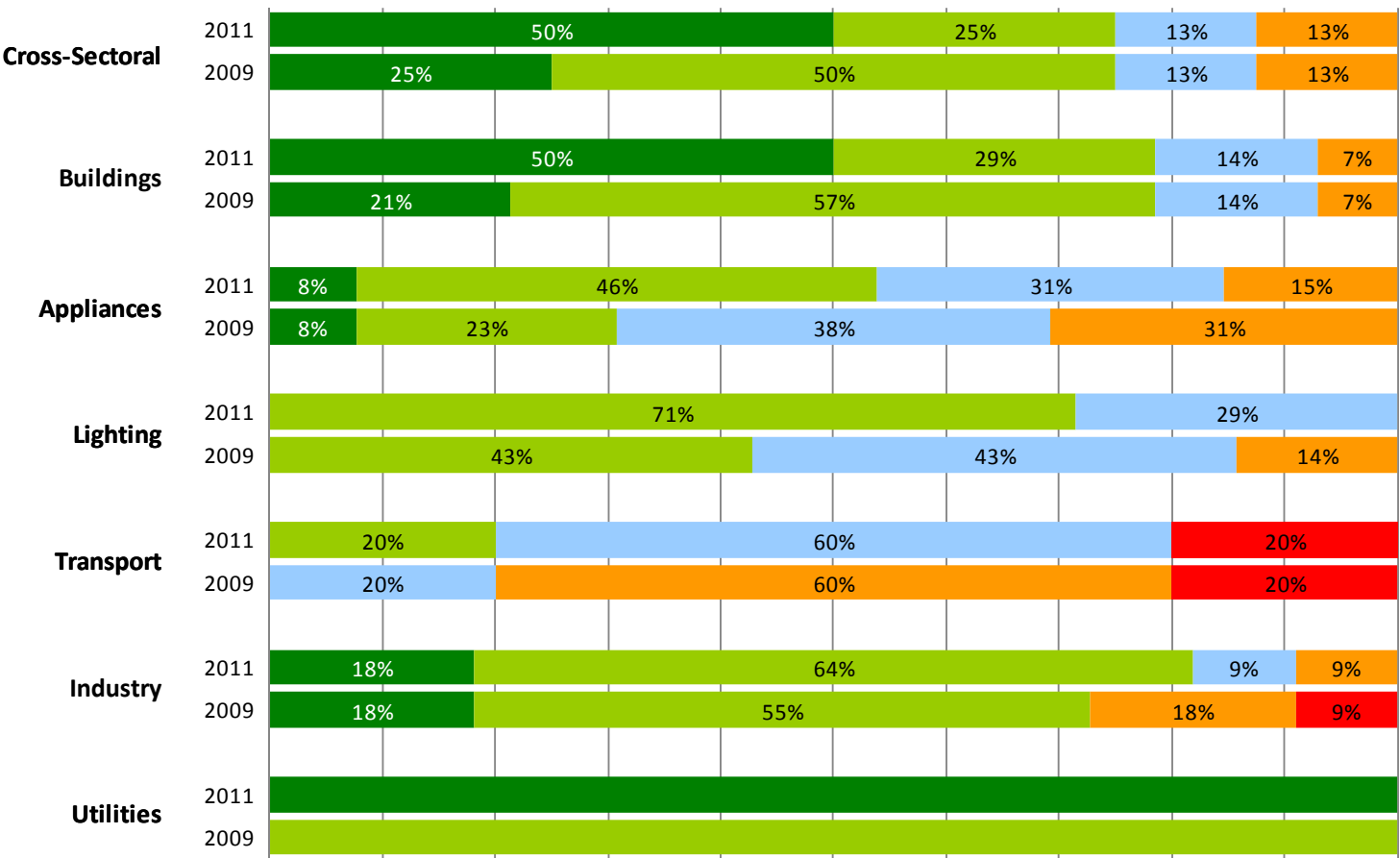

Full implementation

- Plan to implement
Substantial implementation Implementation underway

- Not implemented 


\section{Energy Efficiency Progress Report - United States}

\section{Context}

Energy efficiency has been a feature of US energy policy since the 1970s. Viewed originally as a way to reduce dependence on foreign oil, energy efficiency measures have led to significant improvements in US energy intensity and are now seen as one cost-effective way to mitigate GHG emissions. Between 1990 and 2009, energy intensity declined on average by $1.6 \%$ per year, adjusted for PPP (Figure 32). Most of the decline was due to energy efficiency improvements (Figure 34).

The 2009 economic stimulus package included new energy efficiency initiatives and substantial additional funding for existing programmes. The direct and indirect funding for these programmes totalled more than USD 30 billion, five times greater than 2008 funding levels.

\section{Energy efficiency policy developments since 2009}

The United States has made significant progress with implementing energy efficiency policies since 2009 and is a leader in facilitating private sector energy efficiency investments. Over the past 20 years, the United States has supported private sector adoption of several common measurement and verification (M\&V) protocols. Recently, the Superior Energy Performance initiative began developing and testing an improved M\&V protocol. In parallel, new methods for measuring and verifying energy savings are being developed that take advantage of new measuring devices and statistical methods.

Resources to improve energy-product certification, compliance and enforcement have increased over the last two years.

New requirements for third-party testing have been implemented and verification for products with the ENERGY STAR labels is underway. The US Department of Energy (US DOE) now has its own product test facility and is in the process of constructing an even larger facility. To ensure full compliance with its product standards and ENERGY STAR labelling requirements, US DOE has initiated dozens of compliance actions.

In the appliance sector, MEPs for over forty types of appliances and equipment and voluntary ENERGY STAR labelling guidelines for around fifty products have been established. Over the past two years, US DOE expanded the coverage and updated the stringency of MEPs for a number of major energy using products and has allocated budget resources to further accelerate these efforts.

Through the Solar and LED Energy Access Program (SLED), a Clean Energy Ministerial initiative, the US supports a large-scale effort that targets the approximately 1.6 billion people who lack access to grid electricity. By addressing fundamental barriers to market development, SLED aims to transform the global market for affordable, clean and quality-assured off-grid appliances. The programme will initially focus on replacing fossil fuel-based light sources, like kerosene lanterns, with solar LED lights. The programme is expected to improve lighting services for 10 million people within five years.

In the transport sector, the United States proposed new energy efficiency labelling requirements for tyres in 2009. In addition, manufacturers are now required to meet an estimated combined mpg)-rating of 34.1 for light-duty vehicles by MY2016. In fall 2011, government agencies proposed light-duty vehicle fuel economy standards for the years beyond 2016.

To promote energy efficiency in the industrial sector, US DOE has established MEPs for small and 
medium-sized electric motors in line with international best practice. Updated MEPs for medium-sized electric motors came into effect in December 2010.

The US Government is developing and implementing mechanisms that strengthen the incentives for utilities to deliver cost-effective energy savings to end-users. Twenty-four states, representing over $50 \%$ of the US population and energy demand, have placed energy efficiency resource obligations on their regulated utilities.

\section{Challenges and areas for improvement}

Despite its many achievements, there is scope for the United States to improve its energy efficiency policy portfolio. In the buildings sector, energy certification schemes should be mandatory for all types of buildings. The government should also ensure that information on energy-efficient windows is easily available.

The United States recognises that improvements to fuel-efficiency standards are needed. Following the release of the National Academy of Sciences report evaluating fuel economy standards for medium- and heavy-duty trucks in March 2010, the Obama administration directed agencies to create a national policy for fuel efficiency that reduces oil dependence and decreases GHG emissions from trucks for model years 2014-2018.

The IEA encourages the US government to promote driver education programmes to improve eco-driving practices in all states. Currently seventeen states have implemented driver education programmes to improve eco-driving practices.

To promote energy efficiency in SMEs, the US sponsors industrial assessment centers (IACs) that provide free energy assessments. The US should further improve assistance by developing and implementing incentives for SMEs to adopt least-life cycle cost capital acquisition and procurement procedures.

\section{The United States' progress with implementing IEA energy efficiency recommendations}

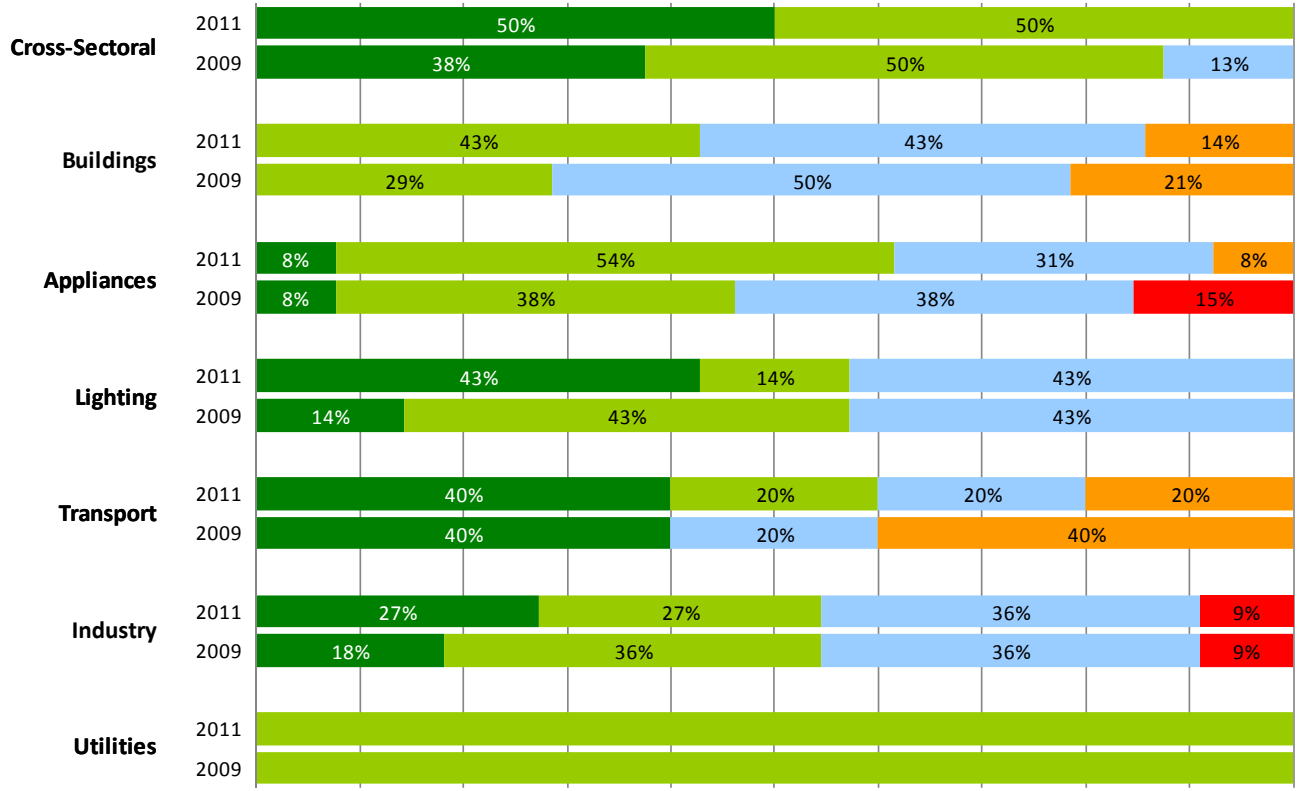

- Full implementation

- Plan to implement
Substantial implementation Implementation underway - Not implemented 


\section{Acronyms, abbreviations and units of measure}

BAFA Federal Office of Economics and Export Control

BfEE Federal Office for Energy Efficiency

BMU Federal Ministry for the Environment, Nature Conservation and Nuclear Safety

BMWi Federal Ministry of Economics and Technology

CAD Canadian dollar

CAFE corporate average fuel economy

CERT carbon emissions reduction target

CHP combined heat and power

$\mathrm{CO}_{2} \quad$ carbon dioxide

CRC carbon reduction commitment

DCCEE Department of Climate Change and Energy Efficiency

COAG Council of Australian Governments

DECC Japan's Database for Energy Consumption of Commercial buildings

dena German Energy Agency

DIHK Association of German Chambers of Industry and Commerce

DTAs digital television adaptors

EBRD European Bank for Reconstruction and Development

EC European Commission

EDL-G Act on Energy Services and Energy Efficiency Measures

EEA European Economic Area

EECA Energy Efficiency and Conservation Authority

EECB Energy Efficiency Coordination Board

EEO Act Energy Efficiency Opportunities Act

EER energy efficiency ratio

EEX energy efficiency exchange

EIE General Directorate of Electrical Power Resources Survey Administration

EJ Exajoules

ELV extra low voltage

EM energy management

EMS energy management system

EMDS electric motor-driven systems

ENEA National Agency for New Technologies, Energy and Sustainable Economic Development 
EPBD Energy Performance of Buildings Directive

EPC energy performance certificate

ERDF European Regional Development Fund

ESCOs energy service companies

ESD EU Directive on energy end-use efficiency and energy services

ETS emissions trading scheme

EU European Union

EUR euro

GDP gross domestic product

GEAK regional Certificate on Buildings Energy Use

GHG greenhouse gas

GSEP Global Superior Energy Performance

Gt gigatonnes

GW gigawatt

GWh gigawatt hour

GWh/y gigawatt hour per year

G gram

GSI Gear-shift indicator

GSEP global superior energy performance

HERS Home energy rating schemes

HVAC Heating, ventilation, and air-conditioning

IACS industrial assessment centers

ICO Institute of Official Credit

IDEA Institute for Diversification and Saving of Energy

IEA International Energy Agency

IPEEC Partnership for Energy Efficiency and Cooperation

ISO International Organization for Standardization

JECC Japan's Database for Energy Consumption of Commercial buildings

JICA Japanese International Cooperation Agency

$\mathrm{Km} \quad$ kilometre

$\mathrm{Km} / \mathrm{L} \quad$ kilometres per litre

kW kilowatt

kWh kilowatt hour

KEMCO Korea Energy Management Corporation

L litre 


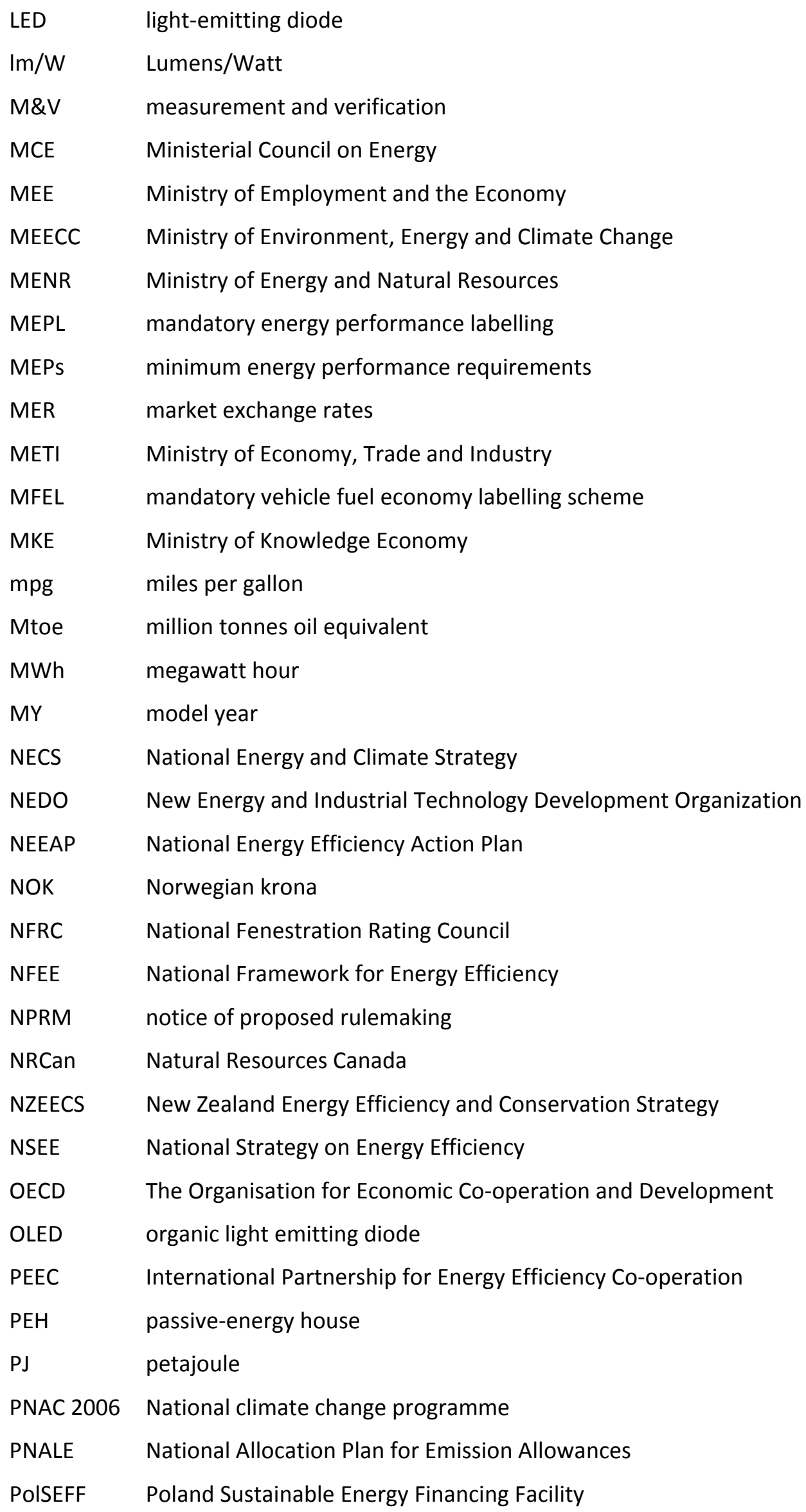


PPP purchasing power parity

RSECE Regulation on energy systems and air handling in buildings

RCCTE Regulation on thermal behaviour characteristics in buildings

Page | 112 SEAI Sustainable Energy Authority of Ireland

SEAD super-efficient equipment and appliance deployment

SEK Swedish krona

SGCIE Management System of Intensive Energy Consumption

SIEA The Slovak Innovation and Energy Agency

SLED solar and LED Energy Access Program

SLOVSEFF Slovak sustainable energy financing facility

SME small and medium-sized enterprise

STB set-top box

toe tonnes of oil equivalent

TFC total final consumption

TJ terajoule

TPES total primary energy supply

TPMS tyre-pressure monitoring systems

TV television

TVSP television service provider

TWh terawatt hour

UK United Kingdom

UNECE United Nations Economic Commission for Europe

UNFCCC United Nations Framework Convention on Climate Change

USD US dollar

US DOE United States Department of Energy

US United States

W Watt

$\mathrm{W} / \mathrm{m}^{2} \quad$ Watts per square metre

YPK. Turkish High Planning Council

ZEB zero-energy building 


\section{References}

EC (European Commission) (2008), Synthesis of the complete assessments of all 27 National Energy Efficiency Action Plans as required by Directive 2006/32/EC on energy end-use efficiency and energy services: Moving forward together on saving energy, Brussels.

IEA (International Energy Agency) (2006), Light's Labour's Lost, OECD/IEA, Paris.

IEA (2007a), Energy use in the new millennium - trends in IEA countries, OECD/IEA, Paris.

IEA (2007b), Mind the Gap: Quantifying Principal-Agent Problems in Energy Efficiency, OECD/IEA, Paris.

IEA (2008a), Worldwide trends in energy use and efficiency - key insights from IEA indicator analysis, OECD/IEA, Paris.

IEA (2008b), Promoting energy efficiency investments - case studies and the residential sector, OECD/IEA and Agence Francaise de Development, Paris.

IEA (2008c), Energy efficiency policy recommendations prepared by the IEA for the G8 under the Gleneagles Plan of Action, OECD/IEA, Paris.

IEA (2008d), Energy technology perspectives - scenarios and strategies to 2050, OECD/IEA, Paris.

IEA (2009a), Worldwide Implementation Now - Boosting the economy with energy efficiency financing. A background paper, IEA, Paris.

IEA (2009b), Innovations in national energy efficiency strategies and action plans - a working paper, The International Energy Agency, in association with the European Commission and the European Energy Network, Paris.

IEA (2009c), GADGETS and GIGAWATTS: policies for energy efficient electronics, OECD/IEA, Paris.

IEA (2010), Energy Efficiency Governance, OECD/IEA, Paris.

IEA (2011), Energy-Efficiency Policy Opportunities for Electric Motor-Driven Systems, OECD/IEA, Paris. 


\section{Annex 1: Consolidated list of IEA 25 energy efficiency policy recommendations}

\section{Cross-sectoral Policies to Support Energy Efficiency}

\subsection{Increased Investment in Energy Efficiency}

a) Governments should facilitate the private sector's involvement in energy efficiency investments by:

i) Adopting, and publicising to the private sector, a common energy efficiency savings verification and measurement protocol, to reduce existing uncertainties in quantifying the benefits of energy efficiency investments and stimulate increased private sector involvement;

ii) Encouraging financial institutions to train their staff and develop evaluation criteria and financial tools for energy efficiency projects;

iii) Reviewing their current subsidies and fiscal incentive programmes to create more favourable grounds for private energy efficiency investments;

iv)Collaborating with the private financial sector to establish public-private tools to facilitate energy efficiency financing;

v) Promoting risk mitigation instruments, such as securitisation or public-private partnerships; and

vi) Implementing institutional frameworks to ensure regular co-operation and exchanges on energy efficiency issues between the public sector and financial institutions.

\subsection{National Energy Efficiency Strategies and Energy Efficiency Goals}

a) Governments should set goals and formulate action plans for improving energy efficiency in each sector of their domestic economies, utilising ongoing IEA works for developing sectoral energy efficiency benchmarks and compiling best practices;

i) Best practice action plans should:

I. Assess energy consumption by end-use in all sectors;

II. Identify the economy's energy savings potentials; and

III. Establish objectives and adequate methods for evaluating the success of the plan.

b) Energy efficiency policy agencies should be adequately resourced.

\subsection{Compliance Monitoring, Enforcement and Evaluation}

a) Governments should ensure that both voluntary and mandatory energy efficiency policies are adequately monitored, enforced and evaluated so as to ensure maximum compliance. At a minimum, this should include:

i) Considering and planning for optimal compliance, monitoring and evaluation procedures at the time new policies and measures are formulated;

ii) Establishing legal and institutional infrastructure for ensuring compliance with energy efficiency requirements; 
iii) Ensuring transparent and fair procedures for assessing compliance; including specification of the methods, frequency and scope of monitoring activities;

iv) Ensuring regular and public reporting of monitoring activities, including instances of non-compliance;

v) Establishing and implementing a suite of enforcement actions commensurate with the scale of non-compliance and the value of lost energy savings; and

vi) Establishing and implementing a robust system for evaluating policy and programme success during and after implementation.

\subsection{Indicators}

a) Governments should ensure that their energy efficiency policies are supported by adequate end-use information by substantially increasing their efforts to collect energy end-use data across all sectors and relating to all energy-types.

i) This will require governments to increase the resources allocated to energy end-use data collection.

ii) At a minimum, governments should ensure that they are able to complete and submit the annual energy efficiency data template developed by the IEA in co-operation with other organisations.

1.5 Monitoring and Reporting Progress with IEA Energy Efficiency Recommendations

a) Governments should agree to track progress in implementing each of the concrete recommendations and to provide the IEA with regular updates.

\section{Energy-efficient Buildings}

\subsection{Building Codes for New Buildings}

a)

i) Governments that do not currently have mandatory energy efficiency standards for new buildings in building codes should urgently set, enforce and regularly update such standards.

ii) Those governments that currently have mandatory energy efficiency standards for new buildings should significantly strengthen those standards.

b) Energy efficiency standards for new buildings should be set by national or state governments and should aim to minimise total costs over a 30-year lifetime.

\subsection{Passive Energy Houses and Zero Energy Buildings}

a) Governments should support and encourage the construction of buildings with very low or no net energy consumption (passive-energy houses and zero-energy buildings) and ensure that these buildings are commonly available in the market.

b) Governments should set objectives for PEH and ZEB market share of all new construction by 2020.

c) Passive Energy Houses or Zero Energy Buildings should be used as benchmark for energy efficiency standards in future updates of building regulations.

\subsection{Existing Buildings}

a) Governments should systematically collect information on energy efficiency in existing buildings and on barriers to energy efficiency. 
b) Standardised indicators should also be calculated for energy efficiency in buildings for international comparison, monitoring and selection of best practices.

c) Based on this information, governments should construct a package of initiatives to address the most important barriers to energy efficiency in buildings.

i) This package should set standards to ensure that energy efficiency improvements are achieved during the refurbishment of all buildings; and

ii) Also, the package should increase awareness of efficiency in the buildings sector and raise the market profile of a building's energy performance.

\subsection{Building Certification}

a) Governments should take actions to make building energy efficiency more visible and to provide information on major energy-saving opportunities. This should include:

i) Mandatory energy certification schemes that ensure that buyers and tenants of buildings receive information on the energy efficiency of buildings and major opportunities for energy savings; and

ii) Structures that ensure that energy efficiency information is available to all actors in the buildings sector at all times.

\subsection{Windows and other Glazed Areas}

a) Governments should set up a policy package to improve energy efficiency in windows and other glazed areas. This policy package should include:

i) Minimum energy efficiency standards for windows and other glazing that are based on least-lifetime costs;

ii) A requirement for window and glazed-product manufacturers to provide energy efficiency labelling for their products; and

iii) Governments establishing demonstration projects for efficient windows and implementing energy-efficient window procurement policies.

\section{Energy-efficient Appliances}

\subsection{Mandatory Energy Performance Requirements or Labels}

a) Governments should adopt mandatory energy performance requirements and, where appropriate, comparative energy labels across the spectrum of appliances and equipment at a level consistent with international best practices.

b) Adequate resources should be allocated to ensure that stringency is maintained and that the requirements are effectively enforced.

\subsection{Low-power Modes for Electronic Equipment}

a) Governments should adopt the same "horizontal" 1-Watt limit and apply it to all products covered by an International Electrotechnical Commission definition of standby power with limited exceptions.

b) Governments should adopt policies, which require electronic devices to enter low-power modes automatically after a reasonable period when not being used.

c) Governments should ensure that network-connected electronic devices minimise energy consumption, with a priority placed on the establishment of industry-wide protocols for power management. 
i) In order to enhance energy efficiency across electronic networks, governments should:

I. Instruct relevant public and private standards authorities to ensure that industry-wide protocols are developed to support power management in appliances and equipment, including networked devices; and

II. Ensure such protocols are developed and implemented.

\subsection{Televisions, Television "set-top" Boxes and Digital Television Adaptors (DTAs)}

a) The IEA concludes that international best practice with respect to energy-efficient set-top boxes includes policies that establish a minimum efficiency standard for Digital Television Adaptors. These regulations should:

i) Specify the maximum power levels while "on" and "off"; and

ii) Ensure that the consumer can easily switch the unit to the lower power level.

b) A second aspect of best practice is to ensure that government-subsidised units meet higher efficiency requirements.

c) Governments should implement energy efficiency policy measures for TVs and set-top boxes designed to:

i) Promote the best performing current TV products and technologies;

ii) Stimulate the market entry of new television technologies, which aim to halve TV energy consumption compared to current performance levels; and

iii) Minimise the energy used by TVSP customers in receiving TV services by ensuring that such requirements are included in relevant franchise or licensing agreements that allow TVSPs to operate.

\subsection{Test Standards and Measurement Protocols}

a) Governments should:

i) Review energy measurement standards currently used, to determine whether they are consistent with national policy requirements; and

ii) Support the development and use of international measurement standards, where appropriate, in order to assist performance comparison and benchmarking for traded products while also reducing compliance costs.

\section{Best Practice in Energy-efficient Lighting}

\subsection{Best Practice and Incandescent Phase-out}

a) The IEA recommends that governments endorse the objective of across-the-board best practice in lighting.

b) Governments should move to phase out the most inefficient incandescent bulbs as soon as commercially and economically viable.

i) In aiming for this objective, appropriate timescales and performance targets must be established; and

ii) Government and industry actions must be coordinated internationally to ensure a sufficient supply of good quality higher efficiency alternative lamps.

4.2 Non-residential Buildings and Phase-out of Inefficient Fuel-based Lighting 
a) Governments should implement a portfolio of measures to ensure energy-efficient least-cost lighting is attained in non-residential buildings. The portfolio of measures should include the following:

i) Energy performance requirements for lighting systems within building codes and ordinances applicable to the installation of lighting in the commercial, public, industrial, outdoor and residential sectors. These requirements should:

I. Include targeted measures to stimulate better control of lighting and the avoidance of illumination of unoccupied spaces;

II. Specify that general service lighting systems in new non-residential buildings, or substantial retrofits of existing non-residential buildings, should draw no more than $10 \mathrm{~W}$ of power per square metre of internal floor area when averaged over the whole building;

III. Be based upon a review of recommended lighting levels, including a full peer review comparing local recommendations with those applied internationally to ensure that there are no excessive lighting levels recommended in national guidelines; and

IV. Hasten the phase-out of inefficient street lighting technologies such as mercury vapour lamps.

b) Governments should support international efforts to stimulate the adoption of higher efficiency alternatives to fuel-based lighting in off-grid communities e.g. via supporting the diffusion of solar powered solid-state lighting devices.

\section{Energy-efficient Transport}

5.1 Fuel-efficient Tyres

a) Governments should:

i) Adopt new international test procedures for measuring the rolling resistance of tyres, with a view to establishing labelling, and possibly maximum rolling resistance limits where appropriate, for road-vehicle tyres; and

ii) Adopt measures to promote proper inflation levels of tyres.

I. This should include governments, acting in cooperation with international organisations including the United Nations Economic Commission for Europe (UNECE), making the fitting of tyre-pressure monitoring systems on new road vehicles mandatory.

5.2 Mandatory Fuel Efficiency Standards for Light-duty Vehicles

a) Governments should:

i) Introduce new mandatory fuel efficiency standards for light-duty vehicles if they do not already exist, or, where they do exist, make those standards more stringent;

ii) Announce the more stringent content of the proposed standards as soon as possible; and

iii) Harmonise, where appropriate, as many aspects of the future standards as possible.

5.3 Mandatory Fuel Efficiency Standards for Heavy-duty Vehicles

a) For heavy-duty vehicles, governments should introduce: 
i) Fuel efficiency standards; and

ii) Related policies including labelling and financial incentives based on the vehicle's fuel efficiency.

\subsection{Eco-driving}

a) Governments should ensure that eco-driving is a central component of government initiatives to improve energy efficiency and reduce $\mathrm{CO}_{2}$ emissions.

i) Governments support for eco-driving should include promotion of driver training and deployment of in-car feedback instruments.

\section{Energy-efficient Industry}

\subsection{High-quality Energy Efficiency Data for Industry}

a) Governments should support the IEA energy efficiency indicator work that underpins critical policy analysis by ensuring that accurate energy intensity time series data for industrial sectors is reported regularly to the IEA.

\subsection{Minimum Energy Performance Standards for Motors}

a) Governments should consider adopting mandatory minimum energy performance standards for electric motors in line with international best practice.

b) Governments should examine barriers to the optimisation of energy efficiency in electric motor-driven systems and design and implement comprehensive policy portfolios aimed at overcoming such barriers.

\subsection{Energy Management}

a) Governments should consider providing effective assistance in the development of energy management (EM) capability through the development and maintenance of EM tools, training, certification and quality assurance.

b) In addition, governments should encourage or require major industrial energy users to implement comprehensive energy management procedures and practices that could include:

i) The development and adoption of a formal energy management policy:

I. Progress with implementation of this policy should be reported to and overseen at company board level and reported in the company report.

II. Within this policy companies would need to demonstrate that effective organisational structures have been implemented to ensure that decisions regarding the procurement of energy-using equipment are taken with full knowledge of the equipment's expected life-cycle costs and that procurement managers have an effective incentive to minimise the life-cycle costs of their acquisitions.

ii) The appointment of full-time qualified energy managers at both the enterprise and plant-specific level as appropriate; and

iii) The establishment of a scheme to monitor, evaluate and report industrial energy consumption and efficiency at the individual company, sector and national level.

I. As a part of this effort, appropriate energy performance benchmarks should be developed, monitored and reported at levels deemed suitable in each sector. 
a) Governments should consider developing and implementing a package of policies and measures to promote energy efficiency in small and medium-sized enterprises (SMEs). This package should include:

i) A system for ensuring that energy audits, carried out by qualified engineers, are widely promoted and easily accessible for all SMEs;

ii) The provision of high quality and relevant information on energy efficiency best practice;

iii) The provision of energy performance benchmarking information, which ideally would be structured to allow international and within economy comparisons; and

iv) Appropriate incentives to adopt least life-cycle cost capital acquisition and procurement procedures.

\section{Energy Utilities and Energy Efficiency}

a) Governments and utility regulators should consider implementing mechanisms that strengthen the incentives for utilities to deliver cost-effective energy savings to end-users such as:

i) Establishing regulation, which decouples utility revenue and profits from energy sales and allows energy savings delivery to compete on equal terms with energy sales; or

ii) Placing energy efficiency obligations on energy utilities, the stringency of which is periodically assessed based on continuing cost effectiveness in delivering energy services, and where;

I. Such obligations may be tradable and structured such that utility costs are recoverable through the rates;

II. The obligations are designed to be consistent with any corresponding mandatory or voluntary $\mathrm{CO}_{2}$ emissions target imposed on utilities; or

iii) Allowing energy efficiency measures to be bid into energy pools, on an equal basis to energy supply options; or

iv) Other appropriate policy measures that encourage utilities to play an active part in funding and/or delivering end-use efficiency improvements among their customer base. 


\section{Annex 2: Comparing recent implementation}

This Annex provides a brief overview of the status of IEA member country implementation of the 25 energy efficiency policy recommendations. It should be used to assist member countries to compare their policy implementation with countries of similar energy economies.

The recommendations were developed as a menu of options to address policy gaps and priorities. The recommendations do not cover all ongoing energy efficiency activities. Rather, they focus on priority energy efficiency policies identified by IEA analysis. While IEA analysis, the energy efficiency professional literature and engagement with experts clearly demonstrates the broad benefits of these IEA priority measures, the recommendations are not weighted to reflect the different energy end-use make-up of different economies. It is therefore the IEA's position that countries should implement a package of the recommendations that is relevant to their energy economy.

Figure 35 Implementation of the IEA 25 energy efficiency policy recommendations, all IEA member countries

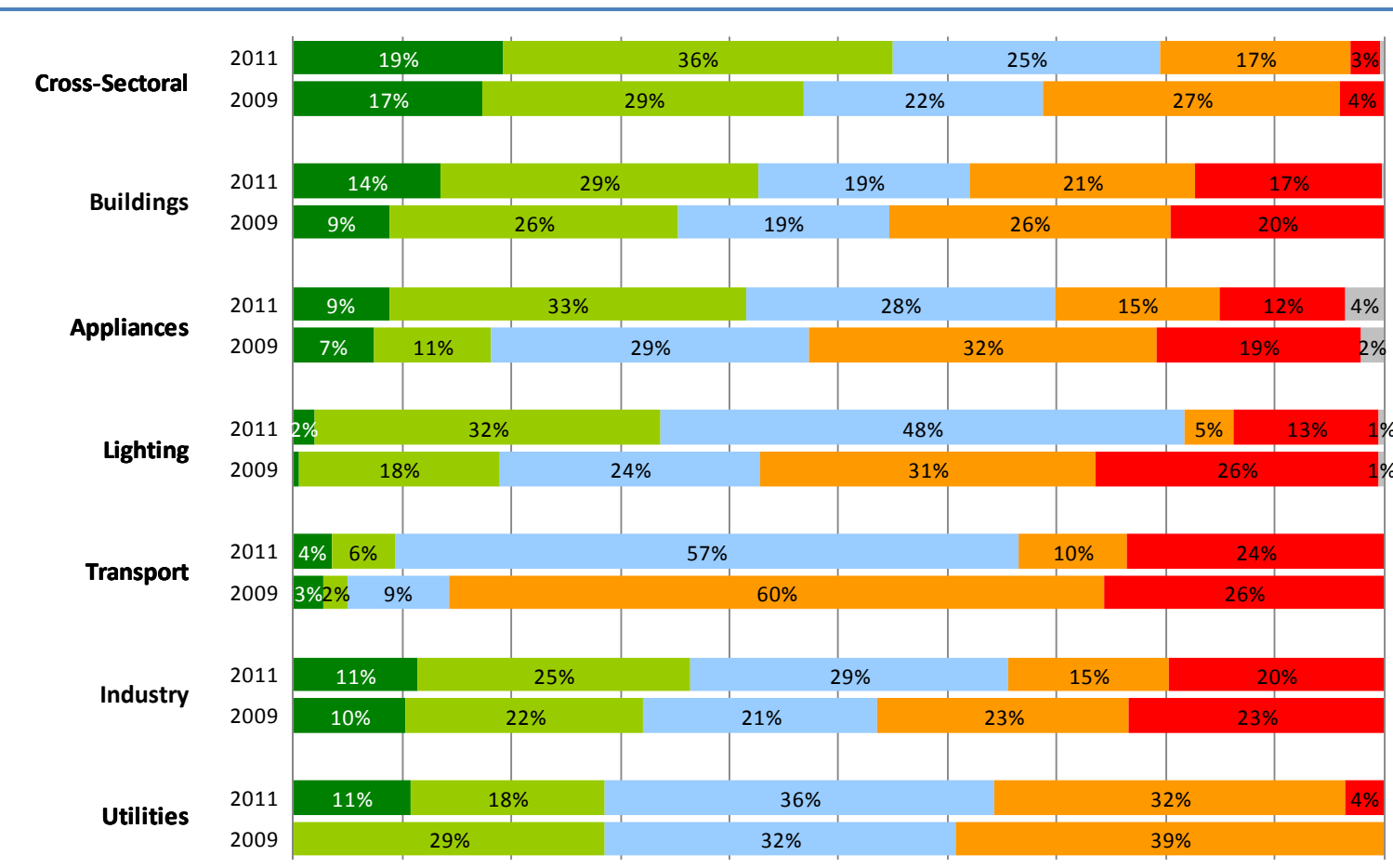

- Full implementation

Plan to implement
Substantial implementation $\square$ Implementation underway

not implemented

From (Figure 35) it is clear that energy efficiency policy developments have been made in all sectors since the 2009 Evaluation. There has been significant progress in the transport sector, although clearly more policy implementation is still needed. There has also been significant progress in the appliance and lighting sectors.

In 2009, a high percentage of recommendations were 'planned'. The 2011 Evaluation revealed many of these planned policies had been implemented. 
Figure 362009 Implementation of applicable IEA recommendations ${ }^{11}$, country comparison

Page | 122

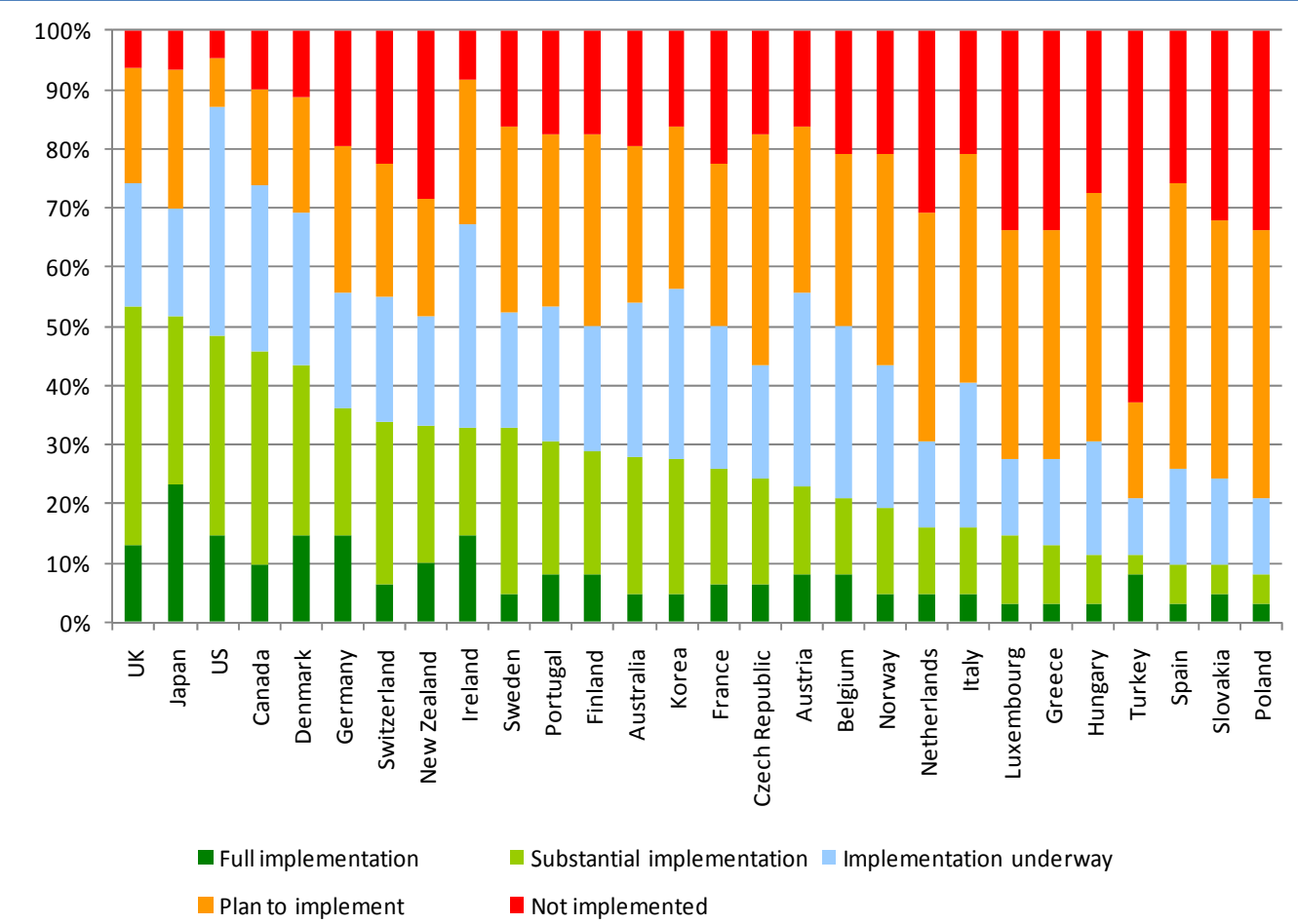

Figure 372011 Implementation of applicable IEA recommendations ${ }^{12}$, country comparison

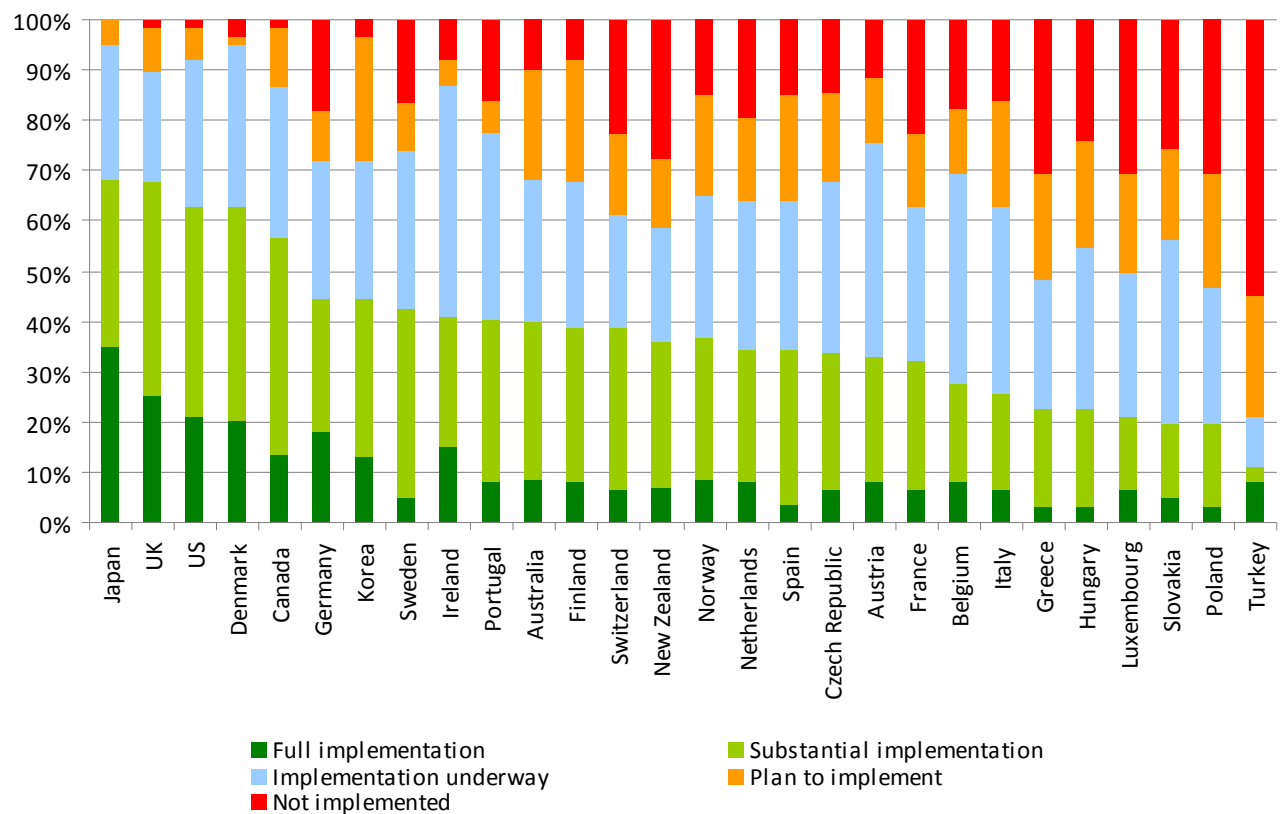

The following graphs compare member country implementation of the IEA 25 energy efficiency policy recommendations as of 15 April 2011.

An analysis of progress with implementing cross-sectoral recommendations reveals a group of

\footnotetext{
${ }^{11}$ That is, proportion of all recommendations minus "not-relevant" recommendations.

${ }^{12}$ That is, proportion of all recommendations minus "not-relevant" recommendations.
} 
countries that are at some stage of implementing all cross-sectoral recommendations (Australia, Canada, Denmark, Japan, Korea, New Zealand and the United States) (Figure 38).

For buildings, Denmark, Germany, Switzerland and the United Kingdom stand out as leaders with respect to implementation of energy efficiency policies (Figure 39). In contrast, more than $60 \%$ of the building recommendations were not implemented in Australia, Greece, Hungary, Poland and Turkey.

The appliance sector has seen many policy developments since the 2009 Evaluation (Figure 40). Most IEA member countries are implementing $65 \%$ or more of the appliance recommendations. New Zealand, Norway, Switzerland, Luxembourg and Turkey stand out as needing more policy developments in this sector. The IEA encourages all countries to consider extending, improving and implementing planned energy efficiency policies.

Progress has been made in implementing lighting policies. Switzerland and Turkey, in particular, should consider further policies to improve the efficiency of lighting (Figure 41).

In 2009, a significant portion of the recommended actions were only planned in the transport sector. According to 2011 results, most IEA member countries are implementing over $85 \%$ of the transport recommendations (Figure 42). Australia, New Zealand, Norway, Switzerland and Turkey stand out as needing further urgent policy developments in this sector.

Implementation of policies to improve industry energy efficiency is varied across IEA member countries (Figure 43). Canada, Japan, Korea and the United Kingdom have implemented over $70 \%$ of the IEA recommendations for this sector, whereas Greece, Hungary, Luxembourg, Poland and the Slovak Republic have implemented fewer than $30 \%$.

If the right institutional framework and enabling conditions are established, energy utilities can play an important role in delivering energy efficiency (Figure 44). Three countries, namely Denmark, Italy and the United Kingdom have fully implemented, and another five have substantially implemented, mechanisms to strengthen incentives for utilities to deliver energy savings. There are still many opportunities for policy development, as almost a third of member countries have either not implemented or are not planning to implement the IEA or similar recommendations in this sector. 

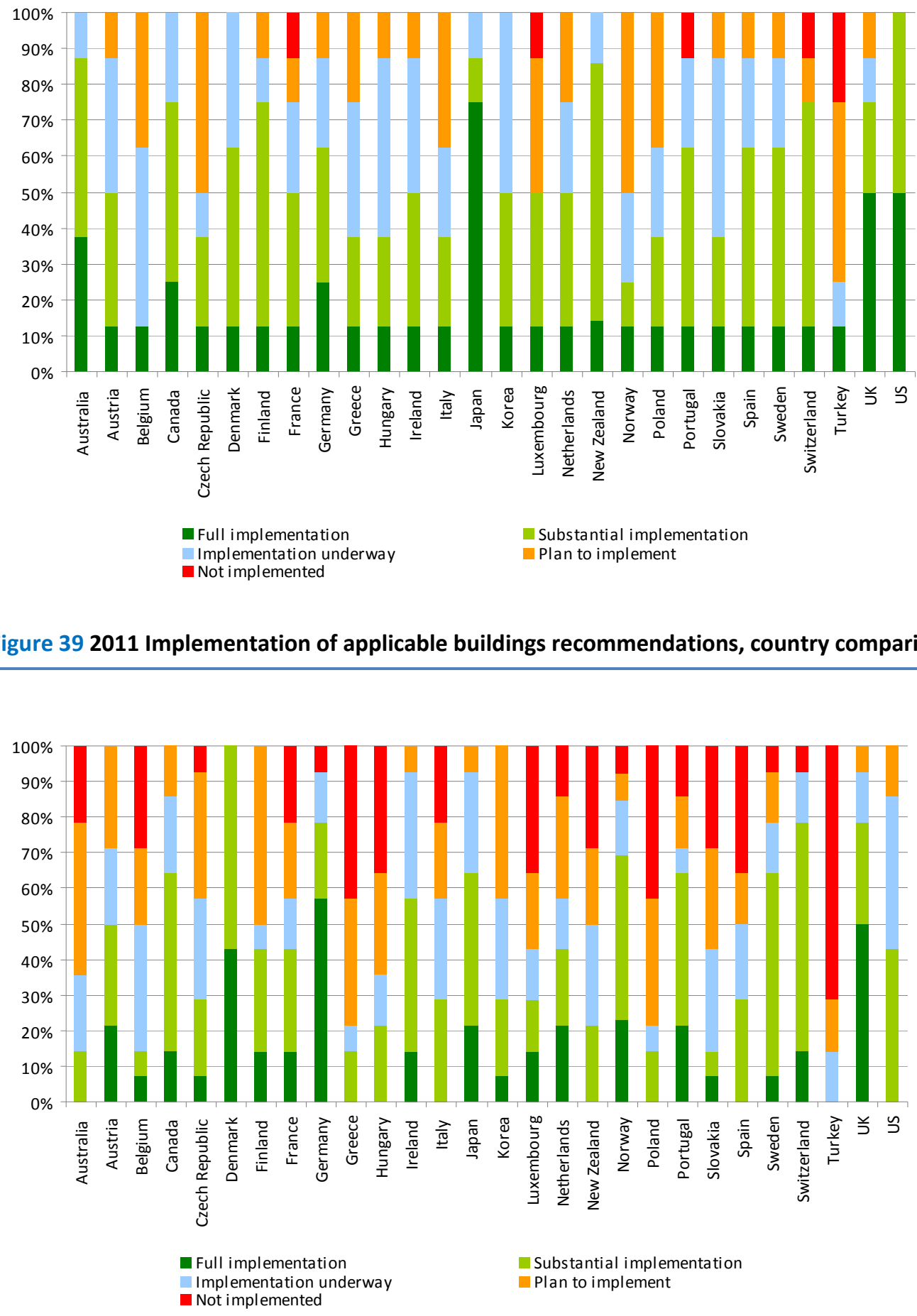

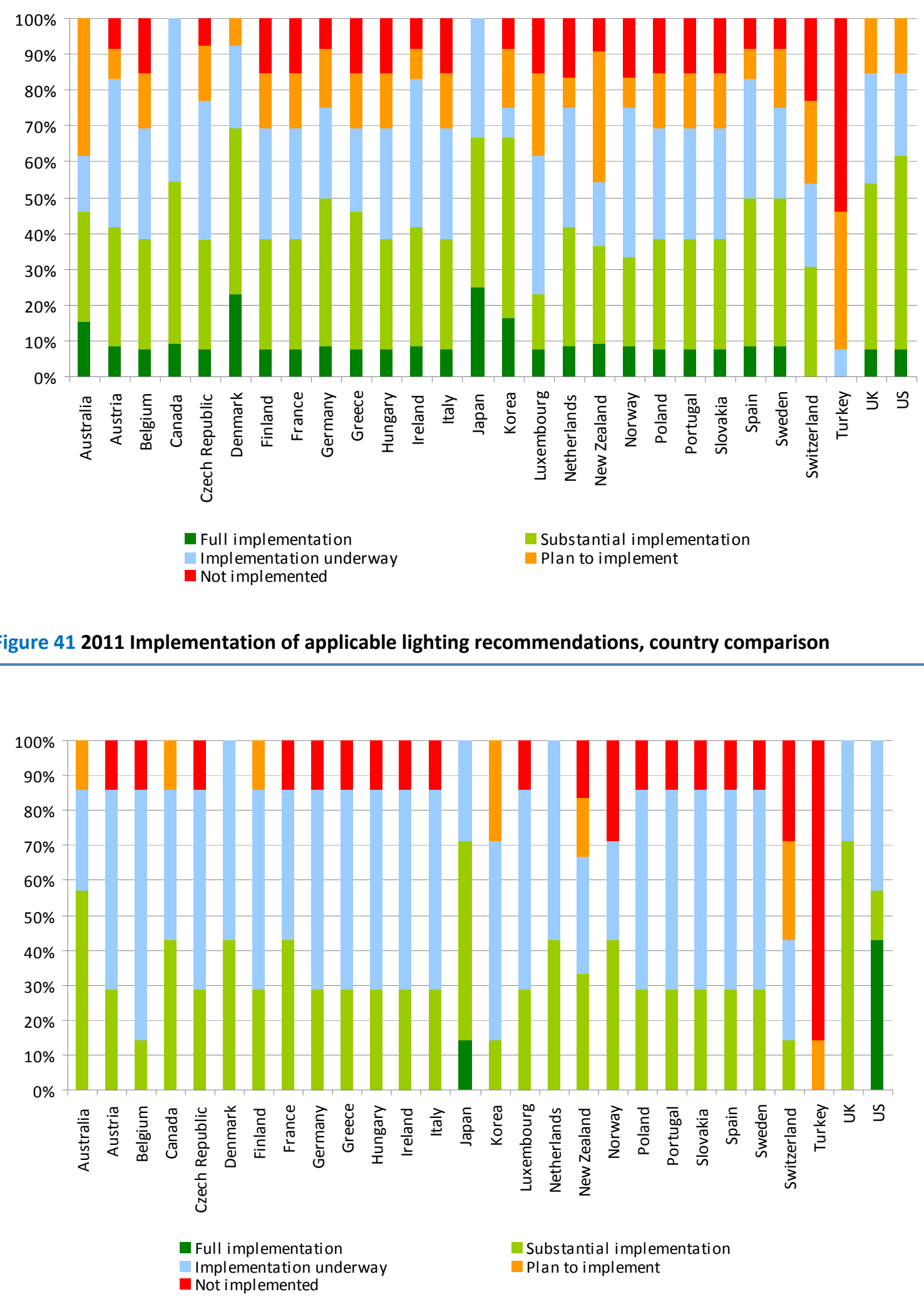


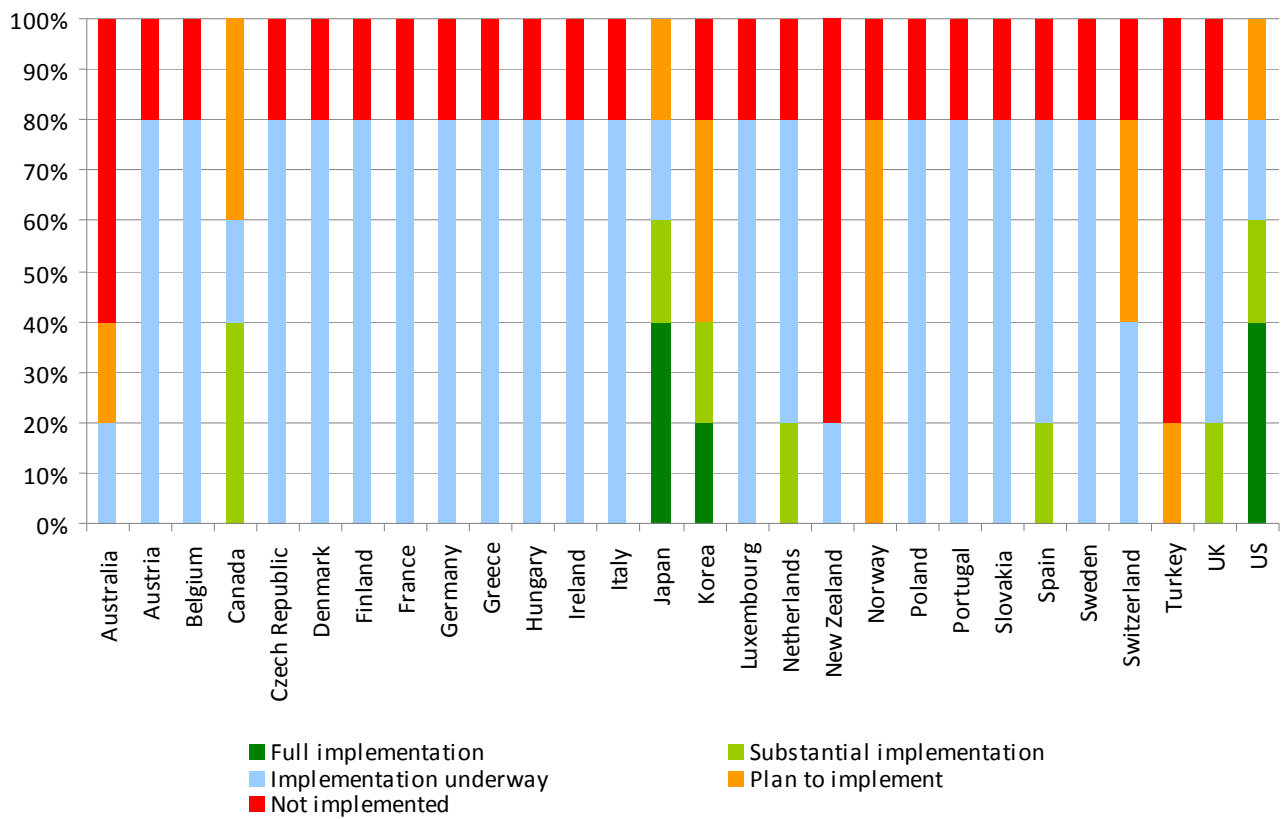

Figure 432011 Implementation of applicable industry recommendations, country comparison

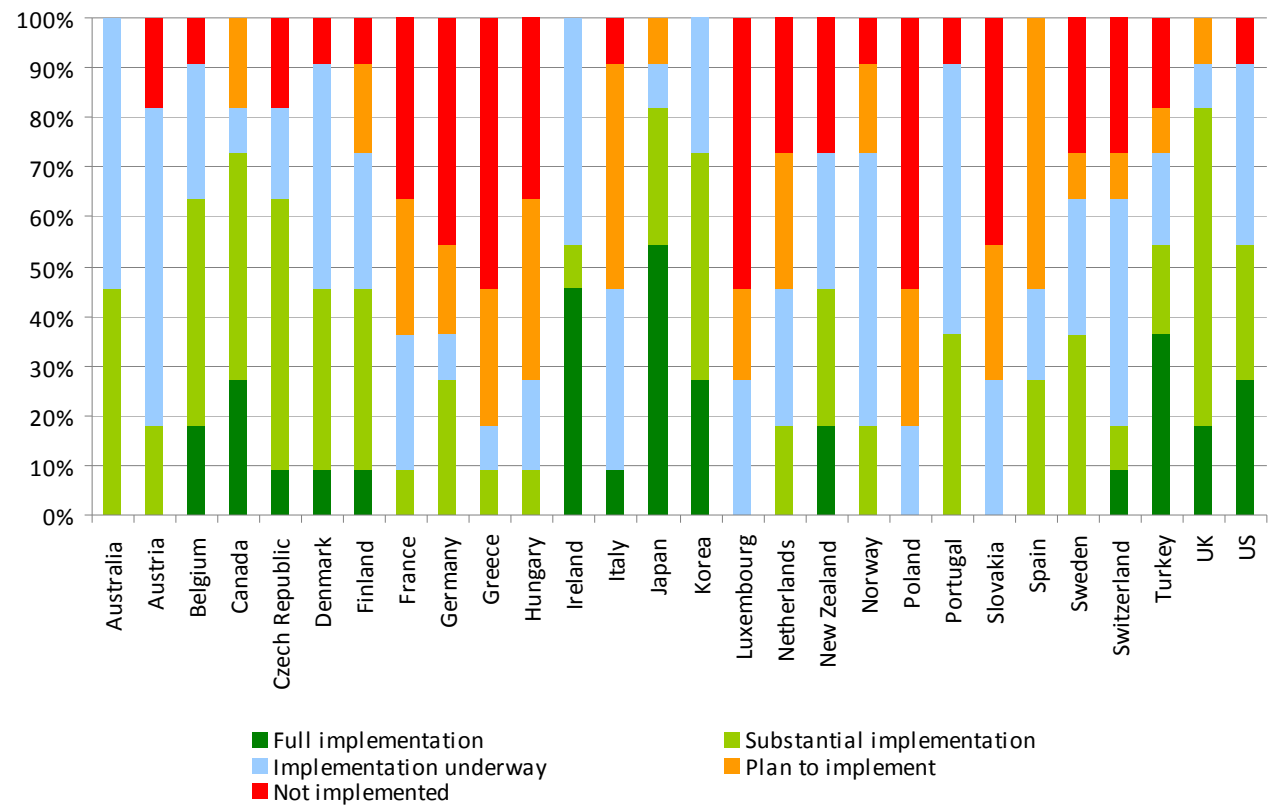




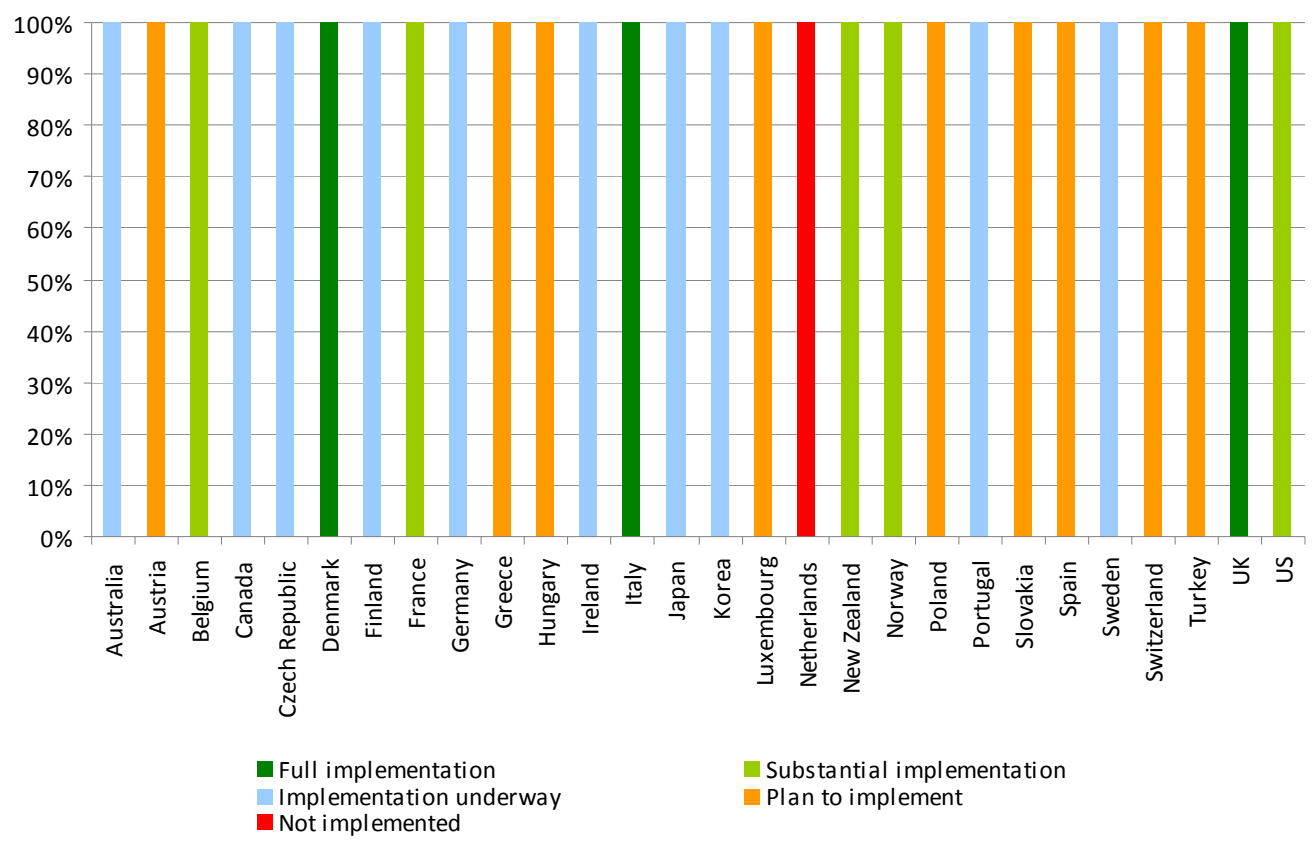

${ }^{13}$ This chart is based on the four elements of the utility recommendation. As each of the utility recommendation elements is optional, the IEA has calculated this bar chart based on the element that achieves the highest level of policy implementation in each country. 


\section{iea}

\section{International Energy Agency}
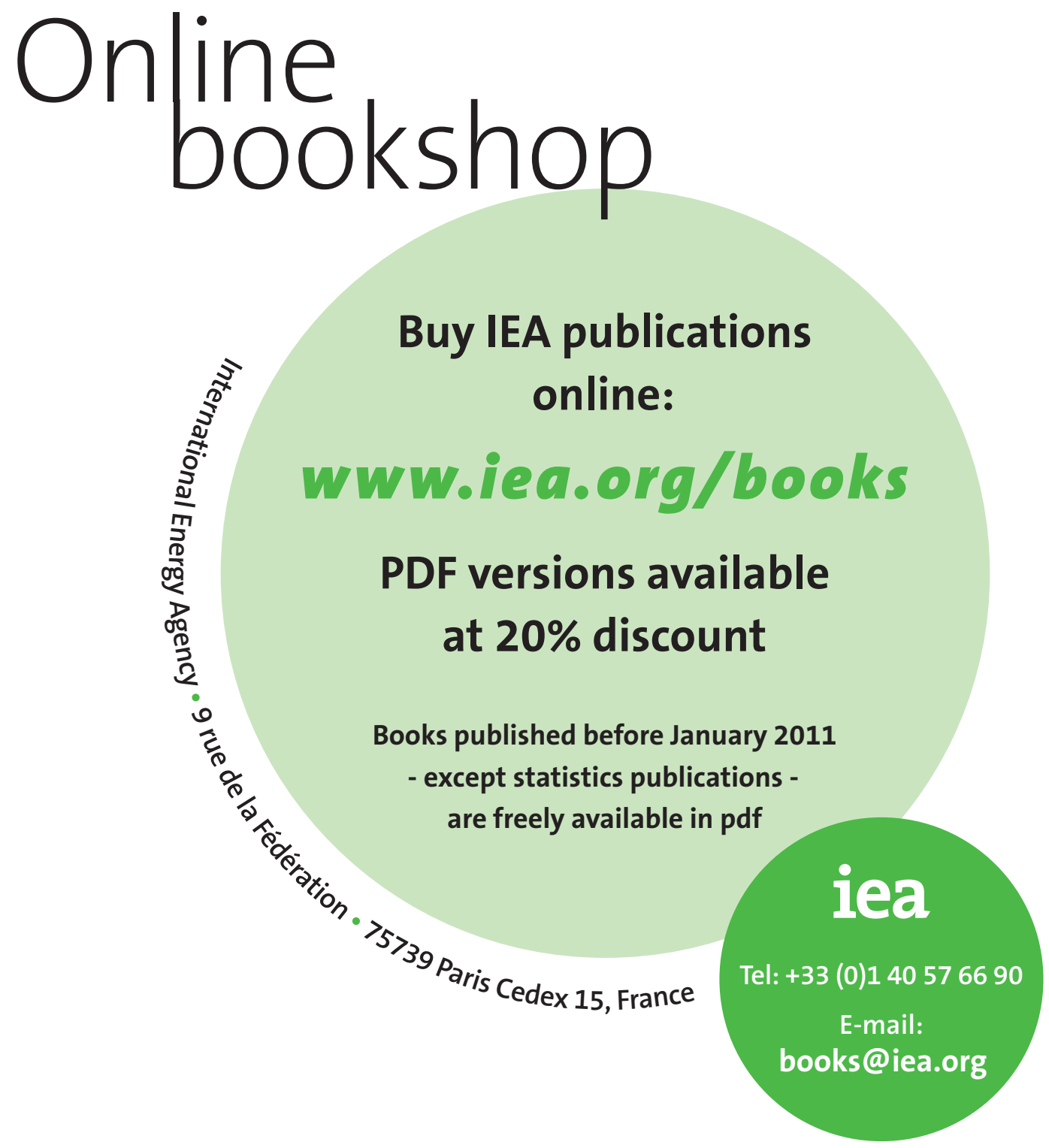